Imperfect Sound Forever: Loudness, Listening Formations, and the Historiography of Sound Reproduction

by

Kyle Devine

A thesis submitted to the Faculty of Graduate and Postdoctoral Affairs in partial fulfillment of the requirements for the degree of

Doctor of Philosophy

in

Cultural Mediations

Carleton University

Ottawa, Ontario

(C) 2012

Kyle Devine 
Library and Archives

Canada

Published Heritage

Branch

395 Wellington Street

Ottawa ON K1A ON4

Canada
Bibliothèque et

Archives Canada

Direction du

Patrimoine de l'édition

395 , rue Wellington

Ottawa ON K1A ON4

Canada
Your file Votre référence

ISBN: 978-0-494-89334-0

Our file Notre référence

ISBN: 978-0-494-89334-0

\section{NOTICE:}

The author has granted a nonexclusive license allowing Library and Archives Canada to reproduce, publish, archive, preserve, conserve, communicate to the public by telecommunication or on the Internet, loan, distrbute and sell theses worldwide, for commercial or noncommercial purposes, in microform, paper, electronic and/or any other formats.

The author retains copyright ownership and moral rights in this thesis. Neither the thesis nor substantial extracts from it may be printed or otherwise reproduced without the author's permission.
AVIS:

L'auteur a accordé une licence non exclusive permettant à la Bibliothèque et Archives Canada de reproduire, publier, archiver, sauvegarder, conserver, transmettre au public par télécommunication ou par l'Internet, prêter, distribuer et vendre des thèses partout dans le monde, à des fins commerciales ou autres, sur support microforme, papier, électronique et/ou autres formats.

L'auteur conserve la propriété du droit d'auteur et des droits moraux qui protege cette thèse. $\mathrm{Ni}$ la thèse ni des extraits substantiels de celle-ci ne doivent être imprimés ou autrement reproduits sans son autorisation.
In compliance with the Canadian Privacy Act some supporting forms may have been removed from this thesis.

While these forms may be included in the document page count, their removal does not represent any loss of content from the thesis.
Conformément à la loi canadienne sur la protection de la vie privée, quelques formulaires secondaires ont été enlevés de cette thèse.

Bien que ces formulaires aient inclus dans la pagination, il n'y aura aucun contenu manquant. 


\begin{abstract}
This thesis engages critically with the historiography of sound reproduction. A significant portion of this literature has been concerned to understand sound reproduction in the context of modernity, as both acoustic consequence and contributing factor. My argument is that the relationship between sound reproduction and "acoustic modernity" has been mapped according to four prominent themes - fidelity, privacy, rationality, objectivity and that each of these themes is valuable and illuminating but limited. Through a series of case studies in loudness and electrical amplification (ca. 1910s-1930s), I complement the existing historiography by demonstrating that while these themes were indeed prominent in discourses of sound reproduction, as ideals they were imperfectly achieved - offset and altered by a variety of equally significant but often contrasting precepts and practices. The goal is not to posit these differences in terms of dualisms or dialectics (fidelity/ infidelity, privacy/publicity, rationality/irrationality, objectivity/subjectivity), but to understand them as mutually constitutive functions of what I call listening formations.

"Listening formation" is an analytical and methodological concept that promotes, if not exactly a "better" definition of acoustic modernity or a multiplicity of acoustic modernities, then a conception of the audible past that is able to hold its various practical and conceptual orientations toward sound in states of co-productive tension. In contrast to a uniform conception of acoustic modernity that is discernible in the historiography of sound reproduction, "listening formation" more readily delineates the vicissitudes of acoustic and musical culture during this period. I argue that if there is anything distinctly
\end{abstract}


modern about the acoustic, or that if there is anything distinctly acoustic about modernity, the distinction has perhaps more to do with the particular logics of listening formations than the rise of a modern soundscape or modern aurality as such. By situating listening formations in relation to the wider reorientations toward knowledge, the environment and the self that characterize the project of modernity, this thesis strives toward a deeper understanding of the modern era as an acoustic phenomenon. 


\section{ACKNOWLEDGMENTS}

As my research headquarters, the Institute for Comparative Studies in Literature, Art and Culture has been world class. In particular, I want to thank Paul Théberge and John Shepherd, along with Franny Nudelman and Barbara Leckie, for offering so much of their time, wisdom and acuity, right from the get-go. Dawn Schmidt and Mitchell Frank made the submission process a breeze. Chris Faulkner taught me two of the most important things: cultural theory and softball.

ICSLAC and Carleton University provided financial support throughout this project. The final years were also funded by the Social Sciences and Humanities Research Council of Canada and the Ontario Graduate Scholarship program. Some of this research is on its way to being printed elsewhere, and I thank those publishers for letting me reproduce parts of the following: "Imperfect Sound Forever: Loudness Wars, Listening Formations, and the History of Sound Reproduction," in Popular Music 32.2 (2013); "Electronic Instruments" and "Sound Studies," in The Grove Dictionary of American Music, second edition (New York: Oxford University Press, 2013).

A lot of the ideas about research and writing that underpin this thesis were hatched during my time at the University of Edinburgh. Thanks to Simon Frith and everyone in his 2006-2007 popular music seminars for so many formative discussions and lasting impressions. Thanks are also due to Simon for welcoming me back as a visiting student in 2009 and, along with the seminar crew, for giving additional shape to this project at a crucial stage. 
A number of allies have offered priceless help, advice and encouragement along the way. Thanks to Anna Khimasia and all my fellow students at ICSLAC, with a special nod to Paul Jasen and the Sound Studies Group - and an extra special nod to Tom Everrett. Tom is a rare colleague and a real friend; without him, this whole process would have been a lot less interesting and a lot less fun. My research would have been more difficult without the assistance of many archivists and librarians. Thanks to Sylvie Bertrand at the Canada Science and Technology Museum, Florence Hayes at Library and Archives Canada, George Kupczak at the AT\&T Archives and History Center, Ken Yaxley (and Crackers!) at the History of Public Address Museum, and to the staffs of the Carleton's Interlibrary Loan department and the W.D. Jordan Special Collections at Queen's University. On my trips to the UK for conferences and research, I'm fortunate to have shared ideas, pints and teas with the best of the best. Thanks to Kirstin Anderson, Melissa Avdeef, Matt Brennan, Martin Cloonan, Kieran Curran, Mary Fogarty, Mark Percival, Nick Prior, Luis Sánchez and Theresa Steward.

I want to thank some other friends, too. To Scott and Rocky, Phil and Triscilla, and Jamie et al., for making Ottawa a home away from home. To Chris, Erin and Eloise, and James and Eric, for making Montreal a home away from home away from home.

Last but not least, I want to thank my family. To my dad, for being so reliably generous, patient and proud. To my brother, my grandparents, and everyone else - from Calgary to Winnipeg and Kilsyth to Bergen - for their support. Most of all, I want to thank my mum. She was there for me when I started at Carleton but did not live to see me finish. This thesis is for her. 


\section{TABLE OF CONTENTS}

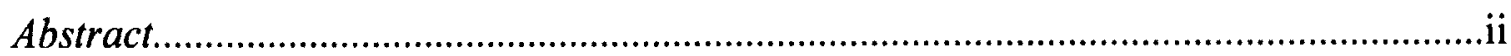

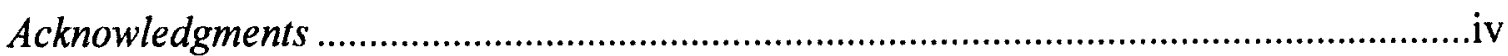

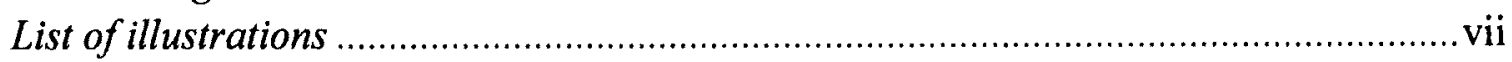

INTRODUCTION

A mysterious music in the air: listening formations and acoustic modernity ....................1

\section{CHAPTER 1}

Fidelity: a complicated cat fight in a mustard mill

CHAPTER 2

Privacy: an imposing loudspeaker .61

CHAPTER 3

Rationality: a new lease on life....

CHAPTER 4

Objectivity: a decibel by any other name

CONCLUSION

Listening formations: for a history of loudness 195

Bibliography .215 


\section{LIST OF ILLUSTRATIONS}

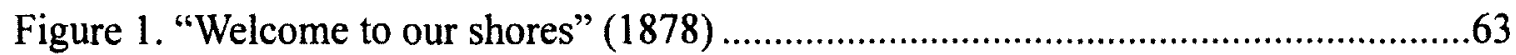

Figure 2. "Radio megaphone is large enough for a diving platform" (1922) ...................71

Figure 3. "Victor dance music . . brings joy with every step" (1922).............................90

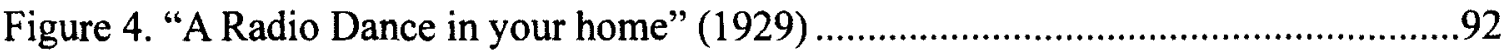

Figure 5. "Section of the cochlea of the guinea pig" (1936).........................................139 


\section{INTRODUCTION A mysterious music in the air: listening formations and acoustic modernity}

This thesis started out as an attempt to mimic one of my favourite books - Oranges, by writer and journalist John McPhee. McPhee opens with a curveball: drinking orange juice, as so many of us do every morning at breakfast, is actually quite curious; it's not a very widespread custom. In fact, drinking orange juice is one among dozens of equally curious ways of consuming oranges around the world. Instead of juicing them or even just peeling them, as we tend to, oranges are halved and salted in Trinidad and Tobago, eaten with knives and forks in parts of Europe. Oranges have an interesting iconographic history, too. They often appear beside wine bottles in the still-lifes of the Dutch and Flemish masters, reflecting a widespread fondness for bitters in the Low Countries. But when Italian Renaissance artists portray oranges at, say, the Last Supper, or alongside the Virgin Mary (as a symbols of wealth and purity), they are guilty of an anachronism: the Bible makes no mention of this citrus fruit, and orange trees did not grow in the Holy Land during the time of Christ. Oranges haven't even always been called oranges: they used to be called apples. In short, Oranges is fascinating because oranges are fascinating.

Books like McPhee's take ordinary things, from aspirin to zippers, and show how they are extraordinary. And this thesis began as an attempt to do the same - only by focusing on loudspeakers. I was interested in how something as everyday as listening to 
electrically amplified sound was, historically speaking, not a very widespread custom. Going back to the period between the loudspeaker's invention in the 1910s and its ubiquity in 1930s music, radio, cinema, public address - indeed, nearly all aspects of dayto-day life - it becomes apparent that most of what we take for granted about electrically amplified sound was at first unclear to professionals and audiences. For instance, AT\&T refused Peter Jensen's proposal to sell them the rights to the Magnavox loudspeaker in 1914 , because the company couldn't imagine a use for the technology. When Jensen approached private investors, they refused to back him, insisting that Jenson's demonstration of the technology (speaking to them over a distance of a few kilometres) was impossible, that Jensen was playing a trick on them. Audiences mistook electrically amplified speech for the voice of God, and broke out into spontaneous dancing when they heard an apparently unmoored music floating through the air. The list of stories like these goes on, until our contemporary uses and understandings of loudspeakers crystallized in the 1930s.

Of course, I knew that stringing together a list of surprising stories about loudspeakers wouldn't cut it as a doctoral thesis, so I looked for the bigger picture. I thought about how the loudspeaker provided new ways of experiencing music and sound. And I questioned what about the loudspeaker was really new, how much of its apparent novelty could be chalked up to the shock and awe that accompany most new technologies. I also wondered about the connections between loudspeakers and other kinds of loud sound: from thunder claps to car horns, and in musical contexts ranging 
from organs to operas, from the electric blues to electronica - all of which led me to think about the loudspeaker as part of a broader cultural history of volume.

Loudness, I quickly discovered as I began to sketch its history, is a surprisingly unhistoricized and under-theorized property of sound and music, especially given its longstanding importance as an object of criticism, a source of pleasure, and an engine of technological change. But I discovered just as quickly that loudness is a voluminous topic, filling the entire world and all of history. A cultural history of loudness was simply too big.

I began to see other potential. In the histories of sound and listening that I was reading to help contextualize my research, I struggled to see where loudspeakers and loudness fit in. Plenty of attention had been given to gramophones and fidelity, to noise and annoyance, and to the ways in which sounds and media like these had redefined listening practices in the context of "modernity." But loudspeakers were apparently of lesser historical interest, even though they seemed to engender social relations and modes of listening that were equally (if differently) "novel" and "modern." Neither did loudspeakers seem to generate the same theoretical excitement that scholars found in the inscriptive and representational particularities of the gramophone. And while loudness was definitely connected to complaints about noise, it was also an obvious part of musical enjoyment. Questions arose. Why were there so many histories and theories of gramophones, and none of loudspeakers? What place might loudness have in discussions of sound, listening and modernity? I started to think that loudness and loudspeakers 
played a significant but largely unrecognized role in the history of sound reproduction, and that the story I was uncovering differed from some of what had been written about that history. The thesis then became about the relationship between loudness and loudspeakers, on the one hand, and the historiography of sound reproduction, on the other.

The question of a history of loudness will surface at several points in these chapters. Although I do suggest the possibility of such a history, and while I will conclude this thesis by saying something about what that history might look like, I cannot pretend to offer a full-blown history of loudness. An effective history of that topic would need to offer much more than I can here.' Still, my hope is that this thesis takes a significant step toward that history, and that it prompts further research in the area. My more modest claim here is that loudspeakers and loudness afford a distinct analytical perspective on the history of sound reproduction, and that this perspective encourages us to rethink some of the ways in which the story of sound reproduction is normally told.

\footnotetext{
${ }^{1}$ To give perhaps only the most obvious example, an effective history of volume would need to take better stock of the relationship between loudness and "noise." Not all noise is loud, and not all loudness is noise. Of course, there is overlap between the two categories. Indeed, loudness and noise are often used as synonyms for each other. But loudness doesn't always fit the everyday definition of noise as unwanted sound, or its anthropological definition as sound out of place. And in the same way that noise is not an exclusively negative cultural category or merely a question of bad taste, so it is with loudness. Certainly, loudness can be construed negatively. Indeed, loud music has been embroiled in controversies of race, gender and youth, and has been variously constructed as barbaric, manly, deviant. But loudness is also understood positively in a variety of contexts: in many music genres, loudness is seen less as a political issue or a danger to hearing, and more as a prerequisite to particular kinds of musical pleasure. For outstanding studies of noise, see Hegarty (2007), Bijsterveld (2008), Mills (2011) and Schwartz (2011).
} 


\section{The problem}

In taking a bird's-eye-view of sound studies, it is possible to identify a topography of acoustic modernity in the historiography of sound reproduction: the gramophone is taken to be the emblematic modern sound technology, fidelity is taken to be the M.O. of the history of sound reproduction, and phonography is taken to be the theoretical problem of the acoustic in the modern era; the privatization of acoustic space and entertainment are taken to be the modern cultural outcomes of sound reproduction, while the abatement of annoying and hazardous noise is seen as the representative public issue of sound in modernity; the rationalization of listening techniques and the disenchantment of sound itself (its objectification) are presented as the trajectories of the acoustic through modernity. ${ }^{2}$ The story of acoustic modernity, from this height, appears to be a story of fidelity, privacy, rationality and objectivity.

On the ground, of course, things look different, more complex. And for that reason no sound scholar claims to have told the story of acoustic modernity. But these four themes do more than casually dot the academic landscape that has been formed around sound reproduction and modernity: it is my argument that in many ways they define it, and that this definition is limited. I suggest that none of these themes was

\footnotetext{
2 On gramophones, fidelity, phonography: Eisenberg (1987), Thompson (1995), Rothenbuhler \& Peters (1997), Engh (1999), Kittler (1999), Gitelman (2000), Lastra (2000), Sterne (2001A, 2003), Wurtzler (2007), Samuels et al. (2010). On privatization and personalization: James (1995), Sterne (1997, 2003), Frith (2007), Chua (2011). On social problems of noise: Smilor (1979), Bailey (1996), Thompson (2002), Bijsterveld (2008), Schwartz (2011). On rationalization of sound and listening: Théberge (1989), Sterne (2001B), Thompson (2002), Bijsterveld (2008), Steege (2008). On disenchantment and objectivity: Thompson (2002), Sterne (2003, 2008), Kursell (2008), Sterne (2008), Chow \& Steintrager (2011).
} 
perfectly achieved - indeed, my interest lies in the various "imperfections" that accompanied the ideals and ideologies of fidelity, privacy, rationality and objectivity. ${ }^{3}$

This thesis thus offers a critical engagement with several of the most common narratives conveyed in the historiography of sound reproduction.

Although I have chosen to write a thesis that differs from some of the best work in sound studies, I see this thesis as highlighting the heterogeneity of the audible past and, thus, complementing the efforts of sound scholars. However, I do contend that the themes I identify are not mirages or straw figures. They are discernable at a certain level of historiographic generality. And while I do not seek to question their validity tout court, I do think that by attending to some of the complexities that are not as easily covered by or as easily absorbed into the usual historiography, we can approach a more effective explanation of the history of sound reproduction.

\section{The approach}

This thesis builds on a tradition of scholarship that attempts to understand the broad reorientations toward knowledge, the environment and the self that have defined the

\footnotetext{
3 "Imperfect," as used here and throughout the thesis, does not carry negative connotations: it does not mean "flawed" or "faulty" so much as unfinished but in-formation. And loudness, of course, isn't meant to come across as merely "bad" or as a quality of sound that "contaminates" ideals of perfection (although it is sometimes construed as such): loudness is also a preference, a positive and productive force. So "imperfect sound forever" describes, not a series of failed attempts to achieve perfection, but a long history of tensions and negotiations between idealistic notions of sound and its practical uses.
} 
modern world, and which characterize the project of modernity. ${ }^{4}$ Such work took on a particular shape through the 1980 s, when art historians and film scholars began refracting this general set of questions through specific cultural forms. Scholars like Jonathan Crary, Tom Gunning and Martin Jay were thus able to contextualize artistic and cinematic practices as aspects of broader epistemic reconfigurations in longer histories of visuality - the upshot of which was the emergence of a field of visual culture studies. ${ }^{5}$ Rather than aesthetic or institutional or auteurist understandings of art and film history, visual studies scholars prefer instead to represent the histories of art and cinema as problems in histories of consciousness and perception. Recently - belatedly - such questions have been raised in relation to acoustic and musical culture, resulting in the crystallization of a field of sound studies during the early 2000 s.

Sound scholars thus seek to understand sound and listening in terms of their cultural and historical contingency. While sound studies' scope is wide (from antiquity to the present, Latin America to Japan, infrasound to ultrasound), ${ }^{6}$ the majority of sound scholars focus on the audible pasts of America and Europe between the late nineteenth

\footnotetext{
${ }^{4}$ Marx (1956, 1968), Weber (1958), Simmel (1964), Benjamin (1968), Tarde (1969) Foucault $(1970,1972)$, Berman (1982), Elias (1994). The literature on modernity - not to mention (aesthetic) modernism and (economic) modernization - is vast and entropic. Thankfully, other scholars have done much to clarify and justify the continuing relevance of this concept for academic analysis, and so I am able to follow Tim Armstrong's (2005, p. ix) definition of modernity as, among other things (e.g. urbanization and the globalization of industrial capitalism), "a series of epistemic shifts in systematic regimes of knowledge, communication and perception." My focus is on sound and listening as aspects of these broader shifts.

${ }^{5}$ Crary (1990), Gunning (1989), Jay (1993). See also the important work of Baxandall (1988), Berger (1972), Mitchell (1986, 1994) and Mulvey (1975). For outstanding summaries and critiques, see Singer (2001), Jay (2002) and Gunning (2006).

${ }^{6}$ Respectively, Burnett \& Gouk (1991) and Bull (2007); Ochoa Gautier (2006) and Dolan (2008); Jasen $(2009,2011)$ and Goodman $(2010)$. Underwater sound environments have recently started to receive attention (Helmreich 2007; Schwartz 2011, pp. 713 ff; Shiga 2012).
} 
and early twentieth centuries. ${ }^{7}$ This literature pays special attention to the role of technology in the conditioning of sound and listening. In the words of another recent aerial survey of the field: "New forms of technological mediation in the late nineteenth century helped constitute a particular modern(ist) engagement with sound, intensified cultural practices of listening, and prompted shifts in practices of signification." ${ }^{8}$ Indeed, it is fair to say that the primary goal of sound studies has thus far been to develop an understanding of the modern era as an acoustic phenomenon, to understand the connections between sound reproduction technologies and acoustic modernity. ${ }^{9}$ This is the aim of my thesis, too. At the same time, my research on loudness suggests that the way sound scholars interpret the acoustic dimension of modernity is open to augmentation.

Acoustic modernity, like modernity more generally, resists uniform definitions and blanket statements. Developments that first appear to be ruptures can be understood as continuities of other trends (as Jonathan Sterne has shown in relation to the "very

\footnotetext{
${ }^{7}$ Three of the foremost studies are Thompson (2002), Sterne (2003), Bijsterveld (2008).

${ }^{8}$ Samuels et al. (2010, p. 332). See also Sterne's (2003, p. 9) argument that "sound-reproduction technology indexes an acoustic modernity" and his exploration of "the ways in which the history of sound contributes to and develops from the 'maelstrom' of modern life." These ideas actually predate the development of sound studies proper; see for example Biocca $(1990$, p. 1): "Between the last decades of the nineteenth century and the early decades of the 20th century, a dramatic change occurred in the world of sound and music. A triumvirate of aural technologies, the telephone, the phonograph, and the radio, permanently altered the way Americans would perceive and use sound." For more on shifting listening practices in relation to sound reproduction, see Lacey (2000), Clarke (2007), Maisonneuve (2009).

${ }^{9}$ In discussing the relationship between the acoustic and the modern, two of the most commonly used labels are "soundscape of modernity" and "modern aurality." I use "acoustic modernity" because, pace Emily Thompson $(2002$, p. 1), "soundscape" remains too environmental (see also Sterne 2012 for a critique of the "emic" character of soundscape). "Aurality," on the other hand, is too personal. "Acoustic" is used here in its everyday sense (that which relates to sound and/or hearing), and so is simultaneously environmental and personal.
} 
possibility" of sound reproduction), while apparently continuous and overarching themes are themselves full of internal tensions and contradictions - which is what I focus on here. Each of the themes I have identified in the historiography was offset and altered by a variety of equally significant but often contrasting precepts and practices. The goal is not to posit these differences in terms of dualisms or dialectics (fidelity/infidelity, privacy/publicity, rationality/irrationality, objectivity/subjectivity), but to understand them as mutually constitutive functions of fragile coalitions.

Conceived in this way, if acoustic modernity has a shape, it is fractal. With such an understanding of culture, as Arjun Appadurai notes, "we will need to ask not how these complex systems, overlapping, fractal shapes constitute a simple, stable (even if large-scale) system, but to ask what its dynamics are."10 As such, the goal of my engagement with acoustic modernity is not necessarily to argue for a more accurate delineation of a period in the history of sound and listening that can be more definitively called "modern." Rather, I want to emphasize the complex and often contradictory logics that are both the essence of this notion, and which consistently threaten its implosion. ${ }^{11}$ When the term acoustic modernity appears in these pages, it is accompanied by an implicit and Derrida-like qualifier: acoustic modernity (if there is such a thing).

I am not bothered by a foundational suspicion in, or an essentially pluralistic understanding of, acoustic modernity. But I do think that the historiography of sound reproduction could be bolstered by a concept better able to make sense of the distinct and

\footnotetext{
${ }^{10}$ Appadurai (1996, p. 46).

${ }^{11}$ The implosion imagery is paraphrased from Erlmann (2010, p. 15).
} 
competing forces at play in the period that is here under investigation. The concept I

propose is the listening formation.

\section{Listening formations}

"Listening formation" was originally put forward by Christopher Faulkner, and I wish to quote him here at length in order to provide a base for the discussion that follows.

Outlining what he calls "the social dimension of speech and audition," Faulkner notes:

Any proper recognition of this dimension would have to understand the construction of what we might call . . . listening formations: that is the whole context of audition for historically specific audiences, taking account of expectations formed for them by the whole culture and technology of speech and hearing of which they are a part. That project ... suggests the need to understand the formation ... of a normative and hegemonic "speaking degree zero," along with departures from it, by looking at the construction of the telephone voice, the role of the gramophone and popular song, the influence of the radio, and the history of speech in the movies ... These are plurivocal discursive practices that have no apparent connection with the conditions for a phenomenological auditory realism. ... Ultimately, we want to think of listening formations as social constructions, not merely as formal, textual instances. The intention here ... is to understand how people understood their material, lived existences in historically specific instances. ${ }^{12}$

In other words: listening formations posit musical sound as simply one strand - albeit a significant strand - in larger contexts of audition; listening formations are social constructions but they are not reducible to textual functions; listening formations are concerned with lived existences without needing to ground that discussion in

12 Faulkner (1994, pp. 165-166). For other foundational work on formations, see Foucault (1970, 1972), Bennett $(1983,1985)$. 
presumptions about auditory realism or phenomenological immediacy; listening

formations account for normative conventions and departures from them. ${ }^{13}$ These are the four notions on which my conception of listening formations is based, and on which I will build throughout this thesis.

While Faulkner wants to speak of listening formations in terms of social constructions more than textual instances, he does seem primarily interested in "the relation of spectator to film" - particularly the expectations that an audience brings to a text and, in turn, the "kinds of social and cultural knowledge" that a text is able to engender. ${ }^{14}$ This circular, intertextual process of representation and meaning-making constitutes a central part of the context of audition in which listeners' expectations are "formed for them." I will have more to say about the problems of social construction and textuality in the conclusion to this thesis. Here I want to expand on Faulkner's notion of audience expectations.

Surely, audiences have expectations; and it is indisputable that these expectations are, to an extent, "formed for them by the whole culture and technology of speech and hearing of which they are a part." But audiences - listeners - are more intentional than

\footnotetext{
${ }^{13}$ Faulkner (ibid., p. 165) makes an additional point about the possibilities of cross-modal sensory history, the exploration of which is unfortunately beyond the scope of this thesis: "Furthermore, the attempt to understand something as complex as a listening formation should not necessarily be restricted to auditory practices alone. Recognition of a larger, interdiscursive context might extend our understanding of the whole regime of sense within which audience expectations can be presumed to have been determined."

${ }^{14}$ Ibid. (p. 166).
} 
Faulkner's "formed for them" might suggest. ${ }^{15}$ Listeners participate in the formation of their formations, even as they are informed by them. This opens out the possibility of incongruence between the ways audiences use cultural objects (from texts like films to technologies like loudspeakers), on the one hand, and the ideals imputed to those cultural objects by the professionals that produce them, on the other. Such ideals, when put into practice, are often reworked, redefined, imperfectly manifested. By focusing on such instances of imperfection and incongruence, this thesis highlights diversity in the history of sound reproduction and acoustic modernity.

At the same time, an emphasis on audiences and contexts of use should not give the impression that listening formations privilege moments of consumption or reception, even if this emphasis would help balance the focus on professionals and production that is evident in the historiography of sound reproduction. ${ }^{16}$ In fact, listening formations are not founded on a distinction between consumption, production, and text; rather, they draw attention to the processes of mediation and systems of circulation in which coformative relationships among audiences, professionals and cultural objects are generated. ${ }^{17}$ As such, the incongruities I describe are not simply matters of listeners doing

\footnotetext{
${ }^{15}$ This is not to say that Faulkner empties audiences of their agency. Indeed, the point of his article is to suggest that "sound (speech) expressly acknowledged . . . a linguistic diversity ... and what it created was a mass listening public, not uniform or homogeneous, but diverse, fragmented, even divided, and with potentially disruptive or unsettling social and political consequences" (ibid., p. 166).

${ }^{16}$ Thompson (2002), Sterne (2003), Bijsterveld (2008), Erlmann (2010).

${ }^{17}$ For more on the "circulatory turn" and the "generative matrix," see Straw (2010B, 2010A). I am also working to extend the science and technology studies notion that "users matter" (Oudshoorn \& Pinch 2003). "Cultural object" is broadly defined to include a range of stuff, from loudness to loudspeakers.
} 
unexpected or unorthodox or unthoughtful things with sound and technology. Loudness and loudspeakers have their own material properties, which are themselves implicated in the movements of circulation and co-formation. In this way, listening formations acknowledge both the intentionality of subjects and the materiality of objects, while ultimately privileging neither. These forms of agency are not dismissed; they are distributed. They are made perceptible in performative processes of circulation, which generate provisional sets of things and people in which sound and listening assume certain material forms and achieve certain levels of public organization. ${ }^{18}$ Listening formations are actualizations of potential energy and are constituted by magnetisms of incongruence.

Although we don't need listening formations to see that acoustic modernity is a period marked by internal contradictions, the idea can assist in conceptualizing the character of those contradictions. I want to avoid an understanding of acoustic modernity that simply pits the normal against the abnormal, and I want to avoid a conception in which anomalies lead straightforwardly to incommensurability and revolution - in which dominant epistemic frameworks replace each other, one after the other. ${ }^{19}$ Speaking of cultural formations more generally, Raymond Williams captures some of the intricate and constant (but not chaotic) movement that characterizes listening formations: "no full account of a formation can be given without attending to individual differences inside it."

\footnotetext{
${ }^{18} \mathrm{I}$ am amalgamating and paraphrasing Bennett (2007A) and Straw (2010A).

${ }^{19}$ The references here are to Kuhn (1962) and Daston \& Galison (2010).
} 
Formations of the more modern kinds may be seen to occur, typically, at points of transition and intersection within a complex social history, but the individuals who at once compose the formations and are composed by them have a further complex range of diverse positions, interests and influences, some of which are resolved (if at times only temporarily) by the formations, others of which remain as internal differences, as tensions, and often as the grounds for subsequent divergences, breakaways, breakups and further attempted formations. ${ }^{20}$

My task in this thesis is thus less to provide an exhaustive description of a particular listening formation in a particular place at a particular time (although the kind of "total history" that such a project would entail would certainly be valuable), and more to outline something about how listening formations operate in a general sense - to say something about their dynamics, their logics. In other words, "listening formation" functions here as a historical concept and an analytic category that promotes, if not exactly a "better" definition of acoustic modernity or even the multiplicity of acoustic modernities, then a conception of the audible past which is able to hold various practical and conceptual relations to sound in states of co-productive tension. ${ }^{21}$ Listening formations do not necessarily define a common denominator across acoustic modernity; rather, they help delineate the vicissitudes of acoustic and musical culture during this period.

\footnotetext{
${ }^{20}$ Williams (1982, pp. 85-86). Note that Williams' (1977) conception is related to - but subtler and more open to constitutive tensions than - his dominant/emergent/residual model of culture.

${ }^{21}$ On multiple modernities, see Eisenstadt (1999), Lash (1999). My conception of listening formations is similar to the relationship between reason and unreason described by Michel Foucault in History of Madness (2006), which he later formulated more explicitly in terms of discursive formations (1972). For a clear explanation of Foucault's discursive logic, which soundly refutes the misinterpretation that the rise of reason turned on the exclusion of madness (madness is "included within the reach of a positive power which preserves the 'abnormal' as the ever-present inverse of the normal"), see Koopman (2010, p. 555).
} 


\section{Sources, threads and limitations}

As a critical engagement with the historiography of sound reproduction, a significant portion of my argument is built on re-readings, not just of existing histories, but of these sources' sources. Wherever possible, I have consulted the original materials on which the secondary literature is based. Of course, I have also undertaken my own historical research, in order to fill in gaps in the available literature and to test my arguments. Although some of this historical work has been archival, most of my attention has been given to sources which were published during the period of my investigation. So the types of publications examined here, while they vary from specialized scientific journals to popular science magazines and from textbooks to newspapers, also share space on the public surface of acoustic modernity and listening formations. ${ }^{22}$ Archival materials have their own merits. But the goal I have set for myself is to provide a clearer description of the public organization of acoustic modernity and the constitutive tensions of listening formations; the best access to those facets of listening formations is through published discourse more than the unpublished inner workings of archives - although, of course, the two are in the end complementary.

Loudness and electrical amplification are the two main threads that have channeled my research, and they offer some substantial consistency across my thematic

\footnotetext{
${ }^{22}$ It would be possible to subject any one of my sources - Radio News, say - to a rigorous and detailed analysis, focusing on how the magazine functioned as a magazine, on how Hugo Gernsback's eccentricities and the everyday commercial environment affected content (although the context is different, for this sort of analysis see Brennan 2007). While such research would certainly be illuminating and valuable, I remain primarily concerned with issues of historiography.
} 
case studies. Loudness served as a keyword that helped me decide where to do my research, and how to interpret my sources. Indeed, I've used loudness as a lens through which the history of sound reproduction can be refocused.

The second thread, electrical amplification, oriented the timescale of my research. Although these pages sometimes stretch back past the nineteenth century and forward to the twenty-first, my main focus is on the years leading up to and following the commercial viability of the electronic vacuum tube and the electrically amplified loudspeaker. This means that my primary period of investigation falls between the $1910 \mathrm{~s}$ and the 1930s, when these new technologies afforded (but neither could nor did determine) new ways of projecting sound, of measuring sound, of thinking about sound and listening to it. As such, my study focuses on a period of turbulence and transition in the history of sound reproduction - a period which, conveniently, provides a particularly vivid illustration of the ongoing sedimentation and erosion of listening formations.

Geographically and generically, my study is promiscuous. I have deliberately sacrificed in-depth engagement with specific national and musical cultures. Of course, listening formations are functions of nation and genre (and vice versa), and I will pay attention to the specificities of each when they are especially consequential. Indeed, there is an impressive body of scholarship devoted to teasing out such differences ${ }^{23}$ However, because the drive of the thesis is toward illustrating certain issues in the historiography of

\footnotetext{
${ }^{23}$ It would be possible, for example, to mount a history of the loudspeaker voice in FDR's America vis-à-vis Hitler's Germany (Carroll 2000, Birdsall 2007), while other comparative research has yielded interesting insights into the specificities of film sound in France and the US, Hollywood and Germany (O'Brien 2005, Loepnick 2002).
} 
sound reproduction, which is an academic conversation that has been constructed across geographic and generic boundaries, broad similarities between national and musical cultures have been more important than particular differences. ${ }^{24}$

While I do tend to focus on popular music genres, the world of art music has also been integral to debates about loudness and the development of electrical sound reproduction technologies. More than any one musical genre, though, loudness and amplification are the centrepieces of this analysis. It is this focus that allows me to traverse a diverse musical terrain. Following the loudspeaker across musical borders means sacrificing generic analysis (my point is not to understand the subtle differences in how the loudspeaker was taken up in, say, sweet jazz vis-à-vis hot jazz) in favour of a cross-section of musical (and, indeed, extra-musical) forms. This thesis focuses on the insights that can be gained from studying various forms of art music, popular music and recorded entertainment together, as overlapping phenomena in a shared history of sound and listening.

This leads me to an overstated but handy distinction: my approach here is that of a cultural sociologist more than that of a historian. My aim is not to provide an exhaustive account of the history of sound reproduction but, rather, to probe aspects of this history to

\footnotetext{
${ }^{24}$ Still, there are national and political cultures that figure more prominently here than others notably America and Britain. Reading the newspapers, popular periodicals, acoustics textbooks and professional and academic journals from this period, it is evident these various spheres drew and built on one another (through citation, reference and republication). This indicates that, even outside my historiographic net, there would perhaps be enough discursive, technological and personal circulation to warrant my broad consideration.
} 
find out how several general and explanatory principles of sound historiography manifest themselves in observed social processes. So my method here is the case study. ${ }^{25}$

\section{The plan}

As a series of case studies, these chapters proceed analytically, not chronologically. The reason for this is that the themes I have identified - fidelity, privacy, rationality, objectivity - do not divide neatly into mutually exclusive sets of years. Rather, they overlap and coincide in various ways. In other words, these themes mark tropes in historiography; they don't mirror history. Instead of chronology, then, the thesis is ordered so that each chapter builds in conceptual complexity and historical generality, and so that each chapter illustrates a different aspect of the logics of listening formations. So while Chapter 1 focuses narrowly on themes of im/perfection in the practices and precepts of "phonography" over half a century, by Chapter 4 we are dealing with a halfmillennium-long history of ideas in relation to the decibel. The biggest questions come toward the end of the thesis. This structure finds expression on another level: my most sustained engagements with questions of historiography and sound studies scholarship appear in the conclusions to each chapter. As much as I am critical of "crescendo" models of the history of loudness, I have no problem with the crescendo as a literary device.

Chapter 1 tackles the most prominent theme in the historiography of sound reproduction: fidelity. I argue that there is a very visible body of scholarship that orbits in what I call the "problem space of fidelity," and I argue that loudness is a particularly (but

\footnotetext{
${ }^{25}$ Some of my framing here is drawn from Frith (1976).
} 
not exclusively) fruitful means of problematizing the historiographic emphasis that has been placed on fidelity. I illustrate that while fidelity is a prevalent concern in the ideals of sound reproduction, listener practices are better characterized by the pragmatics of imperfection. A particularly prominent example of this distinction is provided by the socalled loudness war in contemporary musical culture. Critics of the loudness war maintain that the average volume level of popular music recordings has increased dramatically since the proliferation of digital technology in the 1980s, and that this increase has had detrimental effects on sound quality and the listening experience. My point is not to weigh in on this debate, but to suggest that the issue of loudness in sound recording and playback can be traced back much earlier than the 1980s. In fact, loudness has been a focal point since the earliest days of commercial sound reproduction. Looking at the period between the turn-of-the-century format feud to the arrival of electrical amplification in the 1920s, I situate the loudness war within a longer historical trajectory, and demonstrate a variety of ways in which loudness (along with its attendant logic of imperfection) has been a controversial issue in - and a constitutive element of - the history of sound reproduction.

Chapter 2 looks at narratives of privatization. It is commonly assumed that the proliferation of sound reproduction technologies like phonographs and radios participated in a large-scale privatization and domestication of listening and entertainment during the early twentieth century. Conversely, scholars who focus on public issues of sound during this period tend to focus on the problem of urban noise. This chapter shows that the 
proliferation of sound technologies such as public address systems, radios and jukeboxes contributed to equally significant and novel forms of public listening and entertainment, and that the volume of sound reproduction during this period was as much a source of newfound pleasures and conveniences as it was the abatement of annoying and hazardous noise. I situate these developments and debates within a larger history of shifting ideas about crowds, masses and publics.

Through a study of the invention of electrical amplification, Chapter 3 addresses theses of rationalization in sound reproduction scholarship. I begin in the nineteenth and early twentieth centuries, where I argue a certain technological frame took root in the world of telecommunications. Through certain formations of industry and culture, this communications frame, as I call it, was transferred into a variety of sound reproduction media (e.g. public address, radio, music performance and recording, film sound). But such transfers were not direct: they necessitated two-way processes of translation, through which certain established priorities of both the communications frame and the worlds of music and sound reproduction were modified. After sketching some of these modifications, I look in more detail at the translation of the communications frame into the development of the electric guitar amplifier. I suggest that this frame was central to the development of the electric guitar in certain ways, but not others. In particular, I demonstrate a degree of incongruence between manufacturers and users around the electric guitar's aesthetics of volume. It is this incongruence that leads to broader questions about theses of rationalization in the historiography of sound reproduction. 
Chapter 4 extends Chapter 3's examination of rationalization into the context of objectivity, through a discussion of acoustic science, loudness, and the history of the decibel. My frame here is drawn from science studies, where acoustic science is a growing area of interest. Cutting against the grain of a history going back to Aristotle, which suggests that hearing is a less reasoned, more affective - and thus a less modern and a "lower" - sense than vision, science studies scholars have suggested that sound and listening are equally bound up in sciences and philosophies and cultures of rationalization and objectification. "As there was an Enlightenment," Sterne sallies, "so too was there an 'Ensoniment."' ${ }^{\prime 26}$ I agree, but I also want to suggest that the history of the decibel can help to express the subtlety of this idea. In looking primarily at the period between the rise of acoustic science in the nineteenth century and the invention of the decibel in the 1920s, I emphasize ways in which ideals of objectivity and rationalization in the measurement of loudness collided with the essential subjectivity and, we might say, "irrationality" of the experience of loudness. Such an argument is meant not to lead us back into pointless debates about the hierarchy of the senses, but to the suggestion that the trajectory of "ensoniment" encompasses the same tensions and contradictions identified by scholars of modernity more generally.

Each of these four chapters will raise the question of a history of loudness in various ways; I address that issue most explicitly in the conclusion. Against popular and academic discourses that suggest the history of loudness is a simple crescendo, I argue

\footnotetext{
${ }^{26}$ Sterne (2003, p. 2).
} 
that a study of loudness written from the perspective of listening formations renders irrelevant the comparison of absolute sound levels across time. What listening formations cannot ignore, however, is the question of what it means to experience loudness as a function of history and culture. Without necessarily lapsing into an attempt to understand loudness in terms of what Faulkner calls a "phenomenological auditory realism," the conclusion foregrounds the experience of loudness - not just as an epistemological problem in a history of ideas (as it is in Chapter 4), but as a methodological problem in the study of the audible past, and as a theoretical problem in the conceptualization of listening formations. I address the dual status of sound as a citizen of culture and nature, and will draw the obdurate sociality of listening formations into dialogue with their obdurate materiality in order to advance a particular set of problems in contemporary cultural sociology and sound studies.

\section{Le son, c'est le mouvement}

This thesis presents what I see as particularly prominent and interesting themes in the historiography of sound reproduction, and explores some potential alternatives through loudness and loudspeakers. It is not meant as a final word or an attempt to foreclose other avenues. I have focused on fidelity, privacy, rationality and objectivity because, in my reading of the historiography, they stood out as remarkably vital themes that seemed especially open to augmentation. There are surely other recurring themes and formulas in the literature. For example, I might have included a chapter on loudness and identity, which would have addressed the ways in which questions of race, religion, gender, class 
and disability have been treated by sound scholars. ${ }^{27} \mathrm{Or}$ I might have written a chapter on economy, which would have addressed the institutional and industrial bases of loudspeakers and their relations to other sound technologies and media systems. ${ }^{28}$ Indeed, readers will no doubt come up with examples of their own, in connection with their specialized research interests. My hope is simply to spark further questions about the uniformity of the history of sound reproduction, and prompt further research into the history of loudness.

If this thesis can help to model the field of sound studies a bit more like its object of study - if it can voice some of the dynamism that is the life of sound itself - it will have achieved one of its main goals. In short, I want to keep the discussion going. It is fitting, then, to begin this reexamination of sound studies in the same place Rodolphe Radau began his 1867 study of sound: "Le son, c'est le mouvement . . Le repose est muet. Tout son, tout bruit annonce un mouvement."29

${ }^{27}$ For starting points on these issues, see for example Martin (1991), Sterne (2000), Schmidt (2000), Smith (2004), Mills (2008), Rogers (2010), Keeling \& Kun (2011), Friedner \& Helmreich (2012).

${ }^{28}$ For starting points on these issues, see Kraft (1996), Gomery (2004), Wurtzler (2007).

${ }^{29}$ Radau (1867, p. 1). 


\section{CHAPTER 1 \\ Fidelity: a complicated cat fight in a mustard mill}

Music critic Robert Everett-Green poses an interesting question in The Globe and Mail:

"Is hi-fi sound a thing of the past?" His answer - "For young listeners, it may be" -

essentially fingers the digitalization of music as a prime suspect in what has elsewhere

been labelled the "death of high fidelity." The problem, for Everett-Green, is that "most

people under 25 are getting their music from cheap ear buds, tiny laptop speakers and

compact sound files that have had much of the music's sonic juices squeezed out of

them." While he does hold out hope for the future of hi-fi ("Better earbuds are coming on

the market, and iPod storage capacities are much greater now than when the most

reductive MP3 format was standardized 20 years ago"), the Globe and Mail critic's

nostalgia ultimately gets the better of him. More wistful than wishful, he notes that

"Walking into a serious audio store these days is like entering a time machine ... The

\footnotetext{
1 "Fidelity" is of course a problematic term that refers less to an absolute quality of sound or the degree to which a recording is "faithful" to its source than it does a set of historically situated discourses (Sterne 2003). Indeed, "fidelity" is a misnomer: when people speak of fidelity, they are usually describing something closer to a sound recording's definition (Chion 1994, pp. 98ff). Mindful of the problematic status of "fidelity," I continue to use the word because it is the operative term in the discourses examined here. But placing "fidelity" (and similar terms like "faithful") in scare quotes throughout this thesis would be tedious, so I refrain from doing so. This brief introduction, as well as the spirit of the discussions that follow, should establish my epistemological break with the idea of fidelity, and my critical distance from it. Opening quotations from, respectively, Everett-Green (2011, p. R6) and Levine (2007, p. 15). The question "Is hi-fi sound a thing of the past?" is taken from the online version of Everett-Green's article.
} 
gear is new, but the conversations are much like those your father and grandfather had when they went shopping for hi-fi.",

A century ago, though, Everett-Green's question would have been out of place in a "serious audio store." Indeed, audio enthusiasts throughout the history of sound reproduction would have found his question oddly anachronistic, for many of them assumed that high-fidelity sound was a thing of the future - and that the future was now (whether "now" meant the discs of the 1890s, the electrical recordings of 1920s, the stereophonic tape reels and LPs of the 1950s, or the CDs of the 1980s). In other words, for most of the history of sound reproduction fidelity has been, simultaneously, a promise and a guarantee, a zenith and a horizon. The underlying assumptions here are about objectivity and progress - about fidelity as a measurable, achievable condition, on the one hand, and about a history that inches closer and closer to that condition, on the other. These are Everett-Green's assumptions too, although his outlook is less rosy: he suggests that somewhere along the line we got it right - we arrived at true hi-fi - but that now, because of iPods and earbuds, we're drifting off course. From this perspective, the Globe and Mail article marks something of a one-eighty in the history of sound reproduction: from the hope of hi-fi, to fidelity as a lost cause.

But in another sense, Everett-Green's misgivings are par for the course in the history of sound reproduction: every step of the way, traditionalists have scorned new developments. When disc recording was introduced as a viable alternative to the cylinder

\footnotetext{
${ }^{2}$ Everett Green (2011, p. R6).
} 
in the 1890s, some cylinder supporters penned slanderous editorials against the discs, going so far as to compare the gramophone's "blasty, whang-doodle noises" to "the braying of a wild ass." ${ }^{\prime 3}$ Or take the introduction of electrical recording and playback in the 1920s: although many companies and music fans recognized the potential of electrical methods, there were those who remained steadfast supporters of acoustic recording, clinging to it because they thought it sounded better. This was true on both sides of the Atlantic. Britain's Gramophone was famously allergic to electrical recording (when the magazine's editor, Compton MacKenzie, finally did hear an electrical recording that impressed him, the shock of the experience was said to have literally sickened him) ${ }^{4}$ The American response was more paradoxical: while electrical reproduction may have sounded “"more natural' . . it certainly 'didn't sound like a phonograph."'5 Similarly, when the CD was introduced it had certain advantages over both cassettes and LPs, but the new medium was endlessly badmouthed by audiophiles for its apparently cold, lifeless sound. ${ }^{6}$ From this perspective, iPods and earbuds are nothing new, and EverettGreen is simply one in a long line of old-guard audio enthusiasts that have cursed vanguard technologies for spoiling perfectly good ways of listening.

So fidelity is both an ever-present future and an always-fading golden age. Here we've slid into the scholarly perspective on the history of sound reproduction, which is

\footnotetext{
${ }^{3}$ Sterne (2003, p. 279).

${ }^{4}$ Ginn (1996, n.p.).

${ }^{5}$ Hunt (1954, p. 69).

${ }^{6}$ For an analysis, see Downes (2010).
} 
less concerned with Everett-Green's question as such (is hi-fi really going the way of the dodo?) than with the historical and cultural settings that allow "fidelity" to appear as a reality in the first place. So instead of the mythologies of advertising and popular discourse that suggest fidelity is exactly measurable and ultimately achievable (a position encapsulated in the "perfect sound forever" slogan of early CD ads), critical histories focus on the contingency of fidelity - on the ways in which fidelity has been socially shaped by various groups of people in various circumstances. From this perspective, "every age has its own perfect fidelity." The guiding principles here are not objectivity and progress, but constructionism and anti-Whiggism; not "perfect sound forever" but "perfecting sound forever."

As a starting point for this chapter, Everett-Green's article is interesting for the way it illustrates that the historiography of sound reproduction has been circumscribed by the notion of fidelity. By this I mean that the history of sound reproduction is often framed in one of two ways: either in terms of popular discourses that accept the notion of fidelity as real and debate which technologies are best for the job; or in terms of critical studies that debunk the notion of fidelity, focusing instead on its socially constructed character. Either way, this chapter argues that the historiography of sound reproduction has orbited prominently in a problem space of fidelity. In this problem space, perfect fidelity is either identified as the ultimate goal of sound reproduction, or as a "logic"

\footnotetext{
${ }^{7}$ Sterne (2003, p. 222). It should be clear that, contra Guberman (2011), I am not arguing for a transition into a "post-fidelity" era; rather, I am concerned with ways in which fidelity has always been a secondary concern in certain contexts.
} 
central to the history of sound reproduction. Insightful as this latter work may be, a historiography centred on the critique of fidelity is still a historiography centred on fidelity. Loudness can provide another perspective.

I begin to make this argument through the so-called loudness war that has been waged in contemporary musical culture. I offer a definition of the loudness war and a description of the critical discourse that has been developed by musicians, fans and industry personnel in rallying against this phenomenon. While the ins and outs of the loudness war have been covered elsewhere - most readably by Greg Milner - I review the debates because my perspective is somewhat different. I engage with the loudness war as an observer, in the sociological sense of that word: my goal is to describe systematically the way this phenomenon is understood in the musical world. As such, although it is possible to argue about this issue with facts and figures, ${ }^{8}$ my reason for starting with the loudness war is not because I have an interest in proving that music is or isn't getting louder; nor is it because I have an interest in deciding whether loudness is good or bad.

Rather, the loudness war serves as a gateway to a historical discussion. I want to understand the contemporary loudness war as a set of contradictions between practices of listening and ideals of sound reproduction, and I want to view this set of contradictions in relation to a longer history of changing modes of listening and musical mediation - in the context of a listening formation. To do so, I offer a series of studies (1880-1930) in which

\footnotetext{
${ }^{8}$ See Deruty (2011) for a thorough and surprising analysis of whether recordings are actually getting louder and whether their dynamic range is actually shrinking.
} 
idealistic preferences for fidelity clash with practical realities of loudness: ear tubes $\mathrm{v}$. horns, cylinders v. cylinders, cylinders v. discs, internal v. external horns, mechanical v. electrical amplification. Whereas many discourses of sound reproduction emphasize ways in which volume and fidelity function symbiotically (as the pillars of "good" and "realistic" sound), these studies highlight ways in which volume and fidelity are in some ways and in some cases inversely correlated. What's more, in cases where loudness and fidelity have been inversely correlated, audiences often choose loudness over fidelity, whereas audio enthusiasts tend toward ideals of fidelity. Instead of favouring fidelity, audiences like loudness because of its ability to furnish certain situations with music. This pragmatic orientation often outweighs concern for the minutiae of sonic detail. In other words, a particular form of mediation is preferred because it more readily facilitates a certain mode of listening. In this way, this chapter understands the sets of contradictions between practices of audiences and ideals of audio enthusiasts that constitute the listening formation of the contemporary loudness war as one of a series of "loudness wars"; and, in turn, it understands these loudness wars as consequential moments in the history of sound reproduction.

The historical connections between these loudness wars are not matters of absolute sound level. There are, of course, real gaps between recording levels in 1900 and 2000. But despite these material differences, there are discursive continuities in the way that loudness has been appreciated and deprecated in the ongoing negotiation of listening formations. Indeed, in each of my case studies (and throughout this thesis) "loudness" 
takes on different meanings. As we will see, in the early days of commercial sound reproduction, loudness was needed to facilitate new types of group listening (especially dancing). In the electrically amplified 1920 s, loudness retained this practical element but also became a scapegoat for audio enthusiasts who preferred the familiar tone of acoustic reproduction. In the contemporary loudness war, the issues are compression and dynamic range, or consistency of loudness, more than absolute volume. "Loudness" can thus mean different things to different people at different times, as a function of different listening formations. ${ }^{9}$ It is this contingency, I argue, that makes a history of loudness possible.

\section{The loudness war}

There's no denying that music is louder today than ever before. - Sarah Jones, Mix Magazine, 2005

For a hundred years, loudness was part of the solution to the problem of fidelity. In order for recording companies to bolster the claims of realism and presence and truth-to-theoriginal that pervade the history of sound reproduction, playback had to be faithful (utilizing a frequency range wide enough to approximate the original sounds) - but it also had to be loud (capturing a dynamic range comparable to that of the original sounds). If the volume was feeble, the overall reproduction was less real, less believable, lower in fidelity. So when such journalists as Sarah Jones claim that "music today is louder than ever before," 10 we might also assume that music today is more hi-fi than ever before.

${ }^{9}$ Analagously to fidelity, "loudness" could be read as appearing in scare quotes throughout this thesis. But, again, actually supplying the scare quotes would be tedious for the reader.

${ }^{10}$ Jones (2005). 
There is an element of truth to that idea. But Jones is referring to popular music's socalled loudness war, the critics of which maintain that the average volume level of popular music recordings has increased dramatically since the proliferation of digital technology in the 1980 s, and that this increase has actually had detrimental effects on recording aesthetics. Lower the average volume of popular music recordings, these critics argue, and the result will be higher fidelity.

From this perspective, the loudness war marks an interesting inversion in the history of sound reproduction: if for a hundred years increased loudness was part of the solution to the problem of fidelity, in the twenty-first century the possibilities of digital recording have turned loudness into a problem to which the notion of fidelity is actually the solution. Part of what this inversion points to is the contingent, socially constructed and historically variable character of fidelity - an idea that is well known and widely discussed. But the inversion also points to the contingent, socially constructed and historically variable character of loudness. Taken together, these aspects of the loudness war signal a certain degree of malleability in the relationship between loudness and fidelity.

The loudness war stems from a step in the process of creating a recording called mastering. This step, which occurs after individual sounds and songs have been recorded, edited and mixed, is the final process before a recording is mass-produced (or not-somass-produced, as the case may be); it's the step where mastering engineers finalize the original from which copies will be made. The process involves a variety of tasks, such as 
transferring data from one medium to another, setting the amount of downtime between songs, limiting unwanted noises like hiss and hum, adjusting the frequency spectrum until it sounds "full" or "crisp" (or any other number of hazy descriptors) - and the process can also involve increasing a recording's overall volume.

Increasing a recording's overall volume is achieved using a technique called dynamic range compression, whereby the difference in decibels between the quietest and loudest sections of a recording is reduced. This is accomplished by electronically squishing the sound signal so that the level of quieter sounds is nearer the level of the loudest ones. Compression thus raises not the peak but the average volume level of a recording.

Dynamic range compression is not a new phenomenon, nor is it limited to the world of music recording: it has been an essential element of mediated sound since the early twentieth century (e.g. electronic hearing aids, radio and television broadcasting). And while the reasons for using this kind of compression are as varied as its circumstances of mediation, for the purposes of this chapter I simply need to highlight two of the main reasons that audio professionals and musicians involved in the loudness war argue that compression is desirable. ${ }^{11}$ First, there is an aesthetic argument. Because

\footnotetext{
11 There are of course other factors at play in the use of dynamic range compression: such compression is an effect of sound reproduction systems themselves (from microphones to amplifiers), and has deep roots in the history of radio and musical aesthetics (we expect certain genres to be "louder" than others). To my knowledge there is no detailed history of audio compression, and this is not the place to attempt that monumental but interesting task. For potentially useful starting points, see Berger (1984) on hearing aids, Adorno (2002B) and Milner (2009) on radio, Frith (2002A) and Negus (2006) on television sound. For a different but related topic, see Sterne (2006) on signal compression.
} 
of the mechanics of human ears and brains, compression can give the impression that a recording is, simply, louder - which, for the same psychoacoustic reasons, can give the impression that a recording is, simply, "better."12 This is related to a second, practical reason for using compression: professionals and musicians believe that loud music is more ear-catching than quiet music. The argument here is that whereas people "actually listened" to records in the 1970 s, nowadays more listening happens on the go, in the car, at the pub, and so on. In such situations, less compressed and quieter songs can be hard to hear (because the ratio of music to environmental noise is low) and risk being lost in the shuffle, so to speak..$^{13}$ As Chicago-based mastering engineer Bob Weston explains in his loudness manifesto: "In this age, we all do tend to listen to music in much noisier environments and generally, perhaps, pay less attention to the music we hear. In such an environment, it is tempting to try to make your music 'shout-out' the loudest."14 And while engineers like Weston resist this temptation (for reasons that I will outline momentarily), producers such as Matt Serletic embrace it: "In the Seventies," he says, "you were expected to pay attention ... Modern music should be able to get your attention."'15

\footnotetext{
${ }^{12}$ Though the acoustics and psychoacoustics of loudness are complex and fascinating problems, a detailed discussion is beyond the scope of this thesis. Readers interested in understanding the contemporary science of loudness are referred to any one of a number of acoustics textbooks, such as Everest \& Pohlmann (2009). The history and sociology of the science of loudness, on the other hand, will be pursued in Chapter 4 .

${ }^{13}$ See Plambeck (2010, p. B1).

${ }^{14}$ Weston (n.d.).

${ }^{15}$ Serletic quoted in Levine (2007).
} 
So musicians and audio professionals who support the use of compression to increase the overall volume of a recording tend to do so for two reasons. First, because they believe that loud music sounds "better." Second, and more significantly, because they recognize that certain forms of musical mediation (such as car stereos and MP3 players) facilitate certain ways of listening (music as background, as soundtrack to everyday life) and that recordings which have been made consistently louder through dynamic range compression tend to fare better in such situations (because they garner more attention and constitute a higher signal-to-noise ratio). Combined, these aesthetic and practical points have contributed to an environment where musicians and industry personnel worry that band $X '$ s recording will be quieter than band $Y$ s, which has resulted in a competitive, snowballing drive for loudness. And this snowball effect is otherwise known as the loudness war.

\section{Critics of the loudness war}

In the past decade, the loudness war has elicited a strong critical reaction from certain fans, musicians and sound engineers. These critics tend to make two (related) points, one of which is about the listening experience, whereas the other is about musical aesthetics. In terms of the listening experience, critics argue that loud, heavily compressed recordings exhaust our ears more quickly than quieter, less compressed music. For example, Wall Street Journal-ist Ethan Smith suggests that the more consistent barrage of sound that results from compression can lead to an effect commonly called "ear 
fatigue."16 In the words of Abbey Road mastering engineer Peter Mew, "'The brain is not geared to accept buzzing. [Loud, heavily compressed] CDs induce a sense of fatigue in the listeners. It becomes psychologically tiring and almost impossible to listen to." ${ }^{\prime 17}$ In this way, according to critics of the loudness war, louder overall recording volumes are detrimental to the listening experience.

Aesthetically, critics argue that over-compression and the resultant loudness can obscure musical detail. Long-time Beatles engineer Geoff Emerick complains that "A lot of what is released today is basically a scrunched-up mess. Whole layers of sound are missing."18 Bob Dylan notes that many contemporary recordings "have sound all over them. There's no definition of nothing, no vocal, no nothing, just like - static." ${ }^{19}$ Critics have singled out "albums from Springsteen to Fall Out Boy," ${ }^{20}$ from the Flaming Lips to the Arctic Monkeys to the Red Hot Chili Peppers, as particularly compressed and loud, though the issue came to the fore especially in relation to Metallica's Death Magnetic, which Rolling Stone called "one of 2008's most earsplitting discs."21 The sound of Death Magnetic was considered so offensive that thousands of fans signed an online petition demanding that the album be remastered: "It's so loud, they say, you can't hear the details

\footnotetext{
${ }^{16}$ Smith (2008, p. A1). "Ear fatigue" is a colloquial term used by sound engineers to describe a feeling of psychological enervation after long periods of listening. This is not necessarily the same as "auditory fatigue," which is a technical term that describes a physiological loss of hearing after exposure to sound.

${ }^{17}$ Mew quoted in Sherwin (2007).

${ }^{18}$ Emerick quoted in Sherwin (2007).

${ }^{19}$ Dylan quoted in Levine (2007, p. 15).

${ }^{20}$ Anon (2008, p. 32).

${ }^{21}$ Ibid.
} 
of the music."'22 The critics' argument here, then, is that compression and loudness result in a dearth of detail in recordings, and that the loudness war thus has had an adverse effect on sound quality.

To summarize: critics argue that the loudness war - defined as a snowball effect that is the result of pressure from musicians and industry personnel to master recordings at higher overall levels (as an effort to keep up with the Joneses in terms of volume, and as a response to shifts in musical mediation and listening practices) - is having detrimental effects on both the listening experience and recording aesthetics.

\section{Beginnings of the loudness war}

Dates vary as to when this phenomenon began, but most critics trace it to the proliferation of digital recording and playback technology in the 1980s - to the CD, in other words.

There is an element of truth to this: before digital audio formats, vinyl records and electromagnetic tape placed definite physical limitations on the amount of volume that a recording could exhibit (on a record, for example, louder sounds mean wider grooves, which means less playing time). The $\mathrm{CD}$ eliminated some of these concerns, and allowed for a wider dynamic range than previous playback media. But while the CD does technically allow for higher highs and lower lows, many audio professionals have focused on packing more loud sound into the larger dynamic space, which means that they actually utilize a narrower dynamic range than previous sound media. This

${ }^{22}$ Smith (2008, p. A1); see also Hiatt (2008, p. 11). 
contradiction in the potential of digital audio is what, for many, marks the $\mathrm{CD}$ as the instigator of the loudness war.

However, there is also a sense in which "The invention of digital audio and the compact disc became a new fuel for a previously existing loudness race," in the words of Bob Katz, one of the foremost critics of the loudness war. ${ }^{23}$ Indeed, some of the more historically sensitive critics have recognized that precursors to the loudness wars can be found as far back as the 1960s, when record companies "observed that louder songs in jukeboxes tended to garner more attention than quieter ones," and the 1950 s, when producers of $45 \mathrm{rpm}$ singles jockeyed for the attention of Top 40 radio's program directors. ${ }^{24}$ One critic even observes that "The 'Loudness War' has been going on almost as long as pop music has existed, and probably longer. ${ }^{25}$ The point I want to make in the rest of this chapter is that the loudness war is indeed part of a longer history - and not just a history of popular music production, but a history of sound reproduction and listening formations more generally.

\section{Loud and clear? Volume in the history of sound reproduction}

... it is said by experts that what is gained in volume is lost in fidelity. - Ogilvie Mitchell, editor Talking Machine News, ca. 1922

When speaking of the early days of commercial sound reproduction, Columbia patent attorney Philip Mauro provides some historical perspective on the contemporary loudness

${ }^{23}$ Katz quoted in Sreedhar (2007).

${ }^{24}$ Respectively, Sreedhar (2007), “Loudness Wars" (2009).

${ }^{25}$ Southall (2006). 
war and begins to open up an alternate perspective on the history of sound reproduction. "The main effort during this period," he says, was not for higher fidelity but "for greater volume of sound." 26 What's more, it was understood as a matter of course that higher volume often meant lower fidelity. A reporter in the December 1916 issue of the Sound Wave stated flatly that "We have heard it times without number that the more we increase the volume in a reproduction, the more the true tone quality will suffer." ${ }^{27}$ Talking Machine News editor Ogilvie Mitchell noted something similar: "it is said by experts that what is gained in volume is lost in fidelity."28 Loud and clear sound was thus something of a grail for manufacturers and certain audiences. And even though much effort was put into disproving this "law" of inverse correlation between volume and fidelity, companies and customers often had to choose one or the other. When presented with this choice, consumers and audiences tended to favour volume over fidelity.

\section{The onerous ear tube}

Already in 1886 , the merits of cylinder composition were being weighed against the benefits of sound quality and volume. Although the wax-coated cylinders of Charles Tainter and Chichester Bell's graphophone were "smoother, better defined and more pleasing" than Edison's tinfoil phonograph cylinders, "there was a drawback": they were "considerably lower in volume than the sound generated by the old phonogram. This

\footnotetext{
${ }^{26}$ Mauro $(1900$, p. 39$)$. His emphasis.

${ }^{27}$ James (1998, p. 7).

${ }^{28}$ Mitchell (ca. 1922, p. 50).
} 
necessitated the addition to the machine of stethoscopic ear tubes to further amplify the sound level."29

The word drawback is used again and again to describe the necessity of ear tubes in early phonograph reproduction. There are several explanations for why ear tubes were regarded as a problem (they were, for example, said to be uncomfortable, even unsanitary). But perhaps the central reason lies in the mode of listening which they most readily facilitated. The main "drawback" of this mode of listening is well illustrated by an account of some early, unlicensed phonograph performances in the UK around 1890. Percy Willis, the delinquent entrepreneur who smuggled the machines into the country inside apple barrels, recalls the scene upon landing at Queenstown:

... a splendid start it was. The people came rolling in by dozens and scores. In those days, you know, to hear the record you had to listen with tubes in your ears, and there was no spring motor to drive the machine.... These were drawbacks ... The worst of it was that only one person could listen at a time and, especially with children, there was a good deal of difficulty in subduing the impatience of the waiting crowd. ${ }^{30}$

Spurred by his initial success, Willis continued on, drawing "shoals" of listeners in Cork, Waterford, Limerick and Dublin, with a repertoire ranging from counterfeited speeches of Prime Minister William Gladstone to music hall celebrity Charles Coborn's rendition of "The man who broke the bank at Monte Carlo." Had the technology been available to him, in order to allow these audiences to listen as a group Willis would have almost

\footnotetext{
${ }^{29}$ Schicke (1974, p. 17).

${ }^{30}$ Willis quoted in Mitchell (ca. 1922, pp. 27-28).
} 
certainly compromised the "smoother, better defined and more pleasing" sound of ear tubes in favour of a louder, if less pleasing, amplifying horn. Of course, Willis's motivation was financial (more listeners at once would have meant more revenue). But I want to suggest that audiences were also willing to sacrifice sound quality for volume and that this push for louder reproduction was not so much financially motivated (although penny-pinching was sometimes a factor) ${ }^{31}$ as it was culturally motivated.

By 1888 , molding processes had improved cylinder composition to the point that phonograph expositions often featured three modes of reproduction: single ear tubes, multi-tubes and horns. ${ }^{32}$ In the 1890 s, customers could specify whether they wished to use ear tubes or horns, and some recordings were advertised as good for one or the other, or both. ${ }^{33}$ Single tube reproduction was recommended by manufacturers. Columbia, for example, boasted about the "wonderful fidelity with which the Graphophone reproduces musical and other sounds" but noted that this wonderful fidelity "can not be fully appreciated unless the reproductions are listened to through the ear tubes. ${ }^{\prime 34}$ As such, they advised "the use of the rubber hearing tubes ... where only two or three are to listen." ${ }^{.35}$ While multi-tube contraptions (like those used in the nickel-in-the-slot phonograph parlours) could be used to extend the listening experience to a handful of

\footnotetext{
${ }^{31}$ See Feaster (2007, p. 251 n. 4).

${ }^{32}$ For example, by 1900 Edison Phonographs were sold with a 'two-way hearing tube' and 'a 14inch polished brass horn' - not to mention other goodies like 'a sapphire shaving knife ... a camel's hair chip brush, an oil can, a winding crank and an oak carrying case' (National Phonograph Company 1900, p. 51).

${ }^{33}$ Feaster (2007, p. 182).

${ }^{34}$ Columbia (1897, p. 4).

${ }^{35}$ Phonoscope 1.8 (1897, p. 9) quoted in Feaster (2007, p. 246).
} 
people, there is evidence that even these quasi-communal events - for which Sterne borrows the term "alone together" 36 - were not enough. In 1892, for example, the Buffalo Times described saloon patrons substituting a liquor funnel for ear-tubes, in order to allow a room to listen together. ${ }^{37}$ Indeed, Columbia begrudgingly admitted that "Where a large company is to be entertained, of course a horn is necessary, but it is believed the music that is thrown out through the horn loses much of its sweetness." ${ }^{\text {"3 }}$ The willingness of audiences to sacrifice the quality of tubes for the volume of horns (a preference for imperfection) thus indicates that while they may have possessed the cultural tools necessary for individuated listening ${ }^{39}$ they were not always or even usually content to listen to music in that way. I take up this point in Chapter 2.

\section{Speak to it in undertones, it repeats in thundertones: cylinder v. cylinder} Even though, as we will see, cylinders were eventually overtaken by the louder medium of disc reproduction, this did not prevent cylinder manufacturers from attempting to solve the volume deficiency of their products. Indeed, Columbia was "convinced that the market was ripe for a cylinder machine capable of greater sound volume" and, in 1898, the firm unveiled its Graphophone Grand, which it believed could "satisfy the demand for a louder wax-cylinder talking machine." ${ }^{, 40}$ Three months later, Edison joined what would

\footnotetext{
36 Sterne (2003, p. 163).

${ }^{37}$ Feaster (2007, p. 251).

38 Ibid. (p. 246).

${ }^{39}$ Sterne (2003).

${ }^{40}$ Respectively, Schicke (1974, p. 50), Gelatt (1977, p. 81).
} 
later be described as the "folly" of large cylinders, announcing the Edison Concert Phonograph. ${ }^{41}$

The Grand and the Concert played cylinders with diameters of up to five inches, more than twice that of the cylinders used by standard graphophones and phonographs. The larger diameter meant that the surface speed of the cylinder, and thus the playback volume, were increased to the point that ear tubes were not necessary (the Grand used a fifty-six inch reproduction horn; the Concert was apparently able to fill an auditorium). This solution was so basic and so effective that Mauro thought it "strange indeed that, with so many observers and with so strong an incentive to increase the volume of sound, this simple law has not sooner been discovered." $" 42$

As I have suggested, this "incentive to increase the volume of sound" had something to do with facilitating a collective listening experience. Indeed, it is interesting that volume received as much emphasis as clarity in advertisements for these machines. For example, casings of both Columbia and Edison cylinders proclaimed that they were "Extra Loud," while an 1899 ad for the Graphophone Grand read: "Speak to it in undertones, it repeats in THUNDERTONES. ${ }^{233}$ One important reason for this emphasis on volume was that a relatively novel form of collective listening was on the rise at the time: the phonograph dance.

\footnotetext{
${ }^{41}$ Schicke (1974, p. 51$)$.

42 Mauro (1900, p. 43). Technically, it appears that the law had "sooner been discovered" (Read $\&$ Welch 1976, p. 87). However, my concern here is less about intellectual property and patent battles than simply establishing the importance of volume in the history of sound reproduction.

${ }^{43}$ Respectively, 1894 Columbia Phonograph Company tube ad pictured in Billboard 100th Anniversary Issue, 1894-1994 (01 November 1994, p. 57); Feaster (2007, pp. 200-201).
} 
Though phonographs had been used at dances before this, the machines were used to provide music between numbers. The use of recorded music to accompany live dancing was new, as the apparatus was not previously able to produce a volume suitable for such activity ${ }^{44}$ Following the introduction of Columbia's Graphophone Grand, the Phonoscope wrote in 1899 that "The dream of the dancing master is about to be realized in the mammoth instrument just put upon the market. It is powerful enough to fill any theatre or church for a concert ... Every dancing teacher in the world who can afford it will shortly possess this machine and if he doesn't get one he will be behind the times."45 Such features were emphasised in later ads too. For example, a 1905 ad depicting an Edison Standard Phonograph prompted readers to "DANCE to music played by the Edison Phonograph if you like - it plays waltzes, two-steps, lancers, quadrilles and fancy dances. Loud enough for large halls. ${ }^{\$ 46}$ What is foregrounded here is not the familiar trope of higher and higher fidelity or the social construction of that category in the first place (although these are aspects of the story) ${ }^{47}$ but, rather, the incorporation of newfound volume levels into established forms of collective listening - especially dancing. As I've

\footnotetext{
${ }^{44}$ Feaster (2007, p. 465).

${ }^{45}$ Ibid. (p. 473).

46 Edison Company (1905, p. 1188).

47 The faster surface speeds of the large cylinders did more than increase playback volume: they also enabled these phonograms to capture and reproduce a broader frequency spectrum than could be achieved on regular machines. As such, the development of large cylinders can also be seen, in part, as a chapter in the orthodox version of the history of sound reproduction - which has been well covered in terms of the "quest for fidelity" (Thompson 1995) and the "social genesis of sound fidelity" (Sterne 2003).
} 
framed it here, then, the story of large-diameter cylinders is one in which audiences are less concerned with fidelity than danceability.

I reign supreme, their Queen, the gramophone: cylinder $v$. disc

Music and song my captives, sound my throne,

I reign supreme, their Queen,

THE GRAMOPHONE

- Berliner ad, $1898^{48}$

Ultimately, the large cylinder trend was short-lived. Almost as soon as the concert-sized

cylinders were introduced, better molding processes were developed which afforded

smaller cylinders the same advantages as larger ones, rendering the Graphophone Grand

and the Concert Phonograph obsolete. But it wasn't just large cylinders that were being

eclipsed during the late 1890s: the so-called mauve decade marked the sunset of cylinder reproduction altogether.

Although experiments with disc reproduction were going on much earlier (Edison had tinkered with revolving dinner plate-sized discs as early as 1878$),{ }^{49}$ improvements by Berliner Gramophone and the Victor Talking Machine Company led to the commercial viability of discs around the turn of the century. Discs had several advantages over

\footnotetext{
${ }^{48}$ Excerpted from a poem in a Berliner catalogue ("A riddle - read," 16 November 1898), reprinted in Moogk (1975, p. 391).

${ }^{49}$ Bizarrely, given the mulish commitment to the cylinder that he later demonstrated, an 1878 phonograph demonstration in Ottawa included talk of perfecting a "flat instrument" (Moogk 1975, p. 5), and Edison told the New York Graphic that he intended to 'abolish this whole cylinder and supersede it with a flat circular steel plate about as big as a dinner plate' (Frow 2001, p. 2). Equally strange, given Edison's insistence on marketing the phonograph as a dictation machine, is his early enthusiasm for the disc phonograph's entertainment potential, as reported in the New York World (ibid.).
} 
cylinders: the machines were cheaper, the discs themselves were easier to mass produce and to store and transport, pirating was more difficult (though not impossible), ${ }^{50}$ and they were louder - they "did not require the use of the onerous ear tube." ${ }^{\text {51 }}$ But they did not necessarily sound better.

One of the benefits of cylinders - and one of the reasons that Edison stubbornly continued producing cylinder machines until 1929 - is that the needle maintains a constant surface speed throughout the entire recording, which makes for a consistent quality of sound. On flat discs, by contrast, the surface speed of the needle slows as it reaches the centre of the record, which can result in a phenomenon known as inner groove distortion. Another benefit of cylinder recording is that the tone of the reproduction was thought to be more pleasing than the wax-coated zinc discs used by Berliner, which were "raucous-sounding" and afflicted with a "hissing, sissing, scratching sound," as one listener complained to the editor of The Phonogram in $1901 . .^{52}$ The Phonoscope, as we saw above, vilified the non-Edison discs" "blasty, whang-doodle noises."

But even though, in terms of tone, the odds were stacked against the gramophone, for a confluence of reasons the flat disc became a dominant medium of sound

\footnotetext{
${ }^{50}$ Henry Seymour, a pioneering British recordist who worked independently (producing the Seymour Superphone) and with the EMG Handmade Gramophones company, was apparently also one of the first music pirates. According to David Phillips, an EMG partner, "Another thing Seymour did - he used to get records recorded in those days by the Gramophone Company or Columbia. He had a very clever copying machine that he used to copy records and then market the records with different labels and with fake artists" (James 1998, p. 6). See also Seymour (1918).

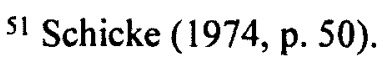

${ }^{52}$ Respectively, Schicke (1974, p. 44), Gelatt (1977, p. 158).
} 
reproduction for much of the twentieth century. Influential among those reasons was the fact that "Compared with the Berliner method, the recording process then employed by the phonograph and graphophone was unable to compete with the Gramophone in volume." ${ }^{33}$ According to Feaster, "Gramophones were thus more likely than standard cylinder phonographs to generate enough volume to accompany live dancing" - meaning that the gramophone's volume was "a selling point which cylinder advocates had been trying in vain to dismiss." ${ }^{\circ 4}$

Not surprisingly, then, the loudness of the gramophone was also a catalyst for change in the wider recording industry: "It may have been in part due to the introduction of the Berliner Gramophone that shortly thereafter the incising methods used in making cylinders were improved so as to also permit the use of horns for reproduction." 55 And while it's true that more advanced molding processes (e.g. the gold-molding developed by Edison) did allow the use of horns and produced cylinders that were "cleaner" and "more accurate" with "less surface noise" than the discs, ${ }^{56}$ cylinder machines simply never achieved the same level of volume as the gramophone. Cylinders thus fell by the wayside. Volume, again, prevailed over fidelity.

In addition to seeing loudness as an impetus for the technological development of sound recording during this period, I want to emphasise two things. First, the popularity

\footnotetext{
${ }^{53}$ Read \& Welch (1976, p. 122).

${ }^{54}$ Feaster (2007, p. 474).

${ }^{55}$ Read \& Welch (1976, p. 123).

56 Ibid. (p. 153).
} 
and commercial success of the gramophone depended significantly on the fact that it was louder than other forms of sound reproduction. Second, while Berliner and others eventually refined the tone of disc reproduction, initially the gramophone's increased volume came at the expense of "sound quality." What's going on here, as with the cylinder feuds, is that tone was being sacrificed in favour of volume, because a certain mode of listening was deemed more desirable than another. Of course, the desire for extra volume also had something to do with the ongoing negotiation of the technology and discourse surrounding fidelity (reproducing sound at levels that approached the original performance was part of the social construction of the category of "realism"). But the point I want to make is that professionals and audiences also sought louder recordings for a more straightforward and practical reason: such records could be listened to by groups of people and, even more significantly during the "crazes" of the 1910s and 1920s, they could be danced to. As with turn-of-the-century lancers and quadrilles, when it came to waltzes and foxtrots, the need to fill a room with sound - the need for volume outweighed the concern for quality.

\section{That pot-bellied drayman of a cabinet: external $v$. internal horns}

In the years leading up to the explosion of electrical recording and playback, listeners continued to coax volume out of their gramophones by physical means. In a sense, this was nothing new: gramophone companies and listeners had often experimented with horn designs. But during the dusk of the acoustic recording era in the 1920s, horns were becoming absurdly large. Some were as long as nine feet; others were three feet wide - 
too large to fit through a standard doorway. In ordering such mammoth horns, customers were sometimes made the butt of a salesperson's practical joke: "Thank you for your order sir, now please may I have the address of your field? 'Er, my field?' Yes sir, your field. We deliver the machine to your field and then you build the house around it." 57 But listeners faced bigger problems than the ribbing of store clerks, because although hulking horns may have tickled the ears, they were eyesores. Cabinet-style phonographs with enclosed horns were introduced around 1904 and, by the 1920s, Talking Machine News editor Ogilvie Mitchell observed that, generally, "The taste of the public now seems to run upon hornless machines." ${ }^{58}$ For Mitchell, this was a step in the wrong direction. Echoing the opinion of many of his fellow audio enthusiasts, he charged the hornless machines with "camouflaging the real instrument," and complained that buyers were being "mulcted" into paying vast sums for such gramophones, "not because of the superior quality of the machine itself, but by reason of its appearance as an article of furniture. ${ }^{" 59}$ Mitchell summarizes the issue as follows:

To our mind the principle of the concealed horn is an entire mistake.... What has now become the old-fashioned horn diffused the sound throughout the apartment. The concealed horn turns the sound down ... It cannot give the value in volume which was obtained from the open horn. ${ }^{60}$

\footnotetext{
57 James (1998, p. 72).

${ }^{58}$ Mitchell (1922, p. 53).

59 Ibid.

${ }^{60}$ Ibid. (pp. 53-54).
} 
Mitchell's problem, in other words, is that fashion trumped fidelity ${ }^{61}$

Compton Mackenzie grumbled more colourfully that "the substitution of the internal for the external horn" was due to the latter's offence against "gentility," a move of "snobbishness" which "seriously imperilled the development of the gramophone."62 He continued:

There is no comparison between the quality of the sound developed by an external horn and that developed by an internal amplifier. But music was sacrificed to gentility, and the makers of gramophones did all they could to encourage the public to suppose that not merely did the cabinet look better in a room, but also that it sounded better. ... The external horn was ugly. The external horn was cheap. The external horn was blatant and overpowering in a room. It vanished from polite society. Yet at this moment any amateur of the gramophone ... will acknowledge that an external horn model of a gramophone costing perhaps nine pounds is better than the pot-bellied drayman of a cabinet which His Master's Voice sells for ninety. ${ }^{63}$

The domestic politics responsible for the popularity of internal horns, and the aestheticisation of the gramophone as furniture more generally, have been studied in detail elsewhere. ${ }^{64}$ I simply want to draw attention to the fact that, once again, perfection, the ostensible logic of the history of sound reproduction, is being subordinated to another concern - in this case, home décor.

\footnotetext{
${ }^{61}$ It should be noted that in this discourse against fashion, volume and fidelity are aligned. Such an alignment adds complexity to this chapter's discussion of volume vis-à-vis fidelity, but it supports my overall argument about imperfection. I take up this point in the conclusion to this chapter.

62 Mackenzie (1925, p. 100).

${ }^{63}$ Ibid.

${ }^{64}$ Barnett (2006).
} 


\section{A complicated cat fight in a mustard mill: mechanical $v$. electrical amplification}

While sound reproduction levels thus continued to affect the technological development of gramophones and the increasing dominance of the discs through the $1910 \mathrm{~s}$ and early 1920 s, there is a sense in which playback volume took on a new musical and cultural prominence during the so-called Roaring Twenties. This point is thrown into sharp relief by looking at the controversies surrounding the introduction of electrical amplification to the gramophone world.

Edison watched skeptically as electrical amplification flooded the recording market, and by the time he was ready to rival the electrical method, he offered too little, too late. In a last-ditch effort to compete in the new world of electrical amplification and the popular but, he thought, misguided "volume fad" that it had spawned, Edison developed a Dance Reproducer for his acoustic Diamond Disc Phonograph, based on the principle that more friction between the stylus and the surface of the record begets more volume. The rationale for this product is explained in an ad from the 17 June 1926 edition of The Saturday Evening Post: "It is called the Dance Reproducer because our experience indicates quite conclusively that volume is wanted principally for Dance Records by people who dance." 65 Unfortunately, for Edison, although the Diamond Disc had a reasonably high output and is recognized as a "high watermark of the acoustic phonograph," it was nevertheless the case that "many prospective customers said that the

\footnotetext{
${ }^{65}$ Frow (2001, pp. 70-71).
} 
Edison phonograph was not loud enough. ${ }^{66}$ This is in stark contrast to the 1912-13 introduction of the Edison disc machines, when "the most common complaint of prospective customers was that the reproduction was too loud" and the machines were sold with wads of fabric that could be jammed down the horn of the machine to muffle the volume ${ }^{67}$ To understand this shift in the desire for volume - this so-called volume fad - it is necessary to look at another medium of sound reproduction within these listening formations: radio.

With the proliferation of radio broadcasting through the 1920 s, gramophone manufacturers and recording companies faced significant challenges. One aspect of this story is of course financial: by the 1930s leisure spending and industry structure had migrated toward radio, contributing to a massive slump in record sales. ${ }^{68}$ But the introduction of radio also opened up a new chapter in the story of loudness that I've been describing.

"Throughout the 1920s," in the words of André Millard, "the phonograph and gramophone manufacturers were aware of the listener's desire for greater volume from their machines. ${ }^{169}$ As I've said, this desire was partly a matter of the widespread popularity of dancing during the 1910 s and 1920 s. However, the very sound of radio-

\footnotetext{
${ }^{66}$ Respectively, Millard (2005, p. 132), Read \& Welch (1976, p. 270).

${ }^{67}$ Read \& Welch (1976, p. 270).

${ }^{68}$ Frith (1988A).

${ }^{69}$ Millard (2005, p. 139).
} 
the sound of vacuum tubes and loudspeakers - also contributed to this so-called volume fad:

Radio ... served to change the standards of public taste in music and its idea of what were desirable qualities in reproduction. Before radio, the average purchaser of a phonograph had wanted a soft-toned quality of reproduction. . . . After radio the demand was for greater volume. ${ }^{70}$

Although Read and Welch's before-and-after depiction of radio sound isn't entirely accurate or even consistent with their overall argument (as I've shown, and as can be gleaned from Tin Foil to Stereo itself, listeners had always been willing to trade tone for volume), it still rings true as a marker of the extent to which volume became an even more prominent concern following the introduction of radio. In Millard's words, "Electronic amplification had a special quality that Americans took to heart and soon wanted to hear from their phonographs."71 However, while the "special" sound of electrical records "was loud enough to dance to" and while "its raucous volume suited the music of the Jazz age," the quality of reproduction "was not as delicate and as well articulated as the reproduction of an Edison Diamond Disc."72 It was for this reason that many recording companies "scorned the radio sound," even as the success of radio - "the

\footnotetext{
${ }^{70}$ Read \& Welch (1976, p. 270).

${ }^{71}$ Millard (2005 p. 139).

72 Ibid.
} 
hot breath of radio's pursuit" - "forced them into a desperate search to find a way of increasing the volume of reproduction." ${ }^{.73}$

As electrically recorded and reproduced sound spread through the musical world, it became obvious that this new method had several technical advantages over the acoustic method: electrical records were clearer (better signal-to-noise ratio, wider frequency range) and the output was not only louder but also easier to control (turning volume knobs instead of "putting a sock in it"). But, as with the transition from cylinders to discs, not everyone agreed that electrical records sounded better. Perhaps the most common and most venomous insult for electrical recording was to call it strident, although the criticisms were more varied and more amusing than that. ${ }^{74}$

Old-guard gramophiles like Compton Mackenzie called the electrical discs "abominable," mocking the "whining infancy of the new recording" and describing the sound of the records as a "jangle of shattered nerves"; his Gramophone columnists and readers complained about "squeaky tone" and "unpleasant twang," saying the quality of reproduction was "more like a complicated cat fight in a mustard mill than anything else I

\footnotetext{
${ }^{73}$ Ibid. "Hot breath" from Hunt (1954, p. 68). It is of course also true that some musicians were happy about the increased volume of electrical amplification (as we will see in Chapter 4), while some critics were unhappy about the contribution of radio loudspeakers to city hubbub (as we will see in Chapter 2). Although this complicates the point I'm making here, this messiness supports my overall argument about the contingency of volume and fidelity.

${ }^{74}$ For some of the broader historical context on stridency, see Straw (2008). In addition to the examples in the next paragraph, the EMG Handmade Gramophone Company provides an interesting resistance to electrical reproduction. EMG took out ads in the Gramophone (1928) which read: "E. M. Ginn Offers A WORD OF ADVICE to all fellow Gramophiles. Don't buy any ELCTRIC REPRODUCER until you have investigated thoroughly the claims made for, and the marvellous results obtainable from, the E.M.G. Hand-Made Scientific Grammophones - then you will be convinced, as I have been, that the same standard of unvarying excellence and reliability is as yet unobtainable in Electrical Reproducers. I have decided, therefore, at considerable expense, to discontinue until further notice all electrical equipment ..." (James 1998, p. 44).
} 
can imagine."75 The young Theodor Adorno was also critical of the new method, admitting in 1927 that electrical recording was quieter, but protesting that "incidental noises ... nevertheless survive in the more shrill tone of the instruments and the singing." ${ }^{" 76}$ Later that same year, a reviewer of Wagner's Valkyrie album, released by HMV, "asks plaintively ... for something a little quieter than the latest of the new recordings." 77 For many readers, Valkyrie drew "attention to the prevailing tendency on the part of recording companies to make their records louder and louder," and the review thus sparked a six-month squabble in The Gramophone's correspondence columns. ${ }^{78}$

Some letters-to-the-editor were in favour of the increased volume, many were against it, and the debate touched on everything from manufacturing processes to needle hardness, microphone placement to room acoustics. The bottom line, though, was that despite the preference of enthusiasts for the tone of acoustic records over the volume of electrical recording and playback, audiences turned down tone so that they could turn up the volume (partly as an effect of shifts in taste and trends toward radio, and partly to facilitate group listening and dancing). Even the corporations and scientists heading up the development of electrical recording and playback did not fully comprehend this desire, and were at first reluctant to introduce the new method. Pioneering electrical recordist Joseph Maxfield looked back on this reluctance "laughingly": "they finally

\footnotetext{
${ }^{75}$ Mackenzie in the January 1926 issue of the Gramophone; see also Gelatt (1977, p. 232).

${ }^{76}$ Adorno (1990, p. 48).

77 Balmain (1928, p. 401).

${ }^{78}$ Luff (1928, p. 401). The loudness of Wagner's music had been criticized before the invention of sound reproduction, which opens up a broader historical discussion about the role of loudness in nineteenth-century musical aesthetics and music criticism. I take up this point in Chapter 4.
} 
shook their wise old white heads and said, 'well, we don't understand it, but if that's what the public wants, let's give it to them."'"79 Speaking of "the controversy concerning the 'loud' record," Columbia recording engineer Arthur Brooks sums this all up rather well: he shared the enthusiast sentiment ("mere volume, sans quality, leaves me stone cold"), but noted that "the dealers maintain that their customers prefer their records loud." 80

\section{Conclusion: fidelity and the historiography of sound reproduction}

This brings us back to the contemporary loudness war where, despite the objections of some musicians and industry personnel, generally loud and heavily compressed recordings prevail because they fare best in the situations in which most people listen to music. The loudness war can thus be seen as one in a series of loudness wars that pervade the history of sound reproduction. And the history of sound reproduction can be understood as a history in which auditory ideals and practicalities are in constant negotiation, where the priorities of audiences and "audiophiles" drift in and out of synch. These negotiations and compromises are the logics of listening formations that have been highlighted through this chapter's focus on loudness.

By no means have I been exhaustive: there are many more instances where the importance of loudness in the history of sound reproduction could be demonstrated, both during the period I have been describing and through the rest of the century. For example, loudness was privileged in certain styles of electric guitar performance as early as the

\footnotetext{
${ }^{79}$ Hunt, (1954, p. 69).

${ }^{80}$ Brooks (1928, p. 489).
} 
1930s; in the discourse of high-fidelity in the 1950s, volume took on a certain role in the gendered redefinition of domestic space - not to mention the role of loudness in live sound and concertgoing. ${ }^{81}$ Additionally, there are many examples of the subordination of "perfection" to other concerns - not only in terms of the fashion of concealed horn machines detailed above, but also intelligibility in a variety of sound media, uniformity in radio broadcasting and television sound, as well as the portability of MP3 files ${ }^{82}$ More than the history of a continual search for "perfect" sound, and more than a constructivist critique of that category, such tradeoffs between ideals of sound and practices of audition, between forms of mediation and modes of listening, point to a history of sound reproduction that orbits less exclusively in the problem space of fidelity.

It is customary in popular discourse and in the advertisements of gramophone companies to cast the history of sound reproduction as a story of progress, a series of refinements on the way to flawless recording and playback - perfect fidelity. The usual academic response has been to deny this teleology by revealing that fidelity is a socially constructed category: less a final destination than a moving target. From this perspective, the category of fidelity is a kind of technical-aesthetic ideal that changes over time - a point which Sterne sums up well and which is worth repeating: "every age has its own perfect fidelity." ${ }^{\circ 3}$ In his more recent work, Sterne reiterates this idea ("The history of

\footnotetext{
${ }^{81}$ On domestic space see Keightley (1996); on the role of loudness in discourses of live music see Percival (2011).

82 Respectively, Lastra (2000), Adorno (2002), Negus (2006), Sterne (2006). Negus's (2006, p. 323 ) analysis highlights the fact that "in the domestic context of television listening, the aesthetic judgment of producers and listeners does not necessarily coincide."

${ }^{83}$ Sterne (2003, p. 222).
} 
sound reproduction in the twentieth century is not, as sales literature might suggest, a story of ever increasing fidelity") but also takes it a step further, noting that the story of sound reproduction "may very well also not be a history of audiences who really care about greater fidelity." 84 This is my point too, although I want to expand Sterne's suggestion in two ways. First, the myth of increasing fidelity is of course more widespread than sales literature: in addition to ads, a variety of journalistic and insider histories have contributed to the centrality of fidelity. ${ }^{85}$ Second, the suggestion that fidelity has mattered less than other factors in the history of sound reproduction is potent, an idea which has the potential to move sound reproduction scholarship beyond its perennial emphasis on the social construction of fidelity. But the full weight of this idea has not yet been borne out in the scholarly literature. Regardless of whether writers or sound scholars are inflating or deflating the myth of fidelity, they assign fidelity such a pivotal role in the history of sound reproduction that it ends up overshadowing other facets - such as loudness.

I would also argue that the history of sound reproduction is not, despite what much academic literature might suggest, a story about the theoretical problem spaces of fidelity. Not exclusively, anyway. Sound reproduction obviously raises some provocative questions about the relationship between originals and copies, about speech and writing, presence and absence, the real and the symbolic, otology and ontology. ${ }^{86}$ These are

\footnotetext{
${ }^{84}$ Sterne (2006, p. 345).

${ }^{85}$ For example, Read \& Welch (1976), Gelatt (1977), Milner (2009).

${ }^{86}$ Respectively, Sterne (2003), Gitelman (2000), Peters (2004), Kittler (1999), Connor (1997).
} 
instances and extensions of what Evan Eisenberg calls "the paradoxes of phonography." As a term, phonography is difficult to define precisely, and the use of it cannot be pinned on any one scholar. In general, though, it is meant as a shorthand way of pointing to a kind of acoustic modernity, in which the development of sound reproduction offered not only new technological possibilities but also new epistemological problems, both of which helped redefine relationships between human consciousness and communication, on the one hand, and the world of sound, on the other. In other words, phonography refers to "a period in our relation to music ... marked by a distinct set of attitudes, practices, and institutions made possible by ... the phonograph" as well as "an anthropological revolution in human history - not just another in a series of technological innovations but one which profoundly interrupts and problematises what it means to be human." 88

Through a study of loudness, though, I have shown that examining sound reproduction primarily in terms of the problem space of fidelity, as fruitful as this has been, is also to limit it as an object of study. Despite fidelity's obvious historical importance, the study of loudness shows that the development of sound reproduction can be productively framed in other ways, too. And despite the conceptual allure of phonography, the study of listening formations pushes toward historical questions as much as theoretical conundrums (to an extent, the study of loudness is less interesting for the theoretical questions it poses than for the theoretical preoccupations it exposes). This isn't to say that theory is irrelevant here. But to understand this history in terms of

\footnotetext{
${ }^{87}$ Eisenberg (1987, p. 158).

${ }^{88}$ Respectively, Rothenbuhler \& Peters (1997, p. 242), Engh (1999, p. 54).
} 
listening formations is to augment the theories of modernity, representation and subjectivity that pervade much sound reproduction scholarship. It's for these reasons that I suggest the historiography of sound reproduction has been circumscribed by histories of fidelity and theories of phonography, and that such circumscription is problematic. So my argument here is offered as a counterweight to the theorists of phonography, who treat sound reproduction principally as a problem of semiotics and post/structuralism and psychoanalysis. And my argument is equally meant to counterbalance the historians of fidelity, who argue above all that the "logic that has attended the development of recorded sound has been one of high fidelity." 89

Because of the extent to which the history of sound reproduction has become synonymous with the history/critique of fidelity - both in the popular imagination and the academic literature - my argument about the relatively minor status of fidelity may seem counterintuitive. But the fact that practicalities of loudness trump ideals of fidelity in so many areas of sound reproduction is perhaps less surprising than the fact that fidelity managed to assume such a prominent and resilient role in the discourses of sound reproduction in the first place. In many ways, the history/critique of fidelity is the story of a dominant discourse but a minority listening practice. Engaging with the history of sound reproduction is thus not, for me, primarily an exercise in mythologizing fidelity (the "perfect sound forever" of ads and popular discourse) or demystifying that category (the "perfecting sound forever" of critical scholars). Rather, the tensions between acoustic

${ }^{89}$ Engh (1999, p. 54). 
ideals and auditory practicalities - the logics of listening formations exhibited by the loudness wars - tell a different story. More like, imperfect sound forever. 


\section{CHAPTER 2 \\ Privacy: an imposing loudspeaker}

Anonymously, in 1878, a writer for the New York Times sounded an alarm:

The phonograph was, at the time of its invention, the most terrible example of depraved ingenuity which the world had seen; but Mr. Edison has since reached a still more conspicuous peak of scientific infamy by inventing the aerophone - an instrument far more devastating in its effects and fraught with the complete destruction of human society. 1

As a pneumatic means of sound amplification able to "convert whispers into roars" audible between one and ten miles away (depending on whom you asked), ${ }^{2}$ the aerophone's apocalyptic potential stemmed from an assumption about how it would be used. "Wives residing in suburban Jersey villages," stewed the columnist, "will call to their husbands at their places of business in the City, and require information as to subjects of purely domestic interest."

Mothers whose children have wandered out of sight will howl over a four-mile tract of country direful threats as to the flaying alive that awaits James Henry and Ann Eliza unless they instantly come home. From morning till midnight our ears

\footnotetext{
1 "The Aerophone" (25 March 1878, p.4). See also "The Aerophone" (13 April 1878).

2 Edison's biographers modestly suggest a distance of one and a half miles, whereas the nameless New York Times columnist claims "no less than four miles." Edison himself claimed ten miles and boasted that he would "have no difficulty in making the machine bore a hole through a board." See "The Aerophone" (25 March 1878), Dyer \& Martin (1929, pp. 212, 225), Figure 1, Jehl (1937, pp. 180-181, 182). Interestingly, the press's hyperbolic descriptions of the aerophone were exceeded by even farther-fetched accounts of another invention: the megaphone. During the summer of 1878, the megaphone-amplified sounds of "cattle munching grass" were reportedly heard six miles away (Jehl 1937, p. 180).
} 
will be tortured with the uproar of aerophone talk... The result will be the complete disorganization of society. Men and women will flee from civilization ... Business, marriage, and all social amusements will be thrown aside, except by totally deaf men, and America will retrograde to the Stone Age with frightful rapidity. ${ }^{3}$

Of course, Edison's own ambitions for the aerophone were far from malicious - the uses he envisaged ranged from the benign ("signaling distant vessels"4) to the ridiculous (giving voice to the Statue of Liberty ${ }^{9}$ ) - and the fears of the nameless writer were obviously, comically, overblown. ${ }^{6}$ But this Times article also prompts a more serious

\footnotetext{
3 "The Aerophone" (25 March 1878, p.4).

${ }^{4}$ Edison $(1878$, p. 1): "The object of this invention is to reproduce the human voice or other sounds with greatly increased volume or force. ... My invention is available for giving orders on vessels, for signaling distant vessels, for military orders, for orders at fires, for communicating between engineers of passing locomotives, for signal-stations, and for addressing large assemblies, or for giving audible utterances that are sufficiently powerful to be heard above surrounding noise or confusion." Edison's inability to predict the ultimate uses to which his inventions would be put is well known. Indeed, he was sometimes at odds with users, as is perhaps most obvious in the case of the phonograph (which he insisted for many years was primarily a dictation device rather than a music machine). This highlights the capacity for incongruence between inventors, users and manufacturers - a point which I take up in more detail in Chapter 3.

5 See Figure 1, from "Awful Possibilities" (21 March 1878). See also "The Aerophone" (25 March 1878, p. 4): "He also boasts that he will attach an aerophone to the gigantic statue of 'Liberty,' which France is to present to this country, provided we will raise money enough to pay for it."

${ }^{6}$ It would be possible to argue that these fears are less exaggerated than they first appear. Consider for example that the telephone had only been "invented" two years prior, in 1876. This means that the Times article was published at a moment when the aerophone and the telephone had comparable functions and capabilities (enabling communication at a distance), and could have conceivably competed for the same job - which is what worried the columnist.
} 


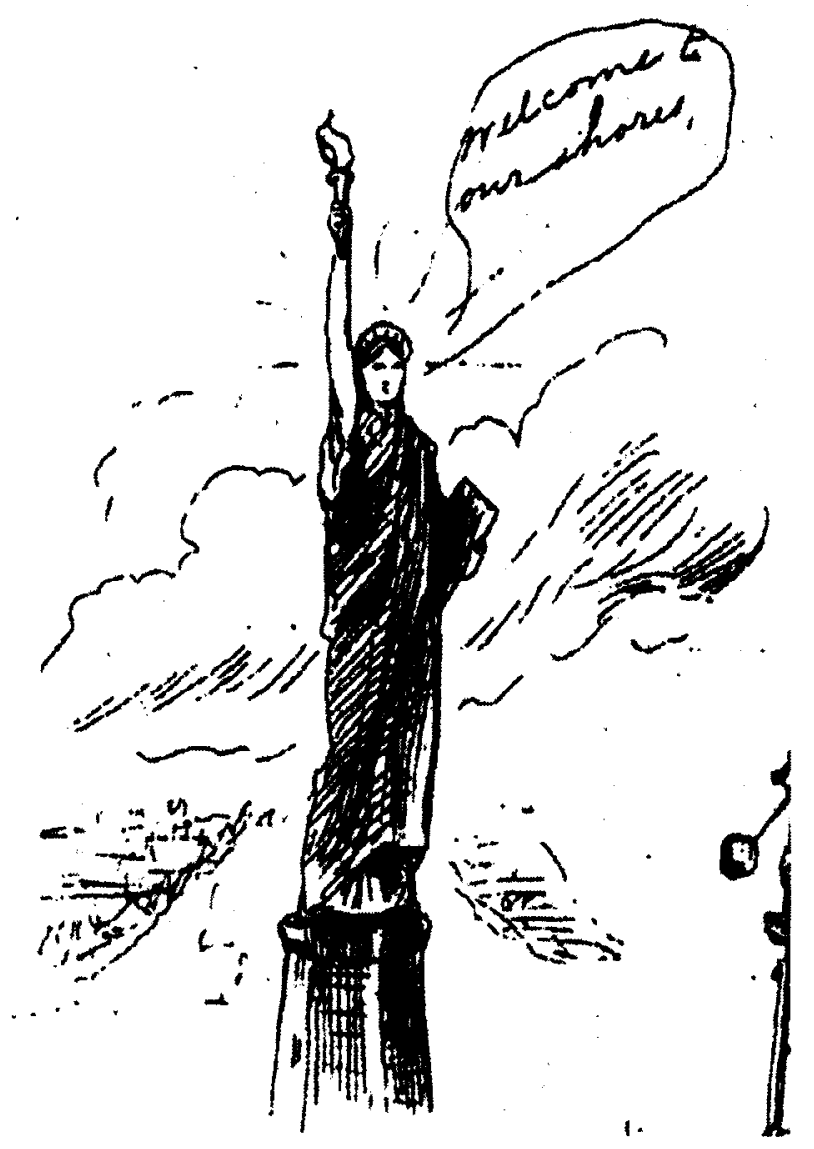

Figure 1. "I can make that statue speak so that it can be heard ten miles." Thomas Edison (1878)

discussion, for it provides a window onto two entwined sets of problems in the late nineteenth and early twentieth centuries: publicity and privacy, on the one hand, noise and silence, on the other ${ }^{7}$

\footnotetext{
${ }^{7}$ Of course, the aerophone is only one among many forms of pneumatic sound technologies that existed before and through this period. For discussions of orchestrions, dance organs and automatic orchestras in relation to film sound and other forms of public entertainment (e.g. dancing saloons, fairgrounds, skating rinks, concert halls), see Bowers (1972), Ord-Hume (1973, pp. $194 \mathrm{ff}$ ) and Altman (2004, pp. $329 \mathrm{ff}$ ). For a discussion of British applications of pneumatics to sound reproduction, embodied in the Victor Auxetophone (invented by Charles Parsons), see Seymour (1918), Appleyard (1933), Carnegie (1934). Although these pneumatic amplifiers support the present discussion by focusing attention on collective listening, dancing and pleasure more than privacy, fidelity or noise abatement, fuller consideration is unfortunately beyond the scope of this thesis. In a larger history of loudness and sound reproduction, such music machines would have to figure prominently.
} 
Richard Butsch outlines the general historical trend here in terms of a "shift from public to private ... a shift from community to family and ultimately to individual." ${ }^{8}$ In this first phase of what I will describe as a three-step process, "Public space was privatized":

... public places ... were redefined from places of community and civic participation to places of private shopping and consumption ... Gatherings were no longer a community with a shared fate, but impersonal crowds of families or individuals with private interests. ${ }^{9}$

The second phase, which is more closely associated with the twentieth century, takes privatization a step further, toward domestication:

Radio and television broadcasting privatized entertainment and provided a reason to stay at home. The home became increasingly a center of entertainment, and the family replaced the community as the group sharing the experience. This carried the process of privatization beyond privatizing public space to withdrawing to private space ... ${ }^{10}$

The third phase sees the individuation - the atomization - of the domestic sphere itself. I will come back to domestication and atomization. Here I want to note that the aerophone uproar bears witness to the first phase of this three-step process. Indeed, the author of the Times piece was not worried that the aerophone would invade the privacy of the home, but that it would impose on publicity, that it would violate a certain expectation of what it

\footnotetext{
${ }^{8}$ Butsch (2000, p. 12).

${ }^{9}$ Ibid. (pp. 12-13).

${ }^{10}$ Ibid. (p. 13).
} 
meant to be in public space. Tellingly, a writer for the London Figaro complained that with the aerophone "Mr. Edison ... has committed a further outrage upon public privacy."11

The idea of public privacy is, in Richard Sennett's terms, a "legacy of the 19th Century's crisis of public life" - which is, in turn, a crisis of modernity. ${ }^{12}$ The historical shift Sennett describes is one from an active and politically engaged public to an assembly of self-absorbed individuals, from public man to the man of the crowd.

Through the nineteenth century, public life became a matter of appearing "as unremarkable as possible": "Isolation in the midst of visibility." 13 This is the root of public privacy, the idea "that each man possessed as a public right an invisible shield, a right to be left alone."14 On its own, this aspect of Sennett's book - larger groups make for less integration - is not particularly remarkable, having been noticed for a century by a range of sociologists. What I find especially interesting about Sennett's thesis, though, is his emphasis that the "invisible shield" is an acoustic shield: "Silence in public," he says, "became the only way one could experience public life, especially street life, without feeling overwhelmed."15 Although Sennett does not discuss the aerophone reportage, it illustrates his thesis remarkably well.

\footnotetext{
11 "The Aerophone" (13 April 1878, p. 557). My emphasis.

12 Sennett (1977, p. 27).

${ }^{13}$ Ibid. (pp. 26, 27).

14 Ibid. (p. 27).

${ }^{15}$ Ibid.
} 
Fast-forward to the 1920 s and thirties, to a time when the occasional aerophone blast had been replaced by the ubiquity of loudspeakers. By then the individual's right to silence in public (which was probably always more of an ideological wish than a historical reality) had again reached a boiling point. "Even in the café," stressed Siegfried Kracauer, "where one wants to roll up into a ball like a porcupine and become aware of one's own insignificance, an imposing loudspeaker effaces every trace of private existence." ${ }^{16}$ As a function of audio technologies, sound scholars have traced public privacy back to the stethoscope, through the car radio, and forward to the iPod. ${ }^{17}$

The second phase of the privatization narrative described by Butsch and others domestication - is similar to the first. The starting point here is that the increasing prominence of city life spurred a redefinition of "personal boundaries," "a reassessment of individual rights": "As the possibilities for solitude diminished, the desire for privacy increased."18 Following the development of individuation in public, the home was put forward as the base of this will to privacy, "an unviolated space ... a retreat from ever-

\footnotetext{
${ }^{16} \mathrm{Kracauer}$ quoted in Bull (2004, p. 189). An interesting parallel can be drawn here between Simmel's (1964) thesis about the calluses that form on perception in "The Metropolis and Mental Life," on the one hand, and British critic Constant Lambert's (1934, pp. 234, 238-239) exasperated tirade against the loudspeaker, on the other: "Although excessive sonority has lost its thrill, we still demand it as an ever-increasing factor in our lives. ... We live in an age of tonal debauch where the blunting of the finer edge of pleasure leads only to a more hysterical and frenetic attempt to recapture it. It is obvious that second-rate mechanical music is the most suitable fare for those to whom musical experience is no more than a mere aural tickling, just as the prostitute provides the most suitable outlet for those to whom sexual experience is no more than the periodic removal of a recurring itch. The loud speaker is the street walker of music."

${ }^{17}$ See Sterne (2003) on "audile technique," Bijsterveld (2010) on car stereos, and Bull (2000, $2004,2007)$ on iPods and personal stereos. See also Chua (2011).

${ }^{18}$ Smilor (1979, p. 25).
} 
encroaching modernity."19 The history of domesticity has been described by numerous scholars. ${ }^{20}$ But my interest here, as above, is in the idea that modernity's most bothersome encroachment was acoustic:

Din especially threatened the right to privacy. ... More than any other environmental pollutant, noise was an invasion of privacy. One could close his windows to keep out smoke and odors ... But an individual had no control over $\operatorname{din}^{21}$

From this perspective, the narrative of privatization (via domestication) makes way for the history of noise as a social problem.

The last stage in this narrative of privatization is atomization. In Butsch's reading, the domestication of audio technology (radio especially) and its attendant privatization of listening were followed by individuation:

Once the household market began to reach saturation ... manufacturers reversed their domestication strategy and began to associate radio with individuals rather than the family and home.... Listening was becoming an individual experience, each person attuned to the radio and insulated from every other. . . Radio both removed people from the crowd of the theater and isolated people from each other in - and out of - the home... This practice removed audiences further from the ground of collective action and provided grounds for critics to decry "hypnotic," "narcotic" effects of broadcasting on individuals. ${ }^{22}$

\footnotetext{
${ }^{19}$ Kruse (1993, p. 6).

${ }^{20}$ For examples from sound and music studies that open out onto the broader literature, see Keightley (1996) and Waksman (2004).

${ }^{21}$ Smilor (1979, p. 25).

22 Butsch (2000, pp. 205, 207).
} 
Theodor Adorno was perhaps the most vocal decrier of "music's function as a drug."23

For Adorno, this isolation of the listener - what his colleague Leo Lowenthal labeled (in a different but not disparate context) the atomization of the individual - was related to radio's "atomization" of musical content. ${ }^{24}$ In Robert Witkin's words, "The atomized contents of pseudo-culture answer to the lives of atomized individuals." ${ }^{25}$ Richard Leppert elaborates:

Adorno was sensitive to the intersubjectivity immanent to ... public listening. ... The radio performance, by contrast, democratically available to anyone with a radio set, is resolutely privatized; the radio listener's intersubjective relation to others is lost, beyond those gathered in front of the console, and even this limited form of intersubjectivity is further constrained by the myriad distractions of the domestic interior. ${ }^{26}$

In other words, if the privatization of the public sphere led to individuation, then the already privatized domestic sphere prompted atomization.

This narrative of privatization (described here in three movements: public privacy, domestication, atomization) has been widely discussed. Indeed, it was a central topic of turn-of-the-century social science, and public discourse more generally, from Edgar Alan Poe's "Man of the Crowd" to the studies of Gustave Le Bon, Georg Simmel and Gabriel Tarde; from the British mass observation surveys and the mass media research of the

\footnotetext{
${ }^{23}$ Adorno (2002B, p. 257).

${ }^{24}$ Adorno (2009, p. 55): "[Radio music] will appear not as a totality in which each part derives its proper meaning only in relation to the other parts, but rather becomes a rapid succession of 'atom-like' sections, each apperceived more or less in isolation." See also Lowenthal (1946).

${ }^{25}$ Witkin (2000, p. 23).

${ }^{26}$ Leppert (2002, p. 224).
} 
Payne Fund and Paul Lazarsfeld to the critiques of mass culture levelled by Adorno and the Frankfurt School. ${ }^{27}$ Butsch characterizes these discourses in terms of a shift from fears about rowdy crowds to concerns about passive masses. But this chapter does not promote a narrative of privatization at the expense of the public sphere - a descent from coffeehouses to couchpotatoes. ${ }^{28}$ Nor does it assume that the most important public issues of sound are social problems of noise. But neither does this chapter tout the potential of sound technology to expand auditory publics or redefine nations as acoustically imagined communities. ${ }^{29}$ Nor does it support the rhetoric that sound technology democratized or refined musical taste, or that it civilized the farmer. ${ }^{30}$ All of these standpoints will find expression at various points in this chapter. But I want to look at the proliferation of the loudspeaker through the 1920 s and 1930 s in less polemical terms.

My aim is to situate the loudspeaker in the context of shifting ideas of public and private space, collective and domestic listening practices, in order to raise questions about a historiography of sound reproduction that is normally framed in terms of noise abatement campaigns and the retreat of sonic entertainment into the domestic sphere. ${ }^{31}$

${ }^{27}$ Respectively, Poe (1984 [1840]), Le Bon (1896), Simmel (1964 [1903]), Tarde (1960 [1901]), Madge (1939), Lazarsfeld (1969), Adorno (2009). For insightful analyses of several of these research programs, see Clark (1969), Jowett et al. (1996), Hubble (2006), Hullot-Kentor (2009). 28 À la Sennett (1977), Eagleton (1984), Habermas (1991) and others.

${ }^{29}$ For a discussion of the German context, see Birdsall (2007). In a broader sociological sense, see Tarde $(1969[1898,1901])$ as a precursor to Anderson (1983).

30 "Democratization" being the American rhetoric; "refinement" being propagated by John Reith and the BBC. For some of the background here, see Frith (1988B). For a period critique of these ideas in relation to radio, see Beuick (1927).

${ }^{31}$ On noise, see Thompson (2002), Bijsterveld (2008), Schwartz (2011). For excellent work on the domesticity of sound, Kruse (1993), Keightley (1996), Lacey (2000), Sterne (2003), Smith (2011). For a broader take on privatization and entertainment, see Nasaw (1993). 
Here I offer another perspective. By examining the willingness of audiences to subject themselves to electrically amplified sound, I demonstrate that changes in the modern acoustic environment - in the day-to-day material organization of listening formations were not only about atomization or abatement, but also the newfound hopes and desires in, and the pleasures and conveniences of, electrically amplified sound (from politics to sports, advertising to workplace communication). And by studying the novel forms of collective listening afforded by the use of sound systems in such everyday contexts, I demonstrate that the changing listening environment was as much about new possibilities in collective listening in public space as it was the domestication and isolation of listening. ${ }^{32}$

\title{
The proliferation of the loudspeaker
}

\section{Public address}

The crowd is the social group of the past ... Whatever its form, standing or seated, immobile or on the march, it is incapable of extension beyond a limited area; when its leaders cease to keep it in hand, when the crowd no longer hears their voices, it breaks loose.... But the public can be extended indefinitely ...

- Gabriel Tarde, "The Public and the Crowd," $1901^{33}$

Many of the earliest uses of public address equipment amounted to novelty. For example,

\begin{abstract}
${ }^{32}$ A parallel can be drawn with film studies: just as the prevalence of moviegoing as a public event was paralleled by equally significant domestic currents (Singer 1988, Klinger 2006), so was the prevalence of sound reproduction as an apparently domestic and individuated phenomenon paralleled by equally significant shifts in the public and collective listening that accompanied the reconfiguration of listening formations during this period.
\end{abstract}

${ }^{33}$ Tarde (1969, p. 281$)$. 


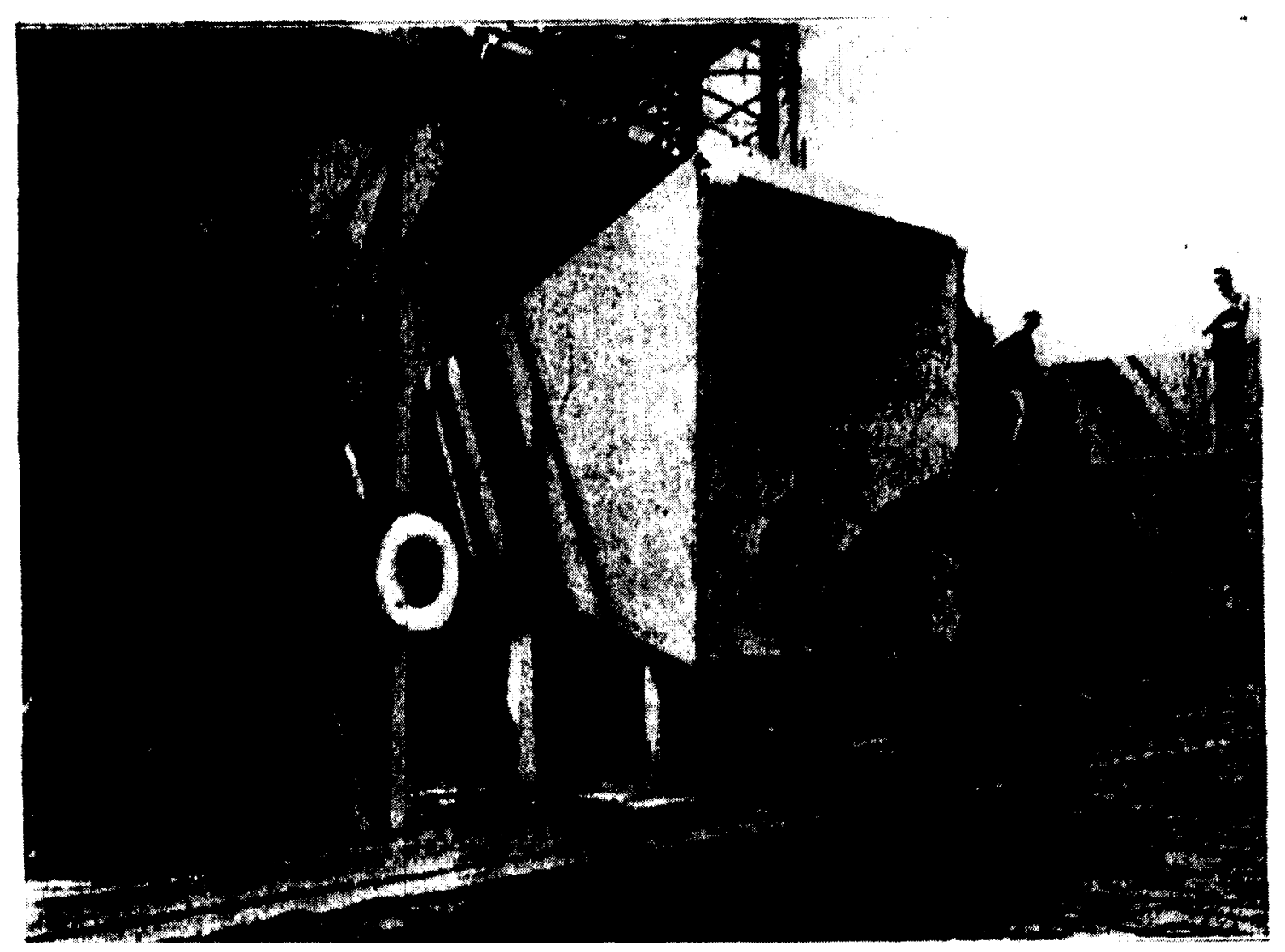

Figure 2. "Radio Megaphone is Large Enough for a Diving Platform," Popular Science (1922)

in an extension of one of the earliest and far-fetched uses for public address systems (a means of air-traffic control), and as a precursor to more sinister uses (a means of crowd control), Peter Jensen and Edwin Pridham's Magnavox was explored for its use in airborne advertising. ${ }^{34}$ Scientists were enthralled with the ability of electrical amplification to act as an acoustic microscope, bringing previously unheard atomic

${ }^{34}$ On air-traffic control, see Pridham (1918). On the RAF's transformation of Vickers Victoria planes into airborne loudspeakers used to terrify rebellious groups in Mesopotamia as early as 1922, see Johnson \& Cloonan (2008, p. 57). On aerial advertising, see "A Voice from the Sky" (1919): "An aviator three thousand feet in the air said, 'Buy a bond!' and crowds of people in front of the Treasury Department Building in Washington heard him plainly." For the origins of the Magnavox, see Chapter 3. 
sounds within earshot. ${ }^{35}$ Others did just the opposite, exploring the possibilities of electrical amplification as a kind of acoustic telescope, for its role in speaking-out more than listening-in. In California, there was a loudspeaker large enough to be used as a seven-person diving platform (see Figure 2) ${ }^{36}$ A New Jersey City Hall was outfitted with a sound system so large that the whole town could hear it, so powerful that "a visitor's clothes flap in time to the music, and entering the tower containing the strongly vibrating air is like walking through mud." ${ }^{37}$

Through the 1920s, though, public address systems took permanent root in a dizzying array of contexts. These ranged from steamships to stadiums, campaigns to courtrooms, workplaces to warning systems. ${ }^{38}$ Education was also seized by electrical amplification. Public schools were recognized as an especially significant potential market, ${ }^{39}$ but universities and colleges were also targeted. In an unusual case, a public address system was installed to socialize the students of the California Technical Institute, who "although they have been well grounded in the principles of science and engineering

\footnotetext{
35 "Noise of Electrons Heard by Human Ears" (1924), "Roar of Atoms Heard by Means of Radio" (1924).

36 "Radio Megaphone is Large Enough for a Diving Platform" (1922, p. 343).

37 "Entire City Can Hear World's Biggest Loudspeaker" (1931, p. 68).

${ }^{38}$ On steamships, see Cameron (1936, p. 259): "The public address systems in steamships are employed for a number of uses; they supply recorded programs to the various public rooms; they are used to transmit the orchestra music from the dining rooms to the decks and public rooms. They are used to make announcements." On sporting events and stadiums, see "Penn Installing Loud Speakers" (1926). On advertising, see "Amplifier Makes Automobile "Speak for Itself" (1922). On courtrooms, see "Court to Install Loud Speaker" (1926). On workplaces and warning systems, see Mitchell (1931, p. 9), Lane (1922).
}

${ }^{39}$ Glover (1931), Mitchell (1931). 
have in many cases been completely lacking in the social graces. ${ }^{{ }^{40}}$ A $1929-1930$ public address catalogue lists a range of other contexts: theatres, auditoriums, dance halls, fairs, club houses, restaurants, advertising trucks - and racetracks. ${ }^{41}$ Indeed, from the National Air Races to the Indianapolis 500, loudspeakers announced pole positions and ordered drivers to start their engines. ${ }^{42}$ Sound systems were put to use very early on in religious services and, by 1940, even the Pope was sermonizing his flocks with the aid of a loudspeaker. ${ }^{43}$

One of the most noticeable uptakes of electrical amplification was in politics, where the technology received almost as much coverage as the figures that used it. Indeed, public address equipment figured prominently in a variety of campaigns and presidencies. Woodrow Wilson, for example, whose poor health had limited his public speaking engagements, was able to continue addressing large outdoor crowds thanks to a custom system developed by Magnavox in $1919 .{ }^{44} \mathrm{~A}$ similar system was used in 1920 , during Democratic nominee James Cox's campaign efforts. ${ }^{45}$ In other cases, loudspeakers were attached to vehicles and used to blare advertisements and political messages through

\footnotetext{
${ }^{40}$ Cameron (1936, p. 256). See also Mitchell (1932, p. 11).

${ }^{41}$ Van-Ashe Radio Co. (1929-1930).

${ }^{42}$ On air racing, see Cameron (1936, pp. 264 ff). On the Indy 500, see the 1929 Electromuse PA ad reproduced in Adams (1987, p. 9).

43 "Sound Amplifier Augments Religious Service" (1921), "Loudspeakers Installed" (1940).

44 Jensen (1975, pp. 114 ff).

45 "200,000 May Hear Cox" (1920), "New Device to Enable 150,000 to Hear Cox" (1920).
} 
neighbourhoods and across the country. ${ }^{46}$ Indeed, loudspeakers were still news in Calvin Coolidge's term..$^{47}$

Perhaps most famous, though, were Warren Harding's inaugural speech and his funeral oration to the Unknown Soldier on Armistice Day, both in 1921. Partly, his inaugural was remarkable for demonstrating that a public address system made for orderly oratory:

There was none of the crowding cruelty which maims and sometimes kills the woman or child who is caught in the press of an unthinking crowd. The newspapers of Washington had told their readers that the voice would be distributed all over the plaza and the park, and naturally there was no great rivalry for front positions. ${ }^{48}$

We get a sense here of what's in a name: public address system. Ideas about the "public" have specific histories, distinct from but overlapping with other understandings of audiences and groups (e.g. crowds, mobs, masses). And if Harding's inaugural signaled new qualities of "crowds" - if it made them more civil - it also marked a quantitative shift in the possibilities of what Murray Schafer calls the acoustic community. ${ }^{49}$

Echoing Plato, early commentators recognized that "Public speaking occupies a

46 "Transcontinental Radio Car Makes First Trip" (1922).

47 “Millions to Hear Inaugural Address" (1925).

48 "A Telephonic Achievement" (1921, p. 3). See also Dooley (1932, p. 14): "The use of the sound installation [at "Central Park Arena, a boxing club in Orange, N.J."] has done more toward keeping the crowd orderly than a squad of police could."

${ }^{49}$ Schafer (1994, p. 215). On the high/low distinction between crowds and publics, see Butsch (2008). A connection should be drawn here to Benedict Anderson's notion of an imagined community. Indeed, my discussion should amplify the significance of Anderson's (1983, pp. $9 \mathrm{ff})$ own invocation of Unknown Soldiers and nationalism. 
place of paramount importance in the conduct of a democratic form of government." 50

There was a time when addressing the acoustic community was relatively easy ("In the day when the country was sparsely settled it was comparatively easy for public men to keep in touch with their people through addresses to small gatherings"); but the increasing American population, and the increasing urbanization of that population, "prompted some to predict the passing of the art of public expression which had been diligently studied and faithfully practiced for many centuries."51 The electrically amplified loudspeaker apparently solved this problem, allowing Harding to address "the greatest number of people that has ever listened to one man's voice at one time in the history of the world." 52 For some, this expanded acoustic community marked "a new day in the psychology of the spoken word." ${ }_{33}$

\footnotetext{
${ }^{50}$ Western Electric (1922, n.p).

${ }^{51}$ Ibid.: "In the day when the country was sparsely settled it was comparatively easy for public men to keep in touch with their people through addresses to small gatherings. But at the present time the population has increased to such an extent that it has been necessary to build mammoth auditoriums to accommodate the throngs which congregate to hear the messages that men of prominence have to deliver. The acoustics of these buildings are often such that the words of the speaker are not clearly audible to a large percentage of those present. This condition prompted some to predict the passing of the art of public expression which had been diligently studied and faithfully practiced for many centuries."

52 "A Telephonic Achievement" (1921, p. 1). For other reports on Harding's inaugural, see "All May Hear Harding Speech" (1920) and "Harding Amplifier Fills Three Rooms" (1921).

53 "A Telephonic Achievement" (1921, p. 2). See also Green \& Maxfield (1923, p. 75): "The social and economic possibilities of the system are scarcely realized by the public as a whole at the present time, when the method resorted to for reaching large numbers of people is usually the printed word. ... A system such as the one which has just been described enables the speaker, even though his voice be relatively weak, to address at one time and in one gathering, several hundred thousand persons, and if the system be used in connection with long distance telephone lines or radio broadcasting, the number which may be reached is increased almost indefinitely. The value of such a situation can hardly be overrated in times of national emergency or stress, when it is necessary for those in responsible positions in the Government to get their message to the people directly."
} 
In the context of Harding's Armistice oration, delivered at Arlington Cemetery and amplified for audiences in New York and San Francisco, ${ }^{54}$ the combination of public address with radiotelephony was even more explicitly tied to the project of nation building:

The solemnity, the majestic simplicity, the almost supernatural perfection by which the head of the world's greatest nation paid tribute to an unknown hero was nearly too much for everyday comprehension. It touched the heart. It kindled the imagination. It reached out over the maze of wires and finding a multitude of auditors made them worshippers. ${ }^{55}$

As with the inaugural, the expansion of the acoustic community was paramount:

"Without a shade of hyperbole, the ceremony marked an epoch in communication ...

The oration of President Harding was heard by over 150,000 people, the largest aggregate gathering that ever heard one man's voice." 56 The Bell System patted itself on the back for its contribution to a "time when a nation's head can speak simultaneously to many such audiences scattered over the length and breadth of the land. For science, manifesting itself in the telephone art, has united East and West." 57 Self-serving though the Bell's rhetoric may have been, it is elegant and seems sincere:

Back of it all lay a new conception of the American heart; a realization that this first public test of telephony's latest triumph had been a triumph for America

\footnotetext{
54 "New York to Hear Harding Oration" (1921), "Nation May Hear Voice of Harding" (1921). 55 "Our Tribute" (1921, p. 26).

${ }^{56}$ Ibid. (pp. 30-31). This prompted speculation that Harding might one day address the entire nation in one place, at one time ("If President Harding Spoke to 120,000,000 People" 1922).

57 "Our Tribute" (1921, p. 32).
} 
itself; a deep and heartfelt feeling of thanks that there had been brought into being a means of binding together with newer and more intimate bonds, the Union which thousands of those who sleep at Arlington had died to preserve $\ldots{ }^{58}$

In both Harding's inaugural and his oration, then, during this period of re-stabilization

following the War, the ability of a public address system to act in the service of nation building - to redefine the character and boundaries of America as an acoustic community - was not lost on politicians or corporations. By 1924, the AT\&T in-house journal Long Lines could proclaim, in marked contrast to the alarm that accompanied the aerophone, that public address had sounded "A New Note in Politics." 59

It would be possible to argue that the acoustic public addressed through the loudspeaker is not the same as the enlightenment public idealized by Sennett and others.

For Sennett, public address equipment would not stimulate "public" life; it would destroy it: the centrality of the orator aligns public address with control rather than dialogue, with

\footnotetext{
${ }^{58}$ Ibid. (p. 33).

59 "A New Note in Politics" (1924). A similar story unfolded overseas, where Fred Warren gave Britons their first tastes of public address at an Armistice ceremony in 1919, and then during a George Bernard Shaw speech to the Labour Party in 1921. Given Warren's relative independence and lack of corporate backing, his amplification systems were necessarily crude - more so than those of AT\&T. Indeed, he looked back on his Armistice system as a "rough-and-ready lash up" and "recalls with a smile" an early microphone: a "carbon button insert in a sardine tin packed with Plasticine!" ("Making PA Pay" 1963, p. 8). On the "rough-and-ready" system, see Warren $(1965$, p. 56): "In the end I settled for a microphone concocted from four telephone type carbon buttons on a single diaphragm, with damping by grease packed cotton wool. The speakers were really crude, virtually an overgrown headphone with massive horseshoe magnets, to this we added a conical horn shaped from tin sheet. The day of the function came and we lashed the two speakers to lamp-standards ... Of course the whole thing was battery operated ... No form of volume control was fitted, the only control being tapping up or down the volts supply to the mike."
} 
passive spectatorship more than active witnessing. ${ }^{60}$ When Tarde contrasted the crowd (the "social group of the past" which "breaks loose" when it "no longer hears their [i.e. its leaders'] voices") with the public (which "can be extended indefinitely"), he was not praising the loudspeaker but instead "the formidable power of the press" that had emerged from the combination of "printing, the railroad, and the telegraph." Newspapers, for Tarde, fostered a public centred on discourse, "a purely spiritual collectivity, a dispersion of individuals who are physically separated and whose cohesion is entirely mental."\%2 Tarde did not live to see the advent of the loudspeaker and, if he did, it is probable that, like Sennett, he would have viewed it as a tool of the crowd rather than a means of expanding a public or "a means of binding together with newer and more intimate bonds," as the Bell System put it. Perhaps, if Tarde had heard the loudspeaker, he would have reconsidered his criticism of Gustave Le Bon: "I . . cannot agree with that vigorous writer, Dr. LeBon, that our age is 'the era of crowds.' It is the era of the public or of publics, and that is a very different thing. ${ }^{* 33}$

\footnotetext{
${ }^{60}$ Sennett (1977, p. 261): "To speak of an end of public life is first to speak of a consequence, issuing from a contradiction in culture of the last century. Personality in public was a contradiction in terms; it ultimately destroyed the public term. For instance, it became logical for people to think of those who could actively display their emotions in public, whether as artists or politicians, as being men of special and superior personality. These men were to control, rather than interact with, the audience in front of whom they appeared. Gradually the audience lost faith in itself to judge them; it became a spectator rather than a witness. The audience thus lost a sense of itself as an active force, as a "public."'

${ }^{61}$ Tarde (1969, p. 281).

${ }^{62}$ Ibid. (p. 277)

${ }^{63} \mathrm{Ibid}$. (p. 281). See Butsch (2008) for an interesting account of how crowd psychology influenced early twentieth-century American sociology.
} 
While contemporary theorists may make more room for the "public" of public address by pointing to the importance of collective, intersubjective interpellation in the formation and maintenance of public life, ${ }^{64}$ my point is that, regardless of whether such audiences (the "publics" of acoustic modernity) are understood as politically progressive or politically regressive, early uses of public address systems were idealized by

participants. What we see here is the range of applications of public address equipment, its broad proliferation, and some of the hopes that were projected onto - and through the loudspeaker during the 1920 s. This moment came after the conception of listening audiences as crowds; and it occurred alongside the repositioning of cinema and radio audiences as masses of atomized individuals. ${ }^{65}$

By 1930, Projection Engineering, one of the few trade papers dedicated to public address, was justly confident in the state of the art and its prospects: "the so-called public-address system is being employed by all industries, amusements and in every walk of life." ${ }^{\prime 66}$ Indeed, a sound amplification industry had solidified and, despite the Depression, business was booming - not just in America but around the world, from Mexican churches to Peruvian parks, Belgian palaces to Chilean theatres, New York

\footnotetext{
${ }^{64}$ In Warner's (2002, p. 418) words: "Our subjectivity is understood as having resonance with others, and immediately so." Of course, I would avoid describing this intersubjective interpellation in terms of "immediacy." Rather, my goal would be precisely to draw attention to the role of technocultural mediation in the process of subject formation. For an analysis that pushes in this direction, albeit in the context of Nazi Germany, see Biddel's (2007) work on "affirmative resonances."

${ }^{65}$ See Butsch (2008, especially Chapter 2).

${ }^{66}$ Simons (1930, p. 18).
} 
airports to speaking cattle in Seattle. ${ }^{67}$ Gordon Mitchell, a frequent contributor to Projection Engineering, summarized the rapid and broad proliferation of public address equipment: "Sound amplification," he said, "has done much to increase the enjoyability of modern life and the efficiency of modern business." ${ }^{\prime 68}$

Not everyone agreed. There were those who thought that loudspeakers transformed Congress into "The screech of a busy sawmill, the quack of a guinea hen, the escaping steam of a locomotive, all mixed with the whir of an airplane." Far from a novelty or a contribution to the "enjoyability" of modern life, loudspeakers were apparently "ruining orderly procedure in the House ... They catch up every sound from the floor, and the result is a loud babel of confusion." ${ }^{69}$ In contrast to the utopian political view of public address, a British critic thought that projecting political speeches through loudspeakers at Hyde Park would be "wearisome." ${ }^{.70}$ Later controversies saw loudspeaker campaigning banned as a nuisance - an injunction which the American Labor Party fought (and lost) on the grounds "that the constitutional right of free speech included the right to use sound amplifying equipment mounted on motor vehicles in public streets and places." $" 11$ will return to this question below, in relation to radio. First, it is relevant to

\footnotetext{
${ }^{67}$ Contexts from Simons (1930). For a description of the emerging global sound empire in cinema, see Thompson (2004). On the relationship between the PA industry and the Depression, see (among many of his other editorials in Projection Engineering) McNicol (1931, p. 4): "Out of joint with the downward tendency of the industries, incidental to the prevailing economic depression, is the steady advance in the number of installations of public address equipment." List of applications from Simons (1930, pp. 18-20, 28).

${ }^{68}$ Mitchell (1931, p. 9).

69 "House asked to remove loud-speaking apparatus" (1924, p. 1).

70 "Radio in the Park" (1928, p. 425).

71 "Loudspeaker Ban is Fought by ALP" (1948, p. 36), "Court Approves Measures" (1948).
} 
explore the positive and negative reactions to the electrically amplified loudspeaker in another consequential - and touchy - setting: musical culture.

\section{Musical Culture}

If through the 1920s the applications (and controversies) of public address were snowballing, "The cost of music," said a Western Electric ad in 1932, was

"tobogganing":

Park-wide music at an operating cost of a few cents an hour - that is what you get with the Western Electric Music Reproducing System! . . Now the same music can be heard in your dance pavilion, your merry-go-round, your swimming pool wherever you want it. ${ }^{72}$

Western Electric was in the business of amplification, and so making a virtue of the fact that bands were no longer required for musical entertainment was in the company's best interest. Many musicians, though, were less enthusiastic. Take for example British critic Edwin Evans, lambasting the development of what he called "Robot Music":

Already now there is no convincing reason why the proprietor of a popular dancehall should engage a band at all. What with the enormous technical improvement in the process of recording, and the attention which wireless has caused to be concentrated on the problem of amplification, a combination of gramophone and loud-speaker can now be produced that gives the required volume and a tonequality good enough to satisfy the taste of the average dancing public. ${ }^{73}$

\footnotetext{
${ }^{72}$ Western Electric ad reproduced in Billboard 100th Anniversary Issue, 1894-1994 (01 November 1994, p. 60). Emphasis in original.

${ }^{73}$ Evans (1928, p. 10).
} 
This anxiety over the technological redundancy of the musician is a steady trope in music history (especially during periods of innovation in electronic and digital instruments), and the actual industrial intricacies of this process have been well documented by music scholars (especially in relation to what the Musicians' Union called the "evil effect" of synchronized sound motion pictures). ${ }^{74}$ But Evans' worries about robot music stemmed from a particular application of electrical amplification ("a combination of gramophone and loud-speaker") - an application that would spark one of its most important controversies in the form of the jukebox.

Coin-operated music machines attained a level popularity in the phonograph parlours of the late nineteenth century; a combination of social and technological limitations, however, meant that their popularity was short-lived. As we saw in Chapter 1, and we will see in the case with radio, one important sociotechnical limitation was the use of ear tubes, which restricted listening to at most a handful of individuals. While there were makeshift solutions to this issue (e.g. liquor funnels), later machines (like 1906's Gabel Automatic Entertainer) offered large amplifying horns, in addition to multiple disc selection and fully automated (if still hand-wound) operation, thus staving off the total extinction of coin-operated music machines. But the real boon - the big bang of the jukebox industry - waited another twenty years:

\footnotetext{
${ }^{74}$ For a summary of this trope, which ranges from theatre organs to digital keyboards and laptop musicians, see Devine (forthcoming 2013B). The best studies of the professional and economic reorganization of music during this early period are Ehrlich (1989) and Kraft (1996). On the "evil effect," see "Europe's Wiring-Up" (1931, p. 6); see also "The Employment Market" (1930). See also Théberge (1997).
} 
Technology did not catch up with the jukebox until 1927, when several companies introduced electrically amplified instruments ... Electrical amplification was the single most important technical improvement in the history of the machine. It created something entirely different from what had come before, and made possible everything that followed. Suddenly the jukebox was capable of competing with loud orchestras. It could entertain large groups of people in large halls, all at once, for a nickel. ${ }^{75}$

The repercussions of electrical amplification in this context were broad and rapid: "Soon, brothels, pool halls, Harlem social clubs, speakeasies, and southern roadside joints replaced their simple player pianos with jukeboxes." ${ }^{" 76}$ Of course, the complaints registered in articles like "Tinned Orchestras: Where the Robots Fail" and "Automaton Deputies: Dancing to 'Unreal' Music" indicate that neither jukeboxes nor sound recording more generally managed to replace live music, and it is relevant to observe the controversies raised by electrical amplification in that context. ${ }^{77}$

\footnotetext{
${ }^{75}$ Lynch \& Henkin (n.d., p. 8).

${ }^{76}$ Boehlert (1994, p. 94).

77 "Tinned Music" (1931) shows that a variety of theatres had unsuccessfully "tried" electrical reproduction in lieu of orchestras (the Apollo, Garrick, Prince of Wales, Ambassadors, Grand Theatre, Fulham, Greyhound Theatre); see also J.M. (1930). On the continued popularity of live music despite the success of the jukebox, see Hazzard-Hordon (1990, p. 112). For a general survey of the history of live music, see Frith et al. (2010). It is worth noting that Frith et al. argue that, before 1955, live music was characterized by an "absence ... of ancillary industries"; indeed, they see the technological crystallization and economic organization of live sound as occurring in step with the rise of rock. (For similar popular accounts, see Court 1984, Duncan 1996. For a broader mythology that music "became electric" for the first time during this period, see Lydon 1974.) While such research makes a strong case that this was true in the realms of ticketing and concert promotion, my study shows that live sound reinforcement and engineering had achieved a significant degree of technological, professional and economic stability (and had undergone a process of acculturation) between 1915 and 1940. As an aside to my main argument about the historiography of sound reproduction, I hope this thesis sheds some light on the vibrant and essential but under-researched prehistory of the culture and industry of electrical amplification, and live music more generally.
} 
When sound systems began appearing in music venues during the 1920 s to assist live musical performance, they ruffled feathers. One critic called the sound system "inventive ability misapplied," wondering rhetorically whether dancehall owners would "engage a band of twelve when he can get more volume from one of five by using the amplifying device." He continued, urging musicians "to protest en bloc against using a device which is damaging their own and also many others' future prospects. Surely the talkies are proving a big enough menace without the need of any more clever (?) ideas." ${ }^{178}$ Al Davison defended his "clever" invention, noting that critics had "failed to appreciate the true position":

Mr. Pearce seems to have overlooked that the size of a dance band is seldom to be governed so much by the volume it can produce as by the variety of tone colours and effects it can feature, and its harmonic fullness. My amplifying device very efficiently increases the volume of each and every man in the band, but it cannot make, say, one saxophone, or (as another instance) one violin sound like a complete section, because each member of the section is playing a different part. ${ }^{79}$

Davison was apparently genuine in his desire, not to put musicians out of work, but to enhance their tone - to offer an "apparatus [which] reduces a musician's labour to that point at which he plays not only more sweetly, but more easily. There is no need for him to exert himself unduly by forcing his tone, as is so often the case when playing in large halls as we are. ${ }^{80}$ In the end, there was truth to both sides of the argument: sound

\footnotetext{
78 Pearce (1929, p. 737).

${ }^{79}$ Davison (1929, p. 737).

${ }^{80}$ Ibid. (p. 738).
} 
systems did facilitate a shift from the semi-orchestral backing of big bands to smaller ensembles, and they also facilitated new musical tones and new roles for voices and musical instruments (see Chapter 3).

While complaints did accompany the proliferation of electrical amplification in live music (both in terms of the "fetish of "big tone" in certain bands, and the "penetrating qualities" of dance music that "disturbs the quiet of the neighbourhood"), ${ }^{81}$ by 1934 the pages of Melody Maker were littered with ads for PA systems. What's more, the magazine was chiding "All those corny halls without microphones," describing "a screaming need for amplifiers." 82 Commentators were baffled by the lack of permanent sound systems in venues across the UK, ${ }^{83}$ making it common, even necessary, for bands to travel with their own PAs. ${ }^{84}$ Indeed, it was at this time that the loudspeaker achieved

\footnotetext{
${ }^{81}$ Respectively, "Who Can Tell Us - ?" (1928, p. 868), “Judges and Jazz" (1927, p. 205). The "Judges and Jazz" piece is about the noise of dancehalls more generally, and refers to the tone of the saxophone, which "may be called the mother-in-law of the musical instrument family" and describes these instruments "desecrating the night air with ... godless notes."

82 "All Those Corny Halls" (1934, p. 2).

${ }^{83} \mathrm{Ibid}$ : "Considering the benefits which are to be obtained by the simple and economical process of installing an electrical amplifying outfit, it seems that the managers or proprietors of these hall must be asleep on their jobs."

${ }^{84}$ Ibid: "As, however, it is quite evident that the landlords will not stick their hands in their pockets to buy the necessary outfits, dance bands are having to consider the advisability of travelling their own sets, and since many appliances have come on to the market recently at prices which are seldom too high for even quite modest organisations, the practice is growing. ... Such sets can be bought on hire-purchase terms at a few shillings per week, and are therefore well within the resources of all serious combinations."
} 
ubiquity in live music. This moment is marked by a question posed matter-of-factly in 1934: "What's a Gig without an Amplifier?"85

I want to withhold judgment on what I think public address systems ultimately meant for the course of music (and politics). My point here is simply to suggest, as a counterpoint to narratives of atomization and noise abatement in acoustic modernity, that new sound technologies during this period also facilitated a variety of collective listening practices, and that these were in many cases welcome developments.

\section{Radio}

I have already discussed the connections between radio and sound systems in facilitating various forms of public address (political speeches, musical performances). Here I want to suggest that even as radio contributed to the atomization of listening and domestication of entertainment, it simultaneously reconfigured aspects of collective listening.

Early radio listeners wore headphones because they had to. As Sterne points out, a 1925 Brandes ad insisted that "You need a headset ... to listen-in without disturbing others; to shut out the noise in the room - and get all the radio fun; to get the truest and clearest reception - always." 86 While it is true that some listeners (and companies) stood by headsets, the loudspeaker had been commercially introduced as an alternative as early

85 "The Silent Partner" (1934, p. 4) points out that, while PAs weren't as readily available in the UK as in the US, "at the same time it must not be forgotten that many British manufacturers have recently put out amplifying units for the use of bands which are fully capable of giving first-class results if they are intelligently handled... . Indeed, it is fair to say that with the choice now available there is no excuse for any but the smallest of bands for not having their own microphone equipment, as prices are reasonable, and, of course, there are hire-purchase facilities."

${ }^{86}$ Brandes ad in Sterne (2003, p. 88). 
as 1922. Indeed, when the Brandes ad ran, it shared magazine pages with an equal number of loudspeaker ads. These ads emphasized, not listening-in, but volume in its truest sense (as a spatial metaphor): "On a boisterous evening when we are all laughing and fooling, the Volutone plays with the loud pedal down and fills the room with music." 87 What's more, obtaining "all the radio fun" was, as we saw with the gramophone, often less a matter of isolation and first-rate reception (which headphones could provide) than socializing and dancing (which they could not) ${ }^{88}$ In these latter contexts, earphones were seen as "bothersome and unsatisfactory. ${ }^{\text {" } 89}$ Indeed, there is ample evidence to suggest that, on the cusps of both horns and loudspeakers, listeners sought - and radio magazines and companies provided - ways of sidestepping the necessity of earphones. Some solutions were as simple as placing headphones in a resonant vase or fishbowl; others involved cobbling together an amplification system

\footnotetext{
${ }^{87}$ Volutone (1924).

${ }^{88} \mathrm{Ads}$ for loudspeakers and vacuum tubes were of course also implicated in the fidelity discourse, and were marked the constant assurance that they provided "wonderful powers of reproduction full in volume, perfect in tone" (Sterling 1924, p. 332) while Mullard (1924, p. 319) claimed their tubes "Increased volume without distortion." Further examples are too numerous to mention. My point here is based on surveys of magazines like Radio Times and Radio News, as well as radio manuals (Amplification without Distortion 1927) and catalogues (Announcing Radiolas, Radiotrons and Accessories 1925, Eatons 1926-1927).

89 "Progress in Radio" (1924, p. 16). See also Paul (1982, p. 3): "The idea of listening to radio through an earphone left much to be desired." Additionally, Paul (1979, p. 67) sketches the trajectory of reproduction technologies in radio: "The era for the popularity of horn speakers was 1922 to 1926 . Before 1922 earphones were the common listening device. During 1926 the paper cone reproducer became popular and by 1927 it was difficult to find horn speaker advertisements in radio magazines."
} 
from gramophone and telephone parts. ${ }^{90}$ In this way, radio did indeed participate in a widespread domestication of entertainment (and technology) that had begun in the late nineteenth century; but this did not necessarily imply the privatization of listening in the home, as radio researchers often assume. ${ }^{91}$

There is also a sense in which radio resisted the pull of domestication altogether in which it simultaneously "went public." This is true not only in contexts in which it was paired with public address systems, but with regard to apparently domestic radios too. Almost as soon as radio broadcasting emerged, listeners started taking their radios outdoors, in settings ranging from car rides to boat cruises, camping trips to picnics. As with gramophones, the ability to furnish music for dancing was central; ${ }^{92}$ so were slurs against earphones:

One disadvantage of so-called portable sets using an antenna has been the reliance upon earphones.... With the new types of portable sets, loud speakers are used and distant as well as nearby stations come in loud and clear over a loud speaker, so that a group of persons may all listen in at one time. ${ }^{93}$

\footnotetext{
${ }^{90}$ Respectively, Beco (1926), Douglas (2004), "Radio Sound Amplifier" (1922). According to this Beco Loudspeaker ad, "with its beautiful appearance and unsurpassed performance as a loudspeaker, and its utility as a handsome flower bowl - it is indeed a splendid instrument. Whether the bowl is empty or filled with water and flowers, the perfect tonal purity, volume and clarity is in no way impaired." All for the low, low price of £5-5-0!

${ }^{91}$ On radio and the domestic sphere, see among numerous examples Butsch (2000, pp. $184 \mathrm{ff}$, especially 195): "domestication of the radio [as a technology] implied privatization [of listening] in the home." On technology and domestication more generally, the classic statement is Cowan (1976). In the cases of radio and other household items, the gendered redefinition of domestic space (and technologies) was a significant issue.

92 "Radio in the Summertime" (1924, p. 308): "Open-air wireless will largely be popularized through loud speakers enabling impromptu dances and concerts to be shared by holiday and picnic parties."

93 "Progress in Radio" (1924, p. 16).
} 
However, while group listening may have been desirable, it was not always clear what it meant in the context of radio. Indeed, the New York Times noted that "rules of etiquette" were "lacking to guide the radio listener." In contrast to the conventions that had been established among concertgoers and moviegoers, "no universal decorum tells us what attitude to adopt in the presence of a loud-speaker." This created a "sense of insecurity" when people gathered to listen to radio (which paralleled the insecurity that performers felt in the radio studio).${ }^{94}$ Beyond the description of the activity and even a typology of the various radio listeners in a given gathering, ${ }^{95}$ the article draws attention to a simple fact that accompanied the rise of the radio and its apparent domestication of entertainment and atomization of listening: people still congregated to listen.

We saw this in Chapter 1, with regard to the gramophone (and, indeed, the same practice accompanied other apparently atomizing media like television): although people may have possessed the cultural tools to listen alone together, they didn't always want to do so. For every ad depicting a sole listener in the den, alone but together, there are others

94 "Rules of Etiquette" (1928, p. XX2).

${ }^{95}$ According to the "Rules of Etiquette" (1928, p. XX2) author, there were three main types of collective radio listener: (1) extroverts "use the chuckle, the snort, the slap on the thigh and the waterfall of laughter"; (2) the sub-extrovert "smokes his pipe in peace with only an occasional chuckle or a grimace"; (3) the complete introvert "feels the urge for a crusade rising within him on hearing the alarming facts presented." 


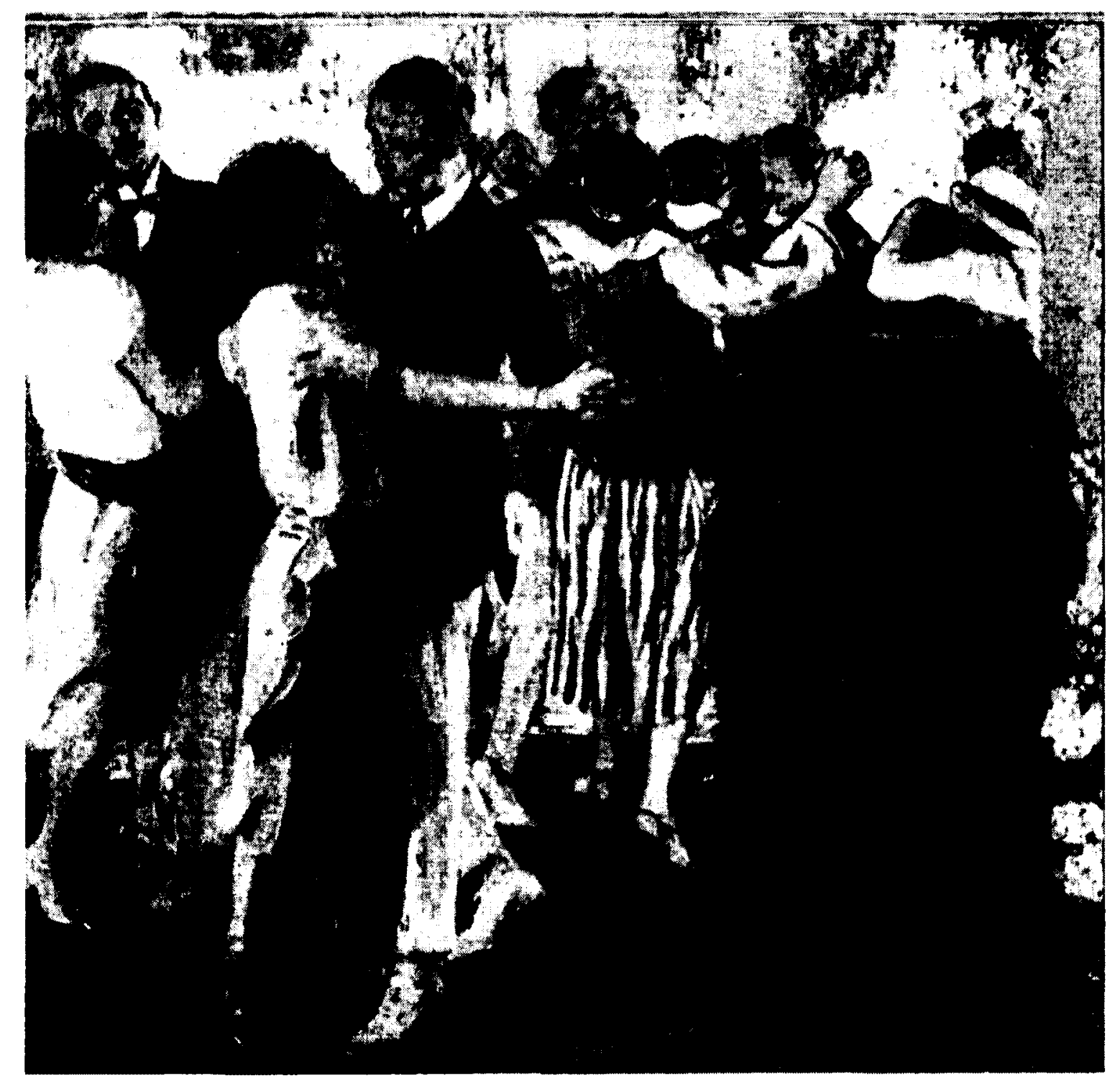

Figure 3. "Victor dance music . . brings joy with every step," Popular Mechanics (1922)

that foreground the ability of sound reproduction technology to furnish collective

listening and dancing. ${ }^{96}$ Take for example the Victrola ad featured in Figure 3. Or

consider a scenario offered by the Amplico radio and gramophone company:

${ }^{96}$ See Victrola (1922). Dance records themselves were also important in this context. Early Gramophone issues featured regular reviews of the booming dance record phenomenon, where record manufacturers emphasized their wares were "ideal for dancing" and that they "increase the volume of your existing gramophone tenfold" (Herbert 1925, p. 495). 
... let us picture the family, with perhaps a young guest or two, eager for entertainment after dinner. Some one makes the happy suggestion "Let's have a dance." In a moment the rugs are rolled up, the furniture moved aside and the improvised ballroom is ready. Neighbors and acquaintances are telephoned and in a short time the house is ringing with laughter and gaiety ... ${ }^{97}$

RCA, too, focused on the possibility of "the radio dance, the radio concert, the radio party" in its 1929 promotions for the Aeriola Grand Broadcasting Receiver (see Figure 4). ${ }^{98}$ The title of this RCA pamphlet - Radio Enters the Home - is significant for the point I'm making here: it suggests that the acceptance of radio into the home was seen as at least as important for kinds of collective listening as it was the individuated experience emphasized in radio research, and which, for Sterne, is encapsulated in the Brandes ad. ${ }^{99}$

These uses of radio not only augment narratives of privatization and atomization; they also show that discourses of public sound during this period are not reducible to social problems of noise. Of course, radio noise was a problem - most famously, perhaps, in New York's Radio Row. While the "Big Babel" was widely recognized as a noisy city, neither its Automobile Row, its many markets, nor Tin Pan Alley could "hold a candle to

\footnotetext{
${ }^{97}$ Amplico ad (ca. late 1920s) reprinted in Smithsonian (1975).

${ }^{98} \operatorname{RCA}(1929$, p. 30).

${ }^{99}$ RCA (1929, pp. 5-11): "Radio has placed a new, inspiring and powerful resource at the disposal of civilization. ... A richer and more complete home-life ... "Not only have home concerts become a national pastime, but dancing to the music of famous orchestras playing in person for the benefit of radio 'fans,' has established itself as a permanent recreation. . . . It is also possible, in this instance, to employ a loud speaker and thus eliminate the head telephone receivers, thereby permitting a roomful of people to hear radio."
} 


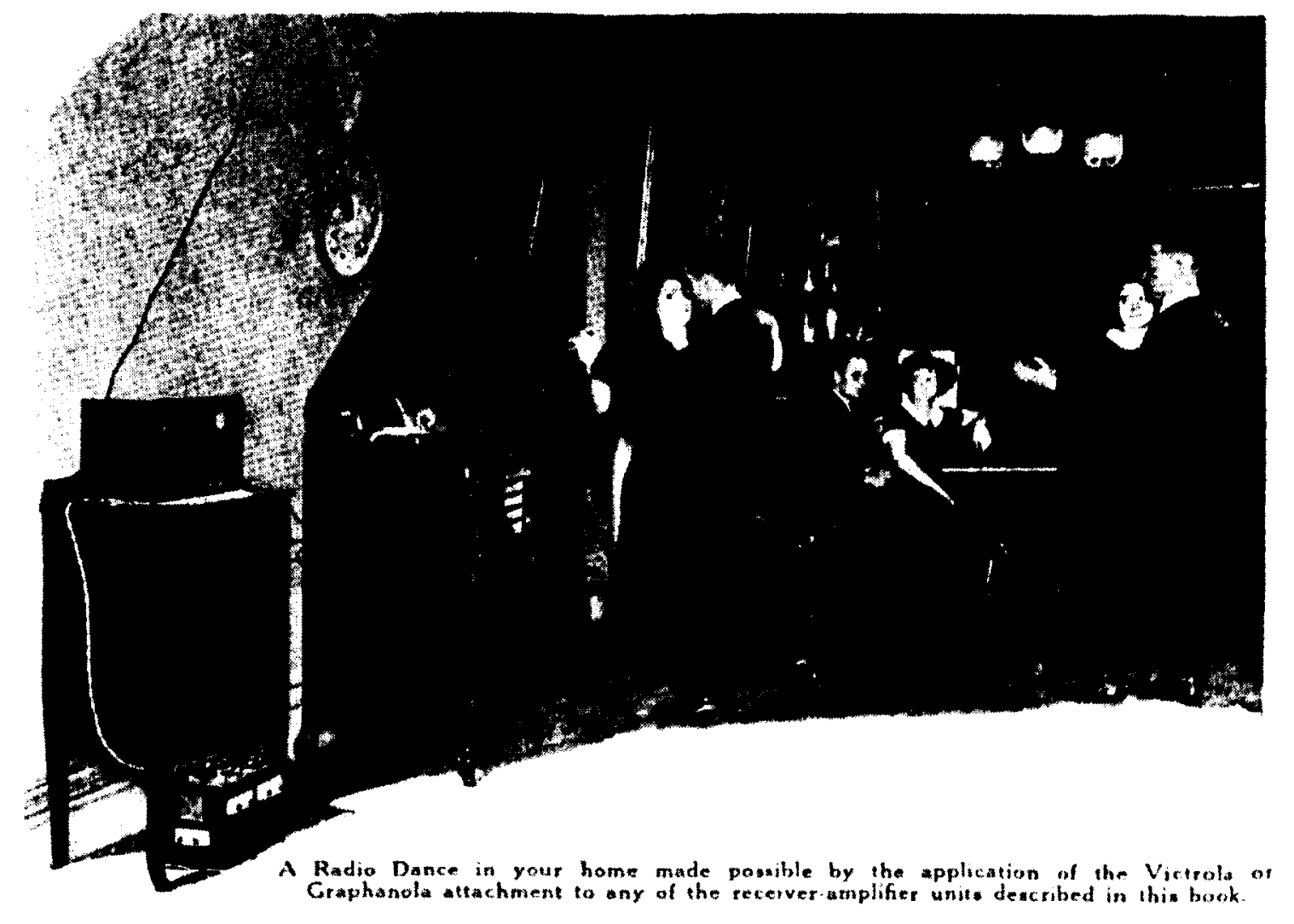

Figure 4. RCA Aeriola Grand Broadcasting Receiver ad (1929)

Radio Row." 100 The Washington Post describes the scene: "Down in Cortlandt street, between lower Broadway and the west Manhattan waterfront, loud speakers lift all day an impenetrable din."101 Indeed: "The radio industry may be an infant . . . but it is an infant with lusty lungs." 102

It was in this context that Fiorello La Guardia "issued a ukase against the loudspeaker":

100 "Bedlam on Radio Row" (1930, p. 144). "Big Babel” from Seymour (1928, p. 12).

101 Seymour (1928, p. 12).

102 "Bedlam on Radio Row" (1930, p. 144). 
The Mayor speaks of them as a "public nuisance" ... A householder can turn off his own radio if he doesn't like the sounds ... But he cannot turn off the loudspeaker which is being paraded down the street outside on a truck. ${ }^{103}$

In the end, La Guardia and others lost the "war on noise"104 - partly due to the uncertainty and confusion that surrounded their weapon of choice (the decibel), as we will see in Chapter 4; partly because the delineation of noise along the lines of rights to private isolation and public expression was never fully settled. The issue thus kept coming back, and later New Yorkers also focused on the crossover between acoustics and basic rights and freedoms:

Loudspeakers on the streets deliberately invade with physical force the privacy of the home. They allow us no freedom of listening ... In the words of the Bill of Rights, loudspeakers on the streets are "cruel and unusual punishments." They are barbarous. ${ }^{105}$

Another reason for losing the war was that for every noise complaint and abatement campaign, there was someone on the other side of the wall who found convenience in the loudspeaker, who took pleasure in it. The infringement of public noises on personal rights is thus only part of the story. What see here is that the apparent privatization of sound - in public, in the home, in the self - was accompanied by equal but opposite reactions.

\footnotetext{
103 Too Loud Speakers" (1934, p. 20). For a detailed discussion of noise abatement under La Guardia, see Radovac (2011). For the pre-1930 history, see Smilor (1979). For broader histories and arguments about noise abatement, see Thompson (2002), Bijsterveld (2008) and Schwartz (2011).

${ }^{104}$ For this terminology, see "Mayor La Guardia's Plea and Proclamation in War on Noise" (1935).

105 Paine (1948, p. 28).
} 


\section{Conclusion: privacy and the historiography of sound reproduction}

The point of this chapter has been to show that the privatization of entertainment (in the home) was incomplete in two senses: first, it was accompanied by an equally significant drive toward new forms of collective listening; second, domestication did not necessarily lead to the atomization of listeners. Noise-wise, my point has been that annoyance was accompanied by pleasure, that despair (over the invasion of privacy) was accompanied by hope (in the restoration of publicity). Taken together, these themes indicate that the proliferation of the loudspeaker is closely linked with significant, material changes in the history of listening formations.

While there have certainly been interesting studies of the relationship between music and sound, on the one hand, and everyday listening and the public auditory field, on the other, ${ }^{106}$ the most commonly told story of sound technology and listening in the twentieth century has to do with how, through the privatization of acoustic experience made possible by the telegraph and the telephone and radio and recording, music and sound became implicated in senses of self and, by extension, senses of personal space. Simon Frith has summarized this well:

Over the last hundred years or so, for both cultural and technological reasons, the Western experience of music has been individualized ... Music is now tied up with people's sense of self. Listening to music has become a way of laying claim to one's own physical and emotional space. We therefore make both a new demand on

${ }^{106}$ For example, Lanza (1994), Sterne (1997), DeNora (2000); Bull (2000, 2004, 2007). 
music (to meet our personal needs) and a new commitment to it, as a symbol of our individuality. ${ }^{107}$

In 2002, Frith noted that the history of this phenomenon was "fascinating and little explored."108 The following year saw the publication of The Audible Past, an extensive historical exploration of the privatization and individualization of acoustic experience. Jonathan Sterne traces the development of privatized acoustic space to the use of stethoscopes in early nineteenth-century medical practice. The split between an exterior, public sound world and an interior, private one, Sterne argues, was born with the stethoscope, disseminated via "headset culture" (especially sound telegraphy), and came to inform listening discourses and practices related to the telephone, the phonograph, the radio - and many other forms of sound reproduction. ${ }^{109}$ Thus, as it became technologically possible and ideologically desirable to isolate and personalize acoustic space, the musical experience simultaneously underwent a process of individualization. So music and sound became bound up with our senses of self and personal space; they became "technologies of the self," to generalize a term used by Tia DeNora. 110 While the development of private acoustic space and personal listening are certainly interesting on their own terms, they are equally interesting as evidence of a shift in collective listening. For example, writing about a specifically musical form of sound

\footnotetext{
${ }^{107}$ Frith (2007, pp. 13-14).

${ }^{108}$ Frith (2002B, p. 40).

${ }^{109}$ Sterne $(2004$, p. $154 \mathrm{ff})$.

${ }^{110}$ DeNora (2000). DeNora is of course building on the work of Foucault (see Martin et al. 1988).
} 
reproduction - the phonograph - William Kenney argues against the idea that

individualized listening was a "ceremony of the solitary":

[This] hypothesis has minimized the number of different, more active, shared ways in which people interacted with recorded music. In addition merely to listening passively to records while alone in their homes or rooms, many people also enjoyed shared patterns of musical activity and participated together, for example, in public juke box listening and dancing cultures ... To emphasize solitary receptivity denies the phonograph's power to stimulate ... new musical cultures. ${ }^{111}$

What's more: "Not simply solitaries, phonograph record lovers listened 'alone together,' discovering in mediated engravings of past musical expressiveness parallel avenues to shared social and cultural circles of resonance, ones that led them to active forms of musical knowledge and involvement." 12 This notion of "alone togetherness" describes a process by which individuals place themselves into imagined cultural narratives while listening to recorded music singly, in their own private acoustic spaces. ${ }^{113}$

With stethoscopes and telephones and radios and phonographs, this notion of personalized acoustic space was something people had become accustomed to, and something they felt entitled to in their encounters with aerophones in the nineteenth century, loudspeakers in the twentieth, and iPods in the twenty-first. Indeed, Sterne predicts:

\footnotetext{
${ }^{111}$ Kenney (1999, p. 3).

112 Ibid. (p. 22).

113 This uniquely modern form of musical identification has been widely observed, perhaps most memorably by Frith (1996).
} 
... even in ... moments of collectivity and togetherness, people's practical techniques of listening involved a certain prior individuation of acoustic space. They entered this audile collective like the mythical individuals who would enter into a social contract: first free and separate and then together. ${ }^{114}$

The underlying notion here, for Sterne, is "audile technique," which serves as a common thread in his depiction of the audible past. To be sure, the seemingly disparate listening experiences examined by Sterne and found in this chapter - stethoscopes, telegraphs, aerophones, public address systems, jukeboxes, radios, phonographs - share similar conditions of technological possibility and are part of similar listening formations. ${ }^{115}$ Certainly, the advent of sound reproduction technologies is conceivable in terms of this long history of audile technique and its attendant alteration of personal auditory space. But focusing on the loudspeaker shows how sound and music also became newly implicated in public space, in the material organization of listening formations. And just

\footnotetext{
114 Sterne (2003, p. 167); see also ibid. (p. 161): "By the 1920s, the possibilities for collective listening to sound-reproduction technologies presumed a prior individuation and segmentation of acoustic space. ... the individuated listener comes before the collective sonic experience."

115 While drawing connections across seemingly disparate media is highly valuable, certain differences in content should not be overlooked. For example, Sterne (2003, p. 165) jumps from the phonograph to the telegraph, noting: "Student operators at a Marconi Wireless School are organized in a cellular fashion. Each has his own partition on the desk, and each wears a headset to hear and write down signals. The experience is highly individuated, standardized, yet also collectivized. These Marconi operators are also listening 'alone together."' But in many cases the phonographic experience is also, and just as importantly, a specifically musical one. If we follow Frith's (1996) work, which suggests that music is a resource for identity, and that musical listening can involve a process of placing oneself in imagined cultural narratives, then the difference in content is significant. It seems reasonable to suggest that the Marconi telegraphers were not relating to the content of their media (dots and dashes, beeps and boops) in the same way as phonograph listeners were relating to music (and thus to each other). I would suggest that while "alone together" is perhaps an accurate depiction of the telegraphy students (bodily proximity but mental distance), to acknowledge the importance of music as a means of identification is to speak, more properly, about the possibility of listening "together alone" (bodily distance but mental proximity).
} 
as a parallel effect of the privatization described by Sterne was actually a new kind of collectivity (a kind of acoustically imagined community), so did sound's newfound ubiquity help to define (and simultaneously dismantle) this new form of acoustic privacy, an entitlement to silence in public space. The shifts in listening formations described in this chapter, as well as their underlying logic, do not therefore support a stable privatization thesis; rather, they instance something like Raymond Williams' description of the mutually constitutive relationship between ideologies of privacy and materialities of publicity. ${ }^{116}$

\footnotetext{
116 Williams (1993, pp. $19 \mathrm{ff}$ ). Note, however, that the term "mobile privatization" does not quite describe - because it too easily resolves - the mutually constitutive tensions and relationships that are afforded in the idea of listening formations.
} 


\section{ChAPTER 3 \\ Rationality: a new lease on life}

Electrically amplified sound has been a part of everyday life since the 1930s. But in 1915, when Peter Jensen demonstrated some of the earliest loudspeaker systems, electrical amplification was astonishing: there are reports of incredulous investors refusing to back the apparently impossible invention, of navy sailors dancing to a seemingly sourceless and therefore "mysterious music in the air," of innocent bystanders who "thought the world was coming to an end and scrambled for cover." This chapter recovers some of the technological and cultural work that was required for electrical amplification to transition from an astonishing novelty to an everyday ubiquity. Like Chapter 2, then, this chapter highlights the unknowns and uncertainties that accompanied the proliferation of the loudspeaker. But the questions dealt with here have less to do with public perceptions of electrical amplification than its technical and musical contexts of use.

I begin in the nineteenth and early twentieth centuries, where, I argue, a kind of technological frame took root in the world of telecommunications. Through certain formations of industry and culture, this "communications frame" was transferred into a

\footnotetext{
1 These reactions are found in Jensen (1975) and Coodley (2007, p. 57). Although it is not the subject of this chapter, accounts of "astonishment" in relation to modern technology cannot be take at face value. Tom Gunning (1989), for example, has argued that early cinema audiences were not naively terrified by the realism and credulity of film, but knowingly amazed by its artifice and incredibility. See also Marvin (1988).
} 
variety of electrical sound reproduction media (e.g. public address, radio, music performance and recording, film sound). ${ }^{2}$ But such transfers were not direct: they necessitated two-way processes of translation, through which certain established imperatives of both the communications frame and the worlds of music and sound reproduction were modified. ${ }^{3}$

After sketching some of these modifications, I look in more detail at the translation of the communications frame into electric guitar amplification. I suggest that this frame was central to the development of the electric guitar in some ways, but not others. In particular, I demonstrate a degree of incongruence between the way electric guitar amplification was conceived by manufacturers and the way it was used by musicians. Whereas manufacturers emphasized ideals of fidelity that had been translated from the world of telecommunications (loudness and clarity in the service of intelligibility), this rationalized approach to sound did not take root in the world of guitar performance, and guitar players developed a different set of sonic preferences based on volume and, later, signal distortion (loudness over clarity in the service of musical

2 I will define my conception of the communications frame in more detail below, but should note here that I am building on the concept of a technological frame, which I use in a broad and inclusive sense, as a way of describing the practical and conceptual resources that given groups of users and manufacturers have at their disposal when it comes to interpretation and problemsolving. For more detailed discussions of technological frames, see Pinch \& Bijker (1987), Bijker (1995), Oudshoorn \& Pinch (2003).

${ }^{3}$ As with the communications frame, my invocation of "worlds" of music and sound reproduction is meant broadly and inclusively. Briefly, musical worlds consist of activities of production and consumption, and the relations of mediation through which people, musical works and sound technologies are co-constituted. I am building here on Howard Becker's (1982) conception of art worlds, as well as contemporary work in cultural sociology and music sociology. The best venue for current debates in the sociology of culture and music, which contains important contributions from Georgina Born, Antoine Hennion, Nick Prior, and many others, is Cultural Sociology. I will return to this literature in the Conclusion. 
expression). This incongruence - a constitutive tension of listening formations - leads to broader questions about the role of rationalization in the historiography of sound reproduction.

The goal of this chapter, then, is to understand electrical amplification as a technology of sound reproduction, and to identify the place of the electric guitar amplifier within the broader technological, historical and historiographic context of sound reproduction. Despite the rise of interest in musical instruments and sound reproduction among technology scholars, ${ }^{4}$ it is worth noting that the electric guitar has not roused much curiosity in the field of technology studies. Notwithstanding some important exceptions to this situation, ${ }^{5}$ and not to mention a variety of journalistic, encyclopedic and collector-oriented efforts to chart economic and technical details of the instrument, the most common academic approach to the electric guitar has been what we might call cultural iconography. And perhaps the majority of scholarship here has focused on the electric guitar as a particularly American icon. Works in this vein have been extremely illuminating, contributing much to our understanding of this technology's complicated symbolic and political history, its involvement in issues of race and class, gender and

\footnotetext{
${ }^{4}$ I point here only to sources which do not appear later, in the course of my argument. See Douglas (1987), Pinch \& Bijsterveld (2003, 2004), Bijsterveld \& Peters (2010), Downes (2010),

${ }^{5}$ For two works that explicitly derive their approaches from technology studies, see McSwain (2002) and Waksman (2004). For works that implicitly engage some aspects of technology studies, see Lydon (1974), Waksman (1999), Millard (2004), Schmidt-Horning (2004),
} 
sexuality, modernity and identity. ${ }^{6}$ Of course, these symbolic and political dimensions are essential to an understanding of the electric guitar as a technology of sound reproduction. But because those histories have been so thoroughly covered elsewhere, this chapter attempts something different.

My question is about what a technology studies-informed examination of electrical amplification in general, and electric guitar amplification in particular, can tell us about the history of sound reproduction more generally. As a foil to existing histories of the surrender of sound and listening to rationality in the modern era, the story of the electric guitar, as I figure it here, highlights ways in which such processes were ongoing but incomplete, attempted but unfinished - imperfect.

\section{The horse does not eat cucumber salad: telephonic imperatives and the communications frame}

The first telephone calls were odd. Instead of the monumental questions tapped out by early telegraphers (what hath God wrought?), legend has it that first-time callers spouted drivel: the horse does not eat cucumber salad. Meaningless, yes; pointless, no.

In some of the earliest experiments, carried out in 1860 s Germany, inventor Philipp Reis started out by trying to talk some sense into the cluster of oak, platinum and pig's bladder that constituted his first telephone. For example, a professor at the institute

\footnotetext{
${ }^{6}$ Bayton (1997), McSwain (1995), Millard (2004), Palmer (1991), Waksman (1999), Walser (1993). For partial exceptions to the American icon paradigm, which are global and transhistorical in scope (while still retaining some focus on the twentieth century, the US and iconography), see Bennett \& Dawe (2001), Coelho (2003), Dawe (2010). I do not treat these works fully here because they are not focused on the electric guitar but, rather, the guitar more generally.
} 
where Reis was teaching "remembered hearing such phrases spoken as ... 'What time is it?' 'What is your name?' and 'Pay attention!' through the wire." ${ }^{\prime 7}$ However, there were those who thought that because these phrases were part of everyday conversation, their comprehension owed more to the educated guesswork of listeners than the sophistication of the telephone per se. Gibberish, they thought, would be a better test of the telephone's abilities:

... another professor, believing that these commonplaces would be too easily recognized, decided to try nonsense, so said to Reis, listening at the receiver, "Der Sonne ist von Kupfer" (The sun is made of copper), which Reis understood as "Der Sonne ist von Zucker" (sugar); not so bad.8

While the extent to which Reis succeeded in transmitting speech is open to question, ${ }^{9}$ what is made clear in these early experiments is his emphasis on a particular quality of mediated sound: intelligibility.

Intelligibility quickly became a central problem in telephone research and, in a particular configuration, remained so until the arrival of the vacuum tube in 1915. Meanwhile, threats to understanding abounded. Take noise and crosstalk, for example. One early historian describes "all manner of strange and uncouth noises on the telephone wires."

\footnotetext{
${ }^{7}$ Harlow $(1936$, p. 346$)$.

${ }^{8}$ Ibid.

${ }^{9}$ For a detailed and fair assessment of Reis's accomplishments, see Kingsbury (1915).
} 
Noises! ... There were sputtering and bubbling, jerking and rasping, whistling and screaming.... There were clicks from telegraph wires, scraps of talk from other telephones, and curious little squeals that were unlike any known sound. ${ }^{10}$

Thomas Watson, we're told, had some ideas about the root of the problem ("perhaps these sounds were signals from the inhabitants of Mars or some other sociable planet"), though he left the actual elimination of these "strange and uncouth noises" to other scientists and engineers. ${ }^{11}$ But if noise was "the most weird and mystifying of all the telephone problems,, 12 the most pressing issues during this period were distance and signal strength.

At the outset of the twentieth century, Bell System head Theodore Vail had an ambitious and explicit goal: universal service. The primary means of powering telephone signals at the time were mechanical amplifiers (loading coils and repeaters), which were known to distort speech at every successive stage of amplification. But under the sign of universal service, any signal was better than no signal at all. So the chief concern of telephone engineers during this period was to amplify signals as much as possible, and to transmit them as far and wide as possible - meaning that as long as a signal was loud enough to be heard on the other end of the line, engineers (and users) accepted a

\footnotetext{
${ }^{10}$ Casson (1921, p. 121).

${ }^{11}$ Ibid. The work of engineers in eliminating these problems (which involved changing grounding patterns, replacing telegraph iron with telephone copper, switching from overhead wires to underground cables) is detailed in Fagen (1975, p. 902).

12 Fagen (1975, p. 120).
} 
considerable degree of signal distortion. ${ }^{13}$ This is clearly laid out in the History of

Engineering and Science in the Bell System:

Before the advent of telephone amplifiers, there was little interest in devising electrical networks for reducing distortion in the transmission of speech. The major problem in transmission was to conserve speech power. The mere correction of defects by circuits that could only absorb power was not an objective of high priority, much as these defects were deplored. ${ }^{14}$

So in 1909 , at a time when a mechanically amplified voice in New York either petered out or was obliterated by the time it reached Denver, Vail's mouth wrote a cheque that his Bell System couldn't cash: if not yet universal service, at least viable transcontinental telephony.

Conjuring this figment of Vail's imagination was a task that fell to Harold Arnold, an employee of Western Electric (a subsidiary of the Bell System). After several years of research and a shift away from mechanical amplification, Arnold succeeded in refining electrical vacuum tube amplification, the upshot of which was a ceremonious conversation between New York and San Francisco in $1915 . .^{15}$ But as electrical signal amplification solved the distance problem, it also reconfigured the status of intelligibility in telephone engineering. Intelligibility became less of a pure limitation to be overcome

\footnotetext{
${ }^{13}$ There were even research projects which attempted to prove that the problems of distortion really weren't so bad after all. See for example Campbell $(1910, p$. 156): "While it is obvious that the telephone seriously distorts speech-waves, nevertheless even those consonants which most nearly resemble each other are not distorted sufficiently to be indistinguishable."

${ }^{14}$ Fagen (1975, p. 902).

${ }^{15}$ For some of the background here, see Fagen (1975), Tyne (1977), Adams \& Butler (1999).
} 
through amplification, and more of an upper and lower limit to be explored through

electronic filtering and manipulation. In the words of Bell historian M.D. Fagen:

It had, of course, been appreciated that the intelligibility of human speech, when electrically transmitted and then reproduced, must depend on the overall responsiveness of the system in some regions of the voice spectrum more than in others. And, to the extent that "naturalness" or recognizability of individual voices was of concern at that time, it must have been suspected that the frequencies contributing thereto were not the frequencies that were most essential to good intelligibility. But all of this had remained qualitative only; for ... the objective had necessarily been to transmit and reproduce as much power as possible at every frequency. ${ }^{16}$

Following the introduction of electrical amplification, concern shifted to eliminating those "inessential" frequencies, in the interest of reducing the bandwidth of a single signal - which, in turn, increased the efficiency of the telephone system by allowing multiple signals to be transmitted through a single cable. ${ }^{17}$ In the context of electrical amplification, then, intelligibility was less an absolute limitation (as it was in the era of mechanical amplification) than a relative value that could be controlled through signal manipulation.

It is thus possible to divide the early history of the telephone into two periods: before 1915 , the desire was to conquer distance (which was a problem of signal strength and, in a sense, loudness); with the introduction of the vacuum tube, "it became possible to concentrate effort on developing microphones and loudspeakers with high-fidelity

\footnotetext{
${ }^{16}$ Fagen (1975, p. 928).

${ }^{17}$ For a more detailed account of this shift, including an explanation of single sideband modulation, see Fagen (1975).
} 
reproduction instead of emphasizing high efficiency alone."18 But this was not high fidelity for the sake of high fidelity. Looking back from the late 1920s, Arnold summarized "the philosophy of the investigation of hearing which has been carried on in Bell Telephone Laboratories during the past fifteen years":

... we must construct devices so perfect that even the keenest ear cannot find a flaw in their rendition, and then step by step we may introduce measured imperfections until an observer can detect a fault ... and thus to reach a reasonable basis of design both for separate instruments and for systems, as a whole, to give a proper balance between cost and performance. ${ }^{19}$

This platform - a hunt for fidelity without any intention of using every part of the animal - provides an interesting contrast with the audio enthusiasts of the musical world, for whom fidelity was an ideal to which music recording and playback should aspire at any cost (a set of discourses and practices well represented by Thomas Edison's tone tests, and by the "Mechanism v. Nature" comparison of cinema orchestras and the Brunswick Panatrope).${ }^{20}$ Indeed, it is the desire to attain minimal intelligibility in the service of efficiency (which was an explicit and necessary rejection of the ideal of fidelity) that constitutes the set of telephonic imperatives at the heart of the communications frame.

\footnotetext{
${ }^{18}$ Fagen (1975, p. 293).

${ }^{19}$ Arnold (1929, pp. xii-xiii).

${ }^{20}$ On the tone tests, see "Mechanism v. Nature" (1928), Thompson (1995). Of course, this is not to say that ideals of fidelity did not circulate in certain capacities among telephone engineers, or that music listeners did not subordinate fidelity to a variety of other concerns (see Chapter 1). For example, we could understand Alexander Graham Bell's (1880) early experiments with binaural telephony as having been informed by fidelity ideals.
} 
So while intelligibility is the umbrella term for the problem of early telephony, before 1915 the problem was defined primarily in terms of distance and signal strength (loudness); afterward, when merely preserving loudness over distances no longer posed as much of a problem, engineers were able to focus more attention on the frequency band (clarity). However, while engineers after 1915 could have chosen to devise ways of transmitting and reproducing the entire frequency band of a speaker's voice (the ideal of fidelity), they understood that not every frequency played an equal part in speech comprehension and voice recognition (the practicalities of intelligibility), and that certain frequencies could be eliminated through electronic filtering. And these leaner signals meant that more conversations could flow through a single cable - which made for a more efficient and economical telephone system. In this way, there was a degree of congruence between what telephone manufacturers were striving for and what telephone users wanted. ${ }^{21}$

The idealistic notions of sound quality and fidelity that are found among early audio enthusiasts and recording companies were thus not a primary concern for early telephone engineers or telephone users (ideals of fidelity were a means to a practical end, not an end in themselves), and are not an essential part of the communications frame as such. Of course, the communications frame was never absolutely pure or completely detached from the idealistic notions of fidelity found in the worlds of music and sound

\footnotetext{
${ }^{21}$ Thayer (1922, p.3): "Is there any difference in interest between the public and our stockholders? I cannot see any. If we serve our stockholders wisely and efficiently, we shall render the largest benefit to the public.... The best brains we have must be applied increasingly to effect economies in construction, maintenance and operation. We must struggle unceasingly for better service and lower rates."
} 
reproduction; indeed, as we will see in Chapter 4, they were deliberately melded in certain situations, such as the collaborations between Bell Labs and conductor Leopold Stokowski. Overall, though, the questions for telephone engineers during this period remained practical: how much of a signal could be discarded without sacrificing too much intelligibility, and while still approximating fidelity? The goal here, the defining feature of the communications frame, was not clarity as some technical absolute, but clear enough to be understood; not fidelity as some abstract ideal, just faithful enough to be recognized.

\section{The communications frame and the world of sound reproduction: transference and translation}

"Telephone studies enter many fields," trumpeted a 1928 New York Times headline:

Without having been originally sought after, almost as though a field when once sowed should bear several rich yields, telephone research has given such byproducts as the public address system, the "audiphone" (aids to the hard-ofhearing), the orthophonic phonograph, the talking movies and the artificial $\operatorname{larynx} .^{22}$

Indeed, it was widely recognized that telephone research was at the root of many developments in the wider world of sound reproduction. As Bell's Joseph Maxfield pointed out, for example, "many of the heretofore unsolved fundamental problems of sound recording and reproduction have been readily solved by the application of a

22 "Telephone Studies Enter Many Fields" (21 October 1928, p. 44). 
detailed knowledge of telephone transmission theory."23 According to Harvey Fletcher, most of these developments - "rewards," he calls them - were "unexpected."24

Unanticipated though these developments may have been, it was not completely accidental that such seemingly focused telephone research had such broad effects: by 1930, Bell actively supported research ranging from acoustics and psychoacoustics of speech and hearing, to binaural sound reproduction and high-fidelity music recording. ${ }^{25}$ This widening of scope occurred in the wake of electrical amplification, and it was, Fletcher says (echoing Arnold), around 1915 that "the research Laboratories of the Bell Telephone System started a comprehensive research program on speech and hearing, and its relation to the design of telephone systems. ${ }^{.26}$ And if this expanded in-house research agenda was responsible for the Bell System's centrality in the development of many forms of sound reproduction technology after 1915, it was the firm's size and prowess that ensured Bell engineers and Bell apparatus - and the communications frame more generally - were central to the dissemination of mediated sound in a variety of cultural spheres.

However, as the communications frame accompanied Bell's engineers and technologies into worlds of sound reproduction besides telephony, it was presented with new challenges, and it underwent alterations. At the same time, the transference of the

\footnotetext{
${ }^{23}$ Maxfield \& Harrison (1926, p. 493).

${ }^{24}$ Fletcher $(1929$, p. v).

${ }^{25}$ For an explanation of why Bell supported such a broad (and sometimes seemingly irrelevant) research agenda, see McGinn (1983, pp. 39 ff). See also Jewett (1940).

${ }^{26}$ Fletcher (1953, p. v).
} 
communications frame brought about shifts in the worlds of sound and music into which it had to be translated. Part of the impetus for change here was that as acoustical scientists and engineers became less troubled by the efficient transmission of signals in lines, they were increasingly confronted with the difficulties of capturing and amplifying sounds in spaces. In areas like public address, radio, music recording and film, the telephonic imperatives of the communications frame brushed up against what we might broadly refer to as the aesthetic imperatives of the worlds of sound and music reproduction. This resulted in two-way processes of translation, through which both frames and worlds were necessarily reconfigured. Focusing on public address, but also touching on radio, music recording and film, I offer a survey of these processes in the interest of illustrating a more general point about the relationship between the communications frame and the worlds of music and sound reproduction.

In the years leading up to 1915 , two Napa Valley residents - Peter Jensen and his colleague Edwin Pridham - had been working with early vacuum tubes in the hopes of developing a loudspeaking telephone receiver. They pitched their receiver to the AT\&T in 1914 , but it was rejected on the grounds that it was "impractical because of its shape and weight."27 Jensen was "disappointed and angry" ("I said, "Those blankety-blanks wouldn't buy a twenty-dollar gold piece for five dollars"') but he and Pridham pressed on. $^{28}$

\footnotetext{
27 Jensen $(1975$, p. 83)

28 Ibid. (pp. 82-83).
} 
Eventually, though, it became clear that, as long as they considered their device solely as a telephone receiver, it wouldn't amount to much. "Like the rest of the radio and telephone engineers of that period," wrote Jensen, "we were strictly "communicationminded'; we thought only in terms of transmitting and receiving intelligence over a distance ... We thought we might make our dynamic telephone talk across a small room, but beyond that our imagination failed us. ${ }^{29}$ According to Jensen, their breakthrough came accidentally in early 1915, when an uncle-in-law, Ray Galbreath, suggested a different use:

Ray was what is often called a practical man; so when we had shown him our new telephone and let him listen to it, he shook his head and said, "If you can't sell it to the telephone company, what chance have you? But now, if you can make it talk a little louder and put a horn on it ... and if you put enough of them around a ball park, maybe we can understand what is being said a little better ..."30

Although this conceptual breakthrough did lead to the development of a forerunner to the modern loudspeaker (the Magnavox), ${ }^{31}$ as well as an early public address system, Jensen's retrospective also illustrates the gravity of the communications frame - the difficulty of transitioning from the problem of in-line transmission that occupied telephone engineers to a concern with in-space reproduction. Early accounts of the performance of public address systems begin to indicate certain shifts and translations in the communications frame.

${ }^{31}$ It is worth noting that many principles of the loudspeaker were known long before Jensen and Pridham made use of them. See Hunt (1954).
} 
Recalling their first experiments with this early form of public address system, in which the apparatus was mounted on the roof of their Napa bungalow, Jensen noted that "Pridham's voice ... sounded to us like a voice not of this earth. Had I closed my eyes it would have been easy to imagine that a supernatural colossus was shouting up the chimney."32 Other contemporaries heard something similar. Local reporter "Scoop" Gleason, for example, let his imagination run wild: "Lincoln's Gettysburg Address reverberating through the air like the roar of a giant! A piano solo resembling the chimes of Westminster Abbey played by the Colossus of Rhodes!"33 And, on 25 December 1915 , the San Francisco Bulletin described a Christmas Eve "sound miracle": "phonograph records that seemed uttered by a giant." ${ }^{.34}$

By the early 1920 s, though, public address systems had become relatively common (if still remarkable) features at political rallies and speeches, and the professionalization of this form of sound reproduction was accompanied less by astonishment and talk of giants, and increasingly by a cooler rhetoric of control, transparency, naturalness. As one sound equipment company put it in their catalogue, the desire was for "a realistic intensification of the speaker's voice - not the development of so much volume that the whole impression gained is of an inhumanly loud and artificial

\footnotetext{
32 Jensen (1975, p. 90).

${ }^{33}$ Gleason (1915).

34 "Throngs Crowd Civic Center" (25 December 1915). Some talk of giants persisted for several years. For example, a Science and Invention article "calculated" that for Harding to speak to the entire US population (120,000,000 at the time), he would have to be 173 -feet tall ("If President Harding Spoke" 1922, p. 909).
} 
voice." 35 Indeed, a "successful system," claimed the Bell System Technical Journal in 1923, was one that could "deliver ... faithful reproduction loud enough for all the audience to hear it comfortably and good intelligibility." If the loudspeakers were in the wrong spot, or if the voice "reached the audience with such volume that their instinct tells them that the speaker should be shouting, the system appears ... unnatural. ${ }^{.36}$ Or, stated positively in a Western Electric pamphlet, "Ideal conditions obtain when the audience is unaware of the loud speaking equipment and is of the impression that it hears the words of the speaker direct." ${ }^{37}$ That public address engineers had begun to achieve "ideal conditions" as early as 1921 is indicated in the following remarks on Warren Harding's political campaign: "The reproduction of President Harding's voice by the Bell Loud Speaker was so perfect that those in the first rows could not tell where the natural voice left off and where the amplified voice began." 38

Although such remarks indicate as much about the acculturation of audiences to new representational conventions as they do the technical success of public address engineers, I want to emphasize that what we see here is something like what we saw above with the telephone: not an attachment to ideals of fidelity (despite the rhetoric of naturalness and perfection), but a willingness to sacrifice fidelity for intelligibility. As

\footnotetext{
${ }^{35}$ Silver-Marshall (1928, p. 3). Emphasis in original.

${ }^{36}$ Green \& Maxfield (1923, p. 117).

${ }^{37}$ Western Electric (ca. 1922, n.p.).

38 "A Telephonic Achievement" (1921, p. 4). See also "Harding Amplifier" (1921, p. 37): "A woman in the crowd remarked, 'It must sound funny near the stand where you can hear both voices.' But nobody heard both voices. The reproduction of Mr. Harding's voice by the Bell loud speaker was so perfect that those in the first rows could not tell where the natural voice left off and where the amplified voice began." See also "Great Strides" $(1922$, p. 11).
} 
William Eccles explained in his 1929 presidential address to the Physical Society of

London, "it is now possible to obtain apparatus capable of helping a public speaker to

address great audiences without any suspicion of artificial aid; and apparatus has been

developed competent to spread intelligible speech to an audience of a million persons."

It has, however, been found better to attempt such feats by dividing the amplified speech currents among a number of well-distributed loud speakers than to deliver it all to one powerful loud speaker; for it is a curious fact that when the intensity of a complicated sound - either speech or orchestral music - is greatly magnified perfectly equally at every frequency - that is to say without any distortion whatever - and delivered to the ear, the listener believes that the sound is badly distorted ... .39

In other words, while audiences in the 1920s (unlike those in 1915) may not have suspected - may have learned not to suspect - that there was anything unnatural about an amplified voice, this was not due to absolute fidelity between speakers and loudspeakers. Just the opposite: a voice seemed most transparently mediated when it was most heavily processed. As the prominent sound engineer James Cameron put it, describing a 500-watt Western Electric sound system:

Speech projected over the speaker ... can actually cut through a din which itself borders on the deafening... The loudspeaker accomplishes this by sacrificing naturalness of reproduction and throwing its maximum energy into that part of the voice frequency range which is most essential to intelligibility. ${ }^{40}$

\footnotetext{
${ }^{39}$ Eccles (1929, p. 237).

${ }^{40}$ Cameron (1936, p. 260$)$.
} 
In this way, public address engineers initiated and responded to a process of translation that necessitated the construction of a complex system of representation based on loudspeaker placement and frequency filtering. In this system, voices seemed most natural when they were at their most artificial.

While the communications frame's privileging of intelligibility over fidelity was therefore translated into the world of public address, the collision of telephonic imperatives with the demands of in-space reproduction and existing modes of public address also necessitated new engineering solutions, the acceptance among audience members of new representational conventions, as well as the refinement of microphone technique and the modification of public speaking - especially political oratory. If the most obvious expression of these latter shifts include crooning and the "radio voice" made famous by Franklin D. Roosevelt in his 1930s fireside chats, the seeds of these vocal conventions were sown in public address. ${ }^{41}$ And while the effect of such conventions - what we might call an aesthetic of intimacy - have been eloquently described by a variety of early commentators, I prefer the jerky brevity of a telegram sent from Harding's campaign crew in 1924: "CONVENTION HALL CROWDED TO OVERFLOWING. STREET JAMMED OUTSIDE. PRESIDENT SPEAKING VERY

\section{LOW ENTIRELY ON LOUDSPEAKER. EVERYTHING O.K."'42}

\footnotetext{
${ }^{41}$ For insightful analyses of crooning, see Frith (1986), McCracken (1999), Johnson (2000), Lockheart (2003). For one among many takes on FDR's fireside chats, see Carroll (2000).

42 "Aesthetic of intimacy" is a phrase I owe to an excellent email thread that circulated among members of the International Association for the Study of Popular Music in 2008. For an eloquent period-description of the aesthetic of intimacy, see "A New Note in Politics" (1924). On Harding's speech, see AT\&T telegram from Truesdell to Grace, Kansas to New York (22 June 1923).
} 
If public address had more to do with in-space reproduction than in-line transmission, the translation of the communications frame into radio broadcasting and music recording was even more obviously organized around the problem of space. Radio provides an important early example here, for it raised questions about (and created new aesthetic conventions for) how musicians and on-air personalities should perform in an unnatural space with no audience, as well as about which kind of spatial signature a broadcast should bear. ${ }^{43}$ These questions spilled over into the recording studio too, due to the "preoccupation of the recording engineers of the early electric period with radio methods." ${ }^{44}$

Oliver Read and Walter Welch explain that the problem of space was inherited by the world of music recording through the prevalence of "these new radio-trained recording experts" in electrical recording studios, and that this led to the development of "Two quite contrary philosophies of recording" - a contradiction which they define in terms of realism versus romanticism. ${ }^{45}$ Realism, the "philosophy" which Read and Welch unapologetically favour, ${ }^{46}$ corresponds to what I have been discussing in terms of fidelity ideals: it strives toward the faithful capture and reproduction of an original performance.

\footnotetext{
${ }^{43}$ For just two of the innumerable pieces on how to perform in the radio studio, see Asquith (1924) and G.M. (1925). On studio techniques, in addition to the indispensable $B B C$ Hand Book (published under slightly varied titles beginning in 1928), see Eckersley (1925, p. 217).

44 Read \& Welch (1976, p. 376).

45 Ibid. (pp. 374, 377).

46 Ibid. (p. 372): "Regardless of whether electrical methods of recording and reproduction are used or not, the objective should be the same as that all-but-forgotten ideal of Thomas A. Edison - absolute fidelity to the original performance."
} 
Romanticism, on the other hand, is more explicitly connected to radio broadcasting - to the forfeit of fidelity as an ideal, and to the acceptance of the practical need to construct artificial spaces in the service of what I have been calling intelligibility. And, like public address, the translation of this telephonic imperative was accompanied by changes in musical practices and aesthetics ranging from the organization of studio recording sessions to the spatial characteristics of music recordings. ${ }^{47}$

In film, the basic spatial questions were similar, although they took on a specific form in debates about sound-scale versus image-scale. One prominent line of argument was championed by engineers like Maxfield of the Bell System. Maxfield maintained that there should be a faithful, realistic correlation between sound and image, so that close-up shots required close-up sounds, and so on. The problems with this view are colourfully illustrated in a 1928 Melody Maker article. Imagining (correctly, it turns out) that the future of film would involve full-colour and three-dimensional images, the author considers the representation "of a canary singing in its cage." On screen, he says, the apparent realism brought by the 3D and the colour would be offset by the unnatural size of the bird. Adding sound would further complicate things:

Let us assume ... that by this time the talking device is improved to such an extent that it may be said to be so perfect an imitation of the real thing that none can distinguish the difference. What would be the effect on our canary then? We should have before us a bird in a cage which, while they would be of correct colour and possibly even appearing to be of three dimensions, would be of

${ }^{47}$ For a source document on changes in studio practice, see Maxfield and Harrison (1926, pp. 498-500). On the various aesthetics of spatialization that developed in recorded music around this time, see Doyle (2005). 
leviathan size. And our elephantine canary would be singing away in the thin voice of the well-recognised three inches of the domestic warbler; or, if proportionate values were observed, it would be chirruping away with a volume capable of drowning a steam engine. In either case the height of absurdity would have been reached, despite the separate perfection of the two simulations. ${ }^{48}$

It is interesting that the Melody Maker critic realized so quickly what it took film sound professionals like Maxfield years to admit (in theory if not always in practice) - namely, that while matching sound-scale and image-scale may have satisfied ideals of fidelity, it actually overextended certain cinematic practices (suspension of disbelief) and conflicted with more specifically cinematic priorities (intelligibility of dialogue in the service of narrative coherence).$^{49}$

I've merely sketched a few prominent cases of the translation of the communications frame into other realms of music and sound reproduction. Still, what emerges from these examples is that there is both a level of consistency in the translation of this technological frame across worlds of sound reproduction (in every case, despite rhetoric to the contrary, practicalities of intelligibility outweighed ideals of fidelity) and a level of specificity in the translation of this frame into particular worlds of sound reproduction: in each case, the priority of intelligibility had to be crafted in relation to slightly different problems and traditions (be it oratory in public address, or narrative in

\footnotetext{
48 "The Anomaly of the Talking Film" (1928, p. 1153).

${ }^{49}$ See also Owens (1928). For detailed explorations of this debate, see Altman $(1985,1992)$ and Lastra (2000). For a subtly but fruitfully different argument, which suggests that the well-known rhetorical differences between Maxfield and RCA's Carl Dreher actually concealed a broader similarity in their work (organized as it was around creating systems of representation, of "signifying fidelity"), see Wurtzler (2007).
} 
film), which resulted not only in the mutation of the frame itself, but also the mutual reshaping of (1) engineering practices and sound technologies (not to mention their corresponding professions/industries $\left.{ }^{50}\right)$; (2) artistic forms, aesthetic preferences and representational norms; and (3) audience expectations and listening practices. If this is the general lesson of technology studies for the history of sound reproduction, I want to turn to a more specific case - and potentially a more complex one.

\section{A new lease on life: amplifying the guitar}

The rise of the electric guitar is often understood as a novel but straightforward solution to a particular problem - volume. Of course, guitar volume had been a serious (and nonelectrical) issue since at least the nineteenth century, where metallic cone-shaped resonators were developed, and where the virtues of metal versus gut strings and finger picking versus plectrum strumming were hotly debated. ${ }^{51}$ There is a sense, though, in which volume became an especially prominent concern in the early twentieth century.

The story goes like this: With the widespread popularity of dance bands and the increasingly large, purpose-built venues of an increasingly urbanized turn-of-the-century United States, guitarists sought higher volume levels in order to compete with larger, louder dance orchestras and larger, noisier audiences. Experimenters and manufacturers responded by developing the electrically amplified guitar from the late 1920 s, in turn

\footnotetext{
${ }^{50}$ On the professional reorganization and economic aspects of public address, see Dreher (1930), Simons (1930), Williams (1931), Warren (1965). Throughout the short career of Projection Engineering, Donald McNicol's editorials provide good perspective on the growth of the sound industry during this early period.

${ }^{51}$ For a discussion of these issues, see Noonan (2008).
} 
allowing bands and audiences to grow even larger, louder and noisier, which then created additional demand for louder guitars - and so on. By 1939, Charlie Christian could reportedly claim that "Electrical amplification has given guitarists a new lease on life," and by the 1960 s rock bands were playing stadiums and Pete Townsend was going deaf. ${ }^{52}$ The cyclical nature of this account gives the impression that the electric guitar was straightforwardly requested and accepted by musicians and audiences. But this is not the whole story. In fact, it conceals a more complex history.

The electrically amplified guitar, like most newly introduced technologies, was a source of confusion and controversy. ${ }^{53}$ In terms of confusion, a young woman encountering the instrument for the first time reacted with the same kind of awe and wonder that early twentieth-century Americans held for electricity more generally: "Oh how marvelous!!" she blurted. "Don't you get a shock when you touch it?"54 Controversy-wise, the patent office was unclear on whether the electric guitar was a musical instrument or an electronic device. ${ }^{55}$ Club owners worried these newfangled guitars would blow fuses and disrupt their businesses, and so discouraged their use. ${ }^{56}$ Old-guard guitarists and musicians resisted, too:

\footnotetext{
${ }^{52}$ Christian (2005, p. 94). On the back-and-forth between Townsend and Jim Marshall that led to some enormously powerful amplifiers, see Maloof (2004, pp. 40-74).

${ }^{53}$ For a broader treatment of this issue, the classic analysis is Marvin (1988).

${ }^{54}$ Miller (1936, p. 13). On awe and wonder in relation to electricity, see Nye (1992).

55 Smith (1987, pp. 17-19).

${ }^{56}$ Guitarist Eddie Durham reminds us that still in the 1930s "A lot of people thought that was a screwy idea, having an amplified guitar, and the ballroom managers were always afraid you'd blow out there lights. There was DC current all over the place so I often had trouble finding electrical outlets while I was touring with Basie" (Feather 1957, p. 130). See also SchmidtHorning (2004, p. 108).
} 
The instrument manufacturers, in hopes of expanding their market, kept pushing the idea of electric guitars in ads and catalogs. But these pleas were lost on most players. A few guitar stars emerged ... but band leaders and composers were sticking to their tried and true formulas, preferring to treat the electric guitar as an oddity or gimmick..$^{57}$

As such, there were efforts to defend the electric guitar against the "conjecture and ... endless barrage of questions from guitarists" that arose when the instrument was first introduced. Against the "fallacy" that the electric guitar was simple to play and limited to clichés, for example, there were attempts to establish it as an instrument that took serious practice and which was "only as limited as the man who plays it." 58 Another writer referred to electric guitars as "instruments of torture" that "made their appearance to crucify the ears of aesthetic musicians" - a comment which, although tongue-in-cheek (he nevertheless had "a yen to own one"), still tells us something about the extent to which guitar purists reacted against amplification. ${ }^{59}$

And more than simply rubbing aesthetes the wrong way, the electric guitar eventually did upset the established musical hierarchy. Band musicians were uneasy about the instrument's disruption of the division of labour, about its migration from an unglamorous rhythm instrument to its prominence as a melodic voice, thus displacing other lead instruments and creating new star performers. There were also intra-guitarist debates over the denigration of traditional musical values and playing techniques, as well

\footnotetext{
${ }^{57}$ Fliegler (1993, p. 12).

${ }^{58}$ Mulcahy (1936, p. 14).

${ }^{59}$ Chambers (1939, p. 271).
} 
as the strange new look of the instrument ${ }^{60}$ The amplifier, too, was a source of uncertainty.

The earliest attempts to electrically amplify the guitar involved playing regular acoustic and resonator instruments through public address systems. ${ }^{61}$ Although this solved the volume problem to some extent, it also resulted in a lot of unwanted noise. Not only did feedback loops become an issue, ${ }^{62}$ but microphones heard too much: from coughs and sneezes to moving chairs and private conversations. ${ }^{63}$ What's more, as an early essay on electrical instrument amplification explains, "A microphone of the broadcasting type picks up the whole orchestra, when it is only the strings that are weak and that do not balance the brass, so the result is as unbalanced as the original." Attempting to eliminate such noises and imbalances involved abandoning many of the usual, telecommunications-derived approaches to microphones and public address systems, and took the form of a different model of technological innovation - something closer to the technical practice that Steve Waksman has described as tinkering. ${ }^{65}$

\footnotetext{
${ }^{60}$ Waksman (1999, pp. 43-44) notes that Les Paul's original solidbody experiment, 1941 's "Log," was thought "unsightly": it "looked like a broomstick with a pickup."

${ }^{61}$ George Beauchamp was experimenting with microphones and PAs by 1925 (Smith 1987). Eddie Durham comments that one of his band leaders, Jimmy Lunceford, "used to bring the microphone right up to the $F$ hole of the guitar, so that between that and the resonator it was almost like having an electric instrument" (Feather 1957, p. 129).

62 The best account of feedback's migration from a problematic to a desired sound is McSwain (2002).

${ }^{63}$ Williams (1933B, p. 4).

${ }^{64}$ Ibid.

${ }^{65}$ Waksman (2004, pp. 679-680).
} 
Working on dining room tables instead of the workbenches in the research labs where engineers like Harold Arnold first developed electrical amplification, a variety of electric guitar experimenters began realizing that the acoustics of the conventional guitar actually interfered with the electrical signal. Microphones and telephone receivers were thus disassembled, while phonograph pickups were stripped of their needles, mounted directly inside the guitar, and amplified using modified radio receivers. Such trial and error led these tinkerers to focus on transmitting and amplifying the electromagnetic vibrations of the strings themselves, rather than the tone of the entire guitar. Indeed, as Lewis Williams, an employee of Lloyd Loar's Vivi-Tone company, wrote: "The subtle etheric flux of a magnet takes a $100 \%$ vibration impression and delivers as much to the aggrandizer for pure tone of any volume." $" 66$ And although Loar was working with the same general principles as Rickenbacker's George Beauchamp, it was Beauchamp who became most recognized for following this line of thinking through to what, in retrospect, is its logical endpoint: a guitar without an acoustical resonating chamber. ${ }^{67}$

Despite being based in a different model of technological innovation (informal tinkering v. laboratory research), we can still note the relevance of the communications

\footnotetext{
${ }^{66}$ Williams (1933A, p. 4.)

${ }^{67}$ It is widely accepted that Loar continued working in the "amplified acoustic frame" after Beauchamp had abandoned it (e.g. Smith 1987, p. 242 n.6; Wright 2000, pp. 75-182). However, there is reason to believe that, at least in Smith's case, the desire to bolster Rickenbacker's claims to have invented the first "real" electric guitar may have skewed his take on Vivi-Tone. Not only was Loar developing pickup units for use on soundboard-less electric keyboard instruments very similar to, but much earlier than, the electric pianos of people like Harold Rhodes (Loar 1934) - but Williams' (1933, p. 4) articles in The Crescendo also emphasize that Vivi-Tone's "unit generator" (i.e. pickup) "Does not use sound board or other instrument units for amplifying [sic]" and "Amplifies the strings alone."
} 
frame to the electric guitar and amplifier. Some of the earliest electric guitar designers worked within what Waksman calls an "amplified acoustic frame," meaning that "builders and manufacturers involved in making electric guitars held to the notion that amplified sound was still largely reliant upon the acoustic qualities of the instrument." By contrast, other designers incorporated aspects of the communications frame, which contributed an emphasis on certain technical priorities, or telephonic imperatives (electrical signals themselves more than conventional acoustics), and which was thus an important impetus to the rise of the electrically amplified guitar as we know it. ${ }^{68}$

The translation of the communications frame into the guitar world is thus similar to those processes of translation examined above: it involved a set of compromises surrounding the subordination of fidelity (i.e. the faithful amplification of a traditional guitar tone) to intelligibility (i.e. the creation of a new type of guitar tone based on the priorities of electronic signals); the attendant visual and sonic transformation of the guitar, along with its new musical role and social significance, were sources of confusion and controversy in the musical world; and, in retrospect, it is possible to see that the communications frame and the musical world worked together, in a relationship of mutual constitution, to shape the electric guitar into a certain type of sound reproduction technology. In this way, the electric guitar presents a classic case in the social construction of technology.

${ }^{68}$ Waksman (2004, pp. 679-680). Waksman makes a similar point with regard to later designers like Leo Fender and Les Paul. 
However, I want to suggest that the telephonic imperatives of the communications frame were further modified in their translation into the musical world of the guitar. So while I have shown the success of the communications frame in establishing the electric guitar as a sound reproduction technology, I also want to argue that this success was only partial: the communications frame also failed, in a certain sense, fully to take root in the guitar world. In particular, I want to look at the electric guitar's aesthetics of volume.

The virtues of loud and clear sound are stressed from the very first promotions of electrically amplified instruments. Appearing in the Chicago Musical Instrument catalogue of 1929, an ad for Stromberg Electro Instruments reads:

The tone in these instruments is amplified many times, through a magnetic pickup built into the instrument which takes the vibrations direct from the sounding board, and passes it through a two-stage amplifier. Every tone is brought out distinctly and evenly, with a volume that will fill even a large hall. ${ }^{69}$

Further underlining the emphasis on loud, clear tone outlined in the Stromberg ad, ViviTone spokesman Williams states that "Because of the inertia and resistance of soundingboard type of instrument [sic], the player must use a severe attack that pulls the string widely off its axis in order to get a loud tone."

This makes an imperfect string pattern so that the harder the string is pulled the more distorted the tone.... But in the electrically energized string instruments the perfect pattern of the string is readily retained for no severity of attack to gain loudness is necessary. The electrical energy affords the power.... To have the

${ }^{69}$ Stromberg ad reprinted in Smith $(1988$, p. 133). 
tone pure whether soft or loud was the aim of Professor Loar who stoutly maintains: "Nothing is so impressive as a loud tone that is sweet." "70

This same communications-derived mentality influenced work on electric guitars and the amplifier itself until well into the 1960s; however, it did not necessarily influence the use of electric guitars.

It was perhaps Leo Fender who most famously held on to the notion that an amplified guitar, like a communications signal, should come through loud and clear. ${ }^{71}$ Indeed, Fender "kept a close eye" on developments in the hi-fi home stereo market, and in 1961 Fender ads still opened by assuring that they were "capable of producing tremendous power, free from distortion, with reserve power available when needed." 72 However, tremendous power and distortion-free reproduction were not always seen by guitarists as positively correlated qualities. Indeed, there are innumerable accounts of guitarists who played loudly enough to "be heard above the blare of the neighbor's radio" and to "rattle the window panes, at that dance next month," plenty of assertions "that nobody could outblast [Guitar] Slim when it came to volume," and a certain amount of shock that Memphis Minnie played her guitar "amplified to machine proportions - a

\footnotetext{
${ }^{70}$ Williams (1933B, p. 4).

${ }^{71}$ My own surveys of music magazines like Down Beat and Guitar Player support this claim (see also Wheeler 2007). In the words of one amp handbook: "An amplifier must never change the shape of the signal fed into it - it must only make the signal bigger" (Darr 1965, p. 91; emphasis in original). Les Paul offers another, albeit somewhat atypical, example of a communicationsminded electric guitarist (see Waksman 1999).

${ }^{72}$ Respectively, Millard (2004, p. 139); Down Beat 27.15 (1961, p. 40).
} 
musical version of electric welders plus a rolling mill." 73 But there are fewer examples of players (as opposed to manufacturers) bragging about how pristine their guitar sounded, despite the high volumes. ${ }^{74}$ So while it is apparent that the volume of the electric guitar was appreciated by many players, they did not necessarily share the manufacturers' desire to maintain "tremendous power, free from distortion." In other words, while the translation of the communications frame into the invention and engineering of electric guitars and amplifiers was relatively smooth, these imperatives were modified in their relationship with the musical world: the practical thrust of intelligibility (loudness and clarity for the sake of comprehension) took on an unexpected aesthetic dimension (loudness over clarity for the sake of musical expression). The careers of guitarists like Memphis Minnie and Guitar Slim (among others) thus illustrate a degree of incongruence between how the guitar amplifier was conceived and marketed by manufacturers, on the one hand, and how it was actually used by musicians, on the other. And this incongruence

\footnotetext{
${ }^{73}$ Respectively, Chambers (1939, p. 271), Ford (1939, p. 601), Palmer (1991, p. 664), McSwain (2002, p. 193).

${ }^{74} \mathrm{Of}$ course, this characterization is genre-dependent. My argument here pertains mostly to blues and rock. Due to different aesthetic imperatives, the positive correlation of loudness and clarity held on longer in genres like country and jazz. Additionally, there are elements of racist backlash against distortion in general, which should not be ignored. For example, Lothinglader (1931, p. 289) refers to recent departures from so-called "clean tone" as a "relapse into 'dirt"': "there has lately appeared in the fashion-setting circle of white musicians in America, a movement which seems to me definitely retrograde. I refer to the deliberate cultivation of a 'dirty' or husky tone.... The purpose of this idea is, I gather, to reproduce the husky tone of the coloured man's voice, and thereby to impart something of the piquant barbarity of the negro to dance music."
} 
is rooted in the two-way translation of the telephonic imperatives of the communications

frame and the aesthetic imperatives of the musical world..$^{75}$

Of course, cooperation between manufacturers and users did eventually exist in

the development of high-powered and deliberately distorted amplifiers (e.g. Marshall and

the Who in the UK, Garnet and the Guess Who in Canada), to say nothing of the effects-

units that have been designed specifically for distortion since the $1960 \mathrm{~s}^{76}$ And while

these amp-manufacturers, like earlier ones, were also schooled in the communications

frame (via connections to engineering and radio), their collaborations with musicians led

to a higher degree of congruence between the communications frame and the musical

${ }^{75}$ Questions remain about the origins of this aesthetic of volume, this other approach to sound. While a full exploration of these questions would require an essay of its own, it is possible to point to an explanation by accounting for the specific demands that listening formations can place on technologies of sound reproduction. For example, forms of sound reproduction like telephony and public address were largely geared toward the problem of speech, whereas the musical world is more obviously geared toward qualitatively different problems like ensemble balance, instrument tone and performance. And compared to the standardizing world of commercial radio broadcasting and the unionizing world of Hollywood film sound in the 1920s and 1930s, the recording industry during this period is less concentrated, and the musical world is more diverse. Less concentration and more generic diversity opened the doors to a wider variety of aesthetic visions and musical value systems, including those based in differences of race and class. There are certainly other factors at play here, and other areas of overlap between the communications frame and the worlds of music and sound reproduction (e.g. when electric guitarists entered the studio, engineers attempted to capture the deliberately distorted sounds of the electric guitar with precision and fidelity). Still, these brief examples serve to highlight some of the particular shapes and demands of musical worlds in the early twentieth century. For a few of the sources on which my characterization of the wider musical world is based, see Pearsall (1976), Sanjek \& Sanjek (1996), Waksman (1999), Marmorstein (2007). On guitar distortion and early studio recordings, see Robert Palmer (1991, pp. $656 \mathrm{ff}$ ).

${ }^{76}$ For an account of this later period, see Millard (2004). Waksman (2009, pp. $61 \mathrm{ff}$ ) provides a subtle discussion of the differences between the "full-bodied distortion" that "relied more squarely on the power of ... Marshall amplifiers," on the one hand, and the stomp-boxes that "generated something that sounded much more like an effect, more piercing and more singlemindedly fuzzy." On the collaboration between Jim Marshall, his employees Ken Bran and Dudley Craven, and Pete Townsend of the Who, see Maloof (2004, pp. 40-74). For some background on Gar Gillies of the Garnet Amplifier Company and Randy Bachman of the Guess Who, see Gillies (2005). 
world - not unlike the relationship between technological innovation and musicianship cultivated by Robert Moog and his synthesizer company. ${ }^{77}$ But I want to end by asking what this earlier period of incongruence tells us about the history of sound reproduction more generally.

\section{Conclusion: rationality and the historiography of sound reproduction}

For Emily Thompson, the history of sound reproduction is a story about the rise of what she calls the soundscape of modernity. This modern soundscape took shape between 1900 and 1933, she argues, as engineers began confronting old problems (like auditorium reverberation) with new technologies (like microphones and loudspeakers). These new electroacoustic instruments offered new possibilities for controlling sound and new criteria for evaluating sound, which developed into a preference among electroacoustic engineers for sound that behaved predictably and rationally, and which came through loud and clear - like electrical signals themselves:

Electrical systems were evaluated by measuring the strength for their signals against the inevitable encroachments of electrical noise, and this measure now became the means by which to judge all sounds. The desire for clear, controlled, signal-like sound became pervasive, and anything that interfered with this goal was now engineered out of existence. ${ }^{78}$

Thompson goes on to demonstrate numerous ways in which this preference for "clear, controlled, signal-like sound" - or, we might say, the ways in which certain telephonic

77 On how Moog tailored his synthesizers to the needs of popular musicians, see Pinch and Trocco (2002).

${ }^{78}$ Thompson $(2002$, p. 3). 
imperatives - became the basis for numerous sound reproduction technologies, and how these technologies became a ubiquitous part of the acoustic environment through various feats of engineering and industry.

Changes in the scientific understanding and technological mediation of the acoustic environment obviously do not occur apart from broader cultural concerns, and so, for Thompson, "a soundscape is simultaneously a physical environment and a way of perceiving that environment; it is both a world and a culture constructed to make sense of that world." 79 Thus, as these engineering priorities and sound reproduction technologies spread into the everyday world of sound, listeners also had to adjust:

Radios, electrically amplified phonographs, public address systems, and sound motion pictures transformed the soundscape by introducing auditors not only to electrically reproduced sound but also new ways of listening. As people selfconsciously consumed these new products they became increasingly "sound conscious," and the sound that they sought was of a particular type. Clear and focused, it issued directly toward them with little opportunity to reflect and reverberate off the surfaces of the room in which it was generated. ${ }^{80}$

To use the terminology I outlined above, Thompson chronicles the translation of the communications frame into a broad range of electrical sound reproduction technologies and, in turn, discusses how, through the proliferation of those technologies and their attendant criteria of acoustic evaluation, the communications frame also came to

\footnotetext{
${ }^{79}$ Ibid. (p. 1).

${ }^{80}$ Ibid. (pp. 233-234).
} 
influence popular listening practices. In this way, the rise of the modern soundscape is paralleled by modern modes of listening.

Jonathan Sterne is the scholar who has done the most to conceptualize and historicize these modes of listening, arguing for a "distinctively modern set of practical orientations toward listening" that he calls audile technique. ${ }^{81} \mathrm{He}$ defines audile technique as "a set of practices of listening that were articulated to science, reason, and instrumentality and that encouraged the coding and rationalization of what was heard." $" 82$ With audile technique as his compass, Sterne charts a history in which listening becomes associated with reason, separated from the other senses, and privatized; in which it becomes a type of virtuosity, a means through which cultural capital can be accrued and distinction displayed; in which it becomes focused and attentive, disciplined and detailoriented. ${ }^{83}$ These listening priorities emerged with the stethoscope in the nineteenth century where, he argues, "the rationalization, codification, and instrumentalization of the sounds produced through mediate auscultation" became "key elements of its modernity as a technique of listening." $" 84$ This set of modern listening techniques evolved into a repertoire for electric telegraphers and telephone users, and it assumed a new cultural prominence around the turn of the twentieth century, as it was translated into the rapidly expanding worlds of sound reproduction:

\footnotetext{
${ }^{81}$ Sterne (2003, p. 95).

82 Ibid. (p. 23).

${ }^{83}$ Ibid. (pp. 87-178).

84 Ibid. (p. 131).
} 
As with mediate auscultation and telegraphy, sound reproduction also required the development of audile technique. Even the earliest experiments were a form of listening practice, and, while this listening practice extended the constructs of audile technique developed earlier in the nineteenth century, it also developed them in new and interesting ways. ${ }^{85}$

A level of mastery over sound and the acoustic environment thus emerged alongside a particular way of relating to them - a mode of listening that involved self-mastery:

"Through techniques of listening, people harnessed, modified, and shaped their powers of auditory perception in the service of rationality." ${ }^{86}$ For Thompson and Sterne, then, the history of sound reproduction is a history of clear sound and keen ears, a history of controlled sound and self-control in relation to sound. To put it another way, the story arc of sound and listening in the modern era can be seen as having been described in terms of rationalization.

Electric guitar amplification is a part of this history. As we saw with the development of the solid-body electric, the communications frame contributed to the guitar the same emphasis on signals themselves, the same rationalized approach to sound, that Thompson charts in other areas of acoustic science and engineering. And as we saw in the manifestos and advertisements for early guitar amplifiers, the telephonic imperatives and rationalized techniques of listening that Sterne finds in various realms of sound reproduction were translated into the work of electric guitar and amplifier pioneers

\footnotetext{
${ }^{85}$ Ibid. (p. 256).

${ }^{86}$ Ibid. (p. 2).
} 
like Loar and Beauchamp (not to mention Fender and Paul). However, other guitarists are less easily accounted for in this history.

Guitar Slim, for example, continued amplifying his guitar using microphones and public address systems long after the electric guitar was viable, rather than adopting the preference for signals themselves found among early experimenters, and emphasized in the work of Thompson. ${ }^{87}$ Memphis Minnie and Eddie Durham were better known for the sheer volume of their guitars than for the balance of loudness and clarity that characterizes the communications frame in general, and early hi-fi discourse in particular - a prioritization of certain aesthetic and expressive imperatives, and an incongruence between users and manufacturers which, of course, eventually evolved into a preference for full-blown distortion in blues and rock. André Millard neatly summarizes this incongruence:

While the makers of amplifiers and the designers of pickups treated distortion as a major technical problem, many guitar players welcomed it as they sought new and more expressive sounds... . The people who bought guitars and amplifiers did not always follow the manufacturers' recommendations, nor did they act like rational buyers. The strategy of technological innovation did not always work, nor did the modernity implied in equipment design. ${ }^{88}$

\footnotetext{
${ }^{87}$ As Earl King remembers, "Slim never used an amplifier. He always used a P.A. set, never an amplifier" (Palmer 1991, p. 655).

${ }^{88}$ Millard (2004, pp. 136-137, 140). My emphases.
} 
So the incongruence between users and manufacturers points toward larger questions about the relationships between sound technologies, on the one hand, and notions of rationalization and modernity, on the other. ${ }^{89}$

To be clear, to raise this question is not to criticize Thompson or Sterne as such: they recognize that the history of sound reproduction is far from monolithic, and neither of them claims to have written a comprehensive or exclusive account of sound and listening in the modern era. But if this incongruence is an integral part of the electric guitar's history, then it is also, necessarily, integral to the history of sound reproduction more generally. So the incongruence between manufacturers and users surrounding the emphasis on loudness among early guitarists calls for a closer look at the idea of rationalization in the historiography of sound reproduction.

It would be possible to end by arguing that this incongruence weakens the case for the rationalization of sound and listening in the modern era, and that some kind of modified historical thesis is required to approach a more effective understanding of the development of sound reproduction. But to make such an argument would be to miss something about the subtly and complexity that rationalization is accorded in a lot of other research. Too often oversimplified as the straightforward triumph of science over

${ }^{89}$ It would be possible to carry this line of argument further. For example, through their lack of concern for clarity in favour of volume and musical expression, it would be possible to suggest that, in contrast to the ideals of transparency in high-fidelity technological mediation seen above in various realms of sound reproduction, certain guitarists have drawn attention to, even explicitly valued, the opacity of the amplifier as a technology of sound reproduction. And instead of the emphasis on the ear and the separation of listening from the other senses that characterize Sterne's history of audile technique, the preference for loudness and the spectacular performance conventions of early electric guitarists - as well as their essential connection to dancing audiences - calls attention to the connections between hearing and the other senses, between the ear and the rest of the body. 
religion, or the relentless bureaucratization and disenchantment of the world,

rationalization is in fact a multifaceted phenomenon that encompasses various logics of rationality. As Weber himself knew, "'rationalism' is a historical concept that contains a world of contradictions within itself." 90 From this perspective, we can see that the forms of rationalization described by Sterne and Thompson emerged in relation to other sets of ideas and practices found in the musical world in general, and early electric guitar amplification in particular. It might seem tempting here to posit this relationship in terms of a link between the scientific rationality of engineers and the aesthetic irrationality of musicians, where the rationalization of sound and listening in the modern era pivots on the exclusion of the irrational. But that is not what I want to suggest. While the stated aims of amplifier manufacturers may appear strictly "rational," there is also a sense in which they battled with "irrational" adherences to ideals of electronics and musicality, while the apparently "irrational" ends of guitarists were achieved through "rational" means (tinkering). As such, it seems better to think in terms of an overall logic of rationalization that is able to admit of multiple modes of rationality (organized around varying levels of prioritization in relation to telephonic and aesthetic imperatives, ideals of fidelity and practicalities of listening). These modes of rationality do not exclude one

\footnotetext{
${ }^{90}$ My usage of rationalization isn't preoccupied with fidelity to Max Weber's own definitions. Still, without needing to scrutinize (much less accept) all of his claims, this concept does provide a useful way of generalizing Thompson and Sterne's theses about sound and listening, as well as a useful bridge between the history of sound reproduction and broader themes of modernity. I recognize that imprecise invocations of rationalization are thorns in the sides of Weberian scholars, and even though I refrain from extensive reference to Weber's writings, let alone the countless essays and books on this contested topic, I have tried to base my discussion in the most rigorous secondary analyses. See Kalberg $(1980,2005)$ and Sica $(1988,2000)$. Weber quoted in Kalberg (1980, p. 1172).
} 
another; rather, they presuppose one another. Seen in this way, the electric guitar actually bolsters the case for the rationalization of sound and listening in the modern era (albeit partly in the discursive sense of being an other). ${ }^{91}$

The relationship that I have described here between the communications frame and the worlds of music and sound reproduction, and the corresponding logic of rationalization, constitutes an important part of the broader logic of listening formations. Thinking in terms of listening formations - which means granting rationality something like the nuanced definition found in Weber's work, and recognizing the corresponding messiness that characterizes the project of modernity more generally - enables the electric guitar to sharpen the notion of rationalization, and to solidify the usefulness of a rationalization thesis, in relation to sound reproduction. And this is where we return to iconographic approaches to this technology of sound reproduction, because they illustrate so vividly that, yes, the electric guitar is a symbol of (American) modernity, but that symbolizing modernity is about embodying contradictions and conflicts more than following univocal trajectories of perfection, privatization, rationalization and, as we will see next, objectification. In other words, what I have tried to show in this technology studies-influenced chapter on the electric guitar is that, if there is anything distinctly modern about sound and listening in the early twentieth century, or that if there is anything distinctly aural about modernity, the distinction perhaps has more to do with the

\footnotetext{
91 See Koopman (2010).
} 
particular logics of listening formations than it does the rise of a modern soundscape or audile technique as such. 


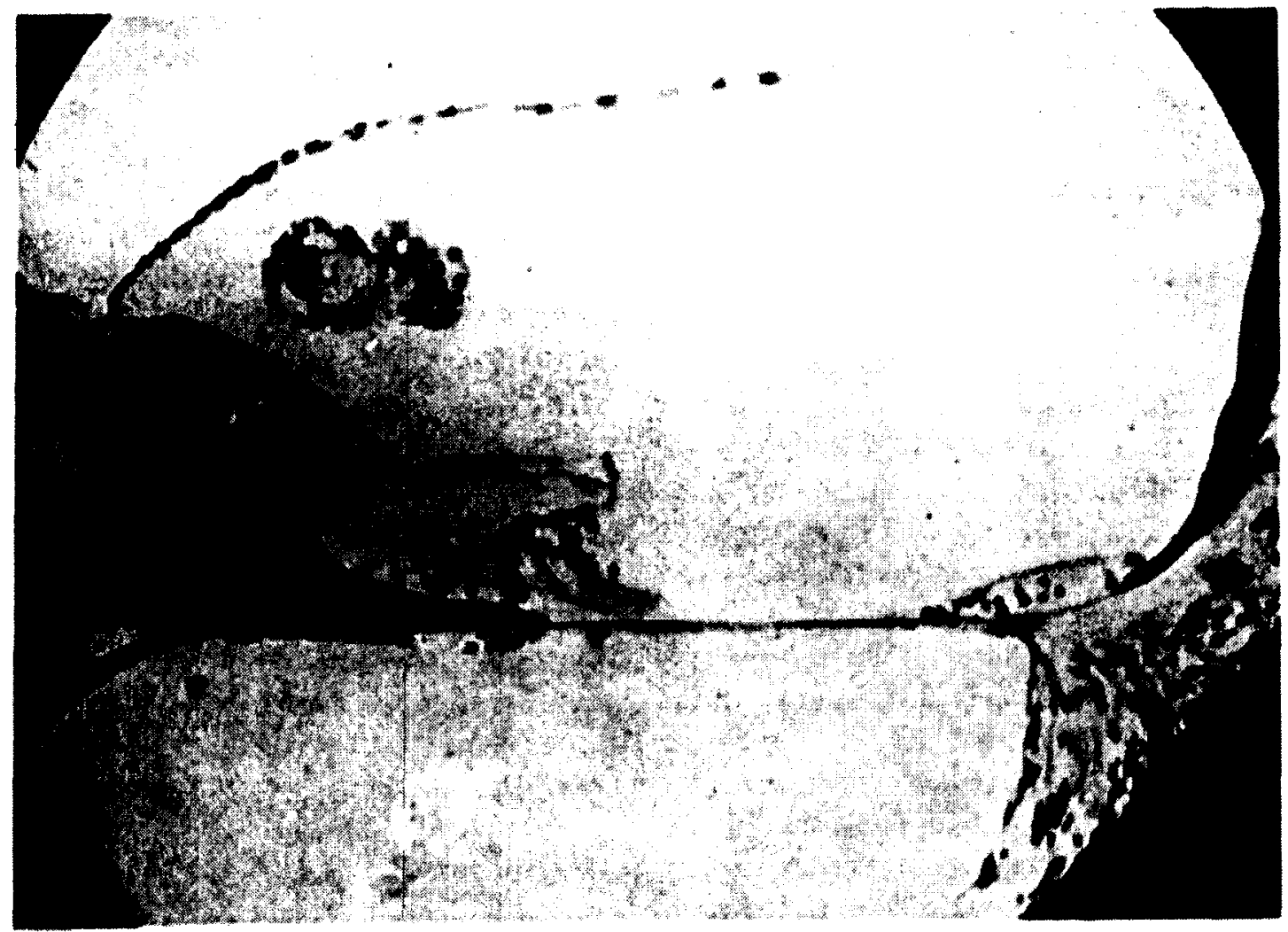

Fio. 6. Eaction of the cochles of the ruinee pir. The outer portion of the organ of Corti hes been dialodred by a loud tone and knocked into the upper left-hand corner of the wealn media. The intermal hair call is atill in its normal poeition and the beallar, Reienner's and tectorial membranee are atill intact.

Figure 5. "Psychophysical Acoustics: Pitch and Loudness," Stanley Stevens \& Hallowell Davis (1936) 


\section{CHAPTER 4 \\ Objectivity: a decibel by any other name}

Forecasting and fantasizing in 1947, Carl Seashore prescribed the future of music:

One of the fundamental marks of musicianship is the mastery of the dynamic control of tones in all musical phrasing and interpretation. The student of this aspect of tone has been greatly hampered because he has had no defined terminology for intensity of tone ... no objective standards, no units of measurement.... But through the science of acoustics there recently has been developed a means of measuring loudness. We now have standards of loudness ... The immediate objective is to make the student loudness-conscious just as he is pitch-conscious - to make him feel at home with loudness, to master the control of loudness; to form definite loudness habits, and objectify feeling values for it. ${ }^{1}$

The development in acoustic science that enthused Seashore was the decibel. He imagined the decibel meter "standing on top of the piano like a metronome," enabling musicians to "watch the swinging of the needle over the decibel scale" in an act "as simple as seeing the time of day by observing the hands of the clock."2 Obviously, Seashore had high hopes for the humble gauge: just as clocks and metronomes tamed time and tempo in the nineteenth century, and just as their use had become second nature,

\footnotetext{
' Seashore (1947, pp. 326-328).

${ }^{2}$ Ibid. (p. 329). For some background on audiometers, see Mills (2011).
} 
so would the decibel allow the quantification and objectification of loudness as a routine part of musical practice. ${ }^{3}$

This wasn't the first time Seashore wrote about loudness: as early as 1919 , he claimed that "the sense of volume is a most vital concept in music ... the manipulation of volume is one of the prime factors at which musicians aim." 4 And Seashore wasn't alone. Vern Knudsen, for example, agreed: "When musicians become acquainted with the tools and techniques of modern acoustics, it is probable that a quantitative rather than a qualitative scale of loudness will be adopted for all musical purposes." Indeed, one of the goals of this chapter is to situate Seashore's interest in loudness as part of a longer history in which volume took on an increasingly prominent role in musical aesthetics and music criticism. But Seashore was a psychologist, and his interest in loudness can also be read in tandem with more general shifts in the acoustic sciences following the first and second scientific revolutions. In both cases, music and science wanted a machine that could objectify loudness; what they got was a convoluted unit of measurement that reaffirmed its essential subjectivity. This chapter tells that story.

\footnotetext{
${ }^{3}$ On timekeeping devices, the rise of industrial capitalism, and changing conceptions of temporality in the nineteenth and early twentieth centuries, see Kern (1983) and Beniger (1986). For a longer historical lead-in, see Cipolla (2003).

${ }^{4}$ Seashore (1919, p. 167). See also Seashore (1938, p. 77): "The builder of instruments, the musical critic, the teacher, and the scientist dealing with the art of music must develop a more conscious recognition of the role of intensity that that which now prevails in judging the beauty of music"; the music student, he continued, "must become aware ... of the countless devices which must be at his command in controlling, modifying, and utilizing loudness characteristics in tone production."

${ }^{5}$ Knudsen (1938, p. 183). See also Recht's (1964) argument for "The Decibel as a Musical Unit."
} 
My argument is organized into three main sections. Part one provides a broad sketch of the musical and cultural discourses leading up to and surrounding Seashore's interest in loudness. As in previous chapters, we see that loudness has its advocates and its detractors. I highlight the prominence of critical reactions toward loudness in everyday life and in musical culture (reactions that gained traction despite widespread curiosity and aesthetic interest in loudness during the early twentieth century). These reactions weren't limited to the op-ed pages of newspapers or music journals, either: they were institutionalized in formal studies of the effects of loud music on hearing and public health (in a way that mirrored earlier concerns about noise and the cityscape). This led to the deployment of a specific unit of measurement - the decibel - in the hopes of quantitatively and objectively policing musical loudness.

But the decibel was not well understood in public discourse, and it stirred up controversy. The questions that present themselves here are: Where did the decibel come from? What was it about the decibel that caused such confusion? The answers are presented in part two. It is here that I deal explicitly with the invention of the decibel as a unit of measurement. Addressing (in turn) the acoustic sciences, telecommunications, and psychophysics, I locate loudness and the decibel in a broad history of ideas about objects and subjects, and in the ways those ideas coalesced in the human sciences around the turn of the twentieth century. 
Part three asks what this history of ideas - a history of objectivity - means for the historiography of sound reproduction. ${ }^{6}$ The questions about perception and objectivity that are raised in this part of my analysis have been more thoroughly navigated in terms of the visual. One of this chapter's aims is thus to place Jonathan Crary's culturallyoriented history of visuality into dialogue with Lorraine Daston and Peter Galison's visually-oriented history of objectivity, to feed both into the audible past, and to filter it all through a discussion of loudness. In doing so, I argue that the parallels and perpendiculars of the successful rationalization of sound (as an object, as a stimulus) clashed with the attempted rationalization of listening (within the subject, in terms of sensation and perception). This raises questions about the status of objectivity in the historiography of sound reproduction. My point is that objectivity is not a singular phenomenon. Whereas sound scholars tend to focus on the ways in which the overlapping "epistemic virtues" of "truth-to-nature" and "mechanical objectivity" (i.e. a will to know the real without the interference of perception or representation) led to a new abstraction of sound qua sound and attendant regulations of subjectivity in acoustic modernity, I emphasize ways in which ideals and practicalities of "structural objectivity" (i.e. an acknowledgment that mechanical objectivity is impossible because perception and representation inevitably shape our knowledge of and access to the real, but nevertheless a will to express that relationship in lawlike form) reconfigured the acoustic in terms of a

${ }^{6}$ The history of objectivity has of course been a major topic in science studies. For a brief but authoritative survey, see Shapin (2012). 
co-productive tension between object and subject. ${ }^{7}$ This reconfiguration, while it may

constitute a central tenet of acoustic modernity (if there is such a thing), also constitutes a logic of listening formations.

Throughout this chapter, I refer to a variety of modes of inquiry into sound. These fields include otology, acoustics, psychoacoustics and musicology. ${ }^{8}$ Each of these fields of study possesses an internal complexity and a richness of tradition that resists easy simplification. Indeed, they all warrant, and many have received, investigations of their own (I will have occasion to cite these studies below). But they can also be seen as overlapping in a broader history of ideas. ${ }^{9}$ This chapter looks at that overlap through the lens of the decibel.

There is no general agreement on a single term that conveys the points of convergence across this constellation of disciplines. Veit Erlmann, in a likeminded analysis of sound and systems of thought, uses "otology." His definition ("the study of the ear") is more general than the usual medical usage (the study of the anatomy and diseases of the ear) and takes on an even broader significance in the course of his study ("modern aurality" in its largest sense). ${ }^{10}$ While I see the value in telescoping between modern aurality and the study of the ear, and while otology works well for Erlmann's

\footnotetext{
${ }^{7}$ My description of these various facets of objectivity as "epistemic virtues," and my definitions of them, are based in Daston \& Galison (1992, 2010).

${ }^{8}$ For simplicity's sake, I have not mentioned some of the broader fields in which these more narrowly sonic fields are rooted - physics, physiology, medicine, psychology, psychophysics, mathematics - although several of these will play a role in my analysis.

${ }^{9}$ See Foucault (1977).

${ }^{10}$ Erlmann (2010, p. 12).
} 
purposes, I find the term both too narrow (I am interested in the messy overlap between studies of the ear, of sound, and of perception) and too broad (his redefinition stretches otology uncomfortably far beyond its usual medical meaning). Erlmann's medical appropriation is therefore not ideal for my purposes. "Acoustics" is a more obvious candidate. But using this term would require the same act of appropriation as Erlmann's otology, given that the official purview of acoustics is physics. I prefer acoustic sciences. "1 "Acoustic" here is used in its everyday form, as that which relates to sound and/or hearing. Indeed, this is close to the broad meaning of "acoustical" found in the Journal of the Acoustical Society of America, which defines itself as a "source of theoretical and experimental research results in the broad interdisciplinary subject of sound" that "serves physical scientists, life scientists, engineers, psychologists, physiologists, architects, musicians, and speech communication specialists." "Acoustic science" is thus meant as an economical and straightforward way of emphasizing the coincidence of several fields - the physics of sound, the physiology of the ear, the psychology of hearing - and their situation in a broader history of ideas. Between these areas - at the interstices of mind and matter, subject and object - lies the history of the decibel.

\section{Origins of the decibel: part one}

\section{Musical aesthetics and cultural discourse}

\footnotetext{
"I mean for this term to evoke, in a roughly analogous but specified sense, Michel Foucault's (1970) study of the human sciences.
} 
Seashore's interest in loudness did not emerge out of the blue. Of course, it is likely that the history of loudness is as old as music itself, and that dynamic variation has always existed in musical performance. Indeed, mention of it can be traced at least as far back as ancient Greece. ${ }^{12}$ But a more attentive concern for volume - and a more relevant origin story in terms of contextualizing Seashore - began to emerge in the work of sixteenthcentury theorists like Zarlino and, in line with the doctrine of the affections, volume was given more definite expressive roles by such seventeenth-century theorists as Descartes, Kircher and Mersenne. ${ }^{13}$ Descartes, for example, opens his Compendium musicae (first published in 1650) with the following passage:

The object of this art [i.e. music] is a sound; the end, to delight and move various affections in us. ... The means conducing to this end, or the affections of a sound, are chiefly two: the ratios of duration or tempo, and of pitch in relation to acuteness and loudness. ${ }^{14}$

Still, dynamic markings did not occur regularly in the scores of Baroque composers.

By the middle of the eighteenth century, with the "tendency towards

intensification and climaxes in the Classical style," dynamics achieved a new prominence

\footnotetext{
12 Remarks on the history of dynamics can be found scattered throughout a variety of musicological studies (e.g. there is a good discussion in Kolneder 1970). My brief analysis here is based mainly on two sources: Elston (1939) and Thiemel (2001).

${ }^{13}$ Claude Palisca (2000) argues that the musical interest in affections can be traced to the sixteenth century.

${ }^{14}$ Descartes $(1653$, p. 1$)$. I have taken certain liberties in modernizing the typography of this early translation. For the sake of clarity, the portion of this quote that appears after the colon is from a much later translation. The original passage reads: "The means conducing to this end, or the affections of a sound, are chiefly two; viz. the differences in the reason of duration or time, and in the reason of its intension or modification into acute or grave." For the later translation, see Gozza (2000B, p. 162). All emphases in original. For details of the English translation/publication of Descartes, see Wardhuagh (2008A).
} 
in compositional practice. ${ }^{15}$ This enhanced interest in the expressive potential of dynamics led to two important developments. First, composers began notating dynamic variation with greater frequency, regularity and specificity. (Indeed, Leopold Mozart's widely known violin textbook of 1756 contains modern definitions of piano and forte, as well as crescendo and descrescendo.) Second, more dynamically flexible instruments were developed, such as the organ swell box and, most famously, the pianoforte. ${ }^{16}$

It was from the late eighteenth century, and especially during the nineteenth, though, that dynamics became a vital part of musical expression and compositional structure. Musicologists such as Hugo Riemann and Ernst Kurth, for example, carefully theorized the role of dynamics in their treatises. ${ }^{17}$ That even more weight was placed on volume can be seen in the writings of many composers, too. Figures from C.P.E. Bach to Mozart to Mahler complained about inadequacies in the execution of dynamic markings. Beethoven, it seems, was particularly sensitive to the issue, directing his publisher to "have all the $p, p p$, cresc., decresc., $f$ and $f f$ crossed out of my opera-none of them will be observed, after all, and if I were to hear them, I would lose all desire to write anything else." ${ }^{18}$ Later in the nineteenth century, when composers began experimenting with the sound palate of the orchestra as much as its harmonic vocabulary, loudness not only took

\footnotetext{
15 Thiemel (2001, p. 820).

16 To my knowledge, there is no large-scale study of volume as a driving force in the history of organology. For an excellent history of the pianoforte (which is tacitly concerned with loudness), see Loesser (1954). For a discussion of powerful, low-frequency sound in the history of organ building, see Jasen (2011).

${ }^{17}$ See Thiemel (1996). The most prominent English-language discussions (Kim 2003, Rehding 2003), while not concerned with loudness or dynamics in particular, provide important context.

${ }^{18}$ Beethoven quoted in Thiemel $(2001$, p. 822).
} 
on a new role in musical aesthetics and music criticism; it also became more tightly bound with wider cultural discourses of loudness, noise and taste.

It is interesting to note that while composers like Berlioz believed the new attention given to instrumentation and orchestration during this period freed music from the slavish reliance on harmonic laws, ${ }^{19}$ critics often complained that new orchestration techniques - especially loud ones - were merely a means of hiding bad writing. In 1835 , for example, George Hogarth accused Rossini of using "the confusion of many loud instruments" to camouflage "incorrect and slovenly harmony."20 Most famously, Wagner's music was often seen as "needlessly luxurious in mere loudness and meriticiousness of sound," while his arrangements were said to produce nothing but "grim noise" and "broken crockery effects."2l This disapproving view of loudness in Wagner held for a century. Writing in 1941, Adorno derided Wagner's use of "the mere magnitude of the sound, into whose waves the listener can dive ... quite apart from any specific musical content. ${ }^{22}$ Indeed, Adorno connected what he saw as the essential hollowness of Wagner's volume with "music's function as a drug."23 Other composers, Adorno thought, made better use of volume: "In Beethoven, where the musical content is highly articulate, the largeness of the sound does not have this irrational function, but is

\footnotetext{
${ }^{19}$ Berlioz (1882).

${ }^{20}$ Hogarth quoted in Demuth (1947, p. 147).

${ }^{21}$ Ibid. (p. 242).

22 Adorno (2002B, p. 258).

${ }^{23}$ Ibid. (p. 257).
} 
the more intrinsically connected with the structural devices of the work." ${ }^{24}$ In addition to furthering my argument about the importance of loudness in nineteenth- and twentiethcentury composition and criticism, the language here - slovenly, needlessly luxurious, grim, irrational - points to the historical connection between musical loudness and musical taste. Indeed, as we have seen and as we shall continue to see, the relationship between loud music and musical taste - especially bad taste - were further established in the twentieth century, from the criticisms of "strident" electrical recordings to the radio craze and the electric guitar, through to the rise of rock music and disco. Before moving into that discussion, though, I want to highlight something else: the coincidence of increased experimentation with the orchestra's sound palate and the dissolution of common practice tonality.

The role of loudness in the dissolution of common practice tonality has not been widely discussed by musicologists, although it was noticed by contemporaries such as Otto Ortmann (who was an important influence on Seashore). ${ }^{25}$ Of course, Ortmann recognized that loudness - or "intensity" in his terminology - "has long been recognized as an important element in musical aesthetics. ${ }^{26}$ However, in trying to come to grips

${ }^{24}$ Ibid. (p. 258). It is interesting to note that Adorno then argues that Wagner's music is better suited for radio. For the dynamic range compression of radio, he believes, does more to destroy the structural role and overall effect of loudness in Beethoven (ibid., pp. 256-261). These comments not only need to be read in relation to chapter l's discussion of compression, perfection and loudness, but in terms of a broader history of the discourse of loudness in Wagner's music. Such an analysis is beyond the scope of this project.

${ }^{25}$ See Gonzol (2004, pp. 177-178 n.23).

${ }^{26}$ Consonant with my discussion of instruments and dynamics, Ortmann (1928, p. 190) notes that loudness "prompted the invention of the pianoforte; it is used from the crescendo on the opening tone of the Bach Aria on the G String, to that in the March of Schelling's Victory Ball." 
with the dissolution of tonality - "the whole-tone combinations of Debussy, the quartertones of Möllendorff, the sixth-tones of Busoni, and finally in the rhythmic and clang effects of Jazz" - Ortmann argues for the special status of loudness. "The analysts," he says, "have sought the reasons for the composer's method in the three elements of music generally accepted as basic: rhythm, melody, and harmony." ${ }^{27}$ But for Ortmann these usual musicological avenues "have overlooked a fourth attribute; one which was raised to a high level of importance as soon as experimentation with complex tone-combinations began. That attribute is tonal intensity." ${ }^{28}$ While his enthusiasm for the musical possibilities of loudness was not unbridled, ${ }^{29}$ Ortmann did note that "of all the tonal elements, intensity is the most vivid. ${ }^{.30}$ Such aesthetic and critical interest in loudness took on an even more prominent role in the context of electrical amplification.

Leopold Stokowski famously extolled the virtues of electrical amplification, and of the musical possibilities of volume that came along with this relatively new technology. Nowhere was this more evident than in a series of demonstrations and

\footnotetext{
${ }^{27}$ Ibid. (p. 178).
}

${ }^{28}$ Ortmann (ibid., pp. 187-179 defines tonal intensity as such: "Intensity in any sense-department may be defined as the degree to which the end-organ of sense is affected. In hearing, the physical attribute of intensity produces the sensation of loudness."

${ }^{29}$ Ortmann (ibid., p. 191) qualified his remarks, noting that loudness and dynamics "can be elaborated in many subtle ways" when "[c]ombined with melodic and rhythmic variations," but that "[u]sed alone, that is to say, without changes in pitch, they are somewhat elemental in their appeal; and used with sliding intonation they become more elemental. Hence they have already become one of the typical characteristics of Jazz." Additionally, Ortmann (ibid., p. 190) registered some reservations about the "lack of systematic development of tonal intensity" both in measurement and compositional technique, citing as a main reason "The impossibility of utilizing a fixed scale of intensity (and the resulting vagueness of such terms as piano or mezzo-forte, since loudness is a sensation and not a physical quantity)."

${ }^{30}$ Ibid. 
performances stemming from Stokowski's collaboration with Bell Labs between 1930 and 1940. While I have already argued that the engineers of this period were less concerned with fidelity as such than with a set of technical and aesthetic compromises between fidelity and intelligibility (see Chapter 3 ), the interaction between Stokowski and Bell was more explicitly concerned with "the possibility of perfect reproduction" for its own sake. ${ }^{31}$ This interaction between the communications frame and the musical world was welcomed by Bell engineers, who saw Stokowski's interest as "a great inspiration to us to have some of these things that seem so dry as we measure them in our mechanical way." 32

In an early report on the collaboration, Stokowski conveyed his excitement about electrical recording: "The limitations of music are becoming less and less," he said, predicting that "electrical-musical instruments" and "sound films of the future" would "be able to convey emotions higher than even thought - things subtle and intangible almost psychic in their being." ${ }^{\prime 3}$ Whatever Stokowski is supposed to have meant by these oracular comments, his enthusiasm for electrical reproduction was echoed in the popular press. Reporting on the Philadelphia-Washington demonstration for the National Academy of Sciences in 1933, the New York Tribune claimed:

Against the charge that electrical reproduction is ruining the musical arts it frequently has been retorted by electricity's friends that one day these new methods of producing and reproducing sounds would provide something

\footnotetext{
31 Jewett (1933, p. 156).

32 Harold Arnold to Stokowski, quoted in McGinn (1983, p. 56).

33 "Advance is Shown in Music Recording" (10 December 1931, p. 28).
} 
incomparably better than anything producible by unaided human hands. The promise comes nearer with the demonstration this week in Philadelphia of the novel methods and apparatus developed jointly by Dr. Stokowski, the Philadelphia Orchestra and the engineers and acoustic experts of the American Telephone and Telegraph Company. ${ }^{34}$

Indeed:

... as Leopold Stokowski turned from the task of commanding conductor to electrical engineer, controlling the telephoned tone of the Philadelphia Orchestra with dials and switches, vast and vital vistas for the whole uncharted future of symphonic and operatic performances was [sic] dazzlingly disclosed, making concrete and convincing Stokowski's persuasive prophesies, justifying his dizziest declarations. ${ }^{35}$

Even the sober scientists at Bell Labs were given to dramatizing the performance of their new electrical system. Frank Jewett, for example, wrote that the 1933 demonstration conveyed "the capability of the reproducing apparatus to give tonal effects far beyond the capability of any human orchestra. ${ }^{.36}$ Meanwhile, Harvey Fletcher boasted that its reproduction was "of a character that may give even greater emotional thrills to music lovers than those experienced from the original music." ${ }^{.37}$

The overarching goal of the research and performances was to reproduce music in "auditory perspective" (a forerunner of stereophonic sound). The reproduction of music in auditory perspective involved advances in the frequency response of recording and

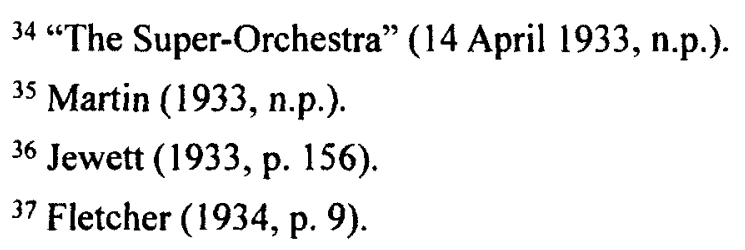


playback equipment, a new preoccupation with the spatial organization of reproduction and, it could be argued, nothing short of a revised theory of hearing. ${ }^{38}$ It also involved increasing the dynamic range of sound systems to match - and exceed - that of an orchestra. Of all the lasting contributions of these experiments to the history of sound reproduction, ${ }^{39}$ it was the volume of the system that most excited Stokowski, and which was the most spectacular for audiences.

Embodying centuries of increased attention to dynamics in musical composition and discourse, Stokowski wrote that "One of the greatest values of music - its power to evoke in us moods and states of feeling and of being - depends greatly upon dynamic contrast and gradation. ${ }^{40}$ Indeed, it was in volume that Stokowski placed some of his highest hopes for the future of music:

I feel with you that there is work to be done before music really can reach the hearts of people by radio and I feel that of the two major problems, frequency and intensity, the latter is more important. We must enlarge the volume range. I believe that eventually music by radio will have more appeal instead of less appeal than music heard in concert because we can lift the top edge of the volume range far above what it is in the concert hall and stretch the bottom edge down to a point just above the threshold which will increase the eloquence of music to a degree

\footnotetext{
${ }^{38}$ Although it is beyond the scope of this analysis, it should be noted that the invention of auditory perspective as a mode of sound reproduction, I would argue, evolved in tandem with the reinvention of auditory perspective as a faculty of hearing. Bell's research (along with similar efforts at EMI) not only paved the way for the technological arrival of stereo, but also laid the foundation for how stereo sound would be made and heard - for the aesthetic conventions of the stereophonic object and the listening conventions of the stereophonic subject. A study of the "re/ invention of auditory perspective" could yield insight into a broader history of stereophonic sound that would have less to do with the history/critique of hi-fi discourse than a broader cultural history of "spatialization." This is a topic I will pursue in a future essay. For useful starting points, see Kern (1893), Doyle (2005), Anderson (2006).

${ }^{39}$ For a survey, see McGinn (1983).

${ }^{40}$ Stokowski (1935, p. 5).
} 
unimaginable at present. ${ }^{41}$

Critics agreed: "The greatest achievement of the new system and its greatest promise lie ... in widening the range of loudness available."42 This enthusiastic response to and the hope for the new musical possibilities of loudness were shared widely. ${ }^{43}$ Loudness and volume even became central to the aesthetics and discourses of several music genres - a development that is perhaps most prominent in the attempts of various rock acts to attain the title of loudest band. ${ }^{44}$ But the enthusiasm and hope were not universal.

The Stokowski-Bell demonstrations themselves, for example, left several audience members "mystified and often terrified": "Some women in the audience, admitting a feeling of 'spookiness,' left the auditorium in fright."45 This chauvinist reportage can be seen as a precursor to controversies of loudness and gender that emerged in the 1940s, when the domestication of high fidelity culture began to reach new heights. As Keir Keightley observes: "Loudness was seen as a source of spousal conflict because it (figuratively) 'repelled' the wife" and because "the equipment capable of producing

\footnotetext{
${ }^{41}$ Stokowski to Bell's Harold Amold, quoted in McGinn (1983, p. 56).

42 "The Super-Orchestra" (14 April 1933, n.p.).

${ }^{43}$ For example, Edward Kellogg (1929) spoke of his experiments at General Electric with a similar buoyancy.

${ }^{44}$ As Lester Bangs (1972) has written of Black Sabbath: "by the time they came to America their record company was ready with a hype fronted by 'LOUDER THAN LED ZEPPELIN' banners ... They were loud, perhaps, with Grand Funk, louder than anything previously heard in human history." For an analysis of the broader connections between loudness and livenesss in rock discourse, see Percival (2011).

45 "Solidified Music Shakes a Building" (25 January 1934, n.p.). This account of the audience "spellbound" but "not a little terrified" - was repeated after the 1940 demonstration. See "Sound Waves 'Rock' Carnegie Hall" (10 April 1940, p. 25).
} 
such volume was also seen as disrupting the interior aesthetics of the home." ${ }^{946}$ The critique of volume was also advanced along lines that were less expressly genderoriented. One of the central pressure points here was gluttony.

In his rubbernecking attempt to come to grips with 1960 s counterculture as it unfolded, New York journalist John Gruen roots the "rock-and-roll craze" in the hi-fi culture described by Keightley:

In effect, current rock-and-roll may be thought of as a phenomenon of electronics, stemming from the public's intoxication with hi-fi equipment and its insistence that performers duplicate the prefab sound and volume that such "home entertainment centers" afford. ${ }^{47}$

For many critics, this "intoxication" manifested itself in the "overkill" of rock systems the 1000-watt Woodstock system; the 3000-watt Isle of Wight system; the thirty-ton, 641speaker, 24,000-watt Grateful Dead system. ${ }^{48}$ Indeed, for Gruen it is obvious that the "gargantuan proportions" of the "rock-and-roll craze" are due to "amplification gigantisme." ${ }^{99}$ Overkill and gigantism, in turn, affected the musical experience:

Volume per se has become the equivalent of darkness in a movie house. Sound, used to envelope the listener physically, becomes a manufactured environment.

\footnotetext{
${ }^{46}$ Keightley (1996, p. 165).

${ }^{47}$ Gruen (1966, p.123).

48 "Overkill" from Court (1984, p. 73). System descriptions from Hope (1975, p. 10). The critical responses to loudness in rock discourse are legion, and a specific discussion is outside the scope of this paper. For an analysis, see Percival (2011).

${ }^{49}$ Gruen (1966, p. 123). His emphasis.
} 
Having a quiet chat in even the remotest corner of the largest discotheque is like attempting a conversation under water. ${ }^{50}$

Gruen's simultaneously mesmerized but disapproving tone then gives way to a more explicitly negative, even philosophical critique, as he notes that "the entire notion of amplification may be looked upon as a vehicle of assault on habitual response based on "who' you are, verbally." Commenting on the "inescapable" connection "between the full volume of rock-and-roll music and the frenzy of rock-and-roll dancing," he stops short of a Deleuzian theory of sound:

The self must now be defined in physical action, but it is no longer the embrace of a dancing partner that defines the physical self. Since amplified sound touches all, equally, partners need not embrace while dancing; sound becomes the real partner. $^{51}$

The relationship between sound and subjectivity described by Gruen - a relationship in which the subject of sound is neither given unto itself nor reduced to a linguistic effect is of course rich with possibilities for theoretical speculation, and I will come back to such issues (albeit not to Gruen's comments directly). The more immediately relevant thing to note is that, despite a strong critical reaction, powerful sound systems descendants of the ones devised by Bell and Stokowski - nevertheless transitioned from novelties to necessities in a variety of contexts between the early and middle of the twentieth century. As this transition occurred, the negative reaction to musical loudness

\footnotetext{
${ }^{50}$ lbid.

${ }^{51}$ Ibid. (pp. 123-124). His emphasis.
} 
also took on a more official, institutional dimension. Musical loudness was translated from a question of aesthetics and taste into a public health concern - and an object of scientific measurement - in ways that had previously been reserved for the noises of industry, transportation and city life. ${ }^{52}$

\section{Institutionalization and measurement}

The institutionalization and objectification of musical loudness took root in response to what were seen as the excesses of music - especially popular music. In the words of longtime audio journalist Barry Fox, writing here under his pseudonym, Adrian Hope:

It is a sad fact of life that most of its pleasures are considered illegal, immoral, or make the participant fat. Until recently, music suffered from none of these stigmas, but research into the effects on hearing of large doses of loud noise suggests that modern pop music very probably makes the listener deaf in the long run. ${ }^{53}$

While Fox's hesitation ("very probably") might have something to do with the fact that the first test subjects were, literally, guinea pigs,${ }^{54}$ other research quickly established a definite connection between popular music and human hearing loss. (The Journal for the Acoustical Society of America, to take only the most obvious example, has regularly featured studies of popular music's effects since 1969.) And one genre was of particular interest in establishing this connection: rock music. Indeed, the rise of rock was

\footnotetext{
52 See Thompson (2002) and Bijsterveld (2008).

${ }^{53}$ Hope (1975, p. 9).

54 "A guinea pig was subjected to a total of $88 \mathrm{~h}$ of high-intensity music played by a popular contemporary musical aggregation" (Lipscomb 1969, pp. 80-81). For earlier uses of guinea pigs as test subjects in loudness research, see Stevens \& Davis (1936).
} 
paralleled by a flurry of research into its dangers to hearing, which fed off and into the negative cultural discourses described above.

The correlation of rock and hearing loss led not only to increased interest in (and regulation of) loudness levels at concerts but also, though the 1970s, discos and other dance music venues..$^{55}$ However, the preferred unit of measure for these sound levels the decibel - was imperfectly understood by many. When Britain's Control of Pollution Act was introduced in 1974, for example, it met with confusion. Part of the reason for this reaction was that the Act failed to provide guidelines on actual sound levels, leaving those decisions up to local, lay committees. But even when sound limits were set by these committees, as in the case of Leeds, where a limit of 96 decibels was imposed, another kind of confusion presented itself. This confusion was of a technical sort, about whether measurements were to be taken according to sound pressure levels (where $96 \mathrm{~dB}$ is twice as much pressure as $90 \mathrm{~dB}$ ) or sound energy levels (where $96 \mathrm{~dB}$ is four times as much energy as $90 \mathrm{~dB}$ ). Even though the possibilities of this unit of measurement were misunderstood and unevenly deployed, the decibel was nevertheless used as the grounds on which loud music was banned in Leeds. ${ }^{56}$ The confusion illustrated here, then, is about

${ }^{55}$ See Bickerdike \& Gregory (1980). Some clubs installed elaborate monitoring systems. One author describes a system in which a warning light would illuminate should a performer exceed a preset threshold, at which time the performer was given a moment to quieten down. If a performer failed to heed the warning, the system "introduces temporary attenuation into the signal leads." Failing that, it cut the mains for a short period ("Monitor for Disco Noise Levels" 1980, p. 15). For just one among hundreds of contemporary examples of concert loudness regulation, see Saxberg (2009).

${ }^{56}$ Fox (Hope 1975, p. 11) expressed frustration with this situation: "One can only hope that when other local authorities around Britain impose sound level limits they will bring in expert technical advisors to ensure that value judgments are not made on the basis of technical misconceptions." Fox's frustration with the confusion and subjectivity in Leeds was thus paralleled by Hope's hope in objectivity. 
what exactly the decibel measures, and how exactly it is to be used. This confusion can be traced back to the earliest use of the decibel in sound measurement and noise abatement.

When the decibel was introduced to the general public in the 1930s, it was in the context of widespread social problems of noise (see also Chapter 2). As the Toronto Daily Star put it:

If breaks continue to squeal on downtown streets; if people in the apartment overhead will insist on playing the radio late at night; if horns and sirens and all the miscellaneous clatter which accompanies modern civilization does not miraculously cease, Canadians will hear more about the decibel. Even a casual pause on any street corner indicates that there are plenty of them about, even though the name has been, heretofore, unfamiliar. ${ }^{57}$

As with the Leeds situation over forty years later, the new sonic "yardstick" w8 was heralded as a scientific and objective way of handling noise problems: "If one is going to deal with noise," claimed the Canadian press, "there must be a means of measuring it, hence, the decibel. It is to an acoustic engineer what the degrees of a clinical thermometer are to the physician or nurse." 59 In a piece that was picked up by papers across the US (referring here to the Madison, Wisconsin version), Gilbert Swan described the role of the decibel in the research of New York's Noise Abatement Committee. Although the reporter wondered about the point of the tests ('I've never quite figured out why a committee has

\footnotetext{
57 "Professor's Decibel Knows Its Noises" (20 March 1931, p. 9).

58 "Yardstick Made for Volume of Sound" (1933, p. 284).

59 "Professor's Decibel Knows Its Noises" (20 March 1931, p. 9).
} 
to go out looking for noise in New York. Perhaps they all live in Yonkers and wear cotton in their ears"), he did express some satisfaction in the knowledge "that the information that the children of the town have their growth stunted - or something - by the city's cacophony; that noises drive us oldsters into premature baldness and into all sorts of nervous ailments, has been obtained variously by neurologists, sound meters and other scientific means." ${ }^{100}$ The decibel thus inspired hope that noise could be reasoned with through the measurement and quantification of loudness.

Decibels also sparked a level of public excitement. Commentators often registered their fascination with the new unit of measurement, especially with the idea that there are "noises that are 10,000,000 times louder than the squeaking of a mouse."61 And there was speculation about what the decibel meant for music. Reporting on a New York opera that was measured with "dispassionate science" and an "electric ear,"62 the Times noted sarcastically that the decibel might be used not just for conditioning performers (which was what most interested Seashore) but for measuring performance:

If any conclusion is to be drawn from the Metropolitan Opera House tests, it is that the sweetest singers produce the most noise. ... Henceforth the laboratory report decides the fate of a star. "Only eighty decibels in "O Paradiso," groans the director as he studies a curve. "The man obviously cannot sing." ... As for applause, it must be more scientifically bought. "One hundred decibels tonight

\footnotetext{
${ }^{60}$ Swan (1930, p. 4). See also Thompson (2002, p. 162).

${ }^{61}$ Ibid.

62 The "electric ear" in question was a General Electric "audio sound meter." Respectively, "Lily Pons 'Noisier' than a Street Car" (28 April 1932, p. 23); "Opera to be Tested by 'Electric Ear'”' (27 April 1932, p. 13).
} 
after the 'Flower Song,' or you're fired," says a new tenor, menacingly, to the chief of the claque five minutes before the curtain rises. ${ }^{63}$

From 1930s cityscapes and opera to 1970 s rock and disco, what these discourses of noise and music share is excitement and hope that the decibel objectifies previously subjective dimensions of sound, thereby providing a means of rationalizing what was previously "irrational." However, the public's understanding of the decibel was, to greater and lesser degrees, wrong. As acousticians and psychologists never fail to remind us, decibels measure the physical energy of sound in terms of a ratio, which bears an indirect and complex relationship to the psychological sensation of sound in terms of loudness. From this perspective, while the decibel does provide a means of quantifying sound intensity, it doesn't actually objectify anything. The decibel is indexical; it merely gives expression to physical properties that are already "objective." And that quantitative expression is not straightforwardly relatable to subjective experience. The decibel does not bridge the subjective and the objective. In Swan's provocative words: 'A 'decibel,' by any other name, would be just as jarring." story of misunderstanding, but of misplaced hope.

What I want to do in the rest of this chapter is situate these apparently disoriented discourses of the decibel in relation to a longer history of ideas about sound and sensation in science and music. I want to show that the cultural confusion surrounding the possibilities of the decibel is a microcosm of, first, a larger set of scientific and technical

63 "Possibilities of Decibels" (29 April 1932, p. 16).

${ }^{64}$ Swan (1930, p. 4). 
problems and, second, a set of epistemological questions in a longer history of philosophy.

\section{Origins of the decibel: part two}

\section{Acoustic science}

Quantifying loudness is challenging, controversial, and, for some, impossible. Quantifying the physical stimulus is relatively easy ... quantifying the sensation the stimulus elicits is not.

- Radocy \& Boyle, Psychological Foundations of Musical Behavior, $2003^{65}$

As we saw above, loudness has been recognized as one of the fundamental parameters of sound since at least Descartes. And, as with musical aesthetics and criticism, the acoustic sciences began paying more attention to loudness through the nineteenth century. ${ }^{66}$ The result was nothing short of a paradigm shift in the understanding of loudness.

Around the turn of the twentieth century, it was generally assumed that "All the different musical sounds in nature, whatever may be their origin, and by whatever means they may be propagated, may be distinguished from each other by three different qualities": loudness, pitch and timbre ${ }^{67}$ As a fundamental property of sound, loudness was apparently straightforward: 'Intensity . . . is merely another name for 'loudness.' . . .

\footnotetext{
${ }^{65}$ Radocy \& Boyle (2003, p. 119).

${ }^{66}$ I develop this point throughout this section, but see also Beyer (1999) who, in one of the few historical accounts of the acoustic sciences, says nothing about loudness before 1850 .

${ }^{67}$ Blaserna (1883, p, 45). See also Taylor (1883).
} 
Intensity depends on the amplitude of the vibrations, and on nothing else." ${ }^{.68}$ In other words, the modern distinction between intensity and loudness, and the dependence of loudness on frequency, were not yet established in the nineteenth century. But acousticians such as Rodolphe Radau had their suspicions:

One would have thought that the apparent intensity of a sound must be proportioned to the mechanical power employed to produce it, but it is not so. When a siren is turned by pressure of air from the bellows, the deep musical notes that it emits are at first far less piercing than the shrill notes produced as the velocity of rotation increases. The ear becomes more sensitive as the pitch of the note is raised ... Therefore it is certain that by the ear we can only compare sounds of the same quality. ${ }^{69}$

As such, whether attempting to determine if watches ticked louder in water or in wine, or if a "mouse nibbling at the wainscot" sounded louder during the day or at night, loudness experiments were understood to share a common imperfection. "The great difficulty," said Radau, "is the want of an instrument to measure the intensity of sound; one is obliged to trust entirely to the ear." ${ }^{" 70}$ On the more physical end of the acoustic science spectrum, the goal was thus to understand loudness without the interference of the ear.

In 1882, twelve years after Radau's work was published in English, the elimination of the ear from acoustics proper seemed to be in sight. Thanks to Lord Rayleigh, who devised a means of visually registering the amplitude of a sound wave, the

\footnotetext{
${ }^{68}$ Buck (1918, p 45); emphasis in original. See also Taylor (1883, pp. 52-53): "The loudness of a musical sound depends entirely ... on the extent of vibratory movement performed by individual particles composing the conveying medium.... The harder we hit the fork the loud is its sound, and the larger . . . are its vibrations." Additionally, see Blaserna (1883) and Stone (1908).

${ }^{69}$ Radau (1870, p. 54)

${ }^{70}$ Radau (1870, pp. 48-54, 53).
} 
measurement of intensity was apparently liberated from its reliance on the unreliable ear. Rayleigh's instrument - the Rayleigh disc - spurred forty years of research into the visualization of "absolute intensity.""11

But the ear refused to die: attempts to quantify intensity as a physical object actually served to reinforce the essential subjectivity of the perception of sound. Rayleigh himself noticed this in his disc experiments: "What strikes one most in its use is the enormous disproportion that it reveals between sounds which, when heard consecutively, appear to be of the same order of magnitude." 72 As such, even as the more physically oriented end of acoustic science was able to register intensity with a form of mechanical objectivity, many continued to struggle with the troublesome (and increasingly widespread) realization that the ear reacted to loud sounds in strange ways. At this moment, the physics of intensity and the psychology of loudness began to go their separate ways. Some turned their back on the problem, recognizing that "Differences of intensity in the waves reaching the ear produce different loudness" but, foreshadowing the wider epistemological debates examined below, insisting that "no simple relation between the intensity and the loudness can be stated, all sensations, indeed, not admitting of quantitative measurement." ${ }^{13}$ Others, seeing that mechanical objectivity answered only a limited range of acoustic questions, necessarily accepted the problem of the relationship between physical intensity, on the one hand, and what Wallace Clement Sabine called the

\footnotetext{
${ }^{71}$ See Rayleigh (1882). See also Boehm (1910), Watson (1910), King (1919), Webster (1919), Thompson (2002, pp. 82-86).

72 Rayleigh (1882, p. 187).

${ }^{73}$ Catchpool (1909, p. 181).
} 
"sense of loudness," on the other. ${ }^{74}$ The goal here was to define this relationship in terms of structural objectivity.

The difficulty with defining the relationship between intensity and loudness was here less philosophical (a burden shouldered more by psychophysics, as we will see) than technical. Of course, there were numerous sound sources (organ pipes, tuning forks, sirens) and sound detectors (Rayleigh discs, phonodeiks, phonautographs) available to the turn-of-the-century acoustic scientist; indeed, there was at the time a successful acoustic instrument business. ${ }^{75}$ But acoustic science was a late-bloomer, ${ }^{76}$ and its tools were seen as unsophisticated, underdeveloped and imprecise in comparison with those instruments used to submit mind and matter to measurement in other sciences. ${ }^{77}$ Indeed, developments in turn-of-the-century acoustic science were judged harshly in retrospect: "In spite of all the discussion that went on," stabs Edwin Boring, "really not so much happened in the sixty years after Helmholtz." impediment to further progress in acoustics," in the words of Stanley Stevens and Hallowell Davis - "was the lack of an efficient method for producing and measuring

\footnotetext{
${ }^{74}$ Sabine (1922, pp. 129-130).

${ }^{75}$ Pantalony (2009).

${ }^{76}$ This is a trope that is often repeated in histories of the acoustic sciences - one which, I would argue, reflects a problematic tendency in these studies (not to mention science studies more broadly) to, as Reed (1997, p. xii) says, "read the past primarily in terms of present concerns." King $(1919$, p. 1) notes that "A few years ago one would have pronounced the science of acoustics dead"; Vogel (1994, p. 261) notes that "“"Eighteenth-century acoustics was a virtually moribund research area."

${ }^{77}$ On the importance of visual and temporal measurement in early psychophysics, see Crary (1999) and Daston \& Galison (2010, p. 264). There is a large body of literature on the importance of time measurement in nineteenth- and early twentieth-century science. For an important foundational study, see Kern (1983). For one recent and interesting account, see Canales (2009).

${ }^{78}$ Boring (1938, p. vi).
} 
sounds of any desired frequency, intensity, or complexity."79 That changed in the early twentieth century, according to Stevens and Davis, when acoustic science hit a growth spurt:

The development of the thermionic vacuum tube has revitalized the science of acoustics. Whereas it was formerly necessary to discuss the production, transmission, and recording of sound energy in terms of purely mechanical devices such as tuning forks, organ-pipes, strings, sirens, tubes, and reeds, we now treat these problems in terms of electrical and electromechanical systems such as microphones, amplifiers, and loud-speakers. ${ }^{80}$

The inadequacies of the pre-electrical acoustic sciences were not merely noticed after the fact, by later scientists on the high horses of hindsight; they were felt by its practitioners, too - nowhere more acutely than in loudness and intensity research.

Alfred Mayer, who is best known nowadays because his discussions of talking machines have been latched onto by scholars of the problem space of fidelity, ${ }^{81}$ was also concerned, in his time, with loudness and intensity:

While the problems of the determination of the pitch of sounds and the explanation of timbre have received their complete elucidation at the hands of Mersenne, Young, De la Tour, König and Helmholtz, the problem of the accurate experimental determination of the relative intensities of given sonorous vibrations has never been solved. ${ }^{82}$

\footnotetext{
${ }^{79}$ Stevens \& Davis (1938, p. 1 ).

${ }^{80} \mathrm{Ibid}$. This trend of course held through the $1930 \mathrm{~s}$, which witnessed "a new and effective period of research in psychophysiological acoustics. Primarily the electrical techniques for the control of the stimulus and for the amplification of physiological potentials have been responsible" (Boring 1942, p. 419).

${ }^{81}$ For example, Lastra (2000). See also Mayer (1879).

${ }^{82}$ Mayer (1873, p. 44).
} 
As such, while Canadian physicist James Loudon could devote pages and paragraphs to pitch and timbre in his 1901 address on "A Century of Progress in Acoustics," he could only muster a single sentence on intensity: "With regard to the question of intensity of sound, it is only necessary to say that there exists here a great lacuna in our acoustical knowledge, as we do not yet possess a means of measuring the physiological intensity of sound." ${ }^{83}$ Though glum about the current state of the art, Loudon's statement was also symptomatic of a growing recognition across the acoustic sciences that the solution to the problem of loudness was not strictly physical, but also psychological:

The study of sound intensities presents many difficulties to the physicist as well as to the psychologist; the determination of the equality of loudness of two sounds, as well as of the law of relation between the physical cause and the sensational result is perhaps the most serious one. ${ }^{84}$

Of course, the instruments that would eventually define this relationship were still just over the horizon. As Hillel Schwartz puts it, "One could order from Rudolf Koenig's catalog a wagonload of acoustic devices ... and never approach a whit closer to what loudness amounted to in the ear." 85 Despite such technical limitations, it is the conceptual innovation that is important here: the very certainty that loudness was in the ear as much as it was in the air, that loudness was a problem of physics and psychology.

\footnotetext{
${ }^{83}$ Loudon (1901, p. 994).

84 Jastrow (1895, p. 544). My emphases.

${ }^{85}$ Schwartz (2011, p. 674). His emphasis.
} 
Thus, Loudon and others like him foresaw a future for loudness, and the possibility of a "revival" of acoustic science more generally, in "the cooperation which physicists may naturally look for from those who are cultivating the new fields of experimental psychology." ${ }^{" 86}$ Three decades later, the decibel was presented as the common ground between the physics of sound and the psychology of sensation, and as the form of measurement that objectified loudness. Loudon, apparently, was right. But "paradigm shifts" don't happen overnight; neither do their attendant epistemic virtues "replace one another like a succession of kings." ${ }^{87}$ Rather, the possibilities for understanding and misunderstanding tend to multiply.

\section{Telecommunications}

We have seen that this new relationship between physics and psychology was not quickly understood in musical culture; neither did its expression come easily in acoustic science and telecommunications. Ernest Wever summarizes the difficulty as follows:

That the loudness of a sound grows with intensity is obvious; from weakly audible it passes to uncomfortably loud and at last to distractingly blaring. It is easy to make rough, general references like these as to how loud a sound is, but it is difficult to discover just what the variation is with physical intensity. ${ }^{88}$

In other words:

\footnotetext{
${ }^{86}$ Loudon (1901, p, 988).

${ }^{87}$ Daston \& Galison (2010, p. 121).

${ }^{88}$ Wever (1949, p. 299).
} 
Since loudness is a subjective matter, it is rather difficult to determine what should made the unit of loudness. Of course, any arbitrary scale of loudness may be used provided that sounds which are equally loud have equal numbers on the scale and that loudness numbers vary progressively as we go from fainter to louder tones, but a system which recognizes some of the characteristics of loudness arising from the physical characteristics of audition would be preferable. ${ }^{89}$

Solving this difficulty - quantifying the link between loudness and intensity - required a scaled relationship between mind and matter. Although it was understood "that the sensibility of the ear to small differences of intensity is some continuous function of the intensity," it was clear by 1923 that the relationship was not as simple as that which had been suggested by earlier psychophysical studies (see below). ${ }^{90}$

Perhaps the biggest obstacle to developing such a scale was the dependence of loudness on frequency. Even Harvey Fletcher himself, before the publication of his famous article on equal-loudness curves (which effectively announces our contemporary understanding of loudness), was stumped:

\begin{abstract}
Although [the formulae for calculating loudness available at the time] are adequate for most practical purposes, they are not satisfactory from the standpoint of understanding the fundamental elements which determine loudness and how they operate when a loudness judgment is made. Attempts to follow these processes and to develop methods for calculating loudness which have a general application have not yet been successful. ${ }^{91}$
\end{abstract}

\footnotetext{
${ }^{89}$ Kingsbury (1927, pp. 595-596).

${ }^{90}$ Knudsen (1923, p. 92).

${ }^{91}$ Fletcher (1929, p. 244). On loudness curves, see Fletcher \& Munson (1933) and the revisions of Robinson \& Dadson (1956).
} 
Of course, Fletcher's 1929 work on loudness (along with the earlier work of Knudsen and Kingsbury) went a long way toward defining the relationship between loudness and intensity. But it is arguable that such research was founded on a prior slippage between mechanical and structural objectivity. This slippage can be seen in the context of telecommunications.

Before electrical amplification, a telephone system's performance was more or less guaranteed if it met certain basic requirements (resistance, leakage, capacitance), which could be straightforwardly measured by electrical current meters. ${ }^{92}$ Comparisons between systems, on the other hand, required ear-balancing tests. Two systems, an existing one and a reference system (represented by the "best connection possible at the time"), would be talked over and compared. An engineer or test subject would then degrade the reference by artificially adding miles of cable until it matched the existing system - "until the received speech was judged equally loud." 93 It was soon understood that the average energy loss of a standardized signal per mile could be expressed logarithmically, and this attenuation was expressed in terms of "transmission units." The transmission unit was adopted by Bell in 1924, and was branded as the decibel in 1929.94 The decibel thus emerged from a need to compare and rate loudness in telephony, and evolved out of ear-balancing tests for measuring transmission equivalents (a

\footnotetext{
92 Fagen (1975, p. 310).

${ }^{93}$ Ibid. (p. 305).

${ }^{94}$ For the announcement, see Martin (1929). The widespread adoption of the decibel was not without controversy (see Beyer 1999, pp. 221-222). In case anyone is interested in the math: "the 800-cycle mile was mathematically equal to $10.56 \log _{10} P_{1} / P_{2}$, where $P_{1}$ and $P_{2}$ are the input and output powers, respectively" (Fagen 1975, p. 307).
} 
subjective method), into a means of expressing the attenuation of an electrical signal's strength over distance (a physical problem).${ }^{95}$ When Bell engineers started "using the term 'sensation units' as a near-synonym for 'transmission units,"'96 a physical measurement was therefore brought to bear on a psychological sensation. This passage of the transmission unit into the sensation unit, and the subsequent adoption of the decibel in noise measurement, was due to a simple convenience: as a logarithmic unit, decibels were able to interact with the non-linearity of human hearing. ${ }^{97}$ But this slippage created a problem. As with the more general translation of the communications frame described in Chapter 3, the transference of problems related to signals in lines, on the one hand, to sounds in spaces, on the other, is accompanied by processes of translation. In the case of the decibel, a unit of measurement that tended to be used to express physical power ratios was conveniently but problematically articulated to subjective sensations. In a sense, this articulation blurred the increasingly distinct lines between intensity and loudness.

In contrast to the shrugging and uncertainty about loudness and intensity that had marked turn-of-the-century acoustic science, an employee of the Metropolitan-Vickers Electrical Company, after surveying American and British and German definitions of

\footnotetext{
${ }^{95}$ It is interesting to note that "the very devices (vacuum tubes and filters) which brought about the need for objective measurements also provided the means to make them" (Fagen 1975, pp. $310-311$ ). From the perspectives of both telecommunications and acoustic science, then, electrical sound reproduction technology is at the centre of the history of the decibel - and vice versa. Electrical sound reproduction is thus something of a double agent: whereas it was responsible for new possibilities in projecting sound (and this has been the focus of my analysis so far), here the technology is being explored for its use in new ways of measuring that same sound and, ultimately but imperfectly, policing it.

${ }^{96}$ Schwartz (2011, p. 684).

${ }^{97}$ Churcher (1935), Schwartz (2011, p. 684).
} 
loudness in the early 1930s, was able to state calmly: "All are agreed that loudness is a sensation rather than a physical quantity. Indeed, the sensation experienced must be the final criterion of loudness." $" 98$ But the serenity instilled by the unified definitions of loudness vis-à-vis intensity was undermined by this engineer's exasperation over their conflation in noise measurement - in the decibel. The issue, as noted in the article's abstract, is that "Both on technical grounds and from experience in industrial noise measurements, it is recognized that the decibel scale, used as a loudness scale, does not yield numerical values proportional to the loudness sensation." 99

In the author's opinion the attaching of the word "loudness," denoting a subjective entity, to the decibel scale, which expresses a purely physical quantity, is to be deprecated . . . because it tends to confuse cause and effect, i.e., stimulus and sensation. ${ }^{100}$

This is precisely what led me to describe cultural discourses of loudness in terms of misunderstanding and misplaced hope. Indeed, as the Metropolitan-Vickers employee scoffs, "the decibel scale has no foundation as a loudness scale."101

By the 1930s, other terms were introduced as a means of addressing some of the problems inherent in the decibel as a unit of measurement, the phon being the most prominent. ${ }^{102}$ While the phon was an explicit attempt to link the perception of loudness to

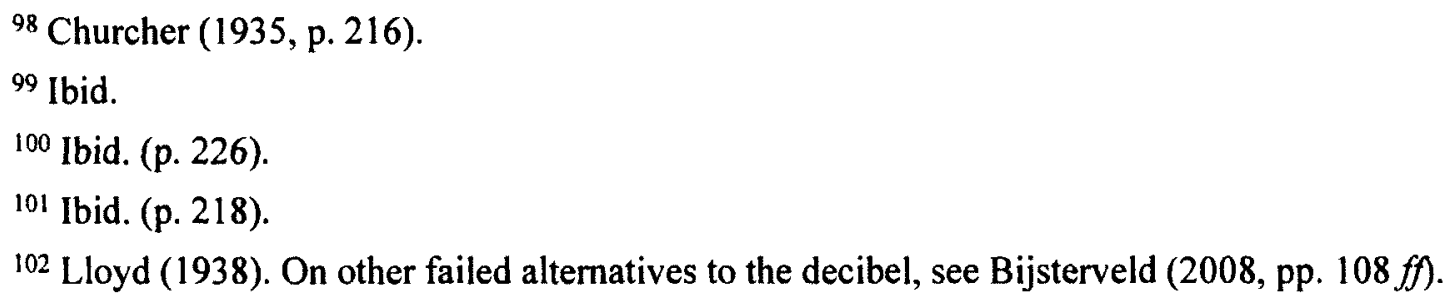


the physics of intensity, and while it was less plagued by misplaced hope than the decibel, it was no less misunderstood, and the fate of the phon ultimately matched that of the decibel. On hope, take for example the following poem from the Observer, conveyed by Kaye in his 1937 presidential address to the mathematical and physical sciences section of the British Association for the Advancement of Science:

Hail! Newest unit, welcome to the host Of ergs and amperes, kilowatts and therms

Best of the lot, you shall be valued most Among these unintelligible terms.

For you alone can make men realise In figures plain, the awful din they make, So that at last some genius may devise A means of curbing it, for Reason's sake ${ }^{103}$

The phon's claims were thus more modest than those made on behalf of the decibel, and this "newest unit" sought to temper the overzealous adoption of the decibel in noise abatement and musical culture. Instead of the hopes of mechanical objectivity that routinely accompanied discourses of the decibel, the phon explicitly began from the question of structural objectivity. The hope placed in the phon was not that it would eliminate subjectivity from acoustic measurement, but that it could rationalize the essentially subjective aspects of loudness, as the Observer poem attests. Ultimately, though, phons were rooted in decibels, and their "failures" were one in the same. ${ }^{104}$

${ }^{103}$ Kaye (1937, p. 35). See also Bijsterveld (2008, p. 106).

${ }^{104}$ On the role of the decibel in the failure of noise abatement, see Thompson (2002, pp. $157 \mathrm{ff}$ ), Schwartz (2011, pp. 693 ff). 
The imperfect utility of the decibel in abating noise, policing concerts and disciplining musical practice (along with the attendant misunderstandings and misplaced hopes) thus stems from a similar scientific uncertainty over the decibel's role as a bridge between subject and object. This scientific uncertainty, in turn, is rooted in a system of thought that took shape through the nineteenth century. Examining this system will foreground the full historical and philosophical weight of the problems that the decibel aimed to solve, but ultimately could not.

\section{Psychophysics}

The rocky marriage of physics and experimental psychology in the acoustic sciences and telecommunications was founded in the field of psychophysics. At the heart of psychophysics, and the second scientific revolution more generally, was one of the fundamental distinctions in the history of philosophy: the distinction between mind and body and matter, between stimulus and sensation and perception. Indeed, for Boring, an early and prominent historian of psychology, "the fundamental task of psychophysics" lies in "the discovery of the relationship between the hitherto unrelated body and mind."105 My interest here is in Boring's assumption that, before psychophysics, body and mind - and by extension mind and matter - were "unrelated." Of course, this is not strictly true. Distinctions - and connections - between mind and body have been drawn throughout history. But the mind-matter problem that Boring viewed as being bridged by psychophysics was of a particular sort.

${ }^{105}$ Boring (1921, p. 455). 
The psychophysical mind-matter problem can be viewed in relation to two foundational but historically specific distinctions in the history of philosophy: the ontological distinction between what we would now think of as subjects and what we would now think of as objects, on the one hand, and the division of objects themselves into primary and secondary qualities, on the other. ${ }^{106}$ (Although questions about primary and secondary qualities are highly interesting, ${ }^{107} \mathrm{I}$ deal in this chapter with the subjectobject distinction.) Even if it is unfairly simplistic to foist these dualisms on Descartes himself, we can understand them as broadly Cartesian legacies, even after they were reformulated in the wake of Kant's "Copernican Revolution." 108 These legacies philosophical problems - were inherited by the fields that flowed into and out of the acoustic sciences during the nineteenth century, and are at the base of scientific understandings of loudness. And so what psychology and (especially) psychophysics

\footnotetext{
106 Daston (1982, pp. 91-92).

107 The primary-secondary distinction took on a fascinating form around the turn of the twentieth century, when psychophysicists tried to determine whether volume (i.e. extensity) and density were properties of sound itself or an attribute of sound given in perception. Although this question is viewed as quaint by contemporary psychologists - "Today, volume and density basically are psychoacoustic curiosities with little musical relevance" (Radocy \& Boyle 2003, p. 119) - in its time it was a high-profile and urgent debate, involving many of the most prominent psychophysicists. Although relevant to the historical sketch offered here, and while the debate raises interesting questions about musical signification - is volume immanent or arbitrary? (Shepherd 2002) - the history of volume in psychophysics must unfortunately be the topic of another essay. For some signal period contributions, see Rich (1916, 1919), Watt (1917), Halverson (1924), Boring (1926), Bannister (1927), Stevens (1934A, 1934B).

${ }^{108}$ Such foisting is unfair because writers before, during and after Descartes's time addressed such issues (e.g. Galileo and Locke), because the concepts of subjectivity and objectivity have a more precise history than this would suggest (Daston \& Galison 2010), and because his thought was itself less homogeneous than has been assumed. Indeed, there is an emerging wave of research that examines Descartes anew, challenging and reconsidering entrenched views of Cartesian epistemology. For a quick but careful sketch of this "renaissance," see Watson (2010). Some of the most striking critiques have come from sound and music studies: see August (1965), Moreno (2004), Erlmann (2010).
} 
instantiate is less the first attempt to bridge mind and matter, but more the translation of what for Descartes was a metaphysical distinction into an empirical question that emerges in the eighteenth century and which is experimentally quantified in the nineteenth. ${ }^{109} \mathrm{~A}$ detour through the histories of psychology and psychophysics (their conditions of possibility) will help clarify the relevance of these shifts to the problem of loudness.

"The consensus in Europe during and immediately after the French Revolution," Edward Reed says, "was that psychology as a science was impossible." 10 This is not to say that psychology was little discussed at the time. On the contrary, it was of great interest - just not as a science. For Immanuel Kant and Thomas Reid, "the two most influential psychologists between ... 1789 and 1830," arguments about the impossibility of psychology as a science stemmed from worries about the reduction of human experience to "a function of matter and motion only - just as Newton had showed how the movements of the planets and the colors of the rainbow were caused by different patters of matter in motion."111 Reid especially, although he laid out the modern distinctions among stimulus, sensation and perception, argued that the relations among these concepts were not explicable in terms of cause and effect - that it was not possible to determine how perception emerges from the sensation of a stimulus. ${ }^{112}$

\footnotetext{
${ }^{109}$ Michell (1999, p. 68).

${ }^{110}$ Reed (1997, p. 22).

${ }^{111} \mathrm{Ibid}$. (pp. 23, 25). For another excellent argument about Kant's critique of psychology, see Leary (1982).

${ }^{112} \operatorname{Reed}(1997$, p. 26).
} 
Gradually, regardless of the relative merits of arguments against scientific psychology, theories and experiments began to emerge at the interstices of sensation and perception. Not only were these endeavours set squarely between mind and matter, but they purported to do what for Kant and Reid was impossible: they quantified the relationship between the psychical and the physical, thereby meeting the requirements for psychology's partnership with science. These endeavours became known as psychophysics.

Ernst Heinrich Weber played a central role in the development of psychophysics. ${ }^{113}$ However, as this is not a detailed history of that field, I will start with Gustav Fechner, who is more relevant for the purposes of this chapter. In his pioneering work of 1860 , Fechner defined psychophysics as "an exact science of the functional relations or relations of dependency between body and mind." 14 Building on the work of Weber, Fechner suggested that "an arithmetic series of psychical 'intensities' likely corresponded to a geometrical series of physical "intensities." 115 In other words, the relationship between the psychical and the physical could be expressed in terms of a law: subjective sensations increased by addition while objective stimuli increased by multiplication. Fechner thus provided a means of quantifying and measuring the relationship between stimulus and sensation, thereby providing a bridge between subject and object. As Boring puts it:

\footnotetext{
${ }^{113}$ See Ross \& Murray (1996), Hui (2008, pp. 15-38).

${ }^{114}$ Fechner quoted in Titchener (1905, p. xxii). See also Fechner (1966).

${ }^{115} \mathrm{Hui}(2008$, p. 27)
} 
A clear recognition of the distinction between mind and body, between consciousness and objects, was the key-note of Fechner's position. . . . Such a dualism can be resolved only by the law of relationship that holds between its two aspects ... so the logarithmic law resolves the dualism of mind and body. There is no doubt, therefore, that Fechnerian psychophysics stands or falls according to its success in distinguishing between measurements of mind and measurements of body, or between sensation and the object of sensation, the stimulus. ${ }^{116}$

It is worth noting that Fechner did not discover this principle experimentally and then extend it to philosophical questions. Rather, he was expressly concerned with finding an objective, experimental basis for his monistic philosophy. ${ }^{117}$ Fechner thus inherited the Cartesian dualism of mind and matter, even as he sought to bridge that gap experimentally, and as he "condemned" it on philosophical grounds. ${ }^{118}$

While Weber and Fechner both paid some attention to the psychophysics of sound, Herman von Helmholtz stood most prominently at the crossroads of subjects and objects in the development of the acoustic sciences. Like Fechner, Helmholtz clearly inherited the philosophical problems of mind and matter. What's more, he worked out connections between the sensation and perception in a way that gave a new shape to the acoustic sciences (not to mention his contributions to similar debates in optics). ${ }^{119}$ Indeed, there should be no question as to the centrality of Helmholtz in "bringing together the

\footnotetext{
${ }^{116}$ Boring (1921, p. 452).

${ }^{117}$ Hui $(2008$, pp. 28 ff). See also Boring $(1942,1966)$ and Reed (1997).

118 Boring, (1966, p. ix). See also Boring (1942, p. 87): "Fechner metaphysically was a monist, but epistemologically he was a dualist." For another exemplary discussion of Fechner, see Marshall (1982).

119 See Crary (1990).
} 
scattered facts about hearing and defining a field of scientific interest."120 His magnum opus in this regard is 1863 's On the Sensations of Tone.

Appearing just three years after Fechner's Elements of Psychophysics, On the Sensations of Tone speaks not only to the importance of the Cartesian legacy in the development of psychophysics, and as a problem in the second scientific revolution more generally; it also marks a turning point in Helmholtz's own thought. In the early 1850 s, "Helmholtz's model of perception ... was rather simple: the external objects act on the sense organs through physical forces.... Helmholtz's model is thus essentially a dualistic one, involving stimulus and perception." 21 By the time Sensations of Tone was published, though, Helmholtz subscribed to "the tripartite division of the sensory process into physical, physiological, and psychological parts." ${ }^{22}$ Although he "explicitly presented this tripartite division of the sensory process to the readers of his Tonemfindungen as the epistemological basis of his theories in physiological acoustics,"123 the broader philosophical questions raised by his theories of sense perception were dealt with more obviously in his later work. Through an examination of this work, more so than the Sensations of Tone itself, it is possible to understand the epistemological terrain in which the science of loudness, and ultimately the decibel, emerged.

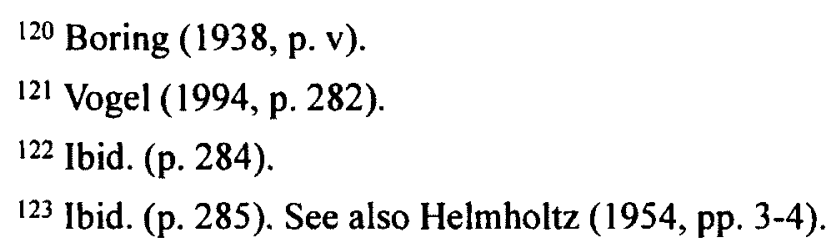


Speaking broadly about the intellectual climate of the nineteenth century, in an address given in 1878 , Helmholtz notes that "the fundamental problem placed at the beginning of all science was the problem of epistemology: .. ' 'In what sense do our representations correspond to actuality?"'124 For his part, Helmholtz argued against the idea that "ready-made representations of objects are elicited through our organic mechanism." 25 Indeed, he called it "a contradictio in adjecto to want to represent the real ... without absorbing it into the form of our manner of representation." $" 126$ Instead, he favoured "the assumption of the empiricist theory, which is that only the non-understood material of sensations originates from external influences, while all representations are formed from it in accordance with the laws of thought." 127 The centrality of perception, for Helmholtz, interfered with access to and knowledge of the external world. Objectivity, in the sense of a direct correspondence between stimulus and perception, an unmediated grasp of the real, was thus neither possible nor desirable from the perspective of Helmholtz's epistemology. Objects themselves were irrelevant. Indeed, he posits an epistemological break with "the concept of the objective," noting that "the concept of a ready-made image of an object usually finds its way into it, and one which does not suit the most primary perceptions." ${ }^{.128}$

\footnotetext{
${ }^{124}$ Helmholtz (1977, p, 117). For some of the broader context here, see Harvey (1989, p. 28).

125 Ibid. (p. 134).

${ }^{126}$ Ibid. (pp. 140-141).

${ }^{127}$ Ibid. (pp. 134-135).

${ }^{128}$ Ibid. (p. 140).
} 
In other words, the epistemological problem he describes - a translated

inheritance from Descartes via Kant that is also at the root of psychophysics - is about the representational character of the relationship between subjects and objects. Although the necessary passage through representation negates an ideology of objectivity that privileges unmediated access to the real (mechanical objectivity), for Helmholtz the ideology of objectivity is about measurement and quantification (structural objectivity). In other words, while Helmholtz calls it an oxymoron "to want to represent the real ... without absorbing it into the form of our manner of representation," he readily admits the possibility of attaining "an acquaintance with the lawlike order in the realm of the actual, admittedly only as portrayed in the sign system of our sense impressions." 29

Unlike Reid and Kant, then, for whom scientific psychology was impossible even though the mind was directly connected with matter (because it was philosophically nonviable and morally objectionable to quantify the relationship between the two), for Helmholtz and the psychophysicists, scientific psychology was possible regardless of the fact that the mind and matter were mediated by representation (because the relationship between the two was structural and, therefore, given to lawlike expression). ${ }^{130}$ The epistemological problem at the beginning of psychophysics, to rephrase Helmholtz, is precisely the problem of the relationship between the real and the symbolic, the signifier

\footnotetext{
${ }^{129}$ Helmholtz (1977, pp. 140-141).

${ }^{130}$ I am not claiming that Helmholtz was a strict idealist, but merely highlighting the idealistic strand in his thought vis-à-vis Reid's direct realism and Kant's empirical realism. Of course, none of these thinkers is reducible to such simple characterizations; all of them embody an array of the intellectual positions available to them at the time. For an argument about Helmholtz's idealism, see Heidelberger (1994). For an argument about Helmholtz's realism, see Lenoir (1997). For more on the senses in Kant, see Curtis (2008).
} 
and the signified. Psychophysics saw that the relation between the two realms was arbitrary but, nevertheless, structural: "the occurrence of specific representations with specific impressions can also be acquired - even when no such connexion is given by nature." 131 Sensations are thus given to expression in lawlike form and, therefore, are not only quantifiable but structurally objective too. This is the epistemological ground zero of psychophysics. ${ }^{132}$

Although early psychophysical models (e.g. the Weber-Fechner law) made the objectification of sensation possible - that is, these models structurally objectified the relationship between mind and matter - they did not define this relationship in a way that remained satisfactory for later acoustic scientists. ${ }^{133}$ Nevertheless, psychophysics shifted the question from attempting to attain a mechanical representation of an object in a way that obviated the subject, to expressing the relationship between subject and object in structural terms. The epistemological revolution of psychophysics thus outlived its

\footnotetext{
${ }^{131}$ Helmholtz (1977, p. 131).

132 There were two problems with the development of psychophysics and scientific psychology more generally - one overarching and conceptual but eventually ignored, the other methodological and specific to acoustic science but eventually, as we have seen, overcome. Conceptually, criticism came during the late nineteenth century in the form of what is called the quantity objection. Like psychophysics, this "vigorous opposition ... took its stand firmly upon the distinction between mind and body"; unlike psychophysics, it "denied the possibility of a quantitative correlation between the two on the ground that mind was not possessed of magnitude and that mental measurement was an impossibility" (Boring 1921, p. 453). Despite this serious and difficult objection, the development of quantitative psychologies continued more or less apace. For the purposes of my historical argument, it is not necessary to take a philosophical position on the ontology or epistemology of measurement. But others have. Important period contributions include Boring (1921) and Stevens (1959). For a contemporary argument, see Michell (1999), who suggests that the quantity objection was never adequately dealt with by psychologists, just ignored. The philosophical problems of quantity, measurement and objectification thus lurk in the shadows of contemporary psychology.

${ }^{133}$ See Fletcher (1929) and Churcher (1935).
} 
empirical validity. In other words, psychophysics, even as it participated in the invention of what Julia Kursell calls the "sound object," also gave perception (the subject) "an objectiveness of its own." 134 This shift has been carefully described in relation to visual culture. Interestingly, though, the trajectories of the visual and the acoustic through this epistemic shift are different: whereas vision had been privileged as a rational and immediate means of accessing an external and objective world, its migration into psychophysics represented a process by which visuality itself became an object of inquiry, which is indicative of a broader "denigration of vision"; 135 hearing, on the other hand, which was always assumed to bear an essentially subjective relationship to an external and objective world, with the rise of psychophysics was paid something of a scientific compliment by being reconfigured as an object of inquiry. In other words, if visualists had something to lose, acousticians had something to prove.

While the differences in the paths of the visual and the acoustic should not be ignored, Crary highlights an important similarity:

Once the empirical truth of vision was determined to lie in the body, vision (and similarly the other senses) could be annexed and controlled by external techniques of manipulation and stimulation. This was the decisive achievement of the science of psychophysics in the mid-nineteenth century, which, by apparently rendering sensation measurable, embedded human perception in the domain of the quantifiable and the abstract. ${ }^{136}$

\footnotetext{
${ }^{134}$ Kursell (2008, p. 29).

135 See Crary (1990), Jay (1993).

${ }^{136}$ Crary (1999, p. 12).
} 
But, to paraphrase Crary's next point, and to translate it into the realms of sound and listening, while this conception of the senses allowed the acoustic to become compatible with many other processes of modernity (e.g. the audile techniques described in Chapter 3), it also opened up the possibility that acoustic experience itself, while amenable to logics of rationalization, was also intrinsically nonrationalizable - that the acoustic, while susceptible to structural objectification, also remained essentially subjective. ${ }^{137}$ This story is not only about the ultimate fallibility of perception despite the processes of training and discipline that resulted in the formation of modern modes of acoustic attention and "aurality," as Benjamin Steege has written; ${ }^{138}$ it is also about the fallibility of representation, the imperfect objectification of sound.

Saying that the objectification of the acoustic turned on the reconfirmation of its subjectivity is not grounds for reigniting an ancient and pointless debate about the hierarchy of the senses; neither does it lead to an argument for the recovery of orality in the so-called ages of literacy and electronic consciousness; nor is it meant simply to reassert the importance of aurality in an apparently visualist modern culture. ${ }^{139}$ Rather, my point is that, under the sign of psychophysics, visuality and aurality underwent similar transformations (albeit from opposite angles), that in both cases ideals of objectivity and problems of subjectivity are necessary and co-formative complements,

\footnotetext{
${ }^{137}$ For the passage that I'm paraphrasing, see ibid.

138 Steege (2007, especially pp. 20,33).

${ }^{139}$ For critiques, see Sterne $(2003,2011)$ and Erimann (2010). Discourses about "return of the ear" were prevalent at the time (e.g. Graham 1924, Rait 1924), not just something imagined by scholars like McLuhan (1962) and Ong (1988).
} 
that such co-formation is a constitutive logic of listening formations and, finally, that listening formations can help delineate this co-productive tension as a constitutive feature of the "warp and woof of modernity." 140

\section{Conclusion: objectivity and the historiography of sound reproduction}

In the historical literature on sound and modernity, there are two main perspectives on objectivity. The first defines acoustic modernity by the newly possible objectification of sound wrought by electrical technologies during the early twentieth century. The second focuses on the nineteenth-century establishment of frequency as the stuff of sound, and the sonic object (as opposed to music) as the content proper to the acoustic sciences. Loudness and the decibel add nuance to these historiographic positions.

Histories of the acoustic sciences distinguish classical acoustics from modern acoustics in two basic ways: in terms of mathematics and in terms of technology. Both developments happened at the turn of the twentieth century. On the one hand, as Robert Beyer notes, it is "the extensive and brilliant use of mathematics" that marks Rayleigh as a paragon of modern acoustics; on the other, it is "the great developments of electroacoustics" which "changed all the rules of acoustic experimentation at the beginning of the twentieth century."141 Emily Thompson makes a similar point. She suggests, in terms which are certainly discernable in my foregoing discussion, that

\footnotetext{
140 Erlmann (2010, p. 15).

${ }^{141}$ Beyer (1999, pp. 91, 138). Although Beyer provides the best contemporary summary (and one of the few that reaches very far into the twentieth century), his account is more technical than cultural.
} 
acoustic scientists "were initially frustrated by a lack of suitable scientific tools for measuring sound" but that, alongside "the development of new electrical instruments in the 1920 s, not only did it become possible to measure sound, but the tools also stimulated new ways of thinking about it." 142

In this way, Thompson's claims about what she calls "the origins of modern acoustics"143 essentially parallel those of the acoustic sciences of the time: "Acoustics is a science of the last thirty years," said the physicist and historian Dayton Miller in 1931; "The modern era of acoustics began in 1915," in Knudsen's mind, "when the thermionic vacuum tube and the high quality microphone became practical devices." 144 We have already seen that Stevens and Davis made similar claims. So did William Eccles in his address on "The New Acoustics," and so do nearly all historians of the acoustic. ${ }^{145}$ The recurring theme here is that the growth of acoustic science since 1800 had been stunted by a lack of mathematics and technology, but that the objectification of sound (and thus the modernization of the acoustic sciences) finally arrived with the invention and proliferation of electrical sound reproduction technologies. From this perspective, electrical sound reproduction is the condition of possibility for acoustic objectivity and, by extension, acoustic modernity more generally.

\footnotetext{
142 Thompson (2002, p. 5).

${ }^{143}$ lbid. (pp. $90 \mathrm{ff}$ ).

${ }^{144}$ Miller quoted in Thompson (2002, p. 59); Knudsen (1938, p. 176).

${ }^{145}$ In addition to Eccles (1929), Miller (1935), Boring (1938, 1942), Knudsen (1938), Stevens \& Davis (1938), Beyer (1999), and Thompson (2002), see Loudon (1901), King (1919), Miller (1935), Stephens \& Bate (1950), Lindsay (1966), Hunt (1978). For similarly teleological accounts of the physiology of the ear, see Kostelijk (1950), Wever \& Lawrence (1954), Politzer (1981).
} 
Jonathan Sterne's characterization of the audible past, on the other hand, hinges on the idea that "the very possibility of sound's reproduction" is predicated on a prior objectification of the acoustic:

... sound reproduction technologies do not simply "objectify" previously unobjectified sound; to the contrary, sound's objectification is a precondition of their existence. This objectification of sound is itself related to the objectification of hearing, since the latter is the faculty by which the former is perceived. If sound is to be understood more and more as an effect which can be measured or registered, then hearing must be one site at which effects are registered; it must itself be objectified. ${ }^{146}$

Sound reproduction technologies, in other words, did not objectify sound for the first time. Rather, "the objectification and abstraction of hearing and sound ... was a prior condition for the construction of sound reproduction technologies."147 Mechanical and electrical reproduction thus rest on a longer history of acoustic objectivity. That longer history, for Sterne, is represented in shifting understandings of frequency (especially during the nineteenth century), and is embodied in what he calls the rise of "sound qua sound."

The point here is not necessarily to disagree with Sterne or Thompson: sound and hearing are indeed associated with a history of objectivity, and twentieth-century technology and nineteenth-century epistemic shifts are significant moments in that history. Rather, it is to call attention to the co-formative character of the historical

\footnotetext{
146 Sterne (2001, p. 270).

147 Sterne (2003, p. 23): "the objectification of sound was not a simple 'effect' or result of soundreproduction technology."
} 
relationship between the acoustic sciences and objectivity in the context of listening formations.

Although rich traditions of musical inquiry have existed for thousands of years, the seventeenth century is most relevant as an anchor for the present discussion. For it was during this era that "Platonic ideas of world harmony, along with the ancient science of speculative music, began to disappear." 148 Indeed, scholars argue that the $1600 \mathrm{~s}$ witnessed a paradigm shift: from "the ancient science of the sounding number, whose principles were rooted in arithmetic and geometry" to "a physico-mathematical discipline set like optics or astronomy in the modern system of the mechanical laws of nature."149 In other words, the transition being described is from the harmony of the spheres to the science of music, which is usually discussed in terms of Quantifying Music, a conceptual transition from Number to Sound. ${ }^{150}$

This period is understood to have been followed by another paradigm shift in the nineteenth century, in accordance with the second scientific revolution: from a scientific approach to the acoustic in terms of music, to a scientific approach to the acoustic in terms of sound. Frequency played a central role in this shift. ${ }^{151}$ As Sterne notes:

Prior to the nineteenth century ... philosophers took music as an idealized theoretical instance of sound, leading to the analysis of pitch and harmony, all the way up to the harmony of the spheres and, for Saint Augustine, God. In contrast,

\footnotetext{
148 Kassler (1979, p. xxxvi).

149 Gozza (2000A, p. 60).

${ }^{150}$ See Cohen (1984), Gozza (2000A/B).

151 So did the use of vowel sounds (Kursell, 2008).
} 
the concept frequency ... offered a way to think about sound as a form of motion or vibration. As the notion of frequency took hold in nineteenth-century physics, acoustics, otology, and physiology, these fields broke with the older philosophies of sound. Where speech and music had been the general categories through which sound was understood, they were now special cases of the general phenomenon of sound. ${ }^{152}$

Friedrich Kittler identifies something similar: as opposed to Pythagorean musical ratios based on subdivisions of a length of string, frequency constitutes "physical time removed from the meters and rhythms of music."

It quantifies movements that are too fast for the human eye, ranging from 20 to 16,000 vibrations per second. . . Frequencies remain frequencies regardless of their respective carrier medium. The symbolic correlation of sound intervals and planetary orbits, which ... made up the harmony of the spheres, is replaced by correspondences in the real. ${ }^{153}$

In other words, "speech, music, and other human sounds were reduced to special categories of noises that could be studied by the sciences of sound. In acoustics frequencies and waves took precedence over any particular meaning that they might have in human life." 154 As H. Floris Cohen summarizes, the ancient question of cosmological consonance and dissonance "could now be reformulated as follows":

why is it that the simple ratios of the vibrational frequencies of sounding bodies correspond to the human sensation of pleasure and beauty in hearing the consonant intervals? The original question had thus undergone a striking transformation in that now an empirical physical phenomenon rather than, as

\footnotetext{
152 Sterne (2003, p. 23).

${ }^{153}$ Kittler (1999, p. 47).

${ }^{154}$ Sterne (2003, p. 43).
} 
before, an abstract mathematical ratio appeared to be responsible for our sense experience ... having once entered the realm of the empirical, it was never to leave again. ${ }^{155}$

This marks the emergence of what Sterne calls sound qua sound. ${ }^{156}$ As such, within the modern acoustic sciences sound became understood, first and foremost, in terms of natural physical properties that could be quantified, empirically measured, scientifically objectified. Sound, Sterne says, became "an object of knowledge in its own right."157

This is the path of sound most often described by historians of the acoustic: from speculative cosmologies of musical harmony to objective understandings of sound qua sound. To be sure, this trajectory - which is also sometimes presented in terms of the disenchantment of music and hearing - is historically viable. ${ }^{158}$ Indeed, it was noticed by commentators at the time: "physical science was conspiring to deflate the status of the queen of the fine arts: Music. ... to the great distress of contemporary aestheticians, [acoustic science] was searching [music's] secrets in terms of vibrations and their effect upon the physiological organism." 159 But the fears of aestheticians do not portray the full picture; neither do the trajectories of disenchantment and sound qua sound posited in the historiography of sound reproduction.

${ }^{155}$ Cohen (1984, p. 97). Emphasis in original.

156 The scientific and philosophical reconceptualization of sound qua sound had parallels in the worlds of avant-garde art and music (think of Varèse's telling definition of music as "organized sound"). Although such a discussion is beyond the scope of my argument, it has been noted by a variety of sound scholars. See Kahn \& Whitehead (1992), Kahn (1999), Weiss (2001), Cox \& Warner (2004), Bijsterveld (2008, chapter 5).

157 Sterne (2003, p. 43).

${ }^{158}$ On what he calls "the project of 'disenchanting' hearing," see Sterne (2008, p. 63).

159 Mueller (1935, p. 371). 
Aesthetic anxiety about the dethroning of music, for example, was offset by musical futurists and avant-gardists, who placed their hopes in the new musical possibilities that they believed would spring from scientific and technological advances. ${ }^{160}$ What's more, musical aesthetics and acoustic science remained in close conference through the nineteenth century and into the twentieth - the very period in which they are assumed to have separated. Seashore is a prime example of the continued dialogue, but there are others. For instance, there is clear relationship between sound and music in the work of many early physical acousticians, ${ }^{161}$ all the major early psychophysical investigators, ${ }^{162}$ and in the widespread debates about the relationship between music theory and psychology. ${ }^{163}$ Indeed, Helmholtz, the most influential founder of the acoustic sciences, explicitly identified his work as "an attempt ... to connect the boundaries of ... physical and physiological acoustics on the one side, and of musical science and esthetics on the other."164 The story of sound qua sound is additionally complicated by national differences, British and German acoustics having remained more closely tied to musical sound and musical instruments longer than the corporate telecommunications agenda in the United States (although, as we have seen, even AT\&T's agenda fostered a continued connection between acoustic science and musical

\footnotetext{
${ }^{160}$ See n. 156.

161 Jackson (2006), Ku (2006).

162 For a detailed account of the broader connection between acoustic science and musical aesthetics in this context, see Hui (2008).

${ }^{163}$ Butler (1973), Marvin (1987), Kim (2003).

164 Helmholtz (1954, p. 1).
} 
aesthetics). ${ }^{165}$ Each of these details puts a dent in the uniformity of sound qua sound. A bigger blow returns in the form of frequency itself.

The objectification of frequency - the sine qua non of sound qua sound - extends much further back than the 1800 s, the period with which Sterne and Kittler are primarily concerned. Indeed, it was known in the 1500s that physical frequency was at the root of pitch perception. ${ }^{166}$ What's more, there is a significant difference in understanding between these two periods. Whereas sixteenth-century theorists assumed an isomorphic, one-to-one correspondence of frequency to pitch, others suspected (and later proved) a more complex relationship between the two. Pitch, it turns out, is a joint function of at least two elements of sound: frequency and intensity. ${ }^{167}$ The difference between knowing that pitch is rooted in frequency, on the one hand, and understanding the psychophysical character of their relationship, on the other, is significant for what it tells us about the trajectory of sound qua sound.

The evolution of sound qua sound, the emergence of sound as an object of knowledge, the disenchantment of music and hearing, the creation of the sound object this all has something to do with seating the acoustic in the physical (rather than the cosmological or the musical). So even though their timelines differ, Sterne and Kittler

\footnotetext{
165 Jackson (2006), Ku (2006).

166 "In the second half of the 16th century" it was understood through the work of Giovanni Battista Benedetti that "the ratios between the times of vibrations [of strings] quantified the musical consonances, which were explained physically through the periodic movement of sounds." Galileo is also credited with the correlation. See Gozza, (2000A, p. 60).

${ }^{167}$ Our contemporary understanding of this relationship was not empirically verified until 1930 (Boring 1924, p. 378).
} 
agree with Cohen that acoustic modernity is marked by the entrance of frequency into a permanent relationship with the empirical. But the nature of what it meant for this relationship to be "empirical" changed significantly over time. The objectification of frequency, it turns out, was not an objectification of pitch - just as the objectification of intensity was not an objectification of loudness. ${ }^{168}$ The quantification of sound in terms of mechanical objectivity is therefore only part of the story. It crisscrossed with the quantification of listening in terms of structural objectivity. This means that the rise of sound qua sound is mixed-up with an emerging understanding of sound qua subject. The moment of (mechanical) objectification in the acoustic sciences is paralleled by the realization (and reconfirmation) that the acoustic is at the same time irrepressibly subjective. Sound did become a new kind of object of knowledge; so did the acoustic subject. Thus, while historians of science show us that the rise of sound qua sound happened earlier than sound scholars suggest, my argument is that this process was less complete than sound scholars suggest.

The rise of sound qua sound is the prior objectification on which, for Sterne, the historicity of sound reproduction is predicated. ${ }^{169}$ However, in the case of frequency (the quintessence of sound qua sound), it is apparent that mechanical objectivity emerged in a complicated relationship with another ideology: structural objectivity. This problem was

168 There is a broader psychophysical history of isomorphism here (Boring 1942, pp. 25-27, 83-90).

169 Incidentally, this goes some way toward explaining the prominence of fidelity in the history of sound reproduction, because ideologues assume an objective sonic reality, on the one hand, and the possibility of capturing traces of that reality through sound reproduction technologies, on the other. Indeed, there is in this broad historical sense an important connection between ideologies of mechanical sound reproduction and ideologies of mechanical objectivity. 
also at the centre of the science of loudness, and the invention of the decibel. Unlike the proponents of mechanical objectivity, the explorers of structural objectivity accepted as basic the mediating role of perception, and the materiality of sound, in the relationship between subject and object. To be clear, the point here is not just that new forms of sonic subjectivity emerged alongside new objective understandings of the acoustic, but that the two were informed by each other. We can thus identify here a logic of listening formations that is able to hold subjects and objects in the same kind of mutually constitutive tension seen in my earlier studies of fidelity, privacy and rationality.

The acoustic sciences thus attest to the ways in which the history of modern thought is not a coherent series of intellectual advances toward objectivity at the expense of subjectivity - or, in Erlmann's terms, toward reason at the expense of resonance. And loudness, in particular, attests to yet another way in which acoustic modernity resists encompassing definitions, uniform logics, singular labels; it reconfirms that the story of acoustic modernity must be told "in terms that do not rely on the sole criteria of objectivity or empirical fact, but that also take into account the deep interpenetration of fact and value, objectivity and affect, and most of all - science and music."170

${ }^{170}$ Erlmann (2010, p. 25). 


\section{CONCLUSION Listening formations: for a history of loudness}

The goal of this thesis has been to highlight some of the diversity and variation underlying several of the most prominent themes in the historiography of sound reproduction. It began as an attempt to do something rather different - namely, to provide a detailed cultural history of the electrically amplified loudspeaker, and then of loudness more generally. Although I ultimately discovered that those topics were too narrow and too broad, my preliminary research into electrical amplification and loudness highlighted issues which, I found, were not adequately dealt with in the sound studies literature. In particular, this research raised questions about four recurring themes in the historiography of sound reproduction: fidelity, privacy, rationality, objectivity. I proposed and developed the idea of listening formations in order to augment the existing conceptualizations of those themes in sound studies. Listening formations emphasize that fidelity, privacy, rationality and objectivity have not been univocal tendencies, and they demonstrate ways in which the history of sound reproduction and the notions of acoustic modernity that it both indexes and constitutes have been generated through dynamics of imperfection and magnetisms of incongruence. Using a series of thematic explorations stemming from the literature on sound reproduction, I attempted to see the ideals and practices of audiences and professionals, on the one hand, and the materialities of electrically amplified loudspeakers and loudness, on the other, as co-constituted in ongoing processes of 
circulation and mediation. By situating these processes - the dynamics and logics of listening formations - in relation to the wider reorientations toward knowledge, the environment and the self that characterize the project of modernity, this thesis has striven toward a deeper understanding of the modern era as an acoustic phenomenon.

In addition to the listening formation and its attendant notions of imperfection and incongruence, some other terms and concepts have proven useful in my study of the historiography of sound reproduction. Chapter 1 introduced the "problem space of fidelity" in order to draw attention to, and possibly move beyond, an analytics of sound reproduction based primarily in the history/critique of fidelity. Chapter 3 developed the "communications frame" as a tool for understanding the processes of translation that exist between the worlds of sound engineering and music, and which can give rise to relations of incongruence between "producers" and "users." Chapter 4 formulated the "acoustic sciences" not only to emphasize the overlap of physics, physiology and psychology in the study of sound, listening and music, but also to situate those fields within a longer intellectual history of the "human sciences," and to highlight the co-constitutive relationship between subjects and objects that has been at the root of that history. I have developed these concepts to aid my own illustration of listening formations; if they are found useful in other areas of sound studies, that will be their ultimate test.

Instead of offering a detailed recapitulation of the arguments of my chapters, though, I want to end by returning to a question that my research led me to short-circuit at the outset: a history of loudness. My main goal in this conclusion is to reflect on the 
possibility of expanding the scope of my analysis, moving the focus outward from the historiography of sound reproduction to a broader history of loudness. In doing so, I address several issues which I believe would necessarily be raised in attempting such a history. In particular, I discuss a move away from certain paradigms of "culturalism" and "constructivism," toward an approach more sensitive to the material bases of sound as a mediated and mediating medium. Thus, I also use this conclusion as an opportunity to elaborate several questions of theory and method at the base of the foregoing discussion questions which, though touched on, have not been systematically articulated.

\section{For a history of loudness}

One of the themes circulating in the material examined in this thesis is that music is getting louder. The apocalyptic potential of the aerophone, for example, was an international concern. Later, Edison himself complained about a "volume fad." During the electrically amplified 1920s, Gramophone readers were conscious of living in an "age of noise" and were sure that records too were getting "louder and louder."2 Oliver Read and Walter Weich "recall the increasing loudness" of "the competing loudspeakers of the business streets and residential neighborhoods" during the 1930s. ${ }^{3}$ For John Gruen, the rise of rock was marked by unprecedented volume: music had been "blown up to billboard size" and the age-old practice of quiet listening had become "tantamount to a

\footnotetext{
${ }^{1}$ Frow (2001, pp. 70-71).

${ }^{2}$ Luff (1928, p. 401).

${ }^{3}$ Read \& Welch (1976, p. 270).
} 
sneaky pleasure." ${ }^{34}$ Critics of the contemporary loudness war also assume that "In this age, we all do tend to listen to music in much noisier environments" and assert that "music today is louder than ever before." 5 Such musical claims are part of a more general history of loudness.

A perennial belief about the modern "soundscape" is that it is loud - and that it is getting louder. From sixteenth-century French poets who considered hanging themselves in order to find relief from "the din of bells," to eighteenth-century British cooks who were appalled by the "hideous din" of London's hawkers and criers; from nineteenthcentury American journalists who cringed at the "warlike din" of mobilization and city life, to twentieth-century Dutch citizens who rallied against the "deafening din" of industry - the enduring assumption here is that we live in din. ${ }^{6}$ Acoustic ecologist Murray Schafer encapsulates this outlook: "It would seem that the world soundscape has reached an apex of vulgarity in our time," he claims, "and many experts have predicted universal deafness as the ultimate consequence unless the problem can be brought quickly under control." From this perspective, loud music is a straightforward reflection of an increasingly loud world, and the history of volume is perennially boiling over.

My question is whether it is possible to understand this history in a way that doesn't assume such crisis-teleologies and crescendos. Rather than seeing my case

\footnotetext{
${ }^{4}$ Gruen (1966, p. 123).

${ }^{5}$ Weston (n.d.), Jones (2005).

${ }^{6}$ Respectively, Corbin (1998, p. 299), Cockayne (2007, p. 107), Smith (2001, p. 213), Bijsterveld (2008, p. 66).

${ }^{7}$ Schafer (1994, p. 3).
} 
studies as parts of a causal historical lineage or in terms of absolute sound level, I've tried to show a variety of ways in which loudness has been constructed as a certain kind of problem in this history, as a part of particular listening formations. Just as sound scholars insist that the history of fidelity is not a straightforward march toward perfection, and just as musicologists contend that the history of harmony is not a hike toward complexity and sophistication, so I would argue that the history of volume is not simply accretive. Indeed, in the same way that every age has its own perfect fidelity, so does every generation believe that its music is the loudest, that its "soundscape" has reached the "apex of vulgarity." This way of thinking about the history of volume is based in the assumption that cultural definitions and experiences of volume remain static over time. But they don't. They are functions of listening formations (and vice versa). Loudness has no objective gauge, and volume has no autonomous history; they are historical variables, not constants against which the movements of history can be plumbed. From this perspective, the history of volume is better measured in discourse than decibels.

But decibels, as we saw in Chapter 4, raise questions about the materiality of sound and listening in ways that trouble any purely discursive understanding of the history of loudness. This brings us back to Faulkner's original conception of listening formations. In particular, it recalls questions of social construction, contexts of audition, and experience - all of which are rooted in the implicit suggestion that practical and conceptual orientations toward sound change as functions of history and culture. The contingency of sound and listening has been widely recognized since the 1990s, although 
this kind of cultural-historical inquiry goes back at least as far as the 1920 s and, perhaps more relevantly, such research has important foundations in Theodor Adorno's 1938 essay on the regression of listening. ${ }^{8}$ This interest in listening runs alongside a much broader body of work in the history of consciousness and perception. The credo of this literature, which goes back to Karl Marx, through Marshall McLuhan, and forward to the new field of sensory studies, was most famously announced by Walter Benjamin:

"During long periods of history," he said, "the mode of human sense perception changes with humanity's entire mode of existence." ${ }^{.9}$ Such work has been an enabling condition and a strut of "culturalist" and "social-constructionist" approaches across the humanities and social sciences.

\footnotetext{
${ }^{8}$ On musicologies of listening since the 1990s, see Gay (1995), Johnson (1995), Burstyn (1997), Botstein (1998), Kassabian (2002), Leppert (2004), Riley (2004), Stockfelt (2004), Clarke (2007), Fitzgerald (2010). On precedents in 1920s German musicology, see Wegman (1998). Although Adorno's understanding of listening is too much a product of his particular critical agenda to be of use in our context, it is important as a historical precedent (Shepherd \& Devine, forthcoming 2013): “Adorno's work is clearly the product of a troubled and contentious period of history and of a severely dislocated biography. With the benefit of hindsight, many of his principal ideas on music are easy to criticize. However, his legacy can be argued to lie more importantly in the character and scope of the questions he asked than in the specifics of the answers he provided. Adorno understood the holistic character of the entire 'musical-historical field.' He saw that various musical traditions in modern Western societies could be understood only through the character of their mutual relations, and that music needed to be understood not only in terms of its formal characteristics but also in terms of the relation of these to the circumstances of its production and reception." Adorno's (2002A, p. 303) own argument runs like this: "The counterpart to the fetishism of music is a regression of listening ... arrested at the infantile stage. Not only do the listening subjects lose ... the capacity for conscious perception of music ... but they stubbornly reject the possibility of such perception. They fluctuate between comprehensive forgetting and sudden dives into recognition. They listen atomistically and dissociate what they hear, but precisely in this dissociation they develop certain capacities which accord less with the concepts of traditional aesthetics than with those of football and motoring. They are not childlike ... But they are childish; their primitivism is not that of the underdeveloped, but that of the forcibly retarded."
}

${ }^{9}$ Benjamin (1968, p. 224). See also Marx (1956, 1968), McLuhan (1962), Simmel (1964), Tarde (1969), Ong (1988), Elias (1994), Howes (2003), Corbin (2005), Jütte (2005). 
Arguably, though, culturalist and constructionist approaches have reached a point of diminishing returns. In Martin Jay's words, "the tide of cultural studies is beginning to recede a bit and the limits of radical culturalism are becoming increasingly apparent."10 Many scholars now emphasize that a strongly constructionist understanding of cultural mediation - which has been the dominant conception in the humanities and social sciences since the alignment of psychoanalysis, semiotics, and (post)structuralism that was achieved in the early to mid twentieth century - has lost its edge, is no longer fully adequate. ${ }^{11}$ Whereas appeals to the "natural" aspects of subjects (in terms of bodies, frameworks of perception, lived experience) and objects (in terms of their materiality, aesthetic properties, affordances) could be shrugged off as "naive" during the heydays of culturalism and constructionism, scholars now recognize that "it is as impossible to reduce natural visual experience to its cultural mediations as it is to disentangle it entirely from them."12 The implication is that treating the subjects, objects and mediations of culture exclusively in terms of their discursive or textual constitution is no longer the

\footnotetext{
10 Jay $(2002$, p. 276).

"See also Hacking (1999). Questions of what to do "after" social construction quickly give way to questions of how the social sciences and humanities might function in moving beyond the modes of critique that have been their M.O. since Marx - critiques which are themselves enabled by constructionism (e.g. Hennion \& Grenier 2000, Latour 2004, Boltasnki \& Chiapello 2005, Sterne \& Leach 2005). The stakes are high and the debates are passionate. However, I'm not sure the question of critique has been adequately historicized. My inclination is thus less to engage in polemics about what Terry Eagleton (1984) calls the function of criticism, and more to point to the need for a history of the idea of criticism, to take a page from the work of John Durham Peters (1999).

12 Jay (2002, pp. 270, 274). On naivety, see Jay (ibid., p. 270): "the primary source of the new insistence on the discursive, textual or institutional constitution of images, which makes any appeal to their natural, universal or transcendental status seem naive, can be found ... in the exponential explosion of what might be called the technical and cultural mediation of visual experience."
} 
requisite mode of analysis here. ${ }^{13}$ Indeed, the humanities and social sciences are urgently searching for ways to discuss the properties of subjects and objects that in some sense exceed, evade, or overflow cultural mediation. This is the case, not just in the fields of visuality and aurality, but from the most grounded sociology to the most rarefied philosophy, from (post-positivist) empiricism to metaphysics to empirical metaphysics. ${ }^{14}$ The question, it seems, is what the study of culture might look like in the wake of "culturalism" as a dominant academic paradigm.

Some of the most empirically rigorous and theoretically sophisticated work on this question has been carried out by cultural sociologists. Many of these scholars position themselves against what are seen as two basic limitations in the work of Pierre Bourdieu: first, the reduction of the intentionalities and identities of individuals to the revelation of hidden social determinants; second, the reduction of the distinctive properties and affordances of cultural objects to "the conditions of reflective social symbols." 15 This paradigm of constructionism leads to what Antoine Hennion calls the

\footnotetext{
${ }^{13}$ Johnson (2008, p. 44) puts it succinctly in relation to physicality and affect: "The body sets limits on the interpretive range, which is then made available for cultural mediation."

${ }^{14}$ Respectively, for example, DeNora (2000), Massumi (2002); Born (2010A), Harman (2002), Latour (2005).

${ }^{15}$ Respectively, Hennion (2007, p. 98), Shepherd \& Devine (forthcoming 2013). Nick Prior has noted that much of this "post-Bourdieuian" scholarship is based on a limited engagement with Bourdieu's project. Indeed, Prior (2011, p. 135) offers an important critique of the "postBourdieuian" trend in contemporary music sociology, convincingly arguing that "Bourdieu's is not the only game in town when it comes to the analysis of art and culture, but it is clearly the most developed, sophisticated and, most importantly, sociological." I agree with Prior that Bourdieu should not be forgotten, but in this context I am trying to harvest the fruit of postBourdieuian scholarship, which is possible without needing to assess the subtlety or fairness with which Bourdieu has been treated by his critics.
} 
"double erasure" of the subject and the object. ${ }^{16}$ The goal, then, for Hennion and others, is to develop a non-reductive sociology of culture that would consider a full range of coformative relationships - from "individuals and institutions to frameworks of perception, through material elements and even the finest details of works of art and their production." 17

Such issues have been especially pressing in the "new" sociologies of art and music during the past decade or so..$^{18}$ Although the case of visual art is interesting and instructive, I focus here on music, where several scholars have identified the "musical experience" as a potentially fruitful site of analysis in developing such a perspective. ${ }^{19} \mathrm{As}$ Georgina Born puts it:

... musical experience (or listening) both results from and engenders mediation. Musical experience entails and proffers relations between objects and subjects; indeed it construes what might be called a musical assemblage - a series or network of relations between musical sounds, human and other subjects, practices, performances, cosmologies, discourses and representations, technologies, spaces, and social relations. ${ }^{20}$

In other words, Born conceives musical experience as a site of mediation in an assemblage of subjects and objects. This is close to my definition of listening formations,

\footnotetext{
${ }^{16}$ Hennion (2007, p. 100).

${ }^{17}$ Hennion (1995, pp. 233-234).

${ }^{18}$ Much of this discussion has played out in the pages of Cultural Sociology.

${ }^{19}$ See for example Shepherd \& Wicke (1999-2000).

${ }^{20}$ Born (2010B, pp. 87-88, 89). Will Straw (2010A) has critiqued Born's work for emphasizing cultural production, not necessarily at the expense of "reception" (which is an old debate), but in a way that tacitly adheres to the very distinction between production and reception (which is an outmoded idea). In this context, though, Born's adoption of the assemblage as a guiding metaphor is closer to Straw's discussion of circulation and the generative matrix.
} 
although I will adapt two aspects of Born's work. First, Born's strong ethnographic orientation leads her to emphasize the present in ways that need to be augmented in light of my research focus. It is not that Born ignores history, but that she uses history in order to provide a deeper reading of her contemporary ethnographic sites. This means that, even as she attacks "the lack of a diachronic dimension" in Bourdieu's "critical armoury," her own theories of the relations between subjects and objects, while they are rooted in historical circumstances, are observed in the present tense. ${ }^{21}$ The question of how to study such complex relationships in the audible past itself - a methodological question necessarily raised by this thesis - is not asked. In fact, this historical dimension is missing from much of the leading work in contemporary music sociology - the work of Tia DeNora and Antoine Hennion, for example..$^{22}$

My second adaptation is to Born's discussion of the musical experience. While I fully agree "that there is a need for systematic and comparative empirical study of listening as a focal musical activity," I am not persuaded by her call to shift "the terms of the discussion from listening to the broader category of musical experience." ${ }^{23}$ In fact, I

\footnotetext{
${ }^{21}$ See Born (2010A, p. 194): "To address this problem, it is necessary to forge new ways of bringing historical analysis together with the insights provided by ethnography. In both my studies [i.e. her books on IRCAM and the BBC] . . . the ethnography is combined with a historical reading of the political, economic and cultural dynamics, broadly, that lie behind the present." See also Born (2005).

${ }^{22}$ See for example DeNora $(2000,2003)$ and Hennion (2007). Both DeNora and Hennion have engaged in historical scholarship - on Beethoven and Bach, respectively. However, DeNora's (1995) early work is constructionist in a way that is less sophisticated than her contemporary ethnographies. Hennion's historical work is nuanced in its understanding of the co-formation of subjects and objects, though his perspective (like Born's) is primarily tied to a Foucaultian "history of the present" (e.g. Hennion \& Fauquet 2001). See also DeNora (2004A).

${ }^{23}$ Born (2010B, p. 80).
} 
would argue just the opposite: musical experience is actually the narrower category, and such experience can profitably be understood in a larger context of audition. From this perspective, pace Born, "sonic experience" would actually be the more appropriate term (and its correlate would be not the "musical assemblage" but the "acoustic assemblage"). However, I would rather overhaul a simple term like listening formation than adopt either of those cumbersome phrases. ${ }^{24}$

All of this is perhaps too abstract. Ultimately, though, listening formations describe lived existences; they share music sociology's ethnographic orientation toward day-to-day life as a site of analysis. ${ }^{25}$ However, sound scholars tend to view the historical study of the listening experience as problematic. For example, Sterne "turns away from attempts to recover and describe people's interior experience of listening ... toward the social and cultural grounds of sonic experience":

The "exteriority" of sound is this book's primary object of study. If sound in itself is a variable rather than a constant, then the history of sound is of necessity an externalist and contextualist endeavor. ${ }^{26}$

\footnotetext{
${ }^{24}$ When I speak of listening in this context, I do not assume a dichotomous relationship with "hearing," the apparently passive, distracted twin of this ostensibly active, attentive process (for the larger history of attention vis-à-vis distraction, see Crary 1999). Similarly, I do not assume that listening refers only to the ears. Listening is always a matter of full-body physiology, from head to toe. Although this is especially obvious in cases of loud music and dance, it is no less true in any other listening situation (e.g. Sterne 2003). For lengthier theorizations of the sonic body, see also Henriques (2011) and Jasen (forthcoming 2012). Additionally, listening is always a coformative and mediated point of mediation in a wider context of audition.

${ }^{25}$ For the broader scholarly context here, which ranges from the history of experience to the history of perception, from the history of mentalities to the history of everyday life, see Berman (1981), Lowe (1982), Burke (1986), Lüdke (1995).

${ }^{26}$ Sterne (2003, pp. 13-14).
} 
In other words, more than "a historical phenomenology or historical ethnography of sound and listening," Sterne wants "to reconsider the historicity of sound reproduction itself, rather than - for instance - considering the documents about sound reproduction as evidence of the experience of those groups. ${ }^{27}$ More bluntly: "the history of sound must move beyond recovering experience to interrogating the conditions under which that experience became possible in the first place. ${ }^{228}$ Veit Erlmann agrees, making a similar move in his history of modern aurality:

I do not dwell much on how a person's "inner listening" may be socially and culturally conditioned. Instead, I focus on what it is about the ear - its structure, its elemental substances, its functioning - that allows such a person to speak of this experience as pertaining to his or her inner self in the first place. ${ }^{29}$

While I'm not sure that Sterne or Erlmann's stance is as opposed to mine as these passages might suggest (in their analyses the line between the genealogy of discourse they advocate and the ethnography of listening they reject is not always clear), both scholars rightly identify the traps of experience as a topic of historical inquiry. Still, listening formations do not turn away from attempting to understand the range of expectations and experiences in a given context of audition. But they do so in a way that

\footnotetext{
27 Sterne (1999, p. 33). My emphasis.

${ }^{28}$ Sterne (2003, p. 28).

${ }^{29}$ Erlmann (2011, pp. 23-24). He continues: "And instead of a history of behaviors tied to the ear ... my account of modern aurality is a history of the 'listener function.' . . one might say that the listener is not simply the recipient of an indefinite number of significations that fill his or her hearing, nor does he or she come after the work. Rather, the listener is a function that fixes these meanings with the goal of circumscribing and prescribing the auditory ways in which individuals acknowledge themselves as subjects."
} 
does not start from presumptions about phenomenological realism, perceptual immediacy, or the transhistorical bases of experience; rather, they emphasize the processes of mediation and circulation in which the listener and the listened-to are coconstituted.

What I am advocating here is a kind of "archival ethnography" that is consonant with the focus of contemporary music sociology on music as social action. DeNora, for example, understands "music as a formative medium in relation to consciousness and action, as a resource for - rather than a medium about - world building. Within this dynamic conception of music's social character," she says, "focus shifts from what music depicts, or what it can be 'read' as saying 'about' society, to what it makes possible." 30 This notion of musical materiality - of how music's "affordances" function with a kind of agency in social action - is explicitly pitted against what DeNora and others view as a basic problem in the field of musicology: the tendency "to see music as structurally similar (homologically linked) to social phenomena, or as a 'representation' of some extramusical phenomenon." ${ }^{\text {31 }}$ Craig Calhoun and Richard Sennett describe this shift in cultural sociology more broadly: it is a study of painting more than paintings. ${ }^{32}$ Calhoun and Sennett go on to relate this approach - culture-as-practice - to the broader "cultural turn" in the social sciences, which, in turn, they then relate to the earlier linguistic turn.

\footnotetext{
${ }^{30}$ DeNora (2003, p. 46).

${ }^{31}$ DeNora (2004B, p. 37). For similar and forceful critiques, see Becker (1989), Martin (1995, 2006), Frith (1996) and Hennion (2003).

${ }^{32}$ Calhoun \& Sennett $(2007$, p. 5).
} 
The recognition that language constitutes its objects and its subjects, and that it mediates access to them both (instead of being merely descriptive and transparent), led to an understanding of culture that was dominated by a fascination with textuality, with language and its attendant processes of representation and meaning-making. However (and this is to link DeNora and others to the above discussion of Jay), contemporary sociologists are more interested in the processes by which a text comes to be and in what kinds of social action it can "afford," than the ways it can be "read" as a finished product. Paralleling this emphasis on materiality and action has been a rise in attention to other aspects of musical culture that are less readily reduced to readings and textuality experience, perception and emotion, for instance. ${ }^{33}$ The physicality of sound and music have been especially significant sites of analysis. In the words of Jeremy Gilbert:

Music has physical effects which can be identified, described and discussed but which are not the same thing as it having meanings, and any attempt to understand how music works in culture must ... be able to say something about those effects without trying to collapse them into meanings. ${ }^{34}$

Sound still signifies in this conception, is still bound up with musical discourse; but Gilbert calls attention to ways in which it is also asignifying, in which the materiality of sound as a basis for the listening experience cannot be restricted "to the condition of the language used to mediate awareness of it and to make talk about it possible." ${ }^{35}$ Listening

\footnotetext{
${ }^{33}$ Respectively, Shepherd \& Wicke (1999-2000), Finnegan (2003), Dibben (2001, 2003), DeNora (2001).

${ }^{34}$ Gilbert (2004, p. 2).

${ }^{35}$ Shepherd \& Wicke (1997, p. 148).
} 
formations are meant to advance such a perspective, by neither collapsing nature into culture nor culture into nature; by recognizing the possibilities and limitations of constructionism; by foregrounding the materiality of sound and listening without reducing them to sound waves and ear drums, on the one hand, or to culturalism and constructionism, on the other.

The push toward understanding the materiality of sound as the basis of music has also manifested as the displacement of human beings from the centre of inquiry, and the expansion of interest from sound to the broader category of vibration. After all, sound is only one small slice of the broader spectrum of frequencies and vibrations that radiate through our world, and humans are one among many creatures that rely on sonorous vibrations for communication and association. For Steve Goodman, this is where "sound studies" (if that name is still meaningful) becomes based in "a nonrepresentational ontology of vibrational force," where "the phenomenology of sonic effects will be transformed into the less anthropocentric environmentality or ecology of vibrational affects. ${ }^{{ }^{36}}$ Gilbert understands that a way of describing such materiality is necessary as part of a broader project of developing a "post-logocentric notion of 'culture." ${ }^{37}$ From here, sound studies becomes something of a philosophical experiment. Gilbert is explicit about this: we need, he says, "a theoretical vocabulary with which to describe and discuss

${ }^{36}$ Goodman (2010, pp. xv, xviii); his emphases. See also Trower (2012) and Jasen (forthcoming 2012).

${ }^{37}$ Gilbert (2004, p. 5). 
modes of social experience which do not operate according to either the significatory or the rhetorical logics of language."

It is here ... that we see the logical, and not merely poetic, reasons for a possible turn to the work of Deleuze and Guattari ... The pragmatic fact is that there is simply no other body of work which goes so far in trying to delineate a new vocabulary for designating the possible organisational forms of human and nonhuman experience outside the limitations of the structuralist paradigm, its psychoanalytic variants and their 'post-structuralist' modifications . . . 38

Goodman's research program, along with Gilbert's call for a "new theoretical vocabulary," are a part of the same large-scale changes in the humanities and social sciences described above - although it is something of a paradox that these quasiempiricist programs give rise to a corresponding move to high theory.

Of course, the theoretical stance developed by Deleuze (and Guattari) is one of the roots of my understanding of listening formations. But listening formations do not require the wholesale adoption of Deleuzian thought. And while I agree that developing a "post-logocentric" understanding of culture is a worthwhile, even necessary task, listening formations do not assume that this task (almost ironically) involves the reinvention of the possibilities of language as a prerequisite.

There are a variety of other terms that highlight certain aspects of listening formations: period ears, structures and modes and ecologies of listening, soundscapes, audile techniques, mangles of practice, mediations, affordances, cyborgs, assemblages,

${ }^{38}$ Gilbert (2004, p. 8). 
actor-networks, generative matrices. ${ }^{39}$ While drawing on aspects of these concepts, listening formations attempt to attend to sonic materiality without the ethnographic present, and they are devoted to understanding the historicity of listening in relation to the material specificity of sound and music. In other words, listening formations, as proposed here, move away from presentism and culturalism, while attempting a particular synthesis of historicism and materialism..$^{40}$

\section{Conclusion}

While recent sociologies of music and culture have advanced our understanding of music as an agent in social action, as well as the place of emotion and embodiment in musical experience, this body of work has been predominantly focused on what we might call the ethnographic present. Questions of history, of how our contemporary uses and experiences of music have come to be what they are, have been downplayed. Sound scholars, on the other hand, have engaged deeply with the history of our practical and conceptual orientations toward sound, but have contributed less to discussions of the specific material properties and experiential dimensions of sound and music. What music sociology offers, then, is an intricate set of theories and methods for understanding musical materiality and the listening experience, while sound studies offers a way to

\footnotetext{
${ }^{39}$ Respectively, Burstyn (1997), Mowitt (1987), Stockfelt (2004), Clarke (2005), Corbin (1998), Thompson (2002), Sterne (2003), Pickering (1995), Hennion (1995), Born (2005, 2012), DeNora (2000), Harraway (1991), Deleuze \& Guattari (1987), Born (2010B), Latour (2005), Straw (2010A).

${ }^{40}$ This is not to say that the above-mentioned concepts do not also deal, in their own ways, with problems of history and materiality.
} 
situate music as one strand in a broader history of sound, and to situate musical experience as part of a longer history of listening. Loudness offers a case in which the strengths of both perspectives can be combined.

From the side of sociology, loud music is an obviously material and embodied resource for social action and it is clearly bound up in institutional definitions, as well as the value judgments and aesthetic priorities of particular musical cultures. From the side of sound studies, the ways we talk about and experience loud sound cannot be taken for granted: they are sociohistorically conditioned as much as they are based in physics and biology. Loudness can therefore be understood in terms of historically shifting and coformative relationships between ways of listening and forms of mediation. That is, loudness helps us understand listening formations as more than signifying systems (although they are that too). Listening formations articulate intersections of subjects and objects, nature and culture, the material and the immaterial, the immanent and the arbitrary - all of which are in constant states of sedimentation and erosion.

Other attempts to understand the character of loudness do exist. Some of this work is highly speculative. From an evolutionary standpoint, loudness is assumed to signal danger; from a functionalist standpoint, it is presumed to act as a sonorous blanket and to align physical and mental activity: "Loud music synchronizes the brains of listeners. . . Loud music enhances group cohesion." ${ }^{\text {41 }}$ More grounded work in physics and psychology focuses on the ability of loud sound to affect our sense of balance, to

\footnotetext{
41 Blesser (2007, p. 6).
} 
make neurons fire at maximum rates, and to act as a "stimulant" that can "significantly change the mind and body state." 42 From this perspective, in trying to account for why people subject themselves to loud sounds despite potential health risks, loudness is likened to "any other drug." ${ }^{13}$ In the words of one prominent music psychology textbook:

People's willingness to expose themselves to music at high sound levels despite dangers to hearing exemplifies risking future harm in the interest of immediate pleasure, as in smoking, excessive eating or drinking, and various forms of addiction. ${ }^{44}$

The comparison is interesting because it invokes Howard Becker's early work on "Becoming a Marijuana User." ${ }^{.45}$ In this famous article, Becker illuminates ways in which drug use and intoxicated experience, far from being simply trait-driven and physiologically given, are equally learned and social. What Becker illustrates synchronically is also true in terms of the diachronic development of practical and conceptual orientations toward sound: experiences of loudness (recalling that "loud" is a relative term) are points of mediation in which the materiality of sound (and not just its signifying potential) and the physiology of bodies (and not just ears) come together and inform one another within historically specific contexts of audition. In this way, a study

\footnotetext{
${ }^{42}$ Respectively, Todd \& Cody (2000), Levitin (2007), Blesser (2007, p. 4).

${ }^{43}$ Blesser (2007, p. 7).

${ }^{44}$ Radocy \& Boyle (2003, p. 128).

${ }^{45}$ Becker (1953).
} 
of loudness conceived in terms of listening formations presses in the direction of a sociology of sound that is also a sociology of sound. ${ }^{46}$

Understanding loudness in this way - in terms of listening formations - moves away from historical models based in crescendos and teleologies, and from explanations based in culturalism and functionalism. Loudness is an irreducible alloy of music and sound, the immanent and the arbitrary, art and science, past and present, subjects and objects, nature and culture. Such a conception could offer an effective response to the lacunae that have marked, and which continue to mark, understandings of loudness in areas ranging from physics to psychology, musicology to sound studies. Listening formations, in short, could provide a basis for responding to a problem that has been well summarized by Daniel Levitin. "A lot of people like really loud music," he says. "We don't yet know why this is so." ${ }^{.47}$

\footnotetext{
${ }^{46}$ My phrasing here is adapted from Dahlhaus (1983), who searched for a way to "write an art history that is a history of art." The idea of a sociology of sound is taken from Shepherd \& Wicke (1997). My conception expands on their work in that I would see their primary goal - that of developing a "second semiology" (i.e. a semiology that accounts for the ways in which the signifying potential of musical sound is not reducible to that of language) - as one among several possible new directions. A second semiology would, of course, be one possible outcome, and one which would have beneficial implications for the textual-analytic programs of musicology and music theory. But, as is evident in my foregoing discussion, listening formations also push beyond questions of signification.

${ }^{47}$ Levitin (2007, p. 71).
} 


\section{BIBLIOGRAPHY}

“200,000 May Hear Cox.” 1920. New York Times (23 August): 3.

“A Current Survey of Gramophone Progress." 1926. The Gramophone 4(3): 99-103.

"A New Note in Politics." 1924. Long Lines 4(3): 17-19.

"A Telephonic Achievement Ranking With the Opening of the Transcontinental Line." 1921. The Transmitter 9(3): 1-6.

“A Voice from the Sky." 1919. Popular Science Monthly 95(1): 81.

Adams, Frank. 1987. Seeburg Jukeboxes: 60 Years of Fun, 1927-1987. Arlington: AMR.

Adams, Stephen, and Orville Butler. 1999. Manufacturing the Future: A History of Western Electric. Cambridge: Cambridge University Press.

Adorno, Theodor. 1990. "The Curves of the Needle." October 55: 48-55.

Adorno, Theodor. 2002A. "On the Fetish Character in Music and the Regression of Listening." In Essays on Music, ed. Richard Leppert. Berkeley, University of California Press.

Adorno, Theodor. 2002B. "The Radio Symphony: An Experiment in Theory." In Essays on Music, ed. Richard Leppert. Berkeley, University of California Press, 2002.

Adorno, Theodor. 2009. Current of Music: Elements of a Radio Theory. Cambridge: Polity.

“Advance is Shown in Music Recording." 1931. New York Times (10 December): 28.

“Aerophone, The." 1878. New York Times (25 March): 4.

"Aerophone, The." 1878. London Figaro (13 April): 557, 559.

Airy, George. 1868. On Sound and Atmospheric Vibrations. London: Macmillan. 
“All May Hear Harding Speech." 1920. Washington Post (29 November): 14.

"All Those Corny Halls without Microphones: A Screaming Need for Amplifiers." 1934. Melody Maker 10(36): 2.

Altman, Rick. 1985. "The Technology of the Voice." Iris 3(1): 3-20.

Altman, Rick, ed. 1992. Sound Theory/Sound Practice. New York: Routledge.

Altman, Rick. 2004. Silent Film Sound. New York: Columbia University Press.

Amplification without Distortion. 1927. Cambridge: Acme Apparatus Company.

“Amplifier Makes Automobile 'Speak for Itself."” 1922. Popular Mechanics 37(1): 25.

Anderson, Benedict. 1983. Imagined Communities. London: Verso.

Anderson, Tim. 2007. "How CDs are Remastering the Art of Noise." The Guardian (18 January): online.

Anderson, Tim. 2010. "Will the Loudness Wars Result in Quieter CDs?" The Guardian (10 January): online.

Anderson, Tim J. 2006. Making Easy Listening: Material Culture and Postwar American Recording. Minneapolis: University of Minnesota Press.

Announcing Radiolas, Radiotrons and Accessories. 1925. Toronto: Canadian General Electric Co.

"Anomaly of the Talking Film, The." 1928. Melody Maker 3(32): 1153.

Appadurai, Arjun. 1996. Modernity at Large: Cultural Dimensions of Globalization. Minneapolis: University of Minnesota Press.

Appleyard, Rollo. 1933. Charles Parsons: His Life and Work. London: Constable.

Armstrong, Tim. 2005. Modernism: A Cultural History. Cambridge: Polity.

Arnold, Harold. 1929. "Introduction." In Harvey Fletcher, Speech and Hearing. New York: Van Nostrand. 
"Attendance at Bell System Exhibit at a Century of Progress Passes Four Million." 1933. Headquarters Bulletin 7(5): 1-2.

August, Bertrand. 1965. "Descartes's Compendium on Music." Journal of the History of Ideas 26(1): 119-132.

"Awful Possibilities of the New Speaking Phonograph." 1878. The Daily Graphic (21 March): n.p.

Bailhache, Patrice. 2001. Une histoire de l'acoustique musicale. Paris: CNRS Éditions.

Bailey, Peter. 1996. "Breaking the Sound Barrier: A Historian Listens to Noise." Body and Society 2(2): 49-66.

Balbi, C. 1926. Loud Speakers: Their Construction, Performance and Maintenance. London: Sir Isaac Pitman \& Sons.

Balmain, C. 1928. "Volume." The Gramophone 5(9): 401.

Baker, Frederick. 1901. How We Hear: A Treatise on the Phenomena of Sound. London: The Vincent Music Co.

Bangs, Lester. 1972. "Black Sabbath: Bring Your Mother to the Gas Chamber." Creem (June).

Banister, H. 1927. "Auditory Theory: A Criticism of Professor Boring's Hypotheses." American Journal of Psychology 38(3): 436-440.

Barnett, HT. 1924. "The Surroundings." The Gramophone 2(5): 166-167.

Barnett, Kyle. 2006. "Furniture Music: The Phonograph as Furniture, 1900-1930." Journal of Popular Music Studies 18(3): 301-324.

Baxandall, Michael. 1988. Painting and Experience. Oxford: Oxford University Press.

Bayton, Mavis. 1997. "Women and the Electric Guitar." In Sexing the Groove: Popular Music and Gender, ed. Sheila Whiteley, 37-49. London: Routledge.

BBC. 1928. The BBC Hand Book. London: BBC. 
BBC. 1929. The BBC Hand Book. London: BBC.

BBC. 1930. The BBC Year-Book. London: BBC.

BBC. 1932. The BBC Year-Book. London: BBC.

Becker, Howard. 1953. "Becoming a Marijuana User." American Journal of Sociology 59 (3): 235-242.

Becker, Howard. 1982. Art Worlds. Berkeley: University of California Press.

Becker, Howard. 1989. "Ethnomusicology and Sociology: A Letter to Charles Seeger." Ethnomusicology 33(2): 275-285.

Beco Loudspeakers. 1926. World-Radio 3(61): 391.

"Bedlam on Radio Row." 1930. New York Times (25 May): 144.

Bell, Alexander Graham. 1880. "Experiments Relating to Binaural Audition." American Journal of Otology 2(3): 169-179.

Bell System at A Century of Progress Exposition of 1933, The. n.d. Unpublished film narrative. AT\&T Archives and History Center, Box 1061; location: 129-04-03.

Beniger, James. 1986. The Control Revolution: Technological and Economic Origins of the Information Society. Cambridge: Harvard University Press.

Bennett, Andy, and Kevin Dawe, eds. 2001. Guitar Cultures. New York: Berg.

Bennett, Tony. 1983. "Texts, Readers, Reading Formations." Bulletin of the Midwest Modern Language Association 16(1): 3-17.

Bennett, Tony. 1985. "Texts in History: The Determinations of Readings and Their Texts." Bulletin of the Midwest Modern Language Association 18(1): 1-16.

Bennett, Tony. 2007A. "Making Culture, Changing Society: The Perspective of 'Culture Studies." Cultural Studies 21(4-5): 610-629.

Bennett, Tony. 2007B. "The Work of Culture." Cultural Sociology 1(1): 31-47. 
Berger, Kenneth. 1984. The Hearing Aid: Its Operation and Development. Livonia: The National Hearing Aid Society.

Berger, John. 1972. Ways of Seeing. London: BBC.

Berlioz, Hector. 1882. A Treatise on Modern Instrumentation and Orchestration. London: Novello, Ewer \& Co.

Berman, Marshall. 1982. All That Is Solid Melts into Air: The Experience of Modernity. New York: Penguin.

Beuick, Marshall. 1927. "The Limited Social Effect of Radio Broadcasting." American Journal of Sociology 32(4): 615-622.

Beyer, Robert. 1999. Sounds of Our Times: Two Hundred Years of Acoustics. New York: AIP Press.

Bickerdike, John, and Anne Gregory. 1980. "Disco Noise." Public Address 23(8): 11-12.

Bijker, Weibe. 1995. Of Bicycles, Bakelites, and Bulbs: Toward a Theory of Sociotechnical Change. Cambridge: MIT Press.

Bijsterveld, Karin. 2003. "The City of Din: Decibels, Noise and Neighbors in the Netherlands, 1910-1980." Osiris 18: 173-193.

Bijsterveld, Karin. 2008. Mechanical Sound: Technology, Culture, and Public Problems of Noise in the Twentieth Century. Cambridge: MIT Press.

Bijsterveld, Karin. 2010. “Acoustic Cocooning: How the Car Became a Place to Unwind." Senses and Society 5(2): 189-211.

Bijsterveld, Karin, and Peter Peters. 2010. "Composing Claims on Musical Instrument Development: A Science and Technology Studies Contribution." Interdisciplinary Science Reviews 35(2): 106-121.

Biocca, Frank. 1988. "The Pursuit of Sound: Radio, Perception and Utopia in the Early Twentieth Century." Media, Culture and Society 10: 61-79.

Biocca, Frank. 1990. "Media and Perceptual Shifts: Early Radio and the Clash of Musical Cultures." Journal of Popular Culture 24(2): 1-15. 
Birdsall, Carolyn. 2007. "Affirmative Resonances in the City? Sound, Imagination and Urban Space in Early 1930s Germany." In Sonic Interventions, ed. Sylvia Mieszkowski et al., 57-86. Amsterdam: Rodopi.

Blaserna, Pietro. 1883. The Theory of Sound in Its Relation to Music. London: Kegan Paul, Trench \& Co.

Blesser, Barry. 2007. "The Seductive (Yet Destructive) Appeal of Loud Music." eContact 9(4): online.

Blesser, Barry, and Linda-Ruth Salter. 2008. "The Unexamined Rewards for Excessive Loudness." Presented at 9th International Commission on Biological Effects of Noise, Foxwoods, Connecticut.

Boehlert, Eric. 1994. "Put Another Nickel In." In Billboard 100th Anniversary Issue, 1894-1994 (01 November): 93-98.

Boehm, W. 1910. "A Method of Measuring Intensity of Sound." Physical Review 31(4): 329-331.

Boltasnki, Luc, and Eve Chiapello. 2005. The New Spirit of Capitalism. New York: Verso.

Boosey, William. 1928. "Mechanical Music." The Performing Right Gazette 2(12): 305-306.

Boring, Edwin. 1921. "The Stimulus-Error." American Journal of Psychology 32(4): 449-471.

Boring, Edwin. 1926. "Auditory Theory with Special Reference to Intensity, Volume, and Localization." American Journal of Psychology 37(2): 157-188.

Boring, Edwin. 1938. "Perspective." In Stanley Stevens and Hallowell Davis, Hearing: Its Psychology and Physiology. New York: Wiley \& Sons.

Boring, Edwin. 1942. Sensation and Perception in the History of Experimental Psychology. New York: Appleton-Century-Crofts.

Boring, Edwin. 1966. "Editor's Introduction: Gustav Theodor Fechner, 1801-1887." In Gustav Fechner, Elements of Psychophysics. New York: Holt, Rinehard \& Winston. 
Born, Georgina. 2005. "On Musical Mediation: Ontology, Technology and Creativity." Twentieth-Century Music 2(1): 7-36.

Born, Georgina. 2010A. "The Social and the Aesthetic: For a Post-Bourdieuian Theory of Cultural Production." Cultural Sociology 4(2): 171-208.

Born, Georgina. 2010B. "Listening, Mediation, Event: Anthropological and Sociological Perspectives." Journal of the Royal Musical Association 135(1): 79-89.

Born, Georgina. 2012. "Music and the Social." In The Cultural Study of Music: A Critical Introduction, 2nd ed., ed Martin Clayton et al., 261-174. London: Routledge.

Botstein, Leon. 1998. "Toward a History of Listening." Musical Quarterly 82(3-4): 427-431.

Bourdieu, Pierre. 1993. The Field of Cultural Production. New York: Columbia University Press.

Bowers, Q. David. 1972. Encyclopedia of Automatic Musical Instruments. New York: Vestal.

Bragg, William. 1925. "The Mocking Voice of Nature: Echoes That Help Us to Hear." Radio Times 6.69 (16 January): 169.

Brennan, Matthew. 2007. Downbeats and Rolling Stones: An Historical Comparison of American Jazz and Rock Journalism. University of Stirling: PhD thesis.

Brigs, G.A. 1948. Loudspeakers: The Why and How of Good Amplification. Bradford: Wharfedale Wireless Works.

Broer, Lawrence, and John Walther, eds. 1990. Dancing Fools and Weary Blues: The Great Escape of the Twenties. Bowling Green: Bowling Green State University Popular Press.

Brooks, Arthur. 1928. "Round the Recording Studios." The Gramophone 5(12): 487-490.

Bruce, Bruce-Porter. 1925. "Health and Headphones." Radio Times 8(97): 233-234.

Buck, Percy. 1918. Acoustics for Musicians. Oxford: Clarendon.

Bull, Michael. 2000. Sounding out the City: Personal Stereos and the Management of 
Everyday Life. Oxford: Berg.

Bull, Michael. 2004. "Thinking about Sound, Proximity and Distance in Western Experience." In Hearing Cultures, ed. Veit Erlmann, 173-190. Oxford: Berg.

Bull, Michael. 2007. Sound Moves: iPod Culture and Urban Experience. New York: Routledge.

Burke, Peter. 1986. "Strengths and Weaknesses in the History of Mentalities." In History of European Ideas 7: 439-451.

Burnett, Charles, Michael Fend and Penelope Gouk, eds. 1991. The Second Sense:

Studies in Hearing and Musical Judgement from Antiquity to the Seventeenth Century.

London: The Warburg Institute.

Burstyn, Shai. 1997. "In Quest of the Period Ear." Early Music 25(4): 692-701.

Butler, David. 1973. An Historical Investigation and Bibliography of Nineteenth Century Music Psychology Literature. Ohio State University: PhD thesis.

Butsch, Richard. 1998. "Crystal Sets and Scarf-Pin Radios: Gender, Technology and the Construction of American Radio Listening in the 1920s." Media, Culture and Society 20: $557-572$.

Butsch, Richard. 2000. The Making of American Audiences: From Stage to Television, 1750-1990. Cambridge: Cambridge University Press.

Butsch, Richard. 2008. The Citizen Audience: Crowds, Publics and Individuals. New York: Routledge.

Calabria, Frank. 1993. Dance of the Sleepwalkers: The Dance Marathon Fad. Bowling Green: Bowling Green State University Popular Press.

Calhoun, Craig, and Richard Sennett. 2007. "Introduction." In Practicing Culture, ed. Craig Calhoun and Richard Sennett, 1-12. New York: Routledge.

Cameron, James. 1936. Sound Equipment, Motion Picture Projection, Public Address Equipment. Woodmont: Cameron Publishing.

Campbell, G. 1910. "Telephonic Intelligibility." The London, Edinburgh and Dublin Philosophical Magazine 19, series 6: 152-159. 
Canales, Jimena. 2009. A Tenth of a Second: A History. Chicago: University of Chicago Press.

Carnegie, A. 1934. "The Parsons Auxetophone." In Scientific Papers and Addresses of the Hon. Sir Charles A. Parsons, 241-245. Cambridge: The University Press.

Carroll, Michael. 2000. "The Disembodied Voice." In Popular Modernity in America: Experience, Technology, Mythohistory. Albany: State University of New York Press.

Carty, J. 1922. "The telephone's development." Bell Telephone Quarterly 1(1): 23-37.

Casson, Herbert. 1910. The History of the Telephone. Chicago: A.C. McClurg.

Chambers, Frank. 1939. "How to Build a 'Junkbox' Electric Guitar." Radio-Craft 11(5): 271, 308-309.

Chepesiuk, Ron. 2005. "Decibel Hell." Environmental Health Perspectives 113(1): A34A41.

Chesterton, G.K. 1925. "Making Listeners Jump!” Radio Times 6(74): 385-386.

Chion, Michel. 1994. Audio-Vision: Sound on Screen. New York: Columbia University Press.

Chow, Ray, and James Steintrager. 2011. "In Pursuit of the Object of Sound." differences 22(2-3): 1-9.

Christian, Charlie. 2005. "Guitarmen, Wake Up and Pluck: Wire for Sound; Let 'Em Hear You Play." Down Beat 72(1): 94.

Chua, Daniel. 2011. "Listening to the Self: The Shawshank Redemption and the Technology of Music." 19th-Century Music 34(3): 341-355.

Churcher, B. 1935. "A Loudness Scale for Industrial Noise Measurements." Journal of the Acoustical Society of America 6(4): 216-226.

Cipolla, Carlo. 2003. Clocks and Culture, 1300-1700. New York: W.W. Norton.

Clark, Terry. 1969. "Introduction." In On Communication and Social Influence, Gabriel Tarde. Chicago: University of Chicago Press. 
Clarke, Eric. 2005. Ways of Listening: An Ecological Approach to the Perception of Musical Meaning. Oxford: Oxford University Press.

Clarke, Eric. 2007. "The Impact of Recording on Listening." Twentieth-Century Music 4 (1): 47-70.

Cockayne, Emily. 2007. Hubbub: Filth, Noise and Stench in England. New Haven: Yale University Press.

Coelho, Victor, ed. 2003. The Cambridge Companion to the Guitar. Cambridge: Cambridge University Press.

Cohen, H. Floris. 1984. Quantifying Music: The Science of Music at the First Stage of the Scientific Revolution, 1580-1650. Dordrecht: D. Reidel.

Cohen, Robert, and Marx Wartofsky, eds. 1977. Herman von Helmholtz: Epistemological Writings. Dordrecht: D. Reidel.

Columbia. 1897. The Graphophone. Indianapolis: Spear \& Co.

“Company Profile: Vitavox Limited." 1976. Public Address 19(1): 16-17.

Connor, Steven. 1997. "The Modern Auditory I." In Rewriting the Self: Histories from the Renaissance to the Present, ed. Roy Porter, 203-223. London: Routledge.

Coodley, Lauren. 2007. Napa: The Transformation of an American Town. San Francisco: Arcadia.

Corbin, Alain. 1998. Village Bells: Sound and Meaning in the Nineteenth-Century French Countryside. New York: Columbia University Press.

Corbin, Alain. 2005. "Charting the Cultural History of the Senses." In Empire of the Senses: The Sensual Culture Reader, ed. David Howes, 128-139. Oxford: Berg.

“Court Approves Measure." 1948. New York Times (02 October): 30.

"Court to Install Loud Speaker to Stop Strain on Jurors' Ears." 1926. New York Times (13 March): 19.

Court, Stephen. 1984. "Live Sound Evolution." Studio Sound 26(6): 72-73. 
Courtney, Lawrence. 1934. "Music is Back in the Home Again." Popular Music and Dancing Weekly 1.12 (29 December): inside cover.

Cowan, Ruth Schwartz. 1976. "The 'Industrial Revolution' in the Home: Household Technology and Social Change in the 20th Century." Technology and Culture 17(1): 1-23.

Cox, Christoph, and Daniel Warner, eds. 2004. Audio Culture: Readings in Modern Music. New York: Continuum.

Curtis, Bruce. 2008. "I Can Tell By the Way You Smell: Dietetics, Smell, Social Theory." Senses and Society 3(1): 5-22.

Crary, Jonathan. 1990. Techniques of the Observer: On Vision and Modernity in the Nineteenth Century. Cambridge: MIT Press.

Crary, Jonathan. 1999. Suspensions of Perception: Attention, Spectacle and Modern Culture. Cambridge: MIT Press.

Dahlhaus, Carl. 1983. Foundations of Music History. Cambridge: Cambridge University Press.

"Dancing to Wireless: A Possibility of the Future." 1922. Radio Times 1(9): 315.

"Daniels to Speak by Radio Today." 1920. New York Times (01 May): 1, 6.

Darr, Jack. 1965. Electric Guitar Amplifier Handbook. Indianapolis: Howard W. Sams.

Daston, Lorraine. 1982. "The Theory of Will versus the Science of Mind." In The Problematic Science: Psychology in Nineteenth-Century Thought, ed. William Woodward and Mitchell Ash, 88-115. New York: Praeger.

Daston, Lorraine. 1992. "Objectivity and the Escape from Perspective." Social Studies of Science 22: 597-618.

Daston, Lorraine, and Peter Galison. 1992. "The Image of Objectivity." Representations 40: 81-128.

Daston, Lorraine, and Peter Galison. 2010. Objectivity. New York: Zone Books.

Davis, A., and G. Kaye. 1932. The Acoustics of Buildings. London: G. Bell \& Sons. 
Davis, Hallowell. 1977. "Psychological and Physiological Acoustics: 1920-1942." Journal of the Acoustical Society of America 6(2): 264-266.

Davison, Al. 1929. ““Al' Replies.” Melody Maker 4(44): 737-738.

Dawe, Kevin. 2010. The New Guitarscape in Critical Theory, Cultural Practice and Performance. Farnham: Ashgate.

De La Fuente, Eduardo. 2007. "The New Sociology of Art: Putting Art Back Into Social Science Approaches to the Arts." Cultural Sociology 1(3): 409-425.

Deleuze, Gilles, and Felix Guattari. 1987. A Thousand Plateaus: Capitalism and Schizophrenia. Minneapolis: University of Minnesota Press.

Demuth, Norman. 1947. An Anthology of Musical Criticism. London: Eyre \& Spottiswoode.

DeNora, Tia. 1995. Beethoven and the Construction of Genius: Musical Politics in Vienna, 1792-1803. Berkeley: University of California Press.

DeNora, Tia. 2000. Music in Everyday Life. Cambridge: Cambridge University Press.

DeNora, Tia. 2001. "Aesthetic Agency and Musical Practice: New Directions in the Sociology of Music and Emotion." In Music and Emotion: Theory and Research, ed. Patrick Juslin and John Sloboda, 161-180. Oxford: Oxford University Press.

DeNora, Tia. 2003. After Adorno: Rethinking Music Sociology. Cambridge: Cambridge University Press.

DeNora, Tia. 2004A. "Historical Perspectives in Music Sociology." Poetics 32(3-4): 211-221.

DeNora, Tia. 2004B. "Musical Practice and Social Structure: A Toolkit." In Empirical Musicology: Aims, Methods, Prospects, ed. Eric Clarke and Nicholas Cook, 35-56. Oxford: Oxford University Press.

Descartes, Rene. 1653. Compendium of Musick. London: Thomas Harper.

"Development of Sound Equipment." 1938. Radio-Craft 9(9): 568-570, 608-609. 
Devine, Kyle. 2013A. "Imperfect Sound Forever: Loudness Wars, Listening Formations, and the History of Sound Reproduction." Popular Music 32(2).

Devine, Kyle. 2013B. "Electronic Instruments." In The Grove Dictionary of American Music, 2nd ed. New York: Oxford University Press.

Devine, Kyle. 2013C. "Sound Studies." In The Grove Dictionary of American Music, 2nd ed. New York: Oxford University Press.

Dibben, Nicola. 2001. "What Do We Hear, When We Hear Music? Musical Perception and Musical Material." Musucae Scientiae 5(2): 161-194.

Dibben, Nicola. 2003. "Musical Materials, Perception, and Listening." In The Cultural Study of Music: A Critical Introduction, ed. Martin Clayton et al., 195-203. London: Routledge.

Dolan, Daniel. 2008. "Cultural Noise: Amplified Sound, Freedom of Expression, and Privacy Rights in Japan." International Journal of Communication 2: 662-690.

Dooley, M. Norman. 1932. "Public Address in a Boxing Club." Projection Engineering 4 (6): 14.

Donahue, Mark. n.d. "The Loudness War." Performer Magazine: online.

Dostrovsky, Sigalia. 1969. The Origins of Vibration Theory: The Scientific Revolution and the Nature of Music. Princeton University: PhD thesis.

Dostrovsky, Sigalia. 1975. "Early Vibration Theory: Physics and Music in the Seventeenth Century." Archive for History of Exact Sciences 14(3): 169-218.

Douglas, Alan. 1989. "Magnavox." In Radio Manufacturers of the 1920s, vol. 2. Vestal: Vestal Press.

Douglas, Susan. 1987. Inventing American Broadcasting, 1899-1922. Baltimore: Johns Hopkins University Press.

Douglas, Susan. 2004. Listening In: Radio and American Imagination. Minneapolis: University of Minnesota Press.

Downes, Kieran. 2010. "Perfect Sound Forever: Innovation, Aesthetics and the Remaking of Compact Disc Playback." Technology and Culture 51(2): 305-331. 
Doyle, Peter. 2005. Echo and Reverb: Fabricating Space in Popular Music Recording, 1900-1960. Middletown: Wesleyan University Press.

Dreher, Carl. 1930. "Sound Personnel and Organization." Projection Engineering 2(5): 12-15.

Duncan, Ben. 1996. "Live Sound." In Rock Hardware: 40 Years of Rock Instrumentation, ed. Paul Trynka, 78-87. London: Balafon.

Duncan, David. 1981. The Tyranny of Opinions Undermined: Science, Pseudo-Science and Scepticism in the Scientific Thought of Merin Mersenne. Vanderbilt University: PhD thesis.

Dunne, J. 1928. "Volume and Quality." The Gramophone 5(10): 441.

Dyer, Frank, and Thomas Martin. 1929. Edison, His Life and Inventions. New York: Harper Brothers.

Eagleton, Terry. 1984. The Function of Criticism. London: Verso.

Eaton's Radio. 1926-1927. Winnipeg: T. Eaton Co.

Eccles, W., et al. 1923-1924. "Discussion on Loudspeakers." Proceedings of the Physical Society of London 36(2): 211-240.

Eccles, W. "The New Acoustics." 1929. Proceedings of the Physical Society 41(229): 231-239.

Eckersley, P. 1925. "Where 'The Noises' Are Made: Secrets of the Broadcasting Studio." Radio Times 6(70): 217.

Edison Company. 1905. "Wonderful Edison Offer." Popular Mechanics 7(11): 1188.

Edison, Thomas. 1878. "Improvement in Speaking-Machines." US Patent 201,760. 4 March.

"Editorial." 1928. The Performing Right Gazette 3(2): 352.

Ehrlich, Cyril. 1989. Harmonious Alliance: History of the Performing Rights Society. Oxford: Oxford University Press. 
Eisenberg, Evan. 1987. The Recording Angel: Explorations in Phonography. New York: McGraw-Hill.

Eisenstadt, Shmuel. 1999. "Multiple Modernities." Canadian Journal of Sociology 24(2): 283-295.

"Electrical Reproducers." 1928. The Gramophone 5(11): 475-476.

Elias, Norbert. 1994. The Civilizing Process. Oxford: Blackwell.

Elston, Albert. 1939. On Musical Dynamics. Harvard University: $\mathrm{PhD}$ thesis.

Engh, Barbara. 1999. “After 'His Master's Voice.”” New Formations 38: 55-63.

Erlmann, Veit. 2010. Reason and Resonance: $A$ History of Modern Aurality. New York: Zone Books.

Erlmann. Veit. 2011. “Descartes's Resonant Subject.” differences 22(2-3): 10-30.

"Europe's Wiring-Up." 1931. The Musicians'Journal 9: 5.

Evans, Edwin. 1928. "Robot Music." The Dominant 1(4): 9-10.

Everest, F.Alton, and Ken Pohlmann. 2009. Master Handbook of Acoustics, Fifth Edition. New York: McGraw-Hill.

Everett-Green, Robert. 2011. "This Bud's Not For Them!" Globe and Mail (06 August): R6.

Fagen, M., ed. 1975. A History of Engineering and Science in the Bell System: The Early Years (1875-1925). New York: Bell Telephone Laboratories.

"Fans Say Rock Music Too Loud." 2008. Rolling Stone 1068/1069: 32.

"Father Knickerbocker Warns Loud-Speakers to be Quiet." 1930. New York Times (13 April): 137.

Faulkner, Christopher. 1994. "René Clair, Marcel Pagnol and the Social Dimension of Speech." Screen 35(2): 157-170. 
Feaster, Patrick. 2007. The Following Record: Making Sense of Phonographic Performance, 1877-1908. Indiana University: $\mathrm{PhD}$ thesis.

Feather, Leonard. 1957. The Book of Jazz: From Then Till Now. New York: Dell.

Finnegan, Ruth. 2003. "Music, Experience and the Anthropology of Emotion." In The Cultural Study of Music: A Critical Introduction, ed. Martin Clayton et al., 181-192. London: Routledge.

Fitzgerald, William. 2010. "Listening, Ancient and Modern." Journal of the Royal Musical Association 135(1): 25-37.

Fletcher, Harvey. 1923. "Physical Measurements of Audition and their Bearing on the Theory of Hearing." Journal of the Franklin Institute 196(3): 289-326.

Fletcher, Harvey. 1929. Speech and Hearing. New York: Van Nostrand.

Fletcher, Harvey. 1933. "An Acoustic Illusion Telephonically Achieved." Bell Laboratories Record 11(10): 286-289.

Fletcher, Harvey. 1934. "Auditory Perspective - Basic Requirements." Transactions of the American Institute of Electrical Engineers 53(1): 9-11.

Fletcher, Harvey. 1935. "New Concepts of the Pitch, the Loudness and the Timbres of Musical Tones." Journal of the Franklin Institute 220(4): 405-429.

Fletcher, Harvey. 1953. Speech and Hearing in Communication. Princeton: Van Nostrand.

Fletcher, Harvey, and W.A. Munson. 1933. "Loudness, Its Definition, Measurement and Calculation." Journal of the Acoustical Society of America 5: 82-108.

Fliegler, Ritchie. 1993. Amps! The Other Half of Rock 'n' Roll. Milwaukee: Hal Leonard. “Foreign Waves Dim Fleet's Message.” 1920. New York Times (02 May): 14.

Ford, Kendall. 1939. “A Home-Made String-Music Pickup.” Radio-Craft 11(2): 601.

Foucault, Michel. 1970. The Order of Things: An Archaeology of the Human Sciences. New York: Vintage. 
Foucault, Michel. 1972. The Archaeology of Knowledge. London: Tavistock.

Foucault, Michel. 1977. "History of Systems of Thought." In Language, CounterMemory, Practice. Ithaca: Cornell University Press.

Foucault, Michel. 2006. History of Madness. New York: Routledge.

Friedner, Michele and Stefan Helmreich. 2012. "Sound Studies meets Deaf Studies." Senses and Society 7(1): 72-86.

Frith, Simon. 1976. Education, Industrialisation and Social Change: the Development of Elementary Schooling in Nineteenth-Century Leeds, a Case Study in Historical Sociology. University of California, Berkeley: $\mathrm{PhD}$ thesis.

Frith, Simon. 1986. "Art versus Technology: The Strange Case of Popular Music." Media, Culture and Society 8: 263-279.

Frith, Simon. 1988A. "The Industrialization of Music." In Music for Pleasure: Essays in the Sociology of Pop. New York: Routledge.

Frith, Simon. 1988B. "The Pleasures of the Hearth: The Making of BBC Light Entertainment." In Music for Pleasure: Essays in the Sociology of Pop. New York: Routledge.

Frith, Simon. 1996. Performing Rites: On the Value of Popular Music. Cambridge: Harvard University Press.

Frith, Simon. 2002A. "Look! Hear! The Uneasy Relationship of Music and Television." Popular Music 21(3): 277-290.

Frith, Simon. 2002B. "Music and Everyday Life." Critical Quarterly 44(1): 35-48.

Frith, Simon. 2007. "Live Music Matters." Scottish Music Review 1(1): 17pp.

Frith, Simon, et al. 2010. "Analyzing Live Music in the UK: Findings One Year into a Three-Year Research Project." Journal of the International Association for the Study of Popular Music 1(1): 30pp.

Frow, George, with Robert Baumbach. 2001. The Edison Disc Phonographs and the Diamond Discs. Los Angeles: Mulholland Press. 
Fryer, Bertram. 1935. "Secrets of the 'Mike."' Popular Music and Dancing Weekly 1(14): 14.

Garner, Samuel. 1878. The Telephone: Its History, Construction, Principles, and Uses. London: Simpton, Marshal \& Co.

G.-E.-Pfro. 1934. “Amplifiers get Popular." Melody Maker 10(58): 4.

Gelatt, Roland. 1977. The Fabulous Phonograph, 1877-1977. New York: Macmillan.

Gilbert, Jeremy. 2004. "Signifying Nothing: Culture, Discourse and the Sociality of Affect." Culture Machine 6: 12pp.

Gillies, Thomas Garnet. 2005. The How and Why of Guitar Tube Amps as "Gar" Sees It. Winnipeg: Garnet Amplifier Company.

Ginn, Joe. 1996. The Magnificent Music Machine. Cimplesham: Joe Ginn.

Gitelman, Lisa. 2000. Scripts, Grooves and Writing Machines: Representing Technology in the Edison Era. Chicago: University of Chicago Press.

Gleason, Edgar. 1915. "Magnavox Tested at the Park: Wonderful Invention by Californians Solves Many Problems." San Francisco Bulletin (11 December): n.p.

Glover, Ralph. 1931. "Sound Systems in Public Schools." Projection Engineering 3(8): 19-20.

Goodman, David. 2010. "Distracted Listening: On Not Making Sound Choices in the 1930s." In Sound in the Age of Mechanical Reproduction, ed. David Suisman and Susan Strasser, 15-46. Philadelphia: University of Pennsylvania Press.

Goodman, Steve. 2010. Sonic Warfare: Sound, Affect and the Ecology of Fear. Cambridge: MIT Press.

Gonzol, David. 1995. Otto Rudolph Ortmann's Theories of Musical Experience and Their Implications for Music Education. University of Maryland: $\mathrm{PhD}$ thesis.

Gonzol, David. 2004. "Otto Rudolph Ortmann, Music Philosophy and Music Education." Philosophy of Music Education Review 12(2): 160-180. 
Gouk, Penelope. 2007. "In Search of Sound: Authenticity, Healing and Redemption in the Early Modern State." Senses and Society 2(3): 303-328.

Gozza, Paulo. 2000A. "Introduction." In Number to Sound: The Musical Way to the Scientific Revolution, ed. Paulo Gozza, 1-63. Dordrecht: Kluwer.

Gozza, Paulo. 2000B. "A Renaissance Mathematics: The Music of Descartes." In Number to Sound: The Musical Way to the Scientific Revolution, ed. Paulo Gozza, 155-172.

Dordrecht: Kluwer.

Grace, Sergius. 1923. “The Bell Public Address System." Bell Telephone Quarterly 2(2): 169-172.

Graham, Stephen. 1924. "Learning to Listen." Radio Times 4(48): 353-354.

"Great Strides Made in the Communications Art." 1922. Wall Street Journal (01 May): 11.

Green, Burdette, and David Butler. 2002. "From Acoustics to Tonpsychologie." In The Cambridge History of Western Music Theory, ed. Thomas Christensen, 246-271. Cambridge: Cambridge University Press.

Green, I., and J. Maxfield. 1923. "Public Address Systems." Transactions of the AIEE 42 (February): 64-75.

Green, I., and J. Maxfield. 1923. "Public Address Systems." The Bell System Technical Journal 2(2): 113-142.

Gruen, John. 1966. The New Bohemia: The Combine Generation. New York: Shorecrest.

Guberman, Daniel. 2011. "Post-Fidelity: A New Age of Music Consumption and Technological Innovation." Journal of Popular Music Studies 23(4): 431-454.

Gunning, Tom. 1989. "An Aesthetic of Astonishment: Early Film and the (In)credulous Spectator." Art \& Text 34: 31-45.

Gunning, Tom. 2006. "Modernity and Cinema: A Culture of Shocks and Flows." In Cinema and Modernity, ed. Murray Pomerance, 297-315. Piscataway: Rutgers University Press. 
Habermas, Jurgen. 1991. The Structural Transformation of the Public Sphere.

Cambridge: MIT Press.

Hacking, Ian. 1999. The Social Construction of What? Cambridge: Harvard University Press.

Haraway, Donna. 1991. Simians, Cyborgs and Women: The Reinvention of Nature. London: Free Association Books.

"Harding Amplifier Fills Three Rooms." 1921. New York Times (01 May): 37.

Harlow, Alvin. 1936. Old Wires and New Waves: The History of the Telegraph, Telephone, and Wireless. New York and London: Appleton Century.

Harman, Graham. 2002. Tool-Being. Peru: Open Court Publishing.

Harvey, David. 1989. The Condition of Postmodernity: An Enquiry into the Origins of Cultural Change. Oxford: Blackwell.

"Hatfield House Claims to have had the First Intercom." 1974. Public Address 17(9): 15.

"Having a 'Mike'." 1930. Melody Maker 5(49): 45.

Hazzard-Gordon, Katrina. 1990. Jookin': The Rise of Social Dance Formations in African-American Culture. Philadelphia: Temple University Press.

Hegarty, Paul. 2007. Noise/Music: A History. New York: Continuum.

Heidelberger, Michael. 1994. "Force, Law and Experiment: The Evolution of Helmholtz's Philosophy of Science." In Herman von Helmholtz and the Foundations of Nineteenth-Century Science, ed. David Cahan, 461-497. Berkeley: University of California Press.

Helmholtz, Herman von. 1954. On the Sensations of Tone, $2 \mathrm{~d}$ ed. New York: Dover.

Helmholtz, Herman von. 1977. "The Facts in Perception." In Herman von Helmholtz: Epistemological Writings, ed. Robert Cohen and Marx Wartofsky, 115-185. Dordrecht: D. Reidel. 
Helmreich, Stefan. 2007. "An Anthropologist Underwater: Immersive Soundscapes, Submarine Cyborgs and Transductive Ethnography." American Ethnologist 34(4): $621-641$.

Hennion, Antoine. 1995. "The History of Art - Lessons in Mediation." Réseaux 3(2): 233-262.

Hennion, Antoine. 2003. "Music and Mediation: Towards a new Sociology of Music." In The Cultural Study of Music: A Critical Introduction, ed. Martin Clayton et al., 80-91. London: Routledge.

Hennion, Antoine. 2007. "Those Things That Hold Us Together: Taste and Sociology." Cultural Sociology 1(1): 97-114.

Hennion, Antoine, and Joël-Marie Fauquet. 2001. "Authority as Performance: The Love of Bach in Nineteenth-Century France." Poetics 29(2): 75-88.

Hennion, Antoine, and Line Grenier. 2000. "Sociology of Art: New Stakes in a PostCritical Time." In The International Handbook of Sociology, ed. Stella Quah and Arnaud Sales, 341-355. London: Sage.

Henriques, Julian. 2011. Sonic Bodies: Reggae Sound Systems, Performance Techniques and Ways of Knowing. New York: Continuum.

Herbert, Richard. 1925. "Dance Notes." The Gramophone 2(12): 495-497.

Hiatt, Brian. 2008. "Fans Complain Metallica Disc is Too Loud." Rolling Stone 1063: 11.

Hill, S. 1942. "Public Address Systems." Transactions of the AIEE 89(17): 232-233.

Hope, Adrian. 1975. "Does Loud Music Make You Deaf?" Public Address 18(9): 9-11.

"House Asked to Remove Loud-Speaking Apparatus." 1924. Washington Post (20 May): 1.

Howes, David. 2003. Sensual Relations: Engaging the Senses in Social and Cultural Theory. Ann Arbor: University of Michigan Press.

Hubble, Nick. 2006. Mass-Observation and Everyday Life: Culture, History, Theory. New York: Macmillan. 
Hui, Alexandra. 2008. Hearing Sound as Music: Psychophysical Studies of Sound Sensation and the Musical Culture of Germany, 1860-1910. UCLA: PhD thesis.

Hullot-Kentor, Robert. 2009. "Editor's Introduction." In Current of Music, Theodor Adorno. Cambridge: Polity.

Hunt, Frederick. 1954. Electroacoustics. Cambridge: Harvard University Press.

Hunt, Frederick. 1978. Origins in Acoustics: The Science of Sound from Antiquity to the Age of Newton. New Haven \& London: Yale University Press.

Hustwitt, Mark. 1983. "The Production of Dance Music in Britain in the 1920s." Popular Music 3: 7-31.

"If President Harding Spoke to 120,000,000 People." 1922. Science and Invention (February): 909, 959.

"Important Contributions to the Field of Amplification." 1936. Down Beat (April): 5.

Israel, Paul, et al., eds. 1998. The Papers of Thomas A. Edison: The Wizard of Menlo Park, 1878. Vol. 4. Baltimore: Johns Hopkins University Press.

Jackson, Myles. 2006. Harmonious Triads: Physicists, Musicians, and Instrument Makers in Nineteenth-Century Germany. Cambridge: MIT Press.

James, Francis. 1998. The EMG Story. Abertillery: Old Bakehouse Publications.

Jasen, Paul. 2009. "Bass Cultures and the Sensory Construction of the Audio-Social." Presented at IASPM Canada Annual Conference, Dalhousie University.

Jasen, Paul. 2011. "Numinous Strategies: Resonating with Divinity." Presented at American Anthropological Association 110th Annual Meeting, Concordia University.

Jasen, Paul. 2012 (forthcoming). Bass: A Myth-Science of the Sonic Body. Carleton University: PhD thesis.

Jastrow, Joseph. 1895. "An Apparatus for the Study of Sound Intensities." Science 3(67): 544-546.

Jay, Martin. 1993. Downcast Eyes: The Denigration of Vision in Twentieth-Century French Thought. Berkeley: University of California Press. 
Jehl, Francis. 1937. Menlo Park Reminiscences. Vol. 1. Dearborn: Edison Institute.

Jensen, Peter. 1975. The Great Voice. Richardson: Havilah Press.

Jewett, Frank. 1933. "Perfect Transmission and Reproduction of Symphonic Music in Auditory Perspective." Bell Telephone Quarterly 12(2): 156-159.

Jewett, Frank. 1940. "Demonstration of Stereophonic Recordings: Introductory Remarks." Bell Telephone Laboratories Press Release (09 April). AT\&T Archives and History Center.

Johnson, Bruce. 2000. The Inaudible Musicians: Gender, Jazz and Australian Modernity. Strawberry Hills: Currency Press.

Johnson, Bruce. 2008. "Quick and Dirty: Sonic Mediations and Affect." In Sonic Mediations: Body, Sound, Technology, ed. Carolyn Birdsall and Antony Enns, 43-60. Newcastle: Cambridge Scholars Press.

Johnson, Bruce, and Martin Cloonan. 2008. The Dark Side of the Tune: Popular Music and Violence. Aldershot: Ashgate.

Johnson, James. 1995. Listening in Paris: A Cultural History. Berkeley: University of California Press.

Jones, Sarah. 2005. "The Big Squeeze: Mastering Engineers Debate Music's Loudness Wars." Mix Magazine (01 December): online.

Jowett, Garth, et al. 1996. Children and the Movies: Media Influence and the Payne Fund Controversy. Cambridge: Cambridge University Press.

“Judges and Jazz." 1927. Melody Maker 2(3): 205.

Jütte, Robert. 2005. A History of the Senses: From Antiquity to Cyberspace. Cambridge: Polity.

Kahn, Douglas. 1999. Noise, Water, Meat: A History of Sound in the Arts. Cambridge: MIT Press.

Kahn, Douglas, and Gregory Whitehead, eds. 1992. Wireless Imagination: Sound, Radio and the Avant-Garde. Cambridge: MIT Press. 
Kalberg, Stephen. 1980. "Max Weber's Types of Rationality: Cornerstones for the Analysis of Rationalization Processes in History." American Journal of Sociology 85(5): 1145-1179.

Kalberg, Stephen. 2005. "Max Weber: The Confrontation with Modernity." In Max Weber: Readings and Commentary on Modernity, ed. Stephen Kalberg, 1-47. Oxford: Blackwell.

Kassabian, Anahid. 2002. "Ubiquitous Listening." In Popular Music Studies, ed. David Hesmondhalgh and Keith Negus, 131-142. London: Arnold.

Kassler, Jamie. 1979. The Science of Music in Britain, 1714-1830. New York: Garland.

Kaye, G. 1937. "Noise and the Nation." In Report of the Meeting of the British Association for the Advancement of Science. London: Office of the British Association.

Keeling, Kara, and Josh Kun, eds. 2011. "Sound Clash: Listening to American Studies." American Quarterly 63(3): 445-862.

Keightley, Keir. 1996. “'Turn it Down!' She Shrieked: Gender, Domestic Space and High Fidelity, 1948-59." Popular Music 15(2): 149-177.

Kellogg, Edward. 1929. "New Musical Effects Produced by Electrical Means." Projection Engineering 1(1): 41-42.

Kennedy, Victor. 1935. "This is How Dance Band 'Vocalising' Began." Popular Music and Dancing Weekly 1.22 (09 March): iii.

Kenney, William. 1999. Recorded Music and American Life: The Phonograph and Popular Memory, 1890-1945. Oxford: Oxford University Press.

Kern, Stephen. 1983. The Culture of Time and Space, 1880-1918. Cambridge: Harvard University Press.

Kim, Youn. 2003. Theories of Musical Hearing 1863-1931: Helmholtz, Stumpf, Riemann, and Kurth in Historical Context. Columbia University: $\mathrm{PhD}$ thesis.

King, Louis Vessot. 1919. "On the Propagation of Sound in the Free Atmosphere and the Acoustic Efficiency of Fog-Signal Machinery." Philosophical Transactions of the Royal Society 218, series A: 211-293. 
King, Louis Vessot. 1919. "The Development of Modern Acoustics." Transactions of the Royal Society of Canada 8, series 3: 1-5.

Kingsbury, B. 1927. "A Direct Comparison of the Loudness of Pure Tones." Physical Review 29(4): 588-600.

Kingsbury, John. 1915. The Telephone and Telephone Exchanges: Their Invention and Development. London: Longmans, Green \& Co.

Kittler, Friedrich. 1999. Gramophone, Film, Typewriter. Stanford: University of California Press.

Klinger, Barbara. 2006. Beyond the Multiplex: Cinema, New Technologies and the Home. Berkeley: University of California Press.

Knudsen, Vern. 1923. "The Sensitivity of the Ear to Small Differences of Intensity and Frequency." Physical Review 21(1): 84-102.

Knudsen, Vern. 1938. "Some Cultural Applications of Modern Acoustics." Journal of the Acoustical Society of America 9(3): 175-184.

Kolneder, Walter. 1970. Antonio Vivaldi: His Life and Work. Berkeley: University of California Press.

Koopman, Colin. 2010. "Revising Foucault: The History and Critique of Modernity." Philosophy and Social Criticism 36(5): 545-565.

Kostelijk, Pieter Jan. 1950. Theories of Hearing. Leiden: Universitaire Pers Leiden.

Kraft, James. 1996. Stage to Studio: Musicians and the Sound Revolution, 1890-1950. Baltimore: Johns Hopkins University Press.

Kruse, Holly. 1993. "Early Audio Technology and Domestic Space." Stanford Humanities Review 3(2): 1-14.

$\mathrm{Ku}$, Ja Hyon. 2006. "British Acoustics and Its Transformation from the 1860 s to the 1910s." Annals of Science 63(4): 395-423.

Kuhn, Thomas. 1962. The Structure of Scientific Revolutions. Chicago: University of Chicago Press. 
Kursell, Julia. 2008. "Sound Objects." In Sounds of Science - Schall im Labor (1880-1930), ed. Julie Kursell, 29-38. Berlin: Max Planck Institute for the History of Science.

Lacey, Kate. 2000. "Toward a Periodization of Listening: Radio and Modern Life." International Journal of Cultural Studies 3(2): 279-288.

Lambert, Constant. 1934. Music Ho! A Study of Music in Decline. London: Faber \& Faber.

Lane, H. 1922. "'Dam is Breaking!" - Heard Four Miles." Popular Mechanics 37(1): 9-12.

Lanza, Joseph. 1994. Elevator Music. New York: St Martin's Press.

Lash, Scott. 1999. Another Modernity, a Different Rationality. Oxford, Blackwell.

Lastra, James. 2000. Sound Technology and the American Cinema: Perception, Representation and Modernity. New York: Columbia University Press.

Latour, Bruno. 1993. We Have Never Been Modern. Cambridge: Harvard University Press.

Latour, Bruno. 2004. "Why Has Critique Run out of Steam? From Matters of Fact to Matters of Concern." Critical Inquiry 30: 225-248.

Latour, Bruno. 2005. Reassembling the Social: An Introduction to Actor-Network-Theory. Oxford: Oxford University Press.

Lazarsfeld, Paul. 1969. "An Episode in the History of Social Research: A Memoir." In The Intellectual Migration: Europe and America, 1930-1960, ed. Donald Fleming and Bernard Bailyn, 270-337. Cambridge: Belknap Press of Harvard University Press.

Leary, David. 1977. "The Philosophical Development of the Conception of Psychology in German, 1780-1850." Journal of the History of the Behavioral Sciences 14: 113-121.

Leary, David. 1982. "Immanuel Kant and the Development of Modern Psychology." In The Problematic Science: Psychology in Nineteenth-Century Thought, ed. William Woodward and Mitchell Ash, 17-42. New York: Praeger. 
Le Bon, Gustave. 1896. The Crowd: A Study of the Popular Mind. New York: Macmillan.

Lenoir, Timothy. 1997. "The Politics of Vision: Optics, Painting and Ideology in Germany, 1845-95." In Instituting Science: The Cultural Production of Scientific Disciplines, ed. Timothy Lenoir, 131-178. Stanford: Stanford University Press.

Leppert, Richard. 2002. "Culture, Technology and Listening: Commentary." In Essays on Music, Theodor Adorno. Berkeley: University of California Press.

Leppert, Richard. 2004. "The Social Discipline of Listening." In Aural Cultures, ed. Jim Drobnick, 19-35. Toronto: YYZ Books.

Levine, Robert. 2007. "The Death of High Fidelity." Rolling Stone 1042/1043: 15.

Levitin, Daniel. 2007. This is Your Brain on Music: The Science of a Human Obsession. New York: Plume.

Lewis, W. David. 1990. "Peter L. Jensen and the Amplification of Sound." In Technology in America: A History of Individuals and Ideas, ed. Carrol Pursell, 190-210. Cambridge: MIT Press.

“Lily Pons 'Noisier' than a Street Car." 1932. New York Times (28 April): 23.

Lindsay, Bruce. 1966. "The Story of Acoustics." Journal of the Acoustical Society of America 39(4): 629-644.

Lindsay, Bruce, ed. 1978. Acoustics: Historical and Philosophical Development. Stroudsburg: Dowden, Hutchinson \& Ross.

Lipscomb, David. 1969. "Exposure to High Intensity 'Hard Rock' Music." Journal of the Acoustical Society of America 46(1): 80-81.

Lloyd, Llewelyn. 1937. Music and Sound. Oxford: Oxford University Press.

Lloyd, Llewelyn. 1938. Decibels and Phons: A Musical Analogy. Oxford: Oxford University Press.

Loar, Lloyd. 1934. "Musical Instrument." US patent 1,995,316 (27 January). 
Lockheart, Paula. 2003. "An History of Early Microphone Singing, 1925-1939: American Mainstream Popular Singing at the Advent of Electronic Microphone Amplification." Popular Music and Society 26(3): 367-385.

Loesser, Arthur. 1954. Men, Women and Pianos: A Social History. New York: Dover.

Loepnick, Lutz. 2002. The Dark Mirror: German Cinema between Hitler and Hollywood. Berkeley: University of California Press.

Lothinglader. 1931. "Keep It Clean: Dirty Tone is Sheer Atavism." Melody Maker 5(64): 289.

"Loudness Wars: Why Music Sounds Worse, The." 2009. NPR Music (31 December): online.

Loudon, James. 1901. "A Century of Progress in Acoustics." Science 14(365): 987-995.

"Loudspeaker Ban is fought by ALP." 1948. New York Times (17 September): 36.

"Loudspeakers Installed in St Peter's in Rome." 1940. New York Times (24 October): 29.

Lowe, Donald. 1982. History of Bourgeois Perception. Chicago: University of Chicago Press.

Lowenthal, Leo. 1946. "The Crisis of the Individual: Terror's Atomization of Man." Commentary 1: 1-8.

Lüdke, Alf. 1995. "What is the History of Everyday Life and Who are Its Practitioners?" In The History of Everyday Life: Reconstructing Historical Experiences and Ways of Life, ed. Alf Lüdke, 3-40. Princeton: Princeton University Press.

Luff, L. 1928. "Volume." The Gramophone 5(9): 401.

Lydon, Michael. 1974. Boogie Lightning: How Music Became Electric. New York: Dial Press.

Lynch, Vincent, and Bill Henkin. n.d. Jukebox: The Golden Age. Berkeley: LancasterMiller.

M., G. 1925. "Ordeal by Wireless: 'Stage Fright' Before the Microphone.” Radio Times 6 (70): 216. 
M., J. 1930. "Automaton Deputies: Dancing to 'Unreal' Music.” Melody Maker 5(60): 1019.

Madge, Charles. 1939. Britain by Mass-Observation. Harmondsworth: Penguin.

“Magnavox Story." 1965. Public Address Engineers Journal 8(3): 68, 70.

"Making PA Pay the Warren Way." 1963. Public Address 6(1): 8-9.

Malaprop, Mrs. 1924. "What I Think of Loud Speakers." Radio Times 5(65): 580.

Maloof, Rich. 2004. Jim Marshall: The Father of Loud. San Francisco: Backbeat.

Maisonneuve, Sophie. 2009. L'invention du disque, 1877-1949: Genènese de l'usage des médias musicaux contemporains. Paris: Éditions des archives contemporaines.

Marmorstein, Gary. The Label: The Story of Columbia Records. New York: Thunder's Mouth Press, 2007.

Marsh, William Sewall. 1933. "Fretted Instrument Progress for Twenty-Five Years." The Crescendo 25(10): 3.

Marshall, Marilyn. 1982. "Physics, Metaphysics and Fechner's Psychophysics." In The Problematic Science: Psychology in Nineteenth-Century Thought, ed. William Woodward and Mitchell Ash, 65-87. New York: Praeger.

Martin, Linton. 1933. "Themes and Variations." Philadelphia Inquirer (16 April): n.p. AT\&T Archives and History Center.

Martin, Luther, et al., eds. 1988. Technologies of the Self: A Seminar with Michel Foucault. Amherst: University of Massachusetts Press.

Martin, Peter. 1995. Sounds and Society: Themes in the Sociology of Music. Manchester: University of Manchester Press.

Martin, Peter. 2006. Music and the Sociological Gaze: Art Worlds and Cultural Production. Manchester: University of Manchester Press.

Martin, W. 1929. "Decibel - The Name for the Transmission Unit." Bell System Technical Journal 8: 1-2. 
Martin, W., and A. Clark. 1923. "Use of Public Address System with Telephone Lines." Transactions of the AIEE 42 (February): 75-85.

Martin, W., and A. Clark. 1923. "Use of Public Address System with Telephone Lines." The Bell System Technical Journal 2(2): 143-161.

Marvin, Carolyn. 1988. When Old Technologies Were New: Thinking about Electric Communication in the Late Nineteenth Century. New York: Oxford University Press.

Marvin, Elizabeth West. 1987. "Tonpsychologie and Musikpsychologie: Historical Perspectives on the Study of Music Perception." Theoria 2: 59-84.

Marx, Karl. 1956. Selected Writings in Sociology and Social Philosophy. New York: McGraw-Hill.

Marx, Karl. 1968. Economic and Philosophic Manuscripts of 1844. New York: International.

Massumi, Brian. 2002. Parables for the Virtual: Movement, Affect, Sensation. Durham: Duke University Press.

Masterson, Kathryn. 2008. "Loudness War Stirs Quiet Revolution." Chicago Tribune (01 January): online.

Mauro, Philip. 1900. "Recent Development of the Art of Recording and Reproducing Sounds." Journal of the Franklin Institute 150(1): 35-43.

Maxfield, J.P., and C. Harrison. 1926. "Methods of High Quality Recording and Reproducing of Music and Speech Based on Telephone Research." Bell System Technical Journal 5(3): 493-523.

Mayer, Alfred. 1873. "On the Experimental Determination of the Relative Intensities of Sound." American Journal of Science and Arts 5(25): 44-46, 123-126.

Mayer, Alfred. 1879. Sound. London: Macmillan.

"Mayor La Guardia's Plea and Proclamation in War on Noise." 1935. New York Times (01 October): 13. 
McCracken, Allison. 1999. "God's Gift to Us Girls: Crooning, Gender, and the ReCreation of American Popular Song, 1928-1933." American Music 17(4): 365-395.

McGinn, Robert. 1983. "Stokowski and the Bell Telephone Laboratories: Collaboration in the Development of High-Fidelity Sound Reproduction." Technology and Culture 24 (1): 38-75.

McLuhan, Marshall. 1962. The Gutenberg Galaxy: The Making of Typographic Man. Toronto: University of Toronto Press.

McNicol, Donald. 1931. "Editorial." Projection Engineering 3(12): 4.

McSwain, Rebecca. 1995. "The Power of the Electric Guitar." Popular Music and Society 19(4): 21-40.

McSwain, Rebecca. 2002. "The Social Reconstruction of a Reverse Salient in Electrical Guitar Technology: Noise, the Solid Body, and Jimi Hendrix." In Music and Technology in the Twentieth Century, ed. Hans-Joachim Braun, 186-198. Baltimore: Johns Hopkins University Press.

"Mechanism v. Nature." 1928. Melody Maker 3(27): 293, 295.

Michell, Joel. 1999. Measurement in Psychology: Critical History of a Methodological Concept. Cambridge: Cambridge University Press.

“"Miking' Less Work of It." 1929. Melody Maker 4(43): 660.

Millard, André. 2004. "Playing with Power: Technology, Modernity, and the Electric Guitar." In The Electric Guitar: A History of an American Icon, ed. André Millard, 123-141. Baltimore: Johns Hopkins University Press.

Millard, André. 2005. America on Record: A History of Recorded Sound. Cambridge: Cambridge University Press.

Miller, Dayton. 1935. Anecdotal History of the Science of Sound: To the Beginning of the 20th Century. New York: Macmillan.

Miller, Jack. 1936. "Steel Guitar has Place in Modern Orchestra." Down Beat (June): 13.

"Millions to Hear Inaugural Address; Loud Speaker Here." 1925. Washington Post (15 February): B7. 
Mills, Mara. 2008. The Dead Room: Deafness and Communications Engineering. Harvard University: $\mathrm{PhD}$ thesis.

Mills, Mara. 2011. "Deafening: Noise and Communication in the Engineering of the Telephone System." Grey Room 43: 118-143.

Milner, Greg. 2009. Perfecting Sound Forever: An Aural History of Recorded Music. New York: Faber \& Faber.

Mitchell, Gordon. 1931. "Applying Public-Address Equipment for Indoor Use." Projection Engineering 3(8): 7-9.

Mitchell, Gordon. 1932. "Public-Address and Radio Distribution System for Colleges." Projection Engineering 4(3): 11-12.

Mitchell, Ogilvie. 1922 (ca.). The Talking Machine Industry. London: Sir Isaac Pitman \& Sons.

Mitchell, W.J.T. 1986. Iconology: Image, Text, Ideology. Chicago: University of Chicago Press.

Mitchell, W.J.T. 1994. Picture Theory: Essays on Verbal and Visual Representation. Chicago: University of Chicago Press.

"Monitor for Disco Noise Levels." 1980. Public Address 23(3): 15.

Moogk, Edward. 1975. Roll Back the Years: History of Canadian Recorded Sound and Its Legacy, Genesis to 1930. Ottawa: National Library of Canada.

Moreno, Jairo. 2004. Musical Representations, Subjects and Objects: The Construction of Musical Thought in Zarlino, Descartes, Rameau, and Weber. Bloomington: Indiana University Press.

Mowitt, John. 1987. "The Sound of Music in the Era of Its Electronic Reproducibility." In Music and Society, ed. Richard Leppert and Susan McClary, 173-197. Cambridge: Cambridge University Press.

Mueller, John. 1935. "Is Art a Product of Its Age?" Social Forces 13(3): 367-375. 
Muhleman, M. L. 1926. "Loud Speakers and Their Characteristics: A Treatise on ElectroAcoustic Instruments." Radio News 8(6): 642-645, 750-752.

Mulcahy, Bob. 1936. "The True Value of the Electric Guitar." Down Beat (October): 14.

Mullard Valves. 1924. Radio Times 5(59): 319.

Mulvey, Laura. 1975. "Visual Pleasure and Narrative Cinema." Screen 16(3): 6-18.

Nasaw, David. 1993. Going Out: The Rise and Fall of Public Amusements. Cambridge: Harvard University Press.

"Nation May Hear Voice of Harding." 1921. Washington Post (11 December): 69.

National Phonograph Company. 1900. The Phonograph and How to Use It. New York: Allen Koenigsberg.

Negus, Keith. 2006. "Musicians On Television: Visible, Audible and Ignored." Journal of the Royal Musical Association 131(2): 310-330.

"New Device to Enable 150,000 to Hear Cox." 1920. New York Times (27 August): 11.

“New York to Hear Harding Oration." 1921. New York Times (06 November): 25.

“New York's Noisiest Place?” 1928. Wall Street Journal (21 June): 2.

"Noise of Electrons Heard by Human Ears." 1924. Science News-Letter 5(191): 5-6.

Noonan, Jeffrey. 2008. The Guitar in America: Victorian Era to Jazz Age. Jackson: University Press of Mississippi.

Nott, James. 2002. Music for the People: Popular Music and Dance in Interwar Britain. Oxford: Oxford University Press.

Nye, David. 1992. Electrifying America: Social Meanings of a New Technology, 1880-1940. Cambridge: MIT Press.

O'Brien, Charles. 2005. Cinema's Conversion to Sound: Technology and Film Style in France and the US. Bloomington: Indiana University Press. 
Ochoa Gautier, Ana Maria. 2006. "Sonic Transculturation, Epistemologies of Purification and the Aural Public Sphere in Latin America." Social Identities 12(6): 803-825.

Ogden, Richard. Hearing. 1924. New York: Harcourt Brace \& Co.

Ong, Walter. 1988. Orality and Literacy: The Technologization of the Word. New York: Routledge.

“Opera to be tested by 'Electric Ear'." 1932. New York Times (27 Apr): 13.

Ord-Hume, Arthur. 1973. Clockwork Music. London: Allen \& Unwin.

Ortega y Gasset, José. 1932. The Revolt of the Masses. New York: W.W. Norton \& Co.

Ortmann, Otto. 1922. "The Sensorial Basis of Music Appreciation." Journal of

Comparative Psychology 2(3): 227-256.

Ortmann, Otto. 1928. "Tonal Intensity as an Aesthetic Determinant." Musical Quarterly 14(2): 178-191.

Oudshoorn Nelly, and Trevor Pinch, eds. 2003. How Users Matter: The Co-Construction of Users and Technology. Cambridge: MIT Press.

"Our Tribute." 1921. Long Lines (December): 26-33.

Osborne, Robin, and Jeremy Tanner. 2007. Art's Agency and Art History. Oxford: Blackwell.

Owens, Arthur. 1928. "The Début of the 'Talkies': What Happened at 'The Jazz Singer."” Melody Maker 3(35): 1277-1278.

Owinsky, Bobby. 2007. The Mastering Engineer's Handbook, 2nd ed. Boston: Thomson Course Technology.

Paine, Gustavus. 1949. "Campaign Loudspeakers Protested." New York Times (03 November): 28.

Palisca, Claude. 2000. "Moving the Affections Through Music: Pre-Cartesian PsychoPhysiological Theories." In Number to Sound: The Musical Way to the Scientific Revolution, ed. Paulo Gozza, 289-308. Dordrecht: Kluwer. 
Palmer, Robert. 1991. "The Church of the Sonic Guitar." South Atlantic Quarterly 90: 650-673.

Pantalony, David. 2009. Altered Sensations: Rudolph Koenig's Acoustical Workshop in Nineteenth-Century Paris. New York: Springer.

Paul, Floyd. 1979. "Horn Speakers." CQ Magazine (December): 67-74.

Paul, Floyd. 1982. "That Wonderful Radio Horn Speaker." California Historical Radio Society Journal 7: 3-5.

Pearce, Frank. 1929. "Misapplied Inventiveness." Melody Maker 4(44): 737.

Pearsall, Ronald. 1976. Popular Music of the Twenties. Totawa: Rowman \& Littlefield.

"Penn Installing Loud Speakers in Stadium So All Spectators Can Follow Every Play." 1926. New York Times (13 April): 21.

Percival, Mark. 2011. "Stone Deaf Forever: Discourses of Live Loudness in Popular Music Journalism." Presented at The Business of Live Music, University of Edinburgh.

Peters, John Durham. 1999. Speaking Into the Air: A History of the Idea of Communication. Chicago: University of Chicago Press.

Peters, John Durham. 2004. "Helmholtz, Edison and Sound History." In Memory Bytes: History, Technology and Digital Culture, ed. Lauren Rabinovitz and Abraham Geil, 177-198. Durham: Duke University Press.

Pickering, Andrew. 1995. The Mangle of Practice: Time, Agency and Science. Chicago: University of Chicago Press.

Pinch, Trevor, and Weibe Bijker. 1987. "The Social Construction of Facts and Artifacts." In The Social Construction of Technological Systems: New Directions in the Sociology and History of Technology, ed. Weibe Bijker, Thomas Hughes and Trevor Pinch, 17-50. Cambridge: MIT Press.

Pinch, Trevor, and Karin Bijsterveld. 2003. "Should One Applaud? Breaches and Boundaries in the Reception of New Technology in Music." Technology and Culture 44 (3): 536-559.

Pinch, Trevor, and Karin Bijsterveld, eds. 2004. "Sound Studies: New Technologies and 
Music." Social Studies of Science 34(5): 635-817.

Pinch, Trevor, and Frank Trocco. 2002. Analog Days: The Invention and Impact of the Moog Synthesizer. Cambridge: MIT Press.

Plambeck, Joseph. 2010. “In Mobile Age, Sound Quality Steps Back.” New York Times (09 May): B1.

Poe, Edgar Alan. 1984. "The Man of the Crowd." In Poetry and Tales. New York: Literary Classics.

Politzer, Adam. 1981. History of Otology. Phoenix: Columella Press.

“Possibilities of Decibels.” 1932. New York Times (29 April): 16.

"Predict Audiences of 50,000,000 Soon." 1921. New York Times (11 December): 31.

"President DuBois Dedicates Hawthorne's Public Address System." 1924. Western Electric News 13(5): 19-24.

Pridham, Edwin. 1918. "Telephone System." US Patent 1,356,403 (07 May).

"Professor's Decibel Knows Its Noises." 1931. Toronto Daily Star (20 March): 9.

"Public Address finds Various Uses." 1931. Projection Engineering 3(12): 17.

Radau, Rodolphe. 1867. L'acoustique; ou les phénomènes du son. Paris: Librairie de L. Hachette.

Radau, Rodolphe. 1870. Wonders in Acoustics; Or, the Phenomena of Sound. Robert Ball, trans. London: Castell Petter \& Galpin.

"Radio in the Park." 1928. Melody Maker 3(28): 425.

"Radio in the Summertime."1924. Radio Times 3(34): 308.

"Radio Megaphone is Large Enough for a Diving Platform." 1922. Popular Mechanics 38(3): 343 .

Radocy, Rudolf, and J. David Boyle. 2003. Psychological Foundations of Musical Behavior. Springfield: Charles C. Thomas. 
Radovac, Lilian. 2011. "The 'War on Noise': Sound and Space in La Guardia's New York." American Quarterly 63(3): 733-760.

Rait, Robert. 1924. "The Return of the Ear." Radio Times 4.47 (15 August): 309-310.

Rayleigh, John. 1882. "On an Instrument Capable of Measuring the Intensity of Aerial Vibrations." Philosophical Magazine 14, 5th series: 186-187.

Rayleigh, John. 1940. The Theory of Sound. London: Macmillan.

RCA. 1929. Radio Enters the Home. Radio Corporation of America.

Read, Oliver, and Walter Welch. 1976. From Tin Foil to Stereo: Evolution of the Phonograph. Indianapolis: Howard W. Sams.

Recht, Maximilian. 1964. "The Decibel as a Musical Unit." Music Educators Journal 50 (4): 102-105.

Reed, Edward. 1997. From Soul to Mind: The Emergence of Psychology from Erasmus Darwin to William James. New Haven: Yale University Press.

Rehding, Alexander. 2003. Hugo Riemann and the Birth of Modern Musical Thought. Cambridge: Cambridge University Press.

Reith, John. 1924. "Listening Without Distraction.” Radio Times 3.35 (23 May): 349-350.

Rice, Chester, and Edward Kellogg. 1925. "Notes on the Development of a New Type of Hornless Loud Speaker." Transactions of the AIEE 44 (April): 461-480.

Rich, Gilbert. 1916. "A Preliminary Study of Tonal Volume." Journal of Experimental Psychology 1(1): 13-22.

Rich, Gilbert. 1919. "A Study of Tonal Attributes." American Journal of Psychology 30 (2): 121-164.

Riley, Matthew. 2004. Musical Listening in the German Enlightenment: Attention, Wonder, and Astonishment. Aldershot: Ashgate.

"Roar of Atoms Heard by Means of Radio." 1924. New York Times (22 November): 2. 
Robinson, D., and R. Dadson. 1956. "A Re-determination of the Equal-Loudness

Relations for Pure Tones." British Journal of Applied Psychology 7: 166-181.

Rogers, Tara. 2010. Synthesizing Sound: Metaphor in Audio-Technical Discourse and Synthesis History. McGill University: $\mathrm{PhD}$ thesis.

Rothenbuhler, Eric, and John Durham Peters. 1997. "Defining Phonography: An Experiment in Theory." The Musical Quarterly 81(2): 242-264.

"Rules of Etiquette Lacking to Guide the Radio Listener." 1928. New York Times (23 September): XX2.

Sabine, Wallace. 1922. "Sense of Loudness." In Collected Papers on Acoustics. Cambridge: Harvard University Press.

Samuels, David, et al. 2010. "Soundscapes: Toward a Sounded Anthropology." Annual Review of Anthropology 39, 329-345.

Sanjek, Russel, and David Sanjek. 1996. Pennies from Heaven: The American Popular Music Business in the Twentieth Century. New York: Da Capo.

Saxberg, Lynn. 2009. "Bluesfest 2009: Bigger, Wetter, Quieter." Ottawa Citizen (20 July): online.

Schafer, R. Murray. 1994. The Soundscape: Our Sonic Environment and the Tuning of the World. Rochester: Destiny.

Schicke, Charles. 1974. Revolution in Sound: A Biography of the Recording Industry. Boston: Little, Brown \& Co.

Schmidt, Leigh Eric. 2000. Hearing Things: Religion, Illusion and the American Enlightenment. Cambridge: Harvard University Press.

Schmidt-Horning, Susan. 2004. "Recording: The Search for Sound."In The Electric Guitar: A History of an American Icon, ed. André Millard, 105-122. Baltimore: Johns Hopkins University Press.

Schwartz, Hillel. 2011. Making Noise: From Babel to the Big Bang and Beyond. New York, Zone Books.

Seashore, Carl. 1919. The Psychology of Musical Talent. Boston: Silver Burdett \& Co. 
Seashore, Carl. 1936. "New Vantage Grounds in the Psychology of Music." Science 84 (2189): 517-522.

Seashore, Carl. 1938. The Psychology of Music. New York: McGraw-Hill.

Seashore, Carl. 1947. In Search of Beauty in Music: A Scientific Approach to Musical Esthetics. New York: Ronald.

Sennett, Richard. 1977. The Fall of Public Man. Toronto: Random House.

Seymour, G. 1928. "Radio Row in New York." Washington Post (29 August): 12.

Seymour, Henry. 1918A. The Reproduction of Sound. Being a Description of the Mechanical Appliances and Technical Processes Employed in the Art. London: W. B. Tattersall.

Seymour, Henry. 1918B. "The Gramophone and Its Accessories." Sound Wave and Talking Machine Record 7(10): 286.

Shapin, Steven. 2012. "The Sciences of Subjectivity." Social Studies of Science 42(2): 170-184.

Shepherd, John. 2002. "How Music Works: Beyond the Immanent and the Arbitrary." Action, Criticism \& Theory for Music Education 1(2): 1-18.

Shepherd, John, and Kyle Devine. 2013. "Sociology of Music." In The Grove Dictionary of American Music, 2nd ed. New York: Oxford University Press.

Shepherd, John, and Peter Wicke. 1997. Music and Cultural Theory. Cambridge: Polity.

Shepherd, John, and Peter Wicke. 1999-2000. "Rethinking Music: Disciplinary Implications." Repercussions 7-8: 105-146.

Sherwin, Adam. 2007. "Why Music Really is Getting Louder." The Times (04 June): online.

Shiga, John. 2012. "Deepwater Surveillance: Multichannel Sound and the Control of Undersea Space." Presented at Living Stereo: History, Culture, Multichannel Sound, Carleton University. 
Sica, Alan. 1988. Weber, Irrationality, and Social Order. Berkeley: University of California Press.

Sica, Alan. 2000. "Rationalization and Culture." In The Cambridge Companion to Weber, ed. Stephen Turner, 42-58. Cambridge: Cambridge University Press.

Siefert, Marsha. 1995. "Aesthetics, Technology and the Capitalization of Culture: How the Talking Machine Became a Musical Instrument." Science in Context 8(2): 417-449.

"Silent Partner, The." 1934. Melody Maker 10(56): 4.

Silver-Marshall. 1928. "Instructions for 685 Public Address Unipac." Chicago: SilverMarshall Inc. Canada Science and Technology Museum Library.

Simmel, Georg. 1964. "The Metropolis and Mental Life." In The Sociology of Georg Simmel. New York: The Free Press.

Simons, Norman. 1930. "Sound Amplification as a Business." Projection Engineering 2 (4): 18-20, 28.

Singer, Ben. 1988. "Early Home Cinema and the Edison Home Projecting Kinetoscope." Film History 2(1): 37-70.

Singer, Ben. 2001. "Making Sense of the Modernity Thesis." In Melodrama and Modernity: Early Sensational Cinema and its Contexts. New York: Columbia University Press.

Smilor, Raymond. 1979. "Personal Boudnaries in the Urban Environment: The Legal Attack on Noise, 1865-1930." Environmental Review 3(3): 24-36.

Smith, Ethan. 2008. "Even Heavy-Metal Fans Complain that Today's Music is Too Loud!!!" Wall Street Journal (26 September): A1.

Smith, Jacob. 2011. Spoken Word: Postwar American Phonograph Cultures. Berkeley: University of California Press.

Smith, Mark. 2001. Listening to Nineteenth-Century America. Chapel Hill: University of North Carolina Press.

Smith, Mark. 2004. "Listening to the Heard Worlds of Antebellum America." In Hearing History: A Reader, ed. Mark Smith, 365-384. Athens: University of Georgia Press. 
Smith, Richard. 1987. The History of Rickenbacker Guitars. Anaheim: Centerstream.

Smith, Richard. 1988. "Rare Bird: Early Electric Guitars, I." Guitar Player 22(3): 133.

Smith, Richard. 1988. "Rare Bird: Early Electrics, II.” Guitar Player 22(4): 144-146.

Smithsonian Institution. 1975. The History of Music Machines. New York: Drake.

"Solidified Music Shakes a Building." 1934. New York Times (25 January): n.p.

"Sound Amplifier Augments Religious Service." 1921. Popular Mechanics 36(3): 324.

"Sound Waves 'Rock' Carnegie Hall As Enhanced Music Is Played." 1940. New York Times (10 April): 25.

Southall, Nick. 2006. "Imperfect Sound Forever." Stylus Magazine (01 May): online.

"Speeches through Radiotelephone Inspire New York Crowds." 1919. Electrical Review (31 May): 895-896.

Sreedhar, Suhas. 2007. "The Future of Music." IEEE Spectrum (August): online.

Steege, Benjamin. 2007. Material Ears: Herman von Helmholtz, Attention and Modern Aurality. Harvard University: $\mathrm{PhD}$ thesis.

Steinberg, J. 1925. "The relation between the loudness of a sound and its physical stimulus." Physical Review 26(4): 507-523.

Stephens, R., and A. Bate. 1950. Wave Motion and Sound. London: Edward Arnold \& Co.

Sterling Loudspeaker. 1924. Radio Times 5(59): 332.

Sterne, Jonathan. 1997. "Sounds Like the Mall of America: Programmed Music and the Architechtonics of Commercial Space." Ethnomusicology 41(1): 22-50.

Sterne, Jonathan. 1999. The Audible Past: Modernity, Technology, and the Cultural History of Sound. University of Illinois: $\mathrm{PhD}$ thesis.

Sterne, Jonathan. 2001. "A Machine to Hear for Them: On the Very Possibility of Sound's Reproduction." Cultural Studies 15(2): 259-294. 
Sterne, Jonathan. 2003. The Audible Past: Cultural Origins of Sound Reproduction. Durham: Duke University Press.

Sterne, Jonathan. 2006. "The Death and Life of Digital Audio." Interdisciplinary Science Reviews 31(4): 343-345.

Sterne, Jonathan. 2008. "Cats and People in the Psychoacoustics Lab." In Sounds of Science - Schall im Labor (1880-1930), ed. Julie Kursell, 63-72. Berlin: Max Planck Institute for the History of Science.

Sterne, Jonathan. 2011. "The Theology of Sound: A Critique of Orality." Canadian Journal of Communication 36(2): 207-225.

Sterne, Jonathan. 2012. "The Stereophonic Spaces of Soundscape." Presented at Living Stereo: History, Culture, Multichannel Sound, Carleton University.

Sterne, Jonathan, and Joan Leach. 2005. "The Point of Social Construction and the Purpose of Critique." Social Epistemology 19(2-3): 189-198.

Stevens, Stanley. 1934A. "The Attributes of Tone." Proceedings of the National Academy of Sciences of the United States 20(7): 457-459.

Stevens, Stanley. 1934B. "Volume and Intensity of Tones." American Journal of Psychology 46(3): 397-408.

Stevens, Stanley. 1959. "The Quantification of Sensation." Daedalus 88(4): 606-621.

Stevens, Stanley. 1975. Psychophysics: Introduction to Its Perceptual, Neural and Social Prospects. New York: Wiley \& Sons.

Stevens, Stanley, and Hallowell Davis. 1936. "Psychophysiological Acoustics: Pitch and Loudness." Journal of the Acoustical Society of America 8(1): 1-13.

Stevens, Stanley, and Hallowell Davis. 1938. Hearing: Its Psychology and Physiology. New York: Wiley \& Sons.

Stewart, G., and Harold Stiles. 1913. "A Method of Producing Known Relative Sound Intensities and a Test of the Rayleigh Disk." Physical Review 1(4): 309-315. 
Stockfelt, Ola. 2004. “Adequate Modes of Listening." In Popular Music: Critical Concepts in Media and Cultural Studies, ed. Simon Frith, 375-391. New York: Routledge.

Stokowski, Leopold. 1935. "New Vistas in Radio." Atlantic Monthly 155(1): 1-16.

Stone, W. 1908. Elementary Lessons on Sound. London: Macmillan.

Straw, Will. 2008. "Squawkies and Talkies," Parallax 14(2): 20-30.

Straw, Will. 2010A. "Cultural Production and the Generative Matrix." Cultural Sociology 4(2): 209-216.

Straw, Will. 2010B. "The Circulatory Turn." In The Wireless Spectrum: The Politics, Practices and Poetics of Mobile Media, ed Barbara Crow et al., 17-28. Toronto: University of Toronto Press.

"Super-Orchestra, The." 1933. New York Tribune (14 April): n.p. AT\&T Archives and History Center.

Swan, Gilbert. 1930. “About New York.” Capital Times (09 August): 4.

Tarde, Gabriel. 1969. "The Public and the Crowd." In On Communication and Social Influence. Chicago: University of Chicago Press.

Tarde, Gabriel. 1969. "Opinion and Conversation." In On Communication and Social Influence. Chicago: University of Chicago Press.

Taylor, Sedley. 1883. Sound and Music: An Elementary Treatise on the Physical Constitution of Musical Sounds and Harmony. London: Macmillan.

“Telephone Studies Enter Many Fields." 1928. New York Times (21 October): 44.

Terrace, H., and Stanley Stevens. 1962. "The Quantification of Tonal Volume." American Journal of Psychology 75(4): 596-604.

Thayer, H.B. 1922. "What are we trying to do?" Bell Telephone Quarterly 1(2): 3.

Théberge, Paul. 1989. "The 'Sound' of Music: Technological Rationalization and the Production of Popular Music." New Formations 8: 99-111. 
Théberge, Paul. 1997. Any Sound You Can Imagine: Making Music/Consuming Technology. Middletown: Wesleyan University Press.

Thiemel, Matthias. 1996. Tonale Dynamik: Theorie, musickalische Praxis und Vortragslehre seit 1800. Sinzig: Studio.

Thiemel, Matthias. 2001. "Dynamics." In The New Grove Dictionary of Music and Musicians (vol. 7), 820-824. New York: Macmillan.

Thomas, Garth. 1949. "Equal-Volume Judgments of Tones." American Journal of Psychology 62(2): 182-201.

Thompson, Emily. 1995. "Machines, Music and the Quest for Fidelity: Marketing the Edison Phonograph in America, 1877-1925." Musical Quarterly 79: 131-171.

Thompson, Emily. 2002. The Soundscape of Modernity: Architectural Acoustics and the Culture of Listening in America, 1900-1933. Cambridge: MIT Press.

Thompson, Emily. 2004. "Wiring the World: Acoustical Engineers and the Empire of Sound in the Motion Picture Industry, 1927-1930." In Hearing Cultures: Essays on Sound, Listening and Modernity, ed. Veit Erlmann, 191-209. Oxford: Berg.

"Throngs Crowd Civic Center." 1915. San Francisco Bulletin (25 December): n.p.

“Tinned Orchestras: Where the Robots Fail." 1931. Melody Maker 3(28): 804.

Titchener, Edward. 1905. Experimental Psychology (vol. 2). London: Macmillan.

Todd, N., and F. Cody. 2000. "Vestibular Responses to Loud Dance Music: A Physiological Basis of the 'Rock and Roll Threshold'?" Journal of the Acoustical Society of America 107: 496-500.

Tönnies, Ferdinand. 1957. Community and Society. New York: Harper and Row.

“Too Loud Speakers.” 1934. New York Times (20 November): 20.

“Transcontinental Radio Car Makes First Trip." 1922. Popular Mechanics 38(4): 508.

Trower, Shelley. 2012. Senses of Vibration: A History of the Pleasure and Pain of Sound. New York: Continuum. 
Tyndall, John. 1964. The Science of Sound. New York: Citadel Press.

Tyne, Gerald. 1977. Saga of the Vacuum Tube. Temple: Antique Electronics Supply.

Urban, Friedrich Maria. 1908. The Application of Statistical Methods to the Problems of Psychophysics. Philadelphia: Psychological Clinic Press,.

Van-Ashe Radio Co. 1929-1930. Radio Catalogue. St Louis: Van-Ashe Radio Co.

Victrola. 1922. Popular Mechanics 38(1): Advertising Section, 1.

Vogel, Stephan. 1994. "Sensations of Tone, Perception of Sound, and Empiricism: Helmholtz's Physiological Acoustics." In Herman von Helmholtz and the Foundations of Nineteenth-Century Science, ed. David Cahan, 259-287. Berkeley: University of California Press.

Volutone. 1924. "Fellows Wireless Loudspeaker." Radio Times 5(64): 559.

Walser, Robert. 1993. Running with the Devil: Power, Gender and Madness in Heavy Metal Music. Hanover: Wesleyan University Press.

Waksman, Steve. 1999. Instruments of Desire: The Electric Guitar and the Shaping of Musical Experience. Cambridge: Harvard University Press,

Waksman, Steve. 2004. "California Noise: Tinkering with Hardcore and Heavy Metal in Southern California." Social Studies of Science 34(5): 675-702.

Waksman, Steve. 2009. This Ain't the Summer of Love: Conflict and Crossover in Heavy Metal and Punk. Berkeley: University of California Press.

Wardhuagh, Benjamin. 2007. "The Logarithmic Ear: Pietro Magnoli's Mathematics of Music." Annals of Science 64(3): 327-348.

Wardhuagh, Benjamin. 2008A. "Musical Logarithms in the Seventeenth Century: Descartes, Mercator, Newton." Historia Mathematica 35: 19-36.

Wardhaugh, Benjamin. 2008B. Music, Experiment and Mathematics in England, 1653-1705. Surrey: Ashgate.

Warner, Michael. 2002. "Publics and Counterpublics." Quarterly Journal of Speech 88 (4): 413-425. 
Warren, Frank. 1965. "Those Early Days." Public Address Engineers Journal 8(3): 56-73.

Watson, Floyd. 1910. "An Apparatus for Measuring Sound." Physical Review 30(4): 471-473.

Watson, Richard. 2010. Review of Raffaella De Rosa, Descartes and the Puzzle of Sensory Representation. Journal of the History of Philosophy 48(4): 526-527.

Watt, Henry. 1917. The Psychology of Sound. Cambridge: Cambridge University Press.

Weber, Max. 1958. The Rational and Social Foundations of Music. Carbondale: Southern Illinois University Press.

Weber, William. 1997. "Did People Listen in the Eighteenth Century?" Early Music 25: 678-692.

Webster, Arthur. 1919. "The Absolute Measurement of the Intensity of Sound." Transactions of the American Institute of Electrical Engineers 38(1): 701-723.

Wegman, Rob. 1998. "“Das musikalische Hören' in the Middle Ages and Renaissance: Prespectives from Pre-War Germany." Musical Quarterly 82(3-4): 434-453.

Weiss, Alan, ed. 2001. Experimental Sound and Radio. Cambridge: MIT Press.

Weston, Bob. n.d. "Loudness." Chicago Mastering Service. Online: n.p.

Western Electric. 1922 (ca.). Amplifying the Voice: A Voice Amplifying System for the Nation's Capital. AT\&T Archives and History Center (location: 5506 01).

Wever, Ernest. 1949. Theory of Hearing. New York Job Wiley \& Sons.

Wever, Ernest, and Merle Lawrence. 1954. Physiological Acoustics. Princeton: Princeton University Press.

Wheeler, Tom. 2007. The Soul of Tone: Celebrating 60 Years of Fender Amps. Milwaukee: Hal Leonard.

White, Timothy. 1994. "His Master's Voice: A Matter of Trust." In Billboard 100th Anniversary Issue, 1894-1994 (01 November): 52-60. 
“Who Can Tell Us - ?" 1928. Melody Maker 3(31): 868.

Wilcox, H. 1932. "Development and Use of Talking Motion Pictures." Journal of the Franklin Institute 214(2): 137-153.

Williams, Henry. 1931. "The Unsound Sound Business." Projection Engineering 3(5): 9-10.

Williams, Lewis. 1933A. "The Theory of Electrically Energized String Instruments." The Crescendo 25(2): 4 .

Williams, Lewis. 1933B. "The Theory of Electrically Energized String Instruments." The Crescendo 25(3): 4 .

Williams, Lewis. 1933C. "The Theory of Electrically Energized String Instruments." The Crescendo 25(4): 4, 13.

Williams, Raymond. 1977. Marxism and Literature. Oxford: Oxford University Press.

Williams, Raymond. 1982. The Sociology of Culture. New York: Schocken.

Williams, Raymond. 1993. Television: Technology and Cultural Form. Hanover:

Wesleyan University Press.

Witkin, Robert. 2003. Adorno on Popular Culture. London: Routledge.

"Wonders of Wireless." 1920. New York Times (30 April): 12.

Wright, Michael. 2000. Guitar Stories, Volume II. Milwaukee: Hal Leonard.

Wurzler, Steve. 2001. The Social Construction of Technological Change: American Mass Media and the Advent of Electrical Sound Technology. University of Iowa: PhD thesis.

Wurtzler, Steve. 2007. Electric Sounds: Technological Change and the Rise of Corporate Mass Media. New York: Columbia University Press.

"Yardstick Made for Volume of Sound." 1933. Science News-Letter 23(630): 284.

Young, Filson. 1924. "The Lament of a Listener." Radio Times 4(40): 23. 